\title{
CARDIOTOXICIDAD DEL ESTADO DE TOLERANCIA A LA GLUCOSA ALTERADA
} Mecanismos Intracelulares y Rol de la $\mathrm{Ca}^{2+}$ Calmodulina Quinasa II

\author{
Leandro Matías Sommese \\ 2018
}

Directora: Dra. Julieta Palomeque, Investigadora Independiente (CONICET), Jefa de trabajos prácticos de la cátedra de Fisiología y Física Biológica de la Facultad de Ciencias Médicas, UNLP.

Co-Directora: Dra. Alicia Mattiazzi, Investigadora Superior (CONICET), Profesora Consulta de la cátedra de Fisiología y Física Biológica de la Facultad de Ciencias Médicas, UNLP.

Centro de Investigaciones Cardiovasculares, Facultad de Ciencias Médicas, UNLPCONICET 
Agradecimientos

En primer lugar, quería reconocer a mis directores, Julieta Palomeque y Alicia Mattiazzi, las cuales me dieron el lugar, me brindaron su conocimiento y su consejo para desarrollar este proyecto. De igual forma quiero mencionar al Centro de Investigaciones Cardiovasculares, con Matín Vila Petroff y Alejandro Aiello como directores del mismo, el cual me aportó el equipamiento y el contexto para poder llevar adelante mis tareas.

Además, en este lugar me encontré que personas que alegraron mi día a día y me ayudaron con los experimentos como Omar, Lorena, Mariela, Luciana y Lucía. Así también quiero agredecer los aportes individuales que fueron escenciales en estos años como Mónica, Oscar, Guillermina, Luis, Malena, Bárbara, Gabriela, Mariano, Paula y cada uno de los integrantes del centro.

Agradezco a Margarita Salas, la cual me prestó su consejo, me escuchó y me ayudó enormemente a poder presentar esta tesis en tiempo y forma. Sin su ayuda seguiría intentando terminar los trámites.

Quería utilizar este espacio para agradecer especialmente a mi familia. Ana, mi más profundo amor, que no sólo me acompañó en este largo periodo sino también me aconsejo, ayudó y me dió el lugar y el tiempo para finalizar la escritura de esta tesis. Maia, mi rayito de sol, que a su forma supo darme las fuerzas para seguir adelante. También quiero agradecer a mis padres y abuelos por apoyar mi formación. 


\section{Contenido}

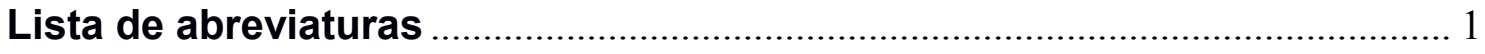

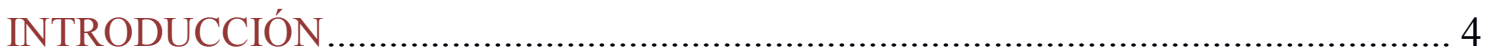

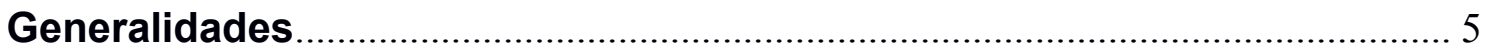

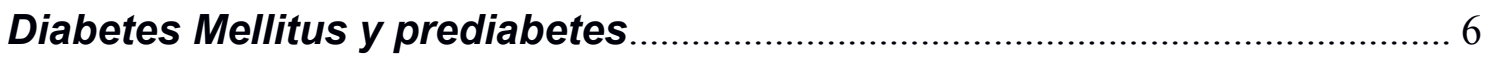

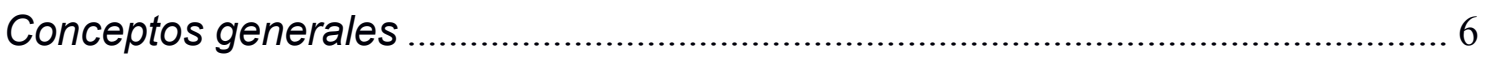

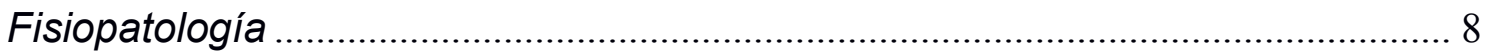

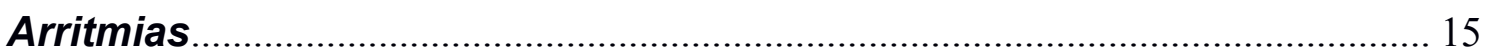

Bases electrofisiológicas del acoplamiento excitocontráctil ................................. 15

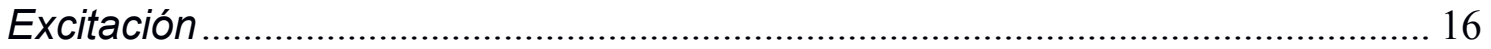

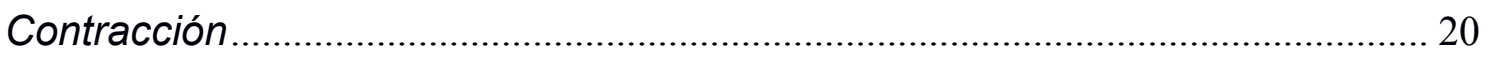

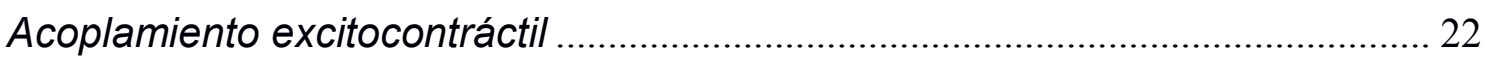

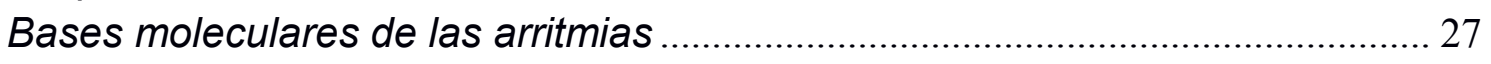

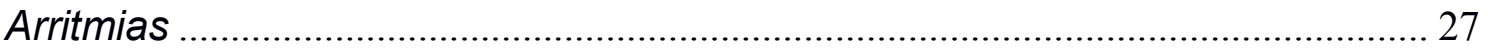

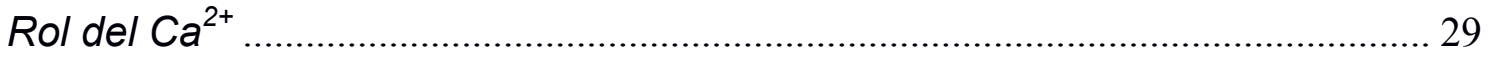

Miocardiopatía diabética: arritmias en Diabetes Mellitus y prediabetes .............. 32

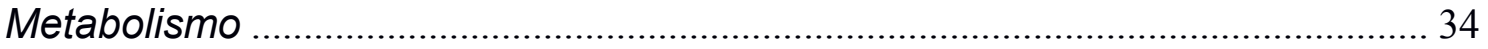

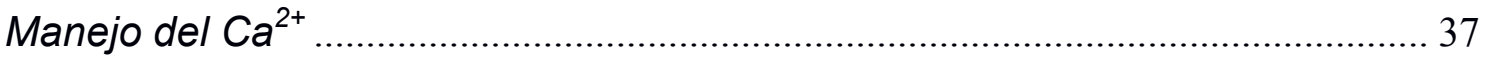

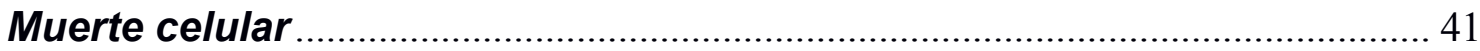

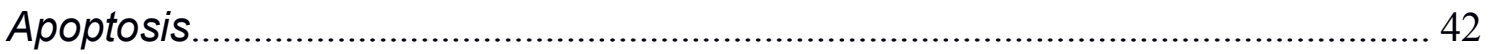

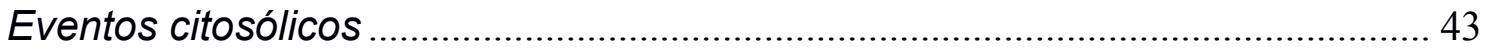

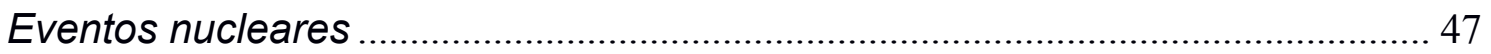

Apoptosis en Diabetes Mellitus y prediabetes .................................................. 47

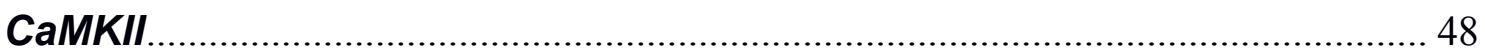

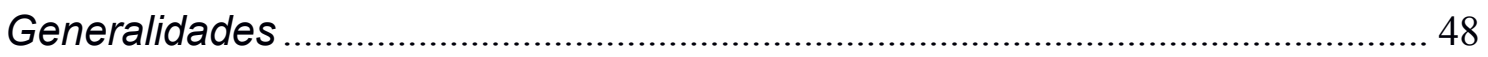

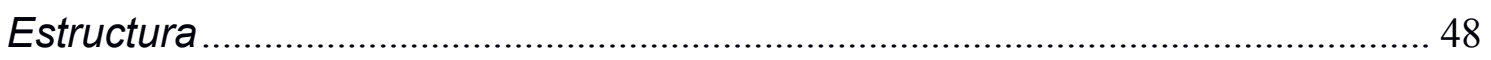

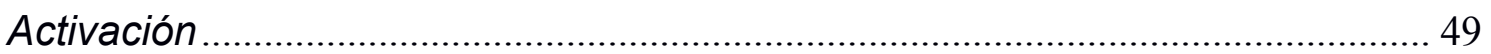

Efectos de la actividad de CaMKII ........................................................................... 51

Rol de CaMKII cardiaca en la miocardiopatía de la Diabetes Mellitus y

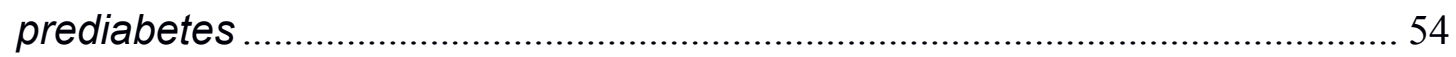

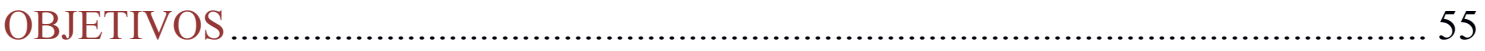

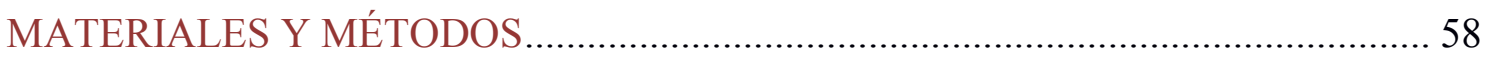

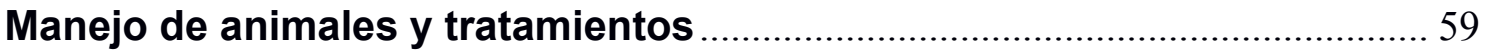

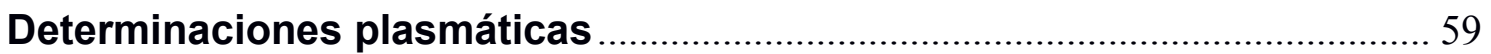

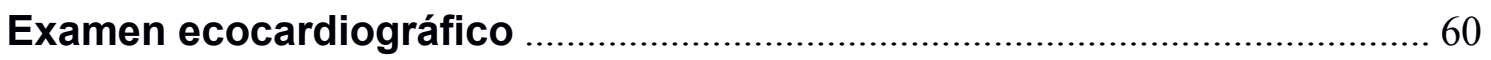

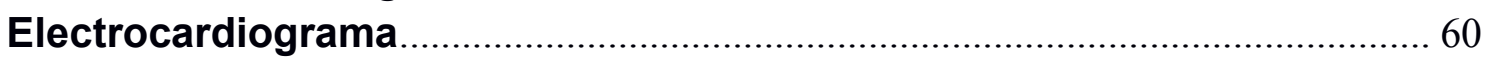

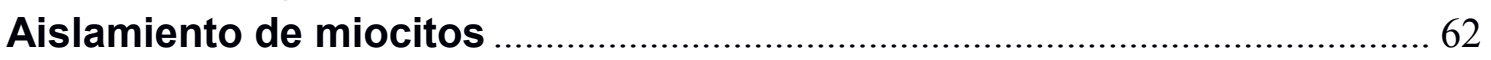

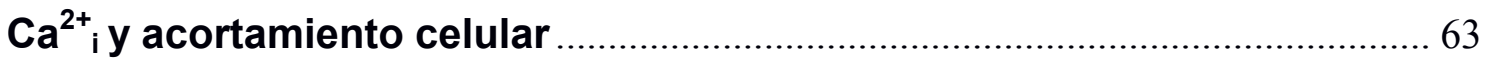

Imágenes de microscopía confocal de cardiomiocitos intactos ................... 65

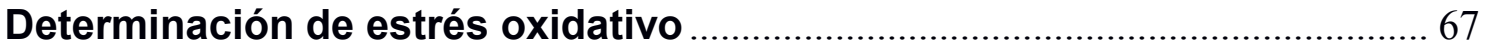

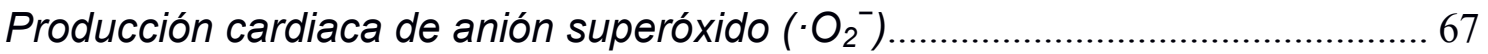

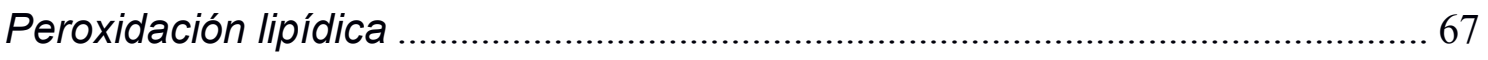

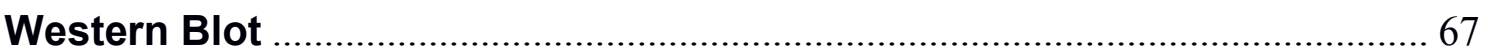




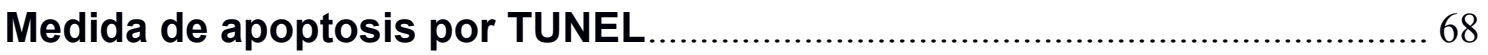

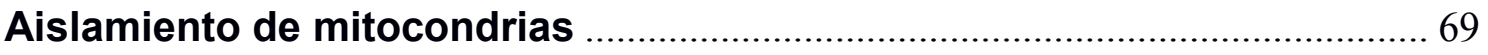

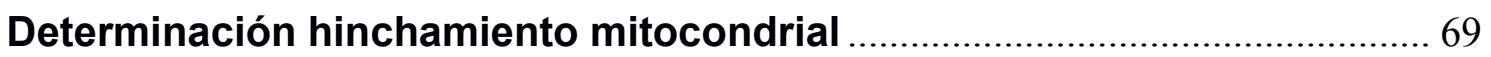

Determinación de $\mathrm{Ca}^{2+}$ mitocondrial .......................................................... 70

Determinación del potencial mitocondrial...................................................... 70

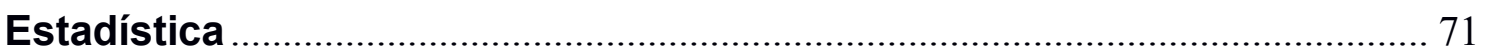

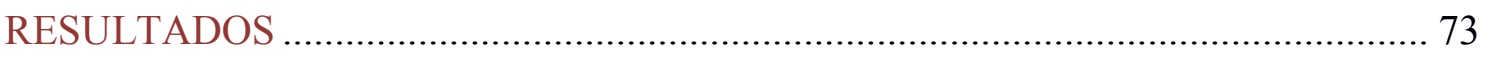

1. Caracterización del modelo de dieta rica en fructosa................................ 74

2. La dieta rica en fructosa aumenta la liberación espontánea de $\mathrm{Ca}^{2+} \ldots . .77$

3. CaMKII media las liberaciones espontáneas de $\mathrm{Ca}^{2+}$ en cardiomiocitos

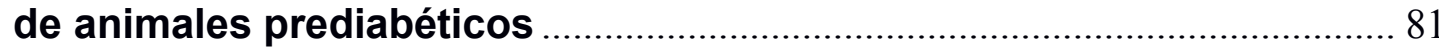

4. Mecanismos celulares de los eventos espontáneos de liberación de $\mathrm{Ca}^{2+}$ y actividad contráctil inducidos por CaMKII en los corazones

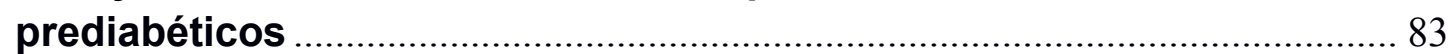

5. Mecanismo de activación de CaMKII y desestabilización de RyR2 ….....86

6. La aparición de eventos de liberación de $\mathrm{Ca}^{2+}$ predispone a la aparición de alteraciones electrocardiográficas ........................................................... 92

7. La dieta rica en fructosa promueve apoptosis en miocitos cardiacos .. 95

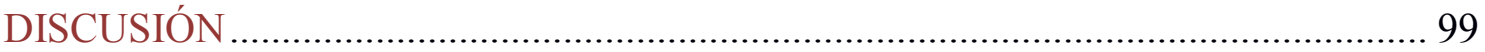

1. La dieta rica en fructosa como modelo de prediabetes ........................... 100

2. Promoción de eventos espontáneos de liberación de $\mathrm{Ca}^{2+}{ }_{i} \mathrm{y}$

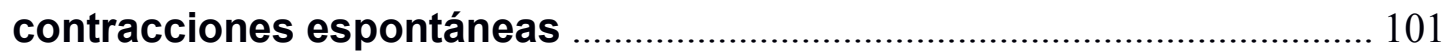

3. Relación entre patrón arritmogénico y la fosforilación de RyR2 …........ 102

4. Posibles mecanismos que podrían conducir a la activación de CaMKII

5. Hipertrofia e insuficiencia cardiaca en ratas prediabéticas .................... 104

6. Relevancia clínica y limitaciones potenciales.......................................... 106

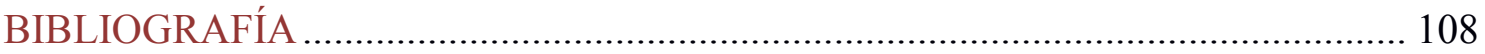




\section{Lista de abreviaturas}

\begin{tabular}{|c|c|}
\hline$\left[\mathrm{Ca}^{2+}\right]_{\mathrm{i}}$ & Concentración intracelular de calcio \\
\hline $\mathrm{ABC}$ & Área bajo la curva \\
\hline ACC & Acetil-coa carboxilasa \\
\hline ACS & Acil-coa sintetasa \\
\hline $\mathrm{AE}$ & Acortamiento fraccional endocárdico \\
\hline AEC & Acoplamiento excitocontráctil \\
\hline AG & Ácidos grasos \\
\hline AGNE & Ácidos grasos no esterificados \\
\hline AlF & Factor inductor de apoptosis \\
\hline AIP & Autocamtida proteína inhibidora \\
\hline AMAM & Ancho en la mitad de amplitud máxima \\
\hline ANT & Adenosina nucleótido translocasa \\
\hline AntiGAD & Autoanticuerpos contra la decarboxilasa de ácido glutámico \\
\hline Apaf1 & Factor apoptótico activador de proteasa 1 \\
\hline ARC & Dominio de reclutamiento de caspasas \\
\hline AT4 & Factor de transcripción 4 \\
\hline ATF6 & Fator de activación de la transcripción 6 \\
\hline $\mathrm{Ca}^{2+}$ & Calcio \\
\hline CAD & DNAsas inducidas por caspasas \\
\hline CaiT & Transitorio de calcio \\
\hline CaMKII & Calcio/calmodulina quinasa II \\
\hline CD & Dieta control \\
\hline $\mathrm{CHOP}$ & Proteína homóloga a C/EBP \\
\hline Cit C & Citocromo C \\
\hline $\mathrm{CMH}$ & Complejo mayor de histocompatibilidad \\
\hline CPT & Carnitina palmitoil transferasa \\
\hline DAD & Posdespolarizaciones tardías \\
\hline DAG & Diacilglicerol \\
\hline DD & Diámetro diastólico \\
\hline DDVI & Diámetro diastólico ventricular izquierdo \\
\hline DM & Diabetes mellitus \\
\hline DMAM & Duración total en la mitad de amplitud máxima \\
\hline DMT1 & Diabetes mellitus tipo 1 \\
\hline DMT2 & Diabetes mellitus tipo 2 \\
\hline DS & Diámetro sistólico \\
\hline DSVI & Diámetro sistólico ventricular izquiero \\
\hline EAD & Posdespolarizaciones tempranas \\
\hline ECG & Electrocardiograma \\
\hline ECV & Enfermedad cardiovascular \\
\hline EELC & Evento espontáneo de liberación de calcio \\
\hline elF2 a & Factor de iniciación eucariótico a \\
\hline ETC & Cadena transportadora de electrones \\
\hline FABPmp & La proteína de unión de AG de la membrana plasmática \\
\hline FAT36 & AG traslocasa/CD36 \\
\hline FATP & Proteína transportadora de AG \\
\hline
\end{tabular}




\begin{tabular}{|c|c|}
\hline $\mathrm{fl}$ & Femptolitros \\
\hline FRD & Dieta rica en fructosa \\
\hline GA & Glucosa en ayunas \\
\hline GAA & Glucosa en ayunas aumentada \\
\hline GLP-1 & Péptido similar a glucagón \\
\hline GLUT & Transportadores de difusión facilitada para hexosas \\
\hline GPPD & Grosor de pared posterior en diástole \\
\hline GPPS & Espesor sistólico de la pared posterior \\
\hline GRP78 & Proteína de membrana regulada por glucosa 78 \\
\hline GSD & Espesor diastólico del septum \\
\hline GSS & Espesor sistólico del septum \\
\hline $\mathrm{HbA} 1 \mathrm{c}$ & Hemoglobina glicosilada \\
\hline HDAC & Histona-deacetilasas de clase II \\
\hline HOMA-IR & Índice de evaluación del modelo homeostático de insulinoresistencia \\
\hline IAP & Proteína inhibidora de apoptosis \\
\hline IC & Insuficiencia cardiaca \\
\hline ICA & Autoanticuerpos contra células de islotes \\
\hline$I_{\mathrm{Ca}}$ & Corriente de calcio \\
\hline ICAD & Inhibidora de CAD \\
\hline$I_{C l(C a)}$ & Corriente de cloro \\
\hline$I_{K}$ & Corriente taría de potasio \\
\hline IMC & Índice de masa corporal \\
\hline IMVI & Índice de masa ventricular inzquierda \\
\hline$I_{\mathrm{Na}}$ & Corriente de sodio \\
\hline IRE1 & Proteína inositol dependiente 1 \\
\hline IRS-1 & Receptor de insulina 1 \\
\hline Iso & Isoproterenol \\
\hline$l_{\text {to }}$ & Corriente transitoria de potasio hacia afuera \\
\hline LCIC & Liberación de calcio inducida por calcio \\
\hline LPL & Lipoproteína lipasa \\
\hline LTCC & Canal lento de $\mathrm{Ca}^{2+}$ operado por voltaje \\
\hline MAPK & Proteínas kinasas activadoras mitogénicas \\
\hline MCAD & Deshidrogenasa de acil-coa de cadena intermedia \\
\hline MCD & Miocardiopatía diabética \\
\hline MEF2 & Factor promotor de miocitos 2 \\
\hline mPTP & Poro de transición de permeabilidad mitocondrial \\
\hline MTP & Proteína de transferencia de AG microsomal \\
\hline MVI & Masa ventrular izquierda \\
\hline MyBPC & Proteína C de unión a la miosina \\
\hline NADPH ox. & Dinucleótido nicotinamida-adenina fosfato oxidasa \\
\hline NCX & Intercambiador sodio/calcio \\
\hline NFAT & Factor nuclear de células T activadas \\
\hline NF-kB & Factores nucleares $\mathrm{K}$ de cadena liviana activadores de células $B$ \\
\hline NOS1 & Óxido nítrico sintasa neuronal \\
\hline PA & Potencial de acción \\
\hline PERK & Quinasa del factor de iniciación eucarótico $2 \alpha$ PKR \\
\hline PI3K & Fosfatidilinositol 3 quinasa \\
\hline PKA & Proteína quinasa $\mathrm{A}$ \\
\hline
\end{tabular}




$\begin{array}{ll}\text { PKC } & \text { Proteína quinasa C } \\ \text { PKD } & \text { Proteína quinasa D } \\ \text { PLN } & \text { Fosfolamban } \\ \text { PMCa } & \text { Bomba de calcio ATPasa de la membrana } \\ \text { PPAR- } \alpha & \text { Proliferador de peroxisomas } \alpha \\ \text { RE } & \text { Retículo endoplasmático } \\ \text { RNS } & \text { Especies reactivas del nitrógeno } \\ \text { ROS } & \text { Especies reactivas del oxígeno } \\ \text { RS } & \text { Retículo sarcoplásmico } \\ \text { RyR2 } & \text { Receptor de rianodina } 2 \\ \text { SERCa } & \text { Bomba ATPasa de calcio del retículo sarco/endoplasmático } \\ \text { SGLT } & \text { Cotransportadores de Na }{ }^{+} / \text {glucosa } \\ \text { SpCa } & \text { Sparks de calcio } \\ \text { TBARS } & \text { Sustancias reactivas al ácido tiobarbitúrico } \\ \text { TG } & \text { Triglicéridos } \\ \text { TGA } & \text { Tolerancia a la glucosa alterada } \\ \text { TGLPR } & \text { Lipoproteína medida por receptor } \\ \text { TnC } & \text { Troponina C } \\ \text { TNF- } \alpha & \text { Factor de necrosis tumoral } \alpha \\ \text { Tnl } & \text { Troponina I } \\ \text { TnT } & \text { Troponina T } \\ \text { TTGI } & \text { Prueba intraperitoneal para tolerancia a la glucosa } \\ \text { UF } & \text { Unidades arbitrarias de fluorescencia } \\ \text { UPR } & \text { Respuesta a proteína desplegada } \\ \text { VDAC } & \text { Canal aniónico dependiente de voltaje } \\ \text { VLDL } & \text { Lipoproteínas de muy baja densidad } \\ \text { WT } & \text { Tipo salvaje (del Inglés Wild Type) } \\ \text { XBP1 } & \text { Factor de regulación transcripcional con actividad endoribonucleasa } \\ \end{array}$




\section{INTRODUCCIÓN}




\section{Generalidades}

La Diabetes Mellitus (DM) es una enfermedad definida por anormalidades en la regulación de los niveles plasmáticos de glucosa en ayunas o postprandial y es frecuentemente asociada con trastornos oculares, renales, del sistema nervioso, del sistema inmune y del sistema cardio-circulatorio. Algunos de los trastornos circulatorios asociados con la diabetes incluyen la enfermedad cardiaca coronaria, accidente cerebrovascular, insuficiencia cardiaca congestiva y enfermedad arterial periférica. Frecuentemente, la DM resulta en muerte prematura por enfermedades cardiovasculares (ECV). ${ }^{1}$

Los efectos de la DM sobre el corazón concluyen en lo que se denomina "miocardiopatía diabética" (MCD). Esta se presenta, inicialmente, con disfunción ventricular diastólica, inhabilitando al corazón a relajarse apropiadamente entre las contracciones. Finalmente, la MCD deriva en una disfunción sistólica, que se traduce en una oferta insuficiente para las demandas del organismo, terminando en insuficiencia cardiaca (IC). La IC de la MCD comparte, a nivel celular, características con la insuficiencia generada por otros agentes etiológicos, como el manejo alterado del $\mathrm{Ca}^{2+}$ intracelular $\left(\mathrm{Ca}^{2+}{ }_{\mathrm{i}}\right)$ y la prolongación de la duración del potencial de acción (PA). Otra manifestación clínica de aparición temprana en el transcurso de la enfermedad es la mayor incidencia de arritmias, incluyendo fibrilación ventricular y muerte súbita. ${ }^{2}$

Durante el desarrollo natural de la DM existe un estado metabólico previo que se denomina prediabetes, definido por un estado de tolerancia a la glucosa alterada (TGA) o test de glucosa en ayunas alterado (GAA). La TGA, generalmente asociada a insulinorresistencia, es considerada factor de mal pronóstico en pacientes con IC. Sin embargo, no es claro aún cómo estas condiciones favorecen el deterioro cardiaco. $^{3}$

Distintos modelos experimentales han demostrado que una dieta rica en fructosa perturba la homeostasis metabólica, aumenta la fructosa plasmática, e induce la resistencia sistémica a la insulina. ${ }^{4,5}$ La dieta rica en fructosa es un modelo bien caracterizado de TGA y se ha descrito que la TGA se asocia con fibrosis miocárdica difusa y cardiomiocitos con una señalización intracelular de viabilidad alterada, hipertrofia ventricular, disminución de la función ventricular izquierda y alteración en el manejo de $\mathrm{Ca}^{2+}$ y de la capacidad de respuesta al $\mathrm{Ca}^{2+}$ de los miofilamentos. ${ }^{4,6}$ Por otro lado, la quinasa dependiente de $\mathrm{Ca}^{2+}$ y Calmodulina II (CaMKII) es una proteína serina/treonina quinasa, la cual es activada a través de la unión de $\mathrm{Ca}^{2+} \mathrm{y}$ Calmodulina. Sin embargo, hay estudios que proponen una activación 
independiente del $\mathrm{Ca}^{2+}{ }_{\mathrm{i}}$, ya sea por estrés oxidativo ${ }^{7}$, nitrosilación ${ }^{8}$, glicosilación ${ }^{9} \mathrm{o}$ por la proteína quinasa $\mathrm{C}(\mathrm{PKC})^{10}$. La CaMKII media la fosforilación de una amplia variedad de proteínas involucradas en procesos celulares vitales, tales como el manejo del $\mathrm{Ca}^{2+}{ }_{i}$, el crecimiento y la muerte celular. Así mismo, participa activamente de la modulación del acoplamiento excitocontráctil y se encuentra relacionada con distintas patologías a través de su actividad quinasa, por ejemplo fosforilando el canal receptor de rianodina (RyR2) en las arritmias por isquemia/reperfusión ${ }^{11}$, y a fosfolamban (PLN) en la progresión a insuficiencia cardiaca en ratas hipertensas ${ }^{12}$.

Con estas generalidades en mente, nuestro objetivo general fue evaluar las posibles alteraciones que presenta el corazón en un modelo de TGA y caracterizarlas. Además, evaluamos la vinculación de la CaMKII y sus blancos celulares con las alteraciones observadas y dilucidamos la forma de activación de esta quinasa, describiendo las vías de señalización intracelular que llevan al deterioro cardiaco de la TGA.

La prediabetes, debido a la falta de síntomas, es una entidad de diagnóstico azaroso; por lo que las bases fisiopatológicas de las complicaciones en esta etapa de la enfermedad son un terreno poco explorado. Considerando que los eventos iniciales sean quizás los disparadores de la MCD, es decir la insuficiencia cardiaca de origen diabético, es oportuno describir la DM consolidada, haciendo énfasis en las complicaciones de la misma, además de las arritmias, la apoptosis y la regulación de CaMKII. Con tal fin aboradaremos los siguientes items:

1) Diabetes mellitus y prediabetes, donde se define la enfermedad de estudio, la fisiopatología y las bases moleculares de la MCD;

2) Arritmias, fisiopatología y relevancia en la DM;

3) Muerte celular, causas y su relación con la MCD y

4) Calcio/Calmodulina quinasa II (CaMKII), estructura, activación, efectos fisiopatológicos y rol en la DM y prediabetes.

\section{Diabetes Mellitus y prediabetes}

a. Conceptos generales

1. Diabetes Mellitus y prediabetes

a. Conceptos generales b. Fisiopatología
La DM comprende un grupo de enfermedades metabólicas caracterizadas por hiperglucemia debida a defectos en la secreción de insulina, en su acción o ambas. Se asocia a diversas complicaciones macro y microvasculares, entre las que se incluyen: retinopatía diabética, nefropatía crónica, neuropatía diabética y enfermedades cardiovasculares. ${ }^{13}$ Estos pacientes presentan, además, deficiencia 
del sistema inmune, debido al alto nivel de glucosa en sangre. La Diabetes puede ser clasificada principalmente en DM tipo 1 (DMT1) y DM tipo 2 (DMT2). La primera aparece durante la infancia y es debida a la destrucción de las células $\beta$ pancreáticas por mecanismos autoinmunes, por el contrario, la segunda se manifiesta durante la adultez y su desarrollo es debido a diversos factores, entre ellos metabólicos y farmacológicos.

La prediabetes (TGA o GAA) es considerada una de las primeras etapas en el desarrollo natural de los desórdenes del metabolismo de la glucosa, y su diagnóstico se realiza a través de la medida de glucemia en ayunas o por el test de tolerancia oral a la glucosa, tomando en ambos casos valores intermedios entre los valores de una persona sana y una con DM. Ésta representa una condición transitoria y es considerada un factor de riesgo para el desarrollo de la diabetes y un aumento en las complicaciones cardiovasculares y microvasculares. La prediabetes, además, está relacionada con la obesidad, la dislipemia y la hipertensión. ${ }^{14}$

Existen varios criterios para el diagnóstico de diabetes. Entre ellos están:

- valores de $\mathrm{HbA} 1 \mathrm{C}$ plasmática mayores a $6.5 \%$,

- dos medidas de glucemia en ayunas mayor a $126 \mathrm{mg} / \mathrm{dl}$ separadas por una semana (el ayuno se define como la falta de ingesta calórica durante al menos 8 horas),

- dos glucemias mayores a $200 \mathrm{mg} / \mathrm{dl}$ durante la test de tolerancia oral a la glucosa (TTOG) (esta prueba debe realizarse como lo indica la Organización mundial de la salud (OMS), con una carga de glucosa equivalente a $75 \mathrm{~g}$ de glucosa anhidra disuelta en agua), y

- una glucemia al azar $\geq 200 \mathrm{mg} / \mathrm{dl}$ (en un paciente con síntomas clásicos de hiperglucemia o crisis hiperglucémica). ${ }^{14}$

En los adultos asintomáticos de cualquier edad con sobrepeso u obesidad (índice de masa corporal (IMC) $\geq 25 \mathrm{~kg} / \mathrm{m}^{2}$ ) y que tienen $\geq 1$ factores de riesgo adicionales para DM (tales como, inactividad física, pariente en primer grado con DM, etnia con alto riesgo para la enfermedad, mujeres que dieron a luz bebés de $5 \mathrm{Kg}$ o más o que fueron diagnosticadas con DM gestacional, hipertensión, niveles por debajo de $0,90 \mathrm{mmol} / \mathrm{L}$ de colesterol $\mathrm{HDL}$ y/o de triglicéridos mayores a 2,82 $\mathrm{mmol} / \mathrm{L}$ en sangre, mujeres con síndrome de ovario poliquístico, valores de $\mathrm{HbA} 1 \mathrm{C}$ mayores a $5,7 \%$, historia de enfermedad cardiovascular, uso de glucocorticoides o antipsicóticos) deben hacerse análisis para detectar DM y prediabetes. En los que no tienen estos factores de riesgo, las pruebas deben comenzarse a la edad de 45 años y debe repetirse cada 3 años. En los pacientes con diagnóstico de prediabetes 
se deben identificar y tratar los factores de riesgo para enfermedades cardiovasculares. ${ }^{14}$

La DM es una enfermedad que posee una prevalencia (proporción de individuos enfermos de una población en un período determinado) en constante crecimiento. Teniendo en cuenta distintos estudios, en el período comprendido entre los años 2005-2014, la prevalencia de la diabetes aumentó de un $8,4 \%$ a un $10,9 \% .{ }^{15}$ Este aumento puede deberse, en parte, al aumento de la prevalencia esperada para la obesidad y la hipertensión, ambos considerados factores de riesgo para la DM; así como también a mejoras en los tratamientos de las complicaciones, ya que el monitoreo de los pacientes y los métodos de detección se vieron reflejados en un aumento de la sobrevida de los pacientes con diabetes ${ }^{16}$.

\section{b. Fisiopatología}

1. Diabetes Mellitus

y prediabetes

a. Conceptos

generales

b. Fisiopatología
Antes de describir la fisiopatología de cada tipo de diabetes repasaremos la fisiología del manejo de la glucosa para contribuir al entendimiento de las alteraciones producidas por dicha patología.

La insulina es una hormona secretada por las células $\beta$ de los islotes de Langerhans pancreáticos, de importancia crucial en la regulación de la glucemia. Es una proteína pequeña compuesta por dos cadenas de aminoácidos (la cadena $\mathrm{A}$ de 21 aminoácidos y la cadena $B$ de 30 aminoácidos) unidas por puentes disulfuro, que al separarse pierde su actividad. La insulina es sintetizada como preproinsulina, que luego es clivada dentro de los gránulos de secreción, generando un péptido llamado 'péptido C'. Debido a su baja vida media, y a que se secreta junto al péptido $\mathrm{C}$, este último sirve como una medida de la tasa de secreción de insulina ${ }^{13}$. La glucosa es el principal estímulo para la síntesis y secreción de la insulina, pero también existen otros moduladores de su secreción. El glucagón, los aminoácidos, la acetilcolina, los agentes $\beta$-adrenérgicos, la gastrina, las secretinas, la colecistocinina e incretinas son algunos de los estimulantes de la secreción de insulina, mientras que la somastostatina y los agentes $\alpha$-adrenérgicos la inhiben ${ }^{13}$. La glucosa ingresa a las células $\beta$ de los islotes de Langerhans pancreáticos por el transportador GLUT2 y es fosforilada para seguir su vía de degradación aumentando así, los niveles de ATP. El cambio en la relación ATP/ADP regula canales de $\mathrm{K}^{+}$sensible a ATP de la membrana plasmática. El ATP lleva al cierre de estos canales, con una consecuente despolarización de la membrana plasmática. La despolarización incrementa la conductancia a través de los canales de $\mathrm{Ca}^{2+}$ dependientes de voltaje, promoviendo el ingreso de $\mathrm{Ca}^{2+}$ a las células $\beta$. Este 
incremento del $\mathrm{Ca}^{2+}$ intracelular permite la movilización de los gránulos de secreción, a través de $\mathrm{Ca}^{2+} /$ Calmodulina y PKC. ${ }^{13}$

Existen diversas familias de transportadores de glucosa en los distintos tejidos, que permiten el ingreso de la misma a las células. Por un lado, está la familia de los cotransportadores de $\mathrm{Na}^{+} /$glucosa (SGLT). Estos aprovechan la energía del gradiente de $\mathrm{Na}^{+}$para generar una corriente en el mismo sentido de glucosa. El SGLT1 se encuentra en el epitelio intestinal y se encarga principalmente de la absorción de glucosa a este nivel, el SGLT2 se expresa fundamentalmente en la corteza renal y está involucrado con a la reabsorción renal de glucosa, y el SGLT3 es considerado un sensor de glucosa de células neuronales y del tejido muscular. ${ }^{17}$ Por otra parte, podemos mencionar a los transportadores de difusión facilitada para hexosas (GLUT), entre los que se encuentra el GLUT2 de las células pancreáticas. Existen trece transportadores dentro de esta familia y se clasifican en tres clases: clase I (GLUT 1-4), clase II (GLUT 5, 7, 9, 11) y clase 3 (GLUT 6, 8, 10, 12 y HMIT). Dada su importancia y ubicación centraremos la descripción en los GLUT de clase I. EI GLUT1 tiene alta afinidad por la glucosa y está presente en tejidos que la utilizan como principal combustible, como los eritrocitos y las células endoteliales. EI GLUT2 es un transportador de baja afinidad por la glucosa y fructosa, se expresa en el hígado humano adulto, el riñón, las células $\beta$ de los islotes de Langerhans y en la membrana basolateral de las células epiteliales del intestino delgado; debido a su baja afinidad y su capacidad de transportar glucosa de forma bidireccional, se considera un sensor de glucosa. EI GLUT3 se expresa, principalmente, en tejido nervioso y posee una alta afinidad por glucosa. El GLUT4 es un transportador de alta afinidad para la glucosa que se expresa fundamentalmente en tejido muscular estriado, tejido muscular cardiaco y adipocito. En este último, la insulina es capaz de inducir su translocación a la membrana. ${ }^{17}$

La insulina promueve el almacenamiento de fuentes de energía como glucógeno y triglicéridos inhibiendo su catabolismo. Además, estimula la síntesis de proteínas en general, y en particular de aquellas involucradas en el anabolismo de hidratos de carbono y lípidos. ${ }^{13}$ Esta actúa, en los distintos tejidos, a través de un receptor de membrana, el receptor de insulina 1 (IRS-1). Este es una glicoproteína formada por dos subunidades $\alpha$ y dos $\beta$ unidas por puentes disulfuro e interacciones no covalentes. En la subunidad a se encuentra el sitio de unión a insulina, mientras que la subunidad $\beta$ es una proteína transmembrana que fija la subunidad a por fuera y su porción intracelular tiene actividad tirosinquinasa. Al unirse la insulina al receptor, éste se autofosforila y permite la fosforilación y activación de la enzima fosfatidilinositol 3 quinasa (PI3K). Esta enzima a su vez fosforila factores de 
transcripción y proteínas involucradas en el metabolismo de hidratos de carbono y lípidos, activando por ejemplo la translocación de los transportadores de la glucosa, GLUT4, desde el citoplasma hasta la membrana celular, proporcionando vías de ingreso de glucosa a la célula. Hay evidencias que indican que la insulina, además permite la activación de la vía de las MAP quinasas a través de la fosforilación de proteínas Ras (proteínas pertenecientes a la familia de las proteínas G monoméricas). ${ }^{13}$

Como ya mencionamos, la DM es un síndrome heterogéneo caracterizado por hiperglucemia y una predisposición a complicaciones crónicas en órganos y tejidos vitales. Su clasificación se basa en el origen de la hiperglucemia en diabetes mellitus idiopática tipo 1 (DMT1), tipo 2 (DMT2), diabetes mellitus secundaria, gestacional y prediabetes (TGA y GAA). La DMT1 resulta de una destrucción de las células $\beta$ de los islotes pancreáticos debido a una respuesta autoinmune. Se han encontrado distintos autoanticuerpos en pacientes con DMT1. Por ejemplo el $90 \%$ de los pacientes presentan autoanticuerpos contra células de islotes (ICA), el 80\% autoanticuerpos contra la decarboxilasa de ácido glutámico (AntiGAD) (esta enzima cataliza la formación de ácido $\gamma$-aminobutírico, existen dos isoformas pero sólo GAD65 se expresa en los islotes pancreáticos), insulina, y tirosin fosfatasa IA-2 e IA2 $\beta$ en suero (esta proteína transmembrana se expresa en los gránulos secretorios de las células $\beta$ y en células neuroendocrinas). ${ }^{13} \mathrm{El}$ proceso se desarrolla en pacientes genéticamente susceptibles, gatillado por uno o más agentes ambientales, con progresión en meses o años durante los cuales el paciente se encuentra asintomático y euglucémico, reflejando el gran número de células $\beta$ que deben destruirse para que se presente el estado de hiperglucemia permanente. Sin embargo, se ha encontrado una correspondencia entre gemelos de un $50 \% .{ }^{18}$ Los principales genes implicados en aumentar el riesgo de padecer DMT1 son los correspondientes al complejo mayor de histocompatibilidad (CMH) y al de la insulina. Sus mutaciones favorecen el reconocimiento de la insulina como autoantígeno y contribuyen a la susceptibilidad. ${ }^{18}$ Sumados a la predisposición genética se han tratado de identificar factores disparadores de la enfermedad. Dentro de los posibles agentes están las infecciones virales y la dieta.

La apoptosis es el mecanismo más frecuente en la destrucción de las células $\beta$ en la DM de origen inmunológico. Los macrófagos y las células T CD4+ y CD8+ median la insulitis y diabetes en modelos animales. Por tanto, existen diversas posibilidades teóricas sobre cómo el sistema inmune destruye las células, ya sea por citoxicidad o mediada por citoquinas sensadas y producidas por linfocitos $T$ 
CD4+. ${ }^{19-21}$ Los estudios realizados sugieren que la destrucción de las células $\beta$ en la DMT1 depende de la interacción entre macrófagos, células T CD4+ y células T CD8+ que establecen una lesión inflamatoria crónica en la que los mediadores solubles como el óxido nítrico y las citoquinas son importantes moléculas efectoras. $^{19}$

Las alteraciones y los síntomas observados en pacientes con DMT1 son debidos a la deficiencia de insulina. Los niveles bajos de insulina conducen a excesiva secreción de glucagón y a una insulinorresistencia en pacientes no controlados. Los pacientes con déficit en la cantidad de insulina tienen una depleción de los niveles de glucógeno hepático, con un aumento de la gluconeogénesis y una disminución de la captación de glucosa por parte de los tejidos lo cual lleva a un aumento de la concentración de glucosa plasmática (figura I.1). Cuando ésta supera el umbral renal de reabsorción se produce glucosuria y por efecto osmótico, poliuria. Debido a la pérdida de líquido se activa el mecanismo de la sed por lo que los individuos toman agua en abundancia (polidipsia). Finalmente, el balance energético negativo conduce a un incremento del apetito que lleva al individuo a una polifagia. En una diabetes no controlada los depósitos de triglicéridos disminuyen, los ácidos grasos libres son usados como fuente de energía en corazón y músculo esquelético. En hígado estos ácidos grasos son utilizados como fuente de energía, y parte del acetilCoA generado se metaboliza en cuerpos cetónicos (acetona, acetoacetato y $\beta$-hidroxibutirato), los que son usados por el cerebro como su principal combustible. $^{13}$ 


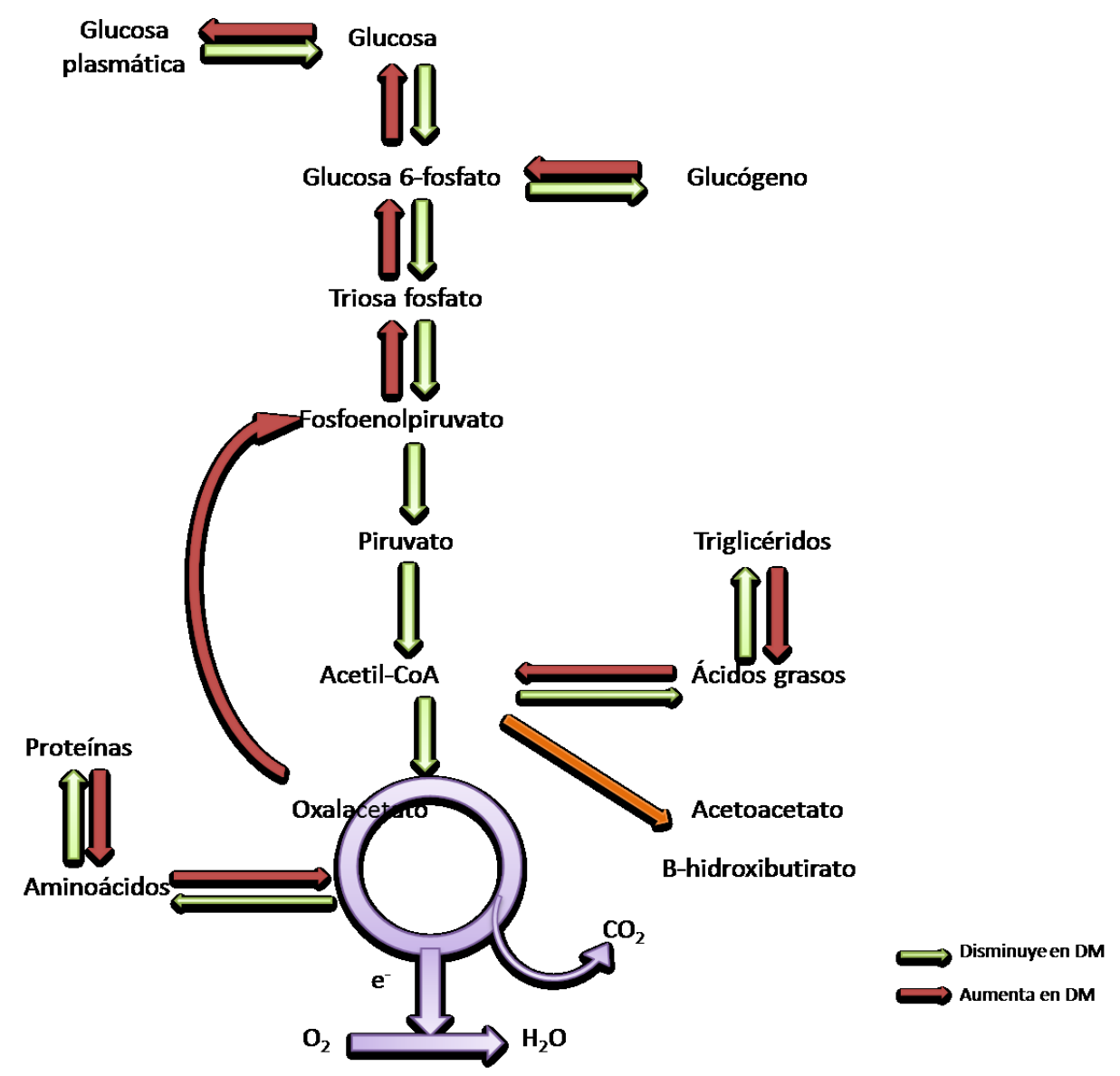

Figura I.1: Metabolismo hepático en el estado de DM.

La DMT2, a diferencia de la DMT1, no se considera una enfermedad autoinmune. Varios son los factores que predisponen a esta enfermedad. Por un lado, estudios epidemiológicos en gemelos y en poblaciones cerradas mostraron una fuerte asociación genética. Por otro lado, la obesidad, la hipertensión y la falta de la actividad física son, entre otros, factores predisponentes para el desarrollo de DMT2.

El desarrollo fisiopatológico de los pacientes con DMT2 es distinto al de los pacientes con DMT1. Los niveles de insulina plasmática son detectables e incluso dan valores elevados. Al realizarles una prueba de tolerancia oral a la glucosa estos pacientes, aún con concentraciones altas de insulina no logran normalizar la glucemia al cabo de las dos horas de la prueba. Esto permite dividirlos en dos grupos, aquellos con una diabetes franca y los que tienen valores elevados de glucemia pero que no alcanzan el límite para el diagnóstico de DMT2, lo que se denomina estado de tolerancia a la glucosa alterada, que entran en el grupo de 
prediabetes. El hecho que estos pacientes tengan una hiperglucemia con hiperinsulinemia es un indicio de una resistencia a la acción de la insulina. ${ }^{22}$ Existen amplias evidencias de factores metabólicos y farmacológicos implicados en la fisiopatología de la DMT2 que pueden causar apoptosis de las células $\beta$ del páncreas. Por ejemplo, experimentos realizados sobre islotes cultivados en medio rico en glucosa, mostraron que en dicho contexto existe un aumento de los procesos de apoptosis, por modulación del balance entre los miembros proteicos pro y antiapoptóticos de la familia $\mathrm{Bcl}^{23}$. Así mismo, experimentos realizados sobre un modelo de DMT2 en ratas diabéticas Zucker (fa/fa), desarrollado por Shimabukuro et.al, se encontró que los islotes presentan valores muy elevados de ácidos grasos libres que aumentan la apoptosis mediada por diferentes mecanismos: la estimulación de la esfingomielinasa y generación de ceramida, aumento de expresión de óxido nítrico y disminución de la expresión de $\mathrm{Bcl}-2^{24}$ (proteína antiapoptótica). Otros ejemplos son el tratamiento con sulfonilureas que a tiempos prolongados en ratones ob/ob dispara una apoptosis dependiente de $\mathrm{Ca}^{2+},{ }^{25}$ y la presencia de depósitos amiloides en los islotes contribuye al deterioro de la función de las células $\beta^{26}$.

La insulinorresistencia es un fenómeno en el cual, para una concentración dada de insulina, no se logra una reducción adecuada de los niveles de glucemia. La DMT2 está relacionada con la insulinorresistencia, de modo que para vencer esa resistencia, las células $\beta$ aumentan la masa celular produciendo una mayor cantidad de insulina y así normalizar los valores de glucemia. Con el tiempo estas células se agotan, pierden su capacidad de compensar la insulinorresistencia llevando a una hiperglucemia persistente, primero postprandial y luego en ayunas, momento en que se declara la DMT2 manifiesta. El índice de evaluación del modelo homeostático de insulinorresistencia (HOMA-IR, por sus iniciales en inglés, HOmeostatic Model Assessment-Insulino Resistance) permite calcular de una manera simplificada la insulinorresistencia: HOMA-IR= [Insulina $\mu \mathrm{UI} / \mathrm{ml}$ * Glucemia $\mathrm{mmol} / \mathrm{l} / 22,5$. Este índice responde a un modelo matemático, y diferencia la deficiencia en la función de las células $\beta$ del páncreas de la insulina resistencia, relacionando los niveles de insulina con la glucemia en ayunas. ${ }^{22,27}$ El tejido adiposo pareciera tener un rol fundamental en el desarrollo de insulinorresistencia por su influencia sobre diversos órganos, a través de moléculas de señalización endócrina como las adipocinas. Por ejemplo sobre el músculo esquelético, con la llegada de los ácidos grasos (AG) se activa el diacilglicerol (DAG) y posteriormente la PKC; la que fosforila el IRS pero no en los aminoácidos tirosina sino en los aminoácidos 
serina, por lo que el IRS ya no queda disponible para la insulina, conduciendo a insulinorresistencia. ${ }^{22}$

La insulinoresistencia, además, se asocia con la falta de activación de la PI3K, molécula que ha sido descripta como un mediador fundamental en la cascada de sobrevida o antiapoptótica de las células. En las células $\beta$, durante el desarrollo de la DMT2, la apoptosis se relaciona con el incremento de estrés oxidativo, derivado de la oxidación de la glucosa y de los $A G$, que disminuye factores de transcripción que ayudan a la reparación y regeneración de estas células. ${ }^{28}$

Existen otros mediadores importantes en el origen de DMT2 como las incretinas y el péptido similar a glucagón (GLP-1), producidas por el intestino. Estos aumentan la producción pancreática de insulina luego de la ingesta de comida por un mecanismo dependiente de los niveles de glucosa, a través de la unión a un receptor específico acoplados aproteínas $G$ en las células $\beta$ y aumento de los niveles de AMPc y de $\mathrm{Ca}^{2+} \cdot 22$

El tratamiento de los pacientes con DM comienza con una buena educación higiénico- dietéticas. En primer lugar, un cambio en los hábitos de alimentación y actividad física ayudan a disminuir el peso, a mejorar el funcionamiento del sistema cardiovascular y a regular la glucemia. Para esto, también, es importante tener en cuenta el apoyo psicológico de los pacientes con DM. Se recomienda el tratamiento nutricional para todas las personas con diabetes tipo 1 y 2 , como un componente eficaz del plan terapéutico general. Los individuos con prediabetes o diabetes deben recibir educación nutricional personalizada. Para los adultos obesos o con sobrepeso y riesgo de DMT2 se recomienda reducir la ingesta calórica manteniendo una dieta saludable y bajar de peso. La evidencia indica que no existe un porcentaje ideal de calorías aportadas por los hidratos de carbono, proteínas y grasas para las personas con DM, por lo tanto, la distribución de macronutrientes debe basarse en la evaluación de cada individuo sobre las características de su alimentación, preferencias y objetivos metabólicos. Para la buena salud, es preferible ingerir los carbohidratos de los vegetales, frutas, granos enteros, legumbres y productos lácteos en lugar de los provenientes de otras fuentes, como las que contienen grasas agregadas, azúcares o sodio. Igual que para el público general, para los diabéticos se recomiendan los alimentos con ácidos grasos de cadena larga (abundantes en los peces grasos) y el ácido n-3 linoléico (abundantes en aceites de semillas como el girasol, maíz, soja y cártamo), por sus efectos beneficiosos sobre las lipoproteínas y la prevención de las enfermedades cardiacas, como se demostró en estudios de observación. ${ }^{14}$ 
2. Arritmias

a. Bases

electrofisiológicas del

acoplamiento

excitocontráctil

i. Excitación
En cuanto al tratamiento farmacológico, la mayoría de las personas con DMT1 deben ser tratadas con inyecciones múltiples de insulina, 3 a 4 inyecciones diarias o insulina basal y prandial, o la infusión subcutánea continua de insulina. La metformina, si no está contraindicada, en caso de debilitamiento renal, y es bien tolerada, es el agente farmacológico inicial preferido para la DMT2. La metformina puede actuar, principalmente, reduciendo la gluconeogénesis y la glucogenolisis hepática, pero también reduce la absorción de glucosa por parte del tracto gastrointestinal a la vez que incrementa la sensibilidad a la insulina en los tejidos periféricos al aumentar la actividad IP3 quinasa del receptor de insulina. ${ }^{29,30}$ En los pacientes con DMT2 de reciente diagnóstico, con hiperglucemia marcada y muy sintomáticos, o en quienes tienen $\mathrm{HbA} 1 \mathrm{C}$ muy elevada, desde el inicio se debe considerar el tratamiento insulínico, con o sin agentes adicionales. Debido a la naturaleza progresiva de la DMT2, la mayoría de estos pacientes finalmente requiere el tratamiento con insulina.

El monitoreo continuo de la glucosa puede ser una herramienta suplementaria de las dosis múltiples de insulina en las personas con hipoglucemias desconocidas y/o episodios hipoglucémicos frecuentes. El uso de $\mathrm{HbA} 1 \mathrm{C}$ en los monitoreos de control de los pacientes brinda la oportunidad de modificar el tratamiento de manera oportuna. El descenso de $\mathrm{HbA} 1 \mathrm{C}$ por debajo del $7 \%$ disminuye las complicaciones microvasculares de la diabetes, y si se hace una vez hecho el diagnóstico de diabetes se asocia con una reducción a largo plazo de la enfermedad macrovascular. Por lo tanto, un objetivo razonable de $\mathrm{HbA} 1 \mathrm{C}$ para muchos adultos no embarazados es $7 \%$.

Por otro lado, para los pacientes con DM la vacunación permite la prevención de las infecciones debidas a su deficiencia inmunológica, mencionada anteriormente. Además, se debe hacer un seguimiento de la aparición de las complicaciones asociadas a la enfermedad midiendo la presión arterial, realizándose electrocardiogramas, y controlar el funcionamiento renal, ocular y lastimaduras en los pies. ${ }^{14}$

\section{Arritmias}

Dado que la miocardiopatía diabética (MCD) afecta la contractilidad, la relajación miocárdica y la ritmicidad, es pertinente introducir las propiedades fisiológicas del corazón sano.

a. Bases electrofisiológicas del acoplamiento excitocontráctil 


\section{i. Excitación}

El corazón es un órgano formado por cuatro cavidades, dos aurículas superiores y dos ventrículos inferiores. Las aurículas reciben la sangre del sistema venoso, que pasa a los ventrículos, desde los cuales, posteriormente es eyectada a la circulación arterial. La aurícula derecha recibe la sangre que proviene de todo el cuerpo a través de las venas cavas, superior e inferior. Así mismo, la aurícula izquierda recibe la sangre de la circulación pulmonar, que desemboca a través de las cuatro venas pulmonares en esta. Por otro lado, el ventrículo derecho impulsa la sangre hacia la circulación pulmonar mientras que el ventrículo izquierdo la envía por la arteria aorta para distribuirla por todo el organismo. Existe un tejido que separa el corazón derecho del izquierdo, denominado septo o tabique y estructuras que separan unas cavidades de otras, evitando que exista reflujo retrógrado denominadas válvulas. Estas están situadas en torno a los orificios auriculoventriculares (la válvula tricúspide del lado derecho y la válvula mitral del izquierdo) y entre los ventrículos y las arterias de salida (la válvula pulmonar y la válvula aórtica).

El corazón posee un sistema de conducción, que se organiza permitiendo una propagación de los impulsos eléctricos de forma sincronizada y coordinada en aurículas y ventrículos. La actividad eléctrica comienza en un grupo de células que generan potenciales de acción de manera espontánea, llamadas células marcapaso. El grupo celular que posee la frecuencia intrínseca más elevada se denomina nodo sinoauricular y se sitúa a nivel de la unión de la vena cava superior y la aurícula derecha. Otro nodo, el nodo auriculoventricular, se localiza en el piso de la aurícula derecha, y contiene células similares a las del nodo sinoauricular, pero su frecuencia intrínseca de descarga es menor. La lenta conducción del impulso a través del nódulo auriculoventricular produce un retardo entre la activación auricular y la ventricular, lo que permite una contracción secuencial de las cámaras. Las fibras inferiores del nodo auriculoventricular convergen y forman el haz de His, un cordón muscular por medio del cual la excitación se transmite de la aurícula al ventrículo. Este desciende por el tabique interventricular y se divide para termina en las denominadas fibras de Purkinje. Estas células de alta velocidad de conducción forman una red a través de la cual transmite el estímulo eléctrico al músculo ventricular. La disposición de estas fibras y su velocidad de conducción permite una transmisión sincrónica en toda la masa ventricular, desde el endocardio al epicardio y desde el ápex hacia la base. En la figura 1.2 se esquematizan los 
potenciales de acción (PA) de distintos puntos en el sistema de conducción cardiaco, su disposición temporal y su correlación con el electrocardiograma (ECG).

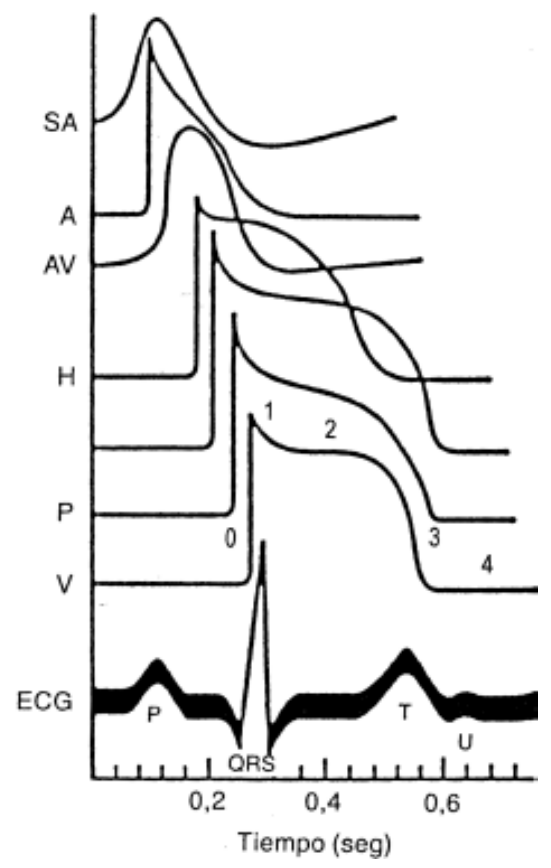

Figura 1.2: Potenciales de acción (PA) representativos de los distintos tejidos de conducción cardiaco. nódulo sinusal (SA), músculo auricular (A), nódulo AV (AV), haz de His $(H)$, ramas del haz de His, fibras de Purkinje $(P)$ y músculo ventricular (V). Los trazados se encuentran en correspondencia temporal entre sí y su correlación con elelectrocardiograma (ECG) y sus ondas ( $P$, QRS, $T, U$ ). Se muestran además las fases del PA ventricular ( 0 , 1, 2, 3 y 4). Nótese la correlación temporal de los distintos PA con el ECG. Imagen modificada de "Bases iónicas, moleculares y genéticas del síndrome del QT prolongado". Aiello et. al., Revista de la Federación Argentina de Cardiología, 2001. ${ }^{31}$

La excitabilidad cardiaca se debe principalmente a la composición proteica de la membrana sarcolemal, que produce gradientes iónicos y cambios transitorios en los flujos iónicos intra-extra celulares, que generan el fenómeno eléctrico que permite las variaciones de $\mathrm{Ca}^{2+}$ que llevan a la contracción. La homeostasis iónica, dentro de cada célula, se mantiene por un sistema conformado por canales iónicos (su apertura y cierre generan el potencial de acción), bombas (crean y mantienen los gradientes iónicos) y mecanismos de intercambio (como el $\mathrm{Na}^{+} / \mathrm{Ca}^{2+}$ que contribuye a modular la fuerza de contracción y la relajación, y la entrada y salida de $\mathrm{Ca}^{2+}$, $\mathrm{Na}^{+} / \mathrm{H}^{+}$y $\mathrm{Cl}^{-} / \mathrm{HCO}_{3}{ }^{-}$que regulan el $\mathrm{pH}$ citoplasmático).

EI PA ventricular resulta de la propagación de una onda de excitación que produce la despolarización de la célula que provoca la apertura y cierre secuenciales de canales iónicos dependientes del voltaje. La duración del potencial de acción de las fibras ventriculares cardiacas es de aproximadamente 250 milisegundos, la cual se debe principalmente a la corriente de $\mathrm{Ca}^{2+}$ que mantiene el flujo entrante de cargas positivas. Las corrientes y, por ende la conformación del PA, varía entre los distintos tipos celulares y también, entre las distintas especies. ${ }^{32}$

El potencial de acción ventricular consta de cinco fases:

- La fase 4 es el período de potencial de membrana en reposo (aproximadamente $-80 \mathrm{mV}$ en las células ventriculares), el cual está determinado 
fundamentalmente por el gradiente y la permeabilidad del $\mathrm{K}^{+}$. La corriente de $\mathrm{K}^{+}$ $\left(I_{K 1}\right)$ que mantienen el potencial de reposo se producen a través de los canales rectificadores hacia adentro, cuya mayor contribución a la repolarización aumenta a medida que el potencial de membrana se acerca al reposo. Este canal es llamado rectificador interno ya que permite el ingreso de $\mathrm{K}^{+}$hacia el interior de la célula a voltaje cercanos al potencial de equilibrio del $\mathrm{K}^{+}$, pero durante la despolarización la corriente que lo atraviesa es hacia afuera como los demás canales de $\mathrm{K}^{+}$; esto se debe en parte a la dependencia de su conductancia con el voltaje. ${ }^{33}$

- La fase 0 constituye la despolarización rápida que depende de la apertura de canales rápidos de $\mathrm{Na}^{+}$. Estos canales son operados por voltaje por lo que luego de una despolarización pasan a un estado activado. Después de la activación pico se produce la inactivación de los canales con una caída de la corriente de $\mathrm{Na}^{+}\left(I_{\mathrm{Na}}\right)$. Una vez que el canal se encuentra en estado inactivo no puede volver a abrirse hasta que vuelva a estar disponible, proceso que es dependiente del voltaje y el tiempo. El voltaje al cual se abre un número de canales de $\mathrm{Na}^{+}$(principalmente $\mathrm{NaV1.5)}$ suficiente para iniciar el potencial de acción representa un umbral.

- La fase 1 consiste en una rápida repolarización transitoria del potencial de membrana. Se debe principalmente a la salida de $\mathrm{K}^{+}$, a través de la corriente transitoria hacia afuera $\left(I_{t o}\right)$, cuya apertura del canal es dependiente del voltaje y del tiempo.

- La fase 2 corresponde a la meseta del potencial de acción cardiaco. La meseta es causada por un balance entre corrientes catiónicas despolarizantes como la corriente de $\mathrm{Ca}^{2+}\left(I_{C a}\right)$, y repolarizantes como la corriente de $\mathrm{Cl}^{-}\left(I_{C l}(C a)\right)$ y las corrientes de $\mathrm{K}^{+}\left(I_{t o 1}\right)$ y de $\mathrm{K}^{+}$tardía $\left(I_{K}\right)$. $I_{C a}$ se produce a través de canales operados por voltaje (principalmente CaV1.2, en el miocardio ventricular) y presentan inactivación lenta. Estos canales son el nexo en el acoplamiento excitocontráctil (AEC) cardiaco.

- La fase 3 corresponde a la repolarización final del potencial de acción y se debe a la corriente generada por la lenta apertura de los canales de $\mathrm{K}^{+}$tardíos $\left(I_{K}\right)$. A medida que el $\mathrm{K}^{+}$efluye de la célula, el potencial de membrana se repolariza y alcanza valores en los cuales se suprime la inhibición de $I_{K 1}$, contribuyendo a la repolarización y a regresar al potencial de membrana en reposo (figura I.3). ${ }^{32}$

Existen, también, corrientes adicionales que contribuyen al potencial de acción en la células cardíacas: la corriente de $\mathrm{K}^{+}$activada por acetilcolina (media el efecto inotrópico negativo de la acetilcolina, es decir su efecto depresor sobre la contracción), la corriente de $\mathrm{Cl}^{-}$estimulada por AMP cíclico (se activa por estimulación $\beta$-adrenérgica generando el acortamiento del PA, lo que facilita el 
aumento de la frecuencia cardiaca que produce la estimulación $\beta$-adrenérgica), ${ }^{34}$ la corriente de la bomba $\mathrm{Na}^{+} / \mathrm{K}^{+}$ATPasa, que participa en el mantenimiento del potencial de membrana en reposo, la corriente de $\mathrm{K}^{+}$sensible a ATP ${ }^{35}$ (importante en condiciones patológicas cuando, por un proceso isquémico, disminuyen los niveles de ATP y la corriente produce una disminución de la duración del PA) y la corriente del intercambiador $\mathrm{Na}^{+} / \mathrm{Ca}^{2+}$ (NCX). EI NCX será descripto en detalle más adelante, pero su función en el potencial de acción se basa en el transporte de 3 iones $\mathrm{Na}^{+}$intercambiados por un ión $\mathrm{Ca}^{2+}$, lo que resulta en un intercambio electrogénico. Este puede funcionar de modo directo, que extruye $\mathrm{Ca}^{2+}$ de la célula ingresando $\mathrm{Na}^{+}$o inverso, sacando $\mathrm{Na}^{+}$intercambiado por $\mathrm{Ca}^{2+}$. El modo en el que trabaja el intercambiador está determinado tanto por el potencial de membrana, como por el gradiente químico del $\mathrm{Na}^{+}$y el $\mathrm{Ca}^{2+}$ a través de la membrana celular; lo que hace compleja su participación en el potencial de acción y en el manejo del $\mathrm{Ca}^{2+} \cdot{ }^{36}$ La corriente del NCX en modo reverso se activa al final de la fase $3 \mathrm{y}$ durante la fase 4 en células del nodo atrial durante el PA debido a la caída del $\mathrm{Ca}^{2+}{ }^{2+}{ }^{37}$ En el ventrículo, a causa del ingreso de $\mathrm{Na}^{+}$durante el inicio del PA, se activa la corriente reversa del NCX produciendo el ingreso de $\mathrm{Ca}^{2+}$; luego el cambio de potencial electroquímico cambia el modo de la corriente permitiendo la salida de $\mathrm{Ca}^{2+}$.

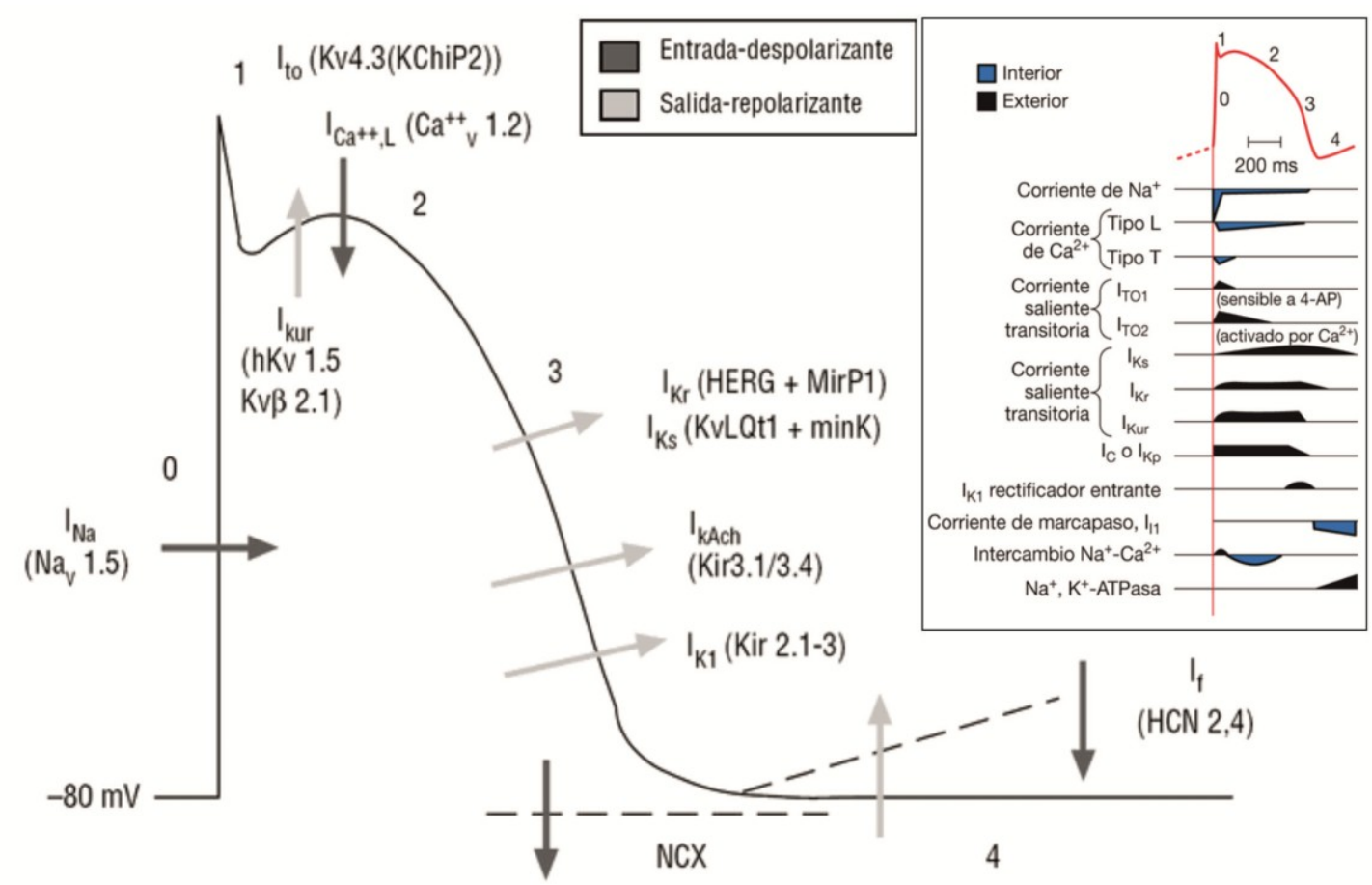

Figura I.3: Potencial de acción en humanos. Se especifican las corrientes que mantienen los cambios en el potencial de membrana y entre paréntesis los principales componentes del canal. I $I_{\mathrm{Na}}$ : corrriente de $\mathrm{Na}^{+}$(Nav 1,5), Ito: corriente transitoria de $K^{+}(K v 4,3), I_{C a}$ : corriente lenta de $\mathrm{Ca}^{2+}(\mathrm{Cav} 1,2)$, 
$I_{K u r:}$ corriente de $K^{+}$rectificadora ultrarrápida ( $h K v 1,5$ y KvB2,1), $I_{K r}$ e $I_{K s}$ : canales de $K^{+}$de apertura lenta (HERG y MirP, KVLQt1 y minK, respectivamente), IkAch: corriente de $K^{+}$activada por acetilcolina (Kir3,1/3,4), I I1: corriente de $K^{+}$rectificadora hacia adentro (Kir2,1-3), If: canal de $K^{+}$activada por hiperpolarización (HCN 2,4), NCX: intercambiador $\mathrm{Na}^{+}-\mathrm{Ca}^{2+}$. Recuadro: puede notarse la duración, intensidad y sentido de las distintas corrientes durante el potencial de acción de cardiomiocitos ventricuares. Imagen modificada de "Efectos del óxido nítrico sobre la función cardíaca". Tamargo et. al., Revista Española de Cardiología, 2006. ${ }^{38}$ Inset modificado de "Antiaarítmicos". Randa HilalDandan, Laurence L. Brunton. Goodman \& Gilman. Manual de farmacología y terapéutica. McGrawHill Education. ${ }^{39}$

Si bien existen métodos invasivos, directos, para estudiar el PA, el electrocardiograma (ECG) permite hacer un acercamiento de los eventos eléctricos de las células de forma sencilla, no invasiva. EI ECG es el registro de las variaciones de potencial creadas en el cuerpo, por la actividad eléctrica del corazón. La morfología y polaridad de estas ondas dependen de la secuencia de activación de los distintos tejidos de conducción y de la localización de los electrodos. El registro electrocardiográfico del ciclo cardiaco se inicia con una onda de baja amplitud, producida por la despolarización de las aurículas (onda P), seguido por un segmento isoeléctrico (intervalo PR), sucedido a su vez por las deflexiones correspondientes a la activación ventricular que configuran el complejo QRS. Luego de otro segmento isoeléctrico (intervalo ST) aparece la onda $\mathrm{T}$, debida a la repolarización de los ventrículos, la cual tiene la misma polaridad que el complejo ya que el proceso sigue el sentido opuesto a la despolarización por la diferencia en la duración de los PA en las distintas fibras ventriculares. Las ondas visualizadas en el ECG corresponden a un promedio de la actividad eléctrica del corazón. Como se puede observar en la figura I.3, el complejo QRS se corresponde con la fase 0 del PA, así, como el segmento ST a la meseta (fase 2) y la onda T a la repolarización tardía (fase 3 ). ${ }^{32}$

\footnotetext{
2. Arritmias

a. Bases

electrofisiológicas del

acoplamiento

excitocontráctil

ii. Contracción
}

ii. Contracción

El corazón es un órgano especializado para la contracción, la cual está coordinada gracias a la capacidad de sus células de responder a estímulos eléctricos, propios o externos, ya que es un tejido excitable. Los cardiomiocitos son los encargados del trabajo mecánico y una población menor de células se encarga de la actividad marcapaso y del sistema de conducción. Los cardiomiocitos son células cilíndricas de entre 10 y $20 \mu \mathrm{m}$ de diámetro y entre 50 y $100 \mu \mathrm{m}$ de longitud. Estas se encuentran conectadas entre sí por los denominados discos intercalares (cada una de las estructuras de unión entre dos células de músculo cardiaco), los cuales 
tienen zonas de baja resistencia eléctrica permitiendo una rápida transmisión de los impulsos eléctricos, los cual permite que el tejido funcione como un sincicio. Los cardiomiocitos pertenecen al grupo de células musculares estriadas, ya que al microscopio óptico muestran una sucesión de bandas transversales claras y oscuras, debidas al ordenamiento de los miofilamentos en las miofibrillas.

Las miofibrillas constituyen el aparato contráctil y se organizan en unidades contráctiles musculares, sarcómeros. Cada sarcómero está compuesto, por filamentos gruesos, compuestos de miosina, y finos, compuestos por filamentos de actina. Los filamentos de actina están formados por una proteína globular monomérica que forma cadenas homopoliméricas. La miosina, por su parte, es un agregado proteico formado por una cadena pesada (de $500 \mathrm{KDa}$ de peso molecular), compuesta por una molécula que posee una cola filamentosa central y una cabeza globular flexible con actividad ATPasa (esencial en el acortamiento del sarcómero en cada contracción) y cuatro livianas responsables de su regulación. La miosina se relaciona con la proteína $C$ de unión a la miosina (MyBPC [myosin binding protein $\mathrm{C}]$ ), que mantiene unido el agregado proteico, en sentido transversal, y regula la producción de fuerza por las cabezas de miosina por modificación de la tensión molecular. ${ }^{40}$

Otras proteínas importantes para la regulación de la contracción muscular son la troponina y la tropomiosina. La tropomiosina se une a la actina evitando la interacción entre esta y la miosina. Finalmente, existen tres proteínas que interactúan con el complejo proteico denominadas troponinas, las cuales presentan distintas funciones: la troponina $\mathrm{T}$, que une el complejo a la tropomiosina; la troponina I, que inhibe junto a la tropomiosina la interacción entre la miosina y la actina; y la troponina $\mathrm{C}$, que tiene capacidad de unirse a $\mathrm{Ca}^{2+}$, lo que produce el corrimiento del complejo troponina-tropomiosina, liberando el sitio de unión de la actina a la miosina que genera la contracción del músculo (figura 1.4). ${ }^{41} \mathrm{La}$ sensibilidad de los miofilamentos al $\mathrm{Ca}^{2+}$ es la relación entre la $\left[\mathrm{Ca}^{2+}\right]$ necesaria para activar el desplazamiento de las miofibrillas y la fuerza de contracción desarrollada. La sensibilidad al $\mathrm{Ca}^{2+}$ es un factor que puede determinar la progresión a latidos ectópicos y a insuficiencia cardíaca. 


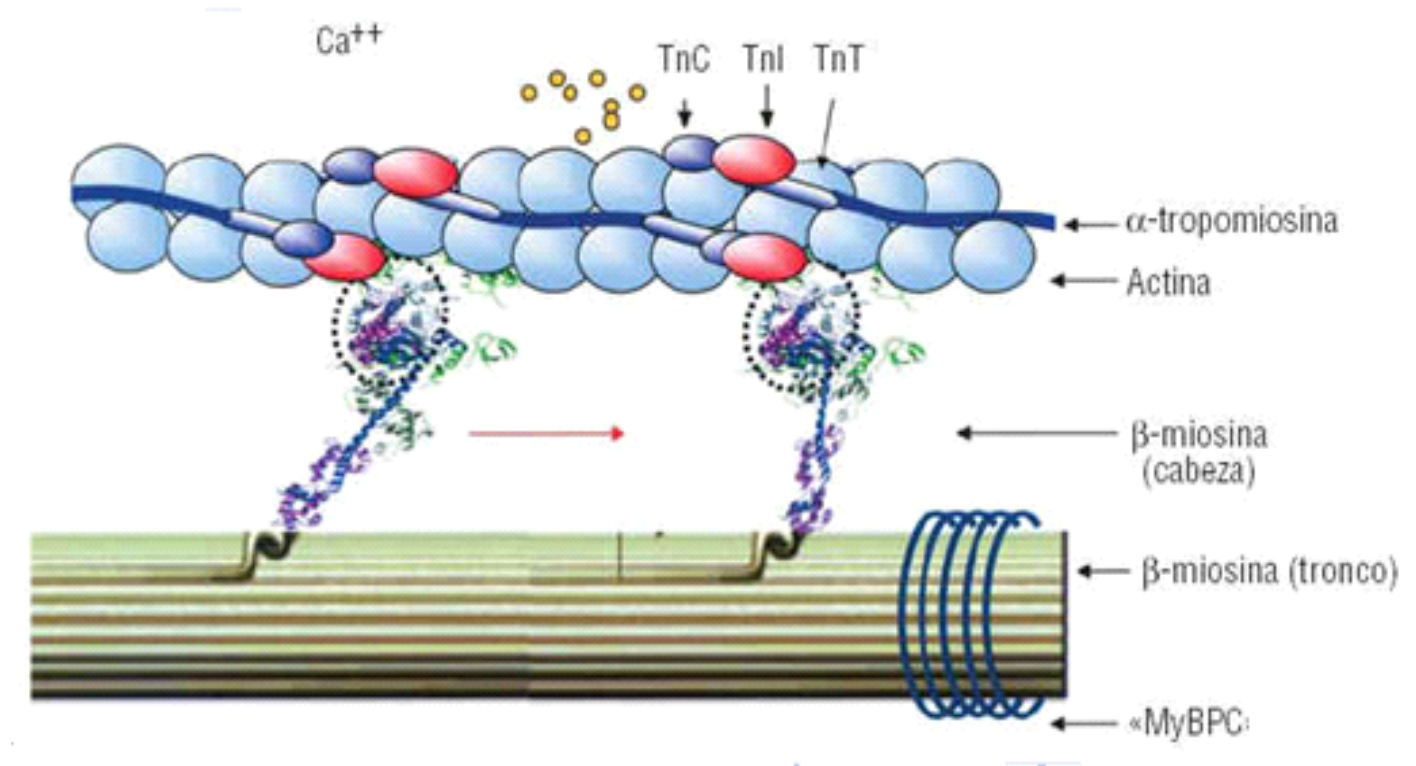

Figura I.4: Esquema de la formación de los puentes cruzados entre las fibras de miosina y actina. TnC: troponinaC, Tnl: troponina I, TnT: troponina T, MyBPC: proteína de unión a miosina C. Imagen modificada de "Miocardiopatía hipertrófica. Bases genéticas e implicaciones clínicas" Francisco Navarro-López, Revista Española de Cardiología, $2004{ }^{42}$

\section{iii. Acoplamiento excitocontráctil}

2. Arritmias a. Bases electrofisiológicas del acoplamiento excitocontráctil

iii. Acoplamiento excitocontráctil
El $\mathrm{Ca}^{2+}$ es el principal mensajero entre la excitación y la contracción. La magnitud y la duración de la fuerza contráctil están determinadas, en gran medida, por las fluctuaciones periódicas en la concentración intracelular de $\mathrm{Ca}^{2+}\left(\left[\mathrm{Ca}^{2+}\right]_{i}\right)$ de los cardiomiocitos, y la dinámica de las mismas. La serie de eventos mediante los cuales el potencial de acción cardiaco genera un aumento citosólico y transitorio en la $\left[\mathrm{Ca}^{2+}\right]_{i}$, que alcanza niveles de entre 0.6 a $3 \mu \mathrm{M}$ en la sístole, y que permite la contracción subsecuente de los miocitos cardiacos se engloban en lo que conocemos como acoplamiento excitocontráctil (AEC). ${ }^{43}$

EI AEC en miocitos ventriculares se desarrolla desde las diadas, ultraestructuras de membrana formadas por la cisterna terminal del retículo sarcoplásmico (RS) e invaginaciones de la membrana celular llamadas túbulos T. La iniciación del AEC comienza cuando el potencial de acción llega a los túbulos T produciéndose la despolarización rápida de la membrana por la apertura de canales de $\mathrm{Na}^{+}$. Estos canales se caracterizan por una rápida inactivación, por lo que permanecen inactivos hasta que la membrana se repolariza al valor de reposo. La despolarización de la membrana celular permite la apertura de canales de $\mathrm{Ca}^{2+}$ voltaje-operados (principalmente CaV1.2 en miocardio ventricular). La corriente de $\mathrm{Ca}^{2+}\left(I_{C a}\right)$ hacia el interior de la célula, que ocurre durante la meseta del potencial de 
acción, es insuficiente para producir el aumento de la $\left[\mathrm{Ca}^{2+}\right]_{i}$ necesario para la contracción a nivel de los miofilamentos. Este aumento se produce por el fenómeno de liberación de $\mathrm{Ca}^{2+}$ inducida por $\mathrm{Ca}^{2+}(\mathrm{LCIC})$, mecanismo por el cual el $\mathrm{Ca}^{2+}$ que ingresa a través de la $I_{C a}$ y dispara la apertura de los canales de RyR2, ${ }^{44}$ los cuales son sensible al $\mathrm{Ca}^{2+}$ que ingresa por la $I_{C a}$, entre otros moduladores (Figura I.5). Finalmente, esto produce una liberación masiva del contenido de $\mathrm{Ca}^{2+}$ del RS. El $\mathrm{Ca}^{2+}$ liberado difunde hasta los miofilamentos uniéndose a la troponina $\mathrm{C}$, la tropomiosina se corre del sitio de unión de la actina para miosina y permite la formación de puentes cruzados entre ambas proteínas llevando a la contracción de la célula. La cantidad de $\mathrm{Ca}^{2+}$ liberada en cada PA, y por lo tanto, la fuerza de contracción depende de múltiples factores, entre ellos, la densidad de la $I_{\text {Ca, }}$ el contenido de $\mathrm{Ca}^{2+}$ del RS y la sensibilidad del RyR2 a determinadas corrientes de $\mathrm{Ca}^{2+}$ (ganancia del AEC). ${ }^{44}$

La relajación depende de la disminución de la $\left[\mathrm{Ca}^{2+}\right]$, que permite la liberación de los puentes cruzados de los miofilamentos. El secuestro de $\mathrm{Ca}^{2+}$ ocurre principalmente por la retoma del mismo por el RS a través de la bomba ATPasa de $\mathrm{Ca}^{2+}$ (SERCa2a), y en menor medida por la salida del ion por el NCX, que, con el potencial de membrana en este punto y la alta $\left[\mathrm{Ca}^{2+}\right]_{i}$ funciona extruyendo $\mathrm{Ca}^{2+} \mathrm{e}$ ingresando $\mathrm{Na}^{+}$a la célula. Otros mecanismos que participan en la remoción del $\mathrm{Ca}^{2+}$ citosólico, aunque con mucha menos participación, son la extrusión de calcio por medio de la bomba ATPasa de $\mathrm{Ca}^{2+}$ sarcolemal y por el transportador mitocondrial de $\mathrm{Ca}^{2+} \cdot 45$.

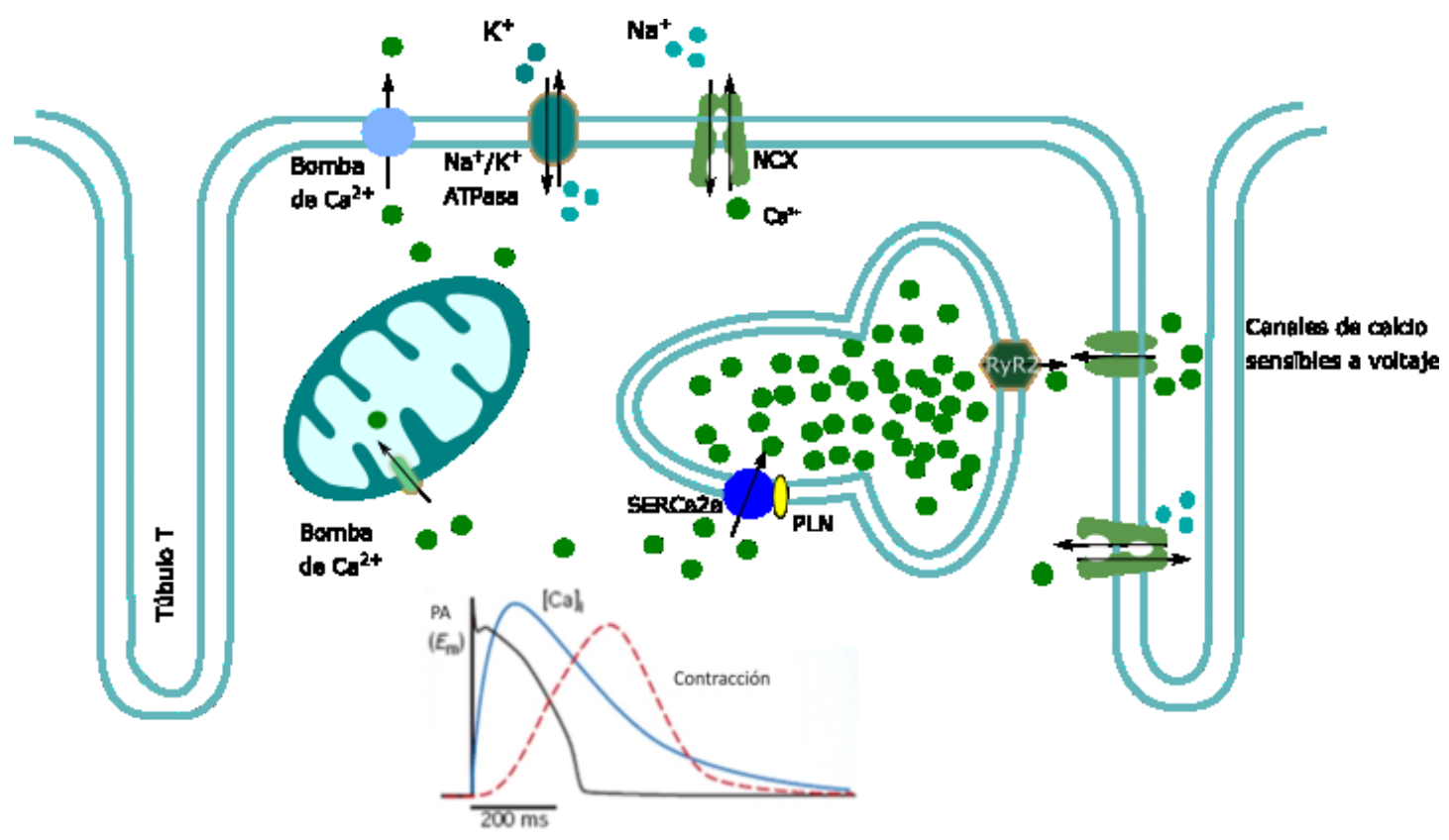

Figura I.5: Representación del acoplamiento excitocontráctil cardiaco. RyR2: receptor de rianodina, $P L B$; fosfolamban, $R S$ : retículo sarcoplasmático, $P A$ : potencial de acción. 
El correcto acoplamiento entre la excitación celular y la contracción requiere de una exacta relación entre proteínas especializadas en el transporte de iones y la contracción, entre las que poseen un rol importante la CaV1.2, el RyR2, la SERCa2a y el NCX.

\section{CaV1.2}

La proteína CaV1.2 conforma el canal lento de $\mathrm{Ca}^{2+}$ operado por voltaje (LTCC), también llamado receptor de dihidropiridinas por su afinidad a dichos compuestos, que permite el ingreso del ion. Está compuesto por cuatro subunidades: la subunidad $\alpha_{1}$ delimita el poro selectivo a $\mathrm{Ca}^{2+}$, contiene el sensor de voltaje y el sitio de unión a la mayoría de los moduladores; y las subunidades accesorias, $\alpha_{2} \delta, \beta$, y $\gamma$ que están involucradas en el anclaje, tráfico y regulación de la proteína. Las características de los LTCC se deben a la subunidad $\alpha_{1}$, entre ellas están, la activación e inactivación dependiente del voltaje, la inhibición dependiente del voltaje por dihidropiridinas, y la facilitación e inactivación dependiente $\mathrm{Ca}^{2+}$. Los LTCC se activan cuando, al despolarizarse la célula, el potencial de membrana alcanza a valores de $-30 \mathrm{mV}$ y la corriente $\left(I_{C a}\right)$ alcanza su máxima amplitud entre 0 y $+10 \mathrm{mV}$ La activación y la inactivación de dichos canales son relativamente lentas, alcanzando el pico máximo al cabo de 1-5 ms, siendo su constante de inactivación mayor a 500 ms. Esta última está regulada por mecanismos dependientes de la $\left[\mathrm{Ca}^{2+}\right]_{\mathrm{i}}$ y del voltaje. En la inactivación dependiente de $\mathrm{Ca}^{2+}$ está involucrada la proteína Calmodulina por estar unida a la porción C-terminal de la subunidad $\alpha_{1}$ actuando como sensor ${ }^{46}$. La fosforilación por PKA y CaMKII incrementa la frecuencia de apertura prolongada del canal y enlentece su inactivación. ${ }^{45}$

\section{RyR2}

El canal RyR2 es una proteína multimérica, que funciona como una unidad liberadora de $\mathrm{Ca}^{2+}$ del RS. Está compuesta por cuatro subunidades acopladas a una variedad de proteínas regulatorias. Las proteínas reguladoras calsecuestrina, triadina y juntina se unen a RyR2 del lado luminal del RS sensando el contenido de $\mathrm{Ca}^{2+}$. En condiciones fisiológicas, la probabilidad de apertura de RyR2 aumenta por la entrada de $\mathrm{Ca}^{2+}$ por la $I_{C a}$. En el músculo cardiaco una gran fracción de los RyR2s están ubicados en las diadas, donde la membrana del RS contiene entre 30 y 250 RyR2s, que están muy próximos a los canales de $\mathrm{Ca}^{2+}$ tipo $\mathrm{L}$ ubicados en la membrana T. ${ }^{43}$ Esta disposición permite que algunos canales de $\mathrm{Ca}^{2+}$ activen 
grupos de RyR2s produciendo el fenómeno de liberación de $\mathrm{Ca}^{2+}$ inducida por $\mathrm{Ca}^{2+}$. La apertura de unos pocos grupos de canales produce una chispa o spark de $\mathrm{Ca}^{2+}$ (CaSp), un evento elemental de $\mathrm{Ca}^{2+}$. Durante cada latido se producen un gran número de CaSp simultáneos y sincronizados, los cuales generan la salida transitoria de $\mathrm{Ca}^{2+}$ que provoca la contracción.

Se ha postulado que existe un mecanismo alostérico de activación del RyR2 por cambios conformacionales en la apertura del LTCC. Esto se sugiere a partir de datos experimentales y de modelado por el método MonteCarlo ${ }^{47}$. Por otra parte, los mecanismos moleculares de regulación endógena del RyR2 propuestos son: 1) la inactivación del RyR2 dependiente de $\mathrm{Ca}^{2+}$, que involucra al $\mathrm{Ca}^{2+}$ tanto del lado del citoplasma como de la región luminal del RS y a proteínas cuya actividad sobre el RyR2 depende de $\mathrm{Ca}^{2+}$, como sorcina, calmodulina y calsecuestrina; 2) el decaimiento espontáneo de la actividad de los RyR2 debido al cerrado estocástico del canal; 3) el agotamiento de las reservas de $\mathrm{Ca}^{2+}$ luminal del $\mathrm{RS}$, lo cual disminuye el flujo de $\mathrm{Ca}^{2+}$ a través del canal; y 4) el decaimiento inducido de la actividad de los RyR2, debido a la compleja relación espacio/ temporal que conduce a la disolución casi instantánea de los gradientes de $\mathrm{Ca}^{2+}$ nanoscópicos dentro de una región local. ${ }^{48}$ La actividad de RyR2 es también regulada por moléculas citosólicas cuyas acciones se producen en dicha cara del canal, como PKA, CaMKII, proteínas fosfatasa 1 y $2 \mathrm{~A}$, calmodulina, y FKBP12.6, así como también la concentración de distintos iones, fundamentalmente $\mathrm{Mg}^{2+} \mathrm{y} \mathrm{H}^{+}$. Por otro lado, otras modificaciones postraduccionales, como la fosforilación, desfosforilación, oxidación, reducción, y nitrosilación también han sido propuestas como moduladoras de la actividad del RyR2.

La modulación del RyR2 resulta compleja, a modo de ejemplo, el aumento de la fosforilación de RyR2 en los sitios $\operatorname{Ser}^{2808}, \operatorname{Ser}^{2030}$ (dependientes de PKA) y Ser ${ }^{2814}$ (dependiente de CaMKII) lleva a un aumento de la probabilidad de apertura del canal, cuyo efecto puede ser fisiológico o patológico dependiendo del contexto en el que se encuentre la célula. ${ }^{43,45,49}$ En contraposición, también existen estudios que describen que la fosforilación en el sitio $\operatorname{Ser}^{2808}$ por PKA no tiene relevancia patológica, y que la desfosforilación del canal también puede inducir su activación. ${ }^{50}$ En condiciones fisiológicas, cada RyR2 tiene alrededor de un $25 \%$ de cisteínas libres capaz de nitrosilarse o glutationisarse reversiblemente. La oxidación de RyR2 puede llevar a un aumento en la liberación de $\mathrm{Ca}^{2+}$ por el RS en respuesta a una señal fisiológica, permitiendo una respuesta inotrópica positiva. Sin embargo, un estrés oxidativo irreversible que incrementa la pérdida de $\mathrm{Ca}^{2+}$, disminuye la carga de $\mathrm{Ca}^{2+}$ del $\mathrm{RS}$ y puede causar finalmente disfunción contráctil. ${ }^{49}$ del músculo 
cardíaco. Otros detalles relevantes sobre la modulación del RyR2 serán discutidos en los siguientes capítulos.

\section{SERCa2a}

La retoma de $\mathrm{Ca}^{2+}$ hacia el RS depende fundamentalmente de la SERCa. Existen 3 isoformas de este transportador: SERCa1a y SERCa1b son variantes expresadas en músculo esquelético, la variante SERCa2a se expresa selectivamente en corazón y músculo esquelético, mientras que SERCa2b se expresa de manera ubicua, finalmente SERCa3 se encuentra en un número limitado de células no musculares y en músculo liso. La bomba de $\mathrm{Ca}^{2+}, \mathrm{SERCa2a}$, está formada por una única cadena proteica con cuatro dominios distintos, uno transmembrana que forma el poro a través del cual el $\mathrm{Ca}^{2+}$ ingresa al RS y tres citosólicos, uno de unión a nucleótidos, otro de fosforilación, y por último un dominio activador). La principal proteína que se relaciona con la SERCa2a es fosfolamban (PLN), una proteína pequeña, de $22 \mathrm{kDa}$, que regula la actividad de la SERCa2a. Cuando PLN se encuentra desfosforilada puede unirse a SERCa2a e inhibir su actividad. Al fosforilarse, ya sea en el residuo $\operatorname{Ser}^{16}$ (por acción de PKA) o en el residuo $\operatorname{Thr}^{17}$ (por la acción de CaMKII) se produce un cambio conformacional que permite su separación de la SERCa2a, haciendo que esta última aumente su actividad. Este aumento de actividad media el efecto inotrópico positivo por aumento del contenido de $\mathrm{Ca}^{2+}$ del RS, por un lado; así como también posee un efecto lusitrópico también positivo, es decir, un aumento en la velocidad de relajación, por acelerar la disminución del $\mathrm{Ca}^{2+}$ citosólico. $^{51}$

\section{NCX}

EI NCX es el principal transportador que extruye el $\mathrm{Ca}^{2+}$ de la célula. Esta proteína posee 10 segmentos transmembrana capaces de transportar $\mathrm{Na}^{+}$y $\mathrm{Ca}^{2+}$ a través de la membrana y una porción citoplasmática que regula su actividad alostéricamente por unión a $\mathrm{Ca}^{2+}$. Se localiza a lo largo de la membrana plasmática, sin embargo existen evidencias de una mayor densidad de esta en los túbulos T. ${ }^{52} A$ través de estudios por microscopia de fluorescencia, se encontró que existe un $27 \%$ de NCX cercanos a los canales RyR2 ubicados en el microdominio de la diada, donde puede tener efectos profundos en el acoplamiento excitocontráctil modificando el transporte local de $\mathrm{Ca}^{2+}{ }^{53} \mathrm{El} \mathrm{NCX}$, como ya se mencionó anteriormente, intercambia tres iones $\mathrm{Na}^{+}$por uno de $\mathrm{Ca}^{2+}$, produciendo un transporte electrogénico. Este intercambiador puede funcionar de dos modos, uno directo extruyendo $\mathrm{Ca}^{2+}$ del citosol e ingresando $\mathrm{Na}^{+}$al miocito, y otro inverso donde se 
2. Arritmias

a. Bases

electrofisiológicas del

acoplamiento excitocontráctil invierten los sentidos. El potencial de extrusión del intercambiador es de $-40 \mathrm{mV}$, de modo que cuando el potencial de membrana está por debajo de este valor NCX actúa en su modo directo, y cuando el potencial de membrana se encuentra por encima, el transportador trabaja en el modo inverso. De este modo, el NCX, tanto en diástole como durante la mayor parte de potencial de acción, actúa de manera directa. ${ }^{54}$ La despolarización de la célula aumenta el $\mathrm{Na}^{+}$intracelular y desplaza el potencial de membrana hacia valores mayores que potencial de inversión del NCX, lo que favorece la entrada de $\mathrm{Ca}^{2+}$. Esta situación es transitoria, ya que el mismo $\mathrm{Ca}^{2+}$ que ingresa por el NCX modifica su funcionamiento y, conjuntamente con la repolarización de la membrana, el intercambiador vuelve a trabajar en modo directo. En síntesis, en dichas condiciones el NCX extruye el $\mathrm{Ca}^{2+}$ en cantidad equivalente a la ingresada por la $I_{C a}$, al mismo tiempo que la SERCa2a retoma el $\mathrm{Ca}^{2+}$ liberado por los RyR2s manteniéndose, de esta manera, el balance del $\mathrm{Ca}^{2+}$. Además, el NCX es modulado por la concentración de $\mathrm{Na}^{+}$intracelular (aunque son necesarias muy altas concentraciones (20 mM) para que se produzca su inactivación), regulación que posiblemente tome relevancia en estados patológicos, como la insuficiencia cardiaca donde la concentración de $\mathrm{Na}^{+}$se eleva significativamente. ${ }^{55}$

Por otro lado, el fenómeno de acoplamiento excitocontráctil (AEC) es modulado por estimulación $\beta$-adenérgica por el neurotransmisor simpático noradrenalina y la hormona suprarrenal adrenalina. Dicha estimulación desempeña un papel fundamental en la modulación de la función cardíaca en respuesta al estrés o el ejercicio, y es una maniobra farmacológica ampliamente utilizada para producir estrés celular. Las principales proteínas de interacción con $\mathrm{Ca}^{2+}$ implicadas en el $A E C$, entre ellas los canales $\mathrm{Ca}^{2+}$ de tipo $\mathrm{L}$, los RyR, y fosfolamban, son proteínas diana conocidas de la proteína $\beta$-AR-adenililciclasa-cAMP, intermediario de la vía de señalización de la proteína quinasa A (PKA). La fosforilación resultante de estas proteínas aumenta las amplitudes transitorias del $\mathrm{Ca}^{2+}$ intracelular y de contracción, y acelera su cinética. ${ }^{56}$ Estos efectos permiten que la estimulación $\beta$-adenérgica pueda ser utilizada como una herramienta para desenmascarar alteraciones en el manejo del $\mathrm{Ca}^{2+}$.

\section{b. Bases moleculares de las arritmias}

\section{i. Arritmias}

Se define arritmia como un trastorno en el que el ritmo del corazón no tiene una frecuencia dentro de un rango normal (entre 60 y 100 latidos por minuto en reposo). Las arritmias pueden clasificarse, según la ubicación anatómica del foco que da origen al trastorno o pueden dividirse según el mecanismo que las origina. Las 
arritmias supraventriculares, se localizan en estructuras que se encuentran por encima del haz de His, mientras que las ventriculares, se originan en el haz de His o en los ventrículos. Por otro lado, las arritmias pueden diferenciarse según sean generadas por alteraciones en la formación del impulso, en la conducción del impulso o de forma mixta, por alteraciones en la formación y la conducción del impulso. Así mismo, la formación del impulso puede ser anormal por la despolarización de las fibras musculares, hasta potenciales de membrana en los que la inactivación de $I_{K}$ y la activación de $I_{C a L}$ provoquen la descarga automática, produciendo así cambios en la frecuencia o aparición de focos ectópicos. ${ }^{57}$ En el caso particular de la conducción, al encontrarse enlentecida o abolida en su totalidad (bloqueo), puede originar arritmias por reentrada. El concepto de reentrada implica que un impulso no se extingue después de haber activado al corazón, sino que vuelve a excitar fibras previamente despolarizadas, que están fuera de su período refractario.

Los principales tipos de arritmias son latidos ectópicos, arritmias supraventriculares, arritmias ventriculares y bradiarritmias. El tipo más frecuente de arritmia es el latido ectópico. ${ }^{58}$, que puede originarse tanto en las aurículas como en los ventrículos, ya sea por exaltación del automatismo o por reentrada. Las extrasístoles ventriculares pueden producir un complejo QRS aberrante y ancho, sin la onda $\mathrm{P}$, y con el doble de distancia entre los dos complejos normales que lo flanquean. ${ }^{32}$ Por otro lado, las arritmias supraventriculares son alteraciones del ritmo cardiaco con aumento de la frecuencia cardiaca (taquicardias), los cuales pueden originarse ya sea en las aurículas, como en el nodo auriculoventricular. Existen distintos tipos de arritmias supraventriculares, entre ellas se incluyen: la taquicardia supraventricular paroxística, el síndrome de Wolff-Parkinson-White y la fibrilación auricular, siendo esta última la arritmia grave más frecuente. En la fibrilación auricular el disparo de los impulsos eléctricos se produce fuera del nodo sinoauricular, propagándose de manera desorganizada y rápida. Como resultado de esto las aurículas no son capaces de bombear la sangre hacia los ventrículos, ni de relajarse lo suficiente para que se lleve a cabo un buen llenado. Esto puede conducir a dos complicaciones principales: accidentes cerebrovasculares, por formación de coágulos en las aurículas; e insuficiencia cardiaca, debido a que los ventrículos laten muy rápido y no puede bombear la sangre suficiente. Pueden suceder eventos de fibrilación auricular transitorios que no conduzcan a estas complicaciones aunque, de no tratarse la enfermedad, los episodios irán en aumento tanto en frecuencia como en duración. La fibrilación auricular puede ser causada por hipertensión arterial $^{59}$, enfermedad cardiaca coronaria ${ }^{60}$ y cardiopatía reumática ${ }^{61}$, 
entre otras causas, aunque en la mayoría de los casos se desconoce su etiología. La inflamación también se cree que desempeñan un papel importante en el desarrollo de la fibrilación auricular. ${ }^{62}$ Finalmente, la taquicardia supraventricular paroxística es una arritmia donde la frecuencia cardiaca es elevada, y comienza y termina repentinamente. Se produce debido a problemas de conexión eléctrica entre las aurículas y los ventrículos, donde puede ocurrir un fenómeno de reentrada. Un tipo especial de taquicardia supraventricular paroxística es el denominado síndrome de Wolff-Parkinson-White. Este es una condición en la que las señales eléctricas del corazón viajan de las aurículas a los ventrículos a lo largo de una vía adicional. Esta vía adicional interrumpe la sincronización de las señales eléctricas del corazón y puede causar una taquicardia ventricular.

Las arritmias ventriculares, que incluyen la taquicardia y la fibrilación ventricular pueden desarrollarse por enfermedad coronaria, y la consecuente isquemia cardiaca, entre otras causas. La taquicardia ventricular es un evento de frecuencia alta y regular de los ventrículos. En la fibrilación ventricular se producen descargas de señales eléctricas desorganizadas que hacen que la contracción efectiva de los ventrículos desaparezca.

Las bradiarritmias se producen si el ritmo cardiaco es más lento de lo normal. Pueden observarse de manera fisiológica en deportistas sanos pero, también puede observarse en patologías que producen isquemia cardiaca, condiciones que dañan o cambian la actividad eléctrica del corazón (como una glándula tiroides hipoactiva o el envejecimiento), un desequilibrio de productos químicos u otras sustancias en la sangre, como el potasio, medicamentos como los bloqueadores beta, antagonistas del calcio y algunos medicamentos antiarrítmicos, entre otros factores. ${ }^{32,58}$.

\section{Arritmias}

a. Bases

electrofisiológicas del acoplamiento excitocontráctil

ii. $\mathrm{Rol}$ del $\mathrm{Ca}^{2+}$

\section{ii. $\quad \mathrm{Rol} \mathrm{del} \mathrm{Ca}^{2+}$}

La pérdida de $\mathrm{Ca}^{2+}$, a través del RyR2, está fuertemente vinculada con la generación de arritmias ventriculares, por formación anormal de impulsos eléctricos. ${ }^{43}$ La pérdida de $\mathrm{Ca}^{2+}$ del RS puede producirse básicamente por dos mecanismos: por una sobrecarga de $\mathrm{Ca}^{2+}$ en el mismo o a causa de un RyR2 disfuncional. Si bien estos dos eventos pueden suceder de forma simultánea, se ha demostrado que la sobrecarga del RS puede ser suficiente para generar pérdidas de $\mathrm{Ca}^{2+}$ en el $\mathrm{RS}^{63}$, aunque sigue en discusión que la disfunción del RyR2 sin la sobre carga pueda desencadenar dichas pérdidas. ${ }^{64}$

Existen distintas formas de pérdida de $\mathrm{Ca}^{2+}$ en diástole: 
- El spark o chispa de $\mathrm{Ca}^{2+}$ : se produce por activación de varios RyR2s,

- la wave u onda de $\mathrm{Ca}^{2+}$ : se produce cuando hay reclutamiento de varios grupos o clusters de RyR2, pero no logran la coordinación apropiada como para generar un transitorio de $\mathrm{Ca}^{2+}$,

- mediada por RyR2 únicos,

- mediada por otros canales de la membrana del RS diferentes al RyR2, por ejemplo el receptor de inositol 1,4,5-trifosfato. ${ }^{43}$

Los sparks son eventos de pérdida de $\mathrm{Ca}^{2+}$ que involucran un grupo de RyR2 (figura I.6, panel izquierdo), alcanzan el pico con una velocidad de aumento del doble de fluorescencia en $10 \mathrm{mseg}$, y se disipan en $20 \mathrm{mseg}$. Las características de frecuencia, amplitud, duración y ancho dependen principalmente de la actividad del RyR2 y de la carga de $\mathrm{Ca}^{2+}$ del RS (que depende de la actividad de la SERCa2a), pero en promedio tienen un diámetro de sección transversal de $2.0 \mu \mathrm{m}$ y un volumen de $8 \mathrm{fl}$ (femtolitros). ${ }^{63}$ La ocurrencia de sparks no sucede por el fenómeno de $\mathrm{LCIC}$, descripto en el AEC, es decir que los sparks ocurren en diástole sin despolarización previa de la membrana sarcoplasmática, por lo que la $I_{C a}$ no está involucrada en su generación ${ }^{63}$. Además, el incremento de la frecuencia de sparks de $\mathrm{Ca}^{2+}$ produce la depleción de $\mathrm{Ca}^{2+}$ del $\mathrm{RS}$ ya que el $\mathrm{Ca}^{2+}$ que se pierde por los RyR2 es removido de la célula por el NCX, lo cual tiene un efecto de retroalimentación negativa que tiende a disminuir la frecuencia de sparks.

Los sparks pueden activar grupos de RyR2 cercanos. Esto se refleja en la activación sincrónica de múltiples sparks vecinos formando un macro spark. El aumento en la amplitud y duración del spark, y de la actividad del RyR2 pueden propiciar la propagación transversal, generando una onda o wave de $\mathrm{Ca}^{2+}$ (figura I.6, panel derecho).
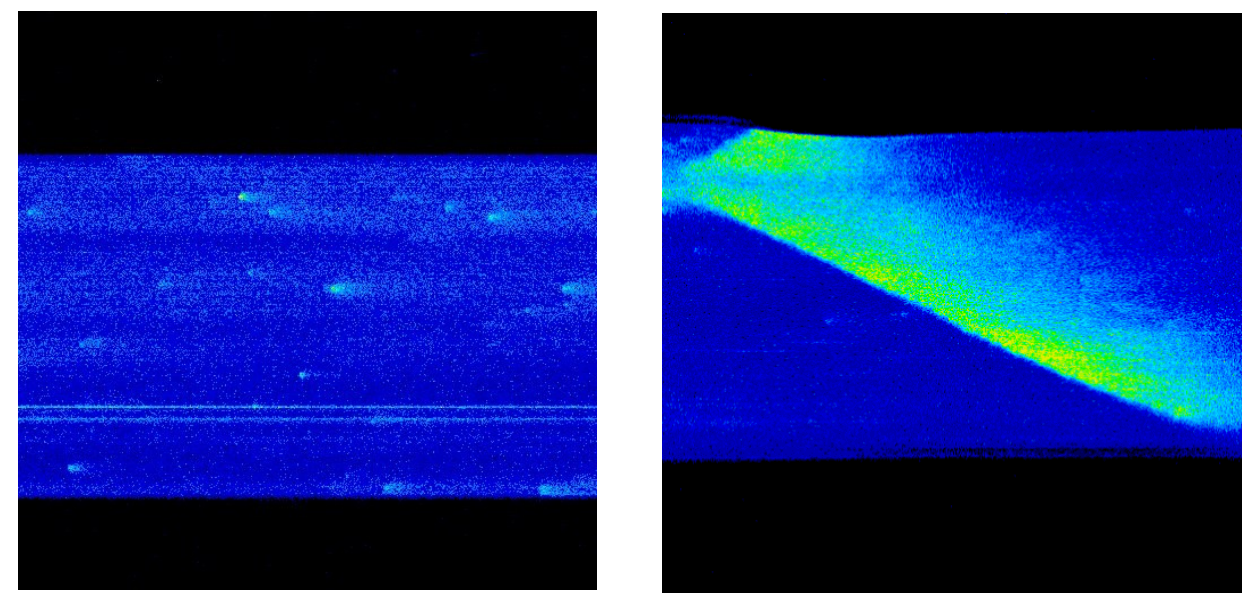
Figura l.6: Imágenes de escaneo lineal por microscopía confocal de miocitos ventriculares intactos aislados de corazones de ratas cargados con el indicador para $\mathrm{Ca}^{2+}$ Fura-2AM, donde se observan sparks (a la izquierda) y una wave (a la derecha).

Las pérdidas espontáneas de $\mathrm{Ca}^{2+}$ del RS, por tanto, participan en la generación de arritmias por medio de posdespolarizaciones $u$ oscilaciones del potencial de membrana, tardías (DAD - delayed afterdepolarization) o tempranas (EAD - early afterdepolarization), generando, si alcanzan el umbral, contracciones fuera de ritmo. $^{65}$

Como se mencionó, las pérdidas de $\mathrm{Ca}^{2+}$ por el RS pueden activar grupos de RyR2 cercanos generando una mayor pérdida del ion. El volumen de $\mathrm{Ca}^{2+}$ liberado al citosol puede ser captado por la SERCa2a (dependiendo de la actividad de la misma) o puede ser extruido de la célula por el $\mathrm{NCX}{ }^{55}$ En este último caso, la disminución del $\mathrm{Ca}^{2+}$ citosólico se produce a expensas del ingreso de $\mathrm{Na}^{+}$. Dependiendo de la magnitud del intercambio de $\mathrm{Ca}^{2+}$ por $\mathrm{Na}^{+}$se va a producir una despolarización de la membrana plasmática, que podrá o no alcanzar el umbral para generar un PA, hecho que se denomina DAD. Las DADs se producen después de la finalización del potencial de acción. Las DADs se forman en condiciones donde el $\mathrm{Ca}^{2+}$ intracelular está elevado, por una corriente denominada $I_{t i}$. Dicha corriente, dependiendo la especie, puede tener distintos componentes; entre ellos, corrientes no selectivas de cationes, la corriente del NCX $\left(I_{N C X}\right)$ y la corriente de $\mathrm{Cl}^{-}$ activada por $\mathrm{Ca}^{2+}$. Se ha encontrado que en corazones humanos solo la corriente del NCX contribuye a la $I_{t i}$ y por ende a la generación de $\operatorname{DAD}^{65,66}$ (figura I.7).

La EAD se define como una disminución de la velocidad o reversión de la repolarización normal durante la fase 2 o la fase 3 del PA. Las EADs ocurren en el contexto de una reducción de las corrientes hacia afuera, un incremento de las corrientes hacia adentro o ambos. En los rangos de voltaje a los cuales ocurren las EADs, las corrientes que contribuyen a su generación son $I_{C a}$ e $I_{N C X}$. La iniciación de la $E A D$ se debe principalmente a la reactivación de la $I_{C a}$. Si la conductancia del $\mathrm{K}^{+}$ comienza a aumentar demasiado lentamente al comenzar la repolarización, la recuperación dependiente del tiempo y el voltaje de la $I_{C a}$ luego de su inactivación, produce la reversión de la repolarización, generando las alteraciones del potencial de membrana de las EAD. ${ }^{67}$ En segundo lugar, la $I_{N C X}$ facilita la formación de EAD. Mientras la $\left[\mathrm{Ca}^{2+}\right]_{i}$ está, todavía, elevada durante la repolarización, la $I_{N C X}$ se vuelve tan importante como las corrientes repolarizantes, conduciendo a una prolongación de la repolarización. Sin embargo esta corriente por sí sola no es capaz de iniciar EAD si la concentración de $\mathrm{Ca}^{2+}$ no aumenta más. ${ }^{68}$ En este sentido, se ha observado que la hiperactividad de CaMKII realza las EADs a través de su efecto 
sobre $I_{\mathrm{Na}}$. Todos estos cambios en su conjunto, además de la fosforilación de RyR, gatillan las EADs ${ }^{69}$

Las EADs son un fenómeno clínicamente importante, debido a que son una causa probable del inicio de arritmias letales asociadas con prolongación del intervalo QT; un intervalo QT largo se asocia a una fase de repolarización del potencial de acción prolongada. ${ }^{70}$

$\bar{A}$

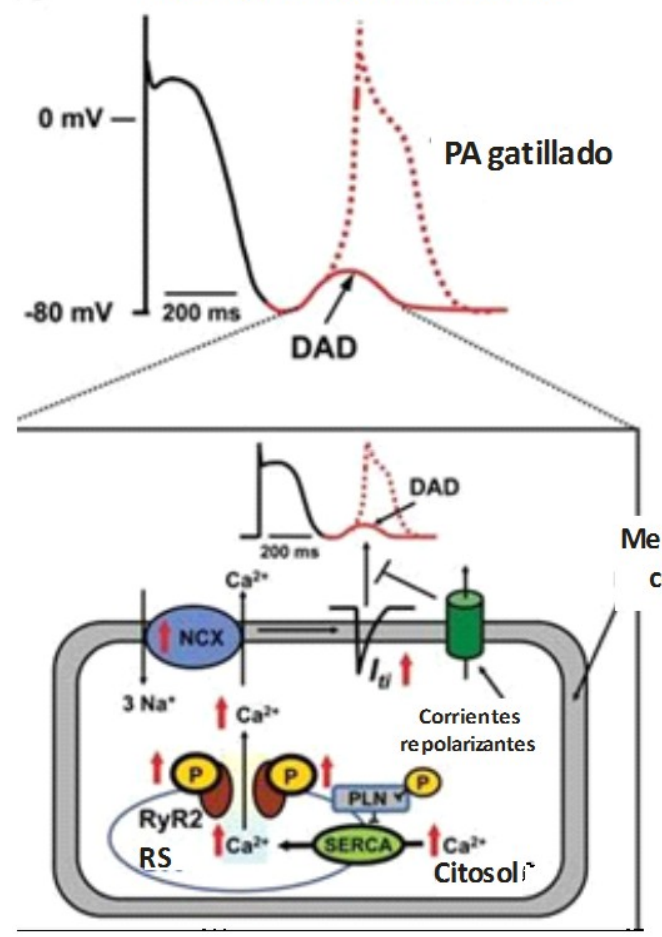

B

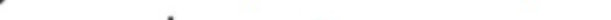

2. Arritmias

a. Bases electrofisiológicas del acoplamiento excitocontráctil c. Miocardiopatía diabética: arritmias en Diabetes Mellitus y prediabetes
Figura l.7: Esquema de generación de posdespolarizaciones tempranas (EAD, del inglés early afterdepolarización) y tardías (DAD, del inglés delayed afterdepolaritation). PA: potencial de acción, NCX: intercambiador $\mathrm{Na}^{+}-\mathrm{Ca}^{2+}, I_{t i}$ : corriente catiónica transitoria hacia adentro, RyR2: receptor de rianodina isoforma 2, RS, retículo sarcoplasmático, PLN: fosfolamban, SERCA: Bomba de $\mathrm{Ca}^{2+}$ del $R S$, I Kur: corrienten de $\mathrm{K}^{+}$ultrarrápido. I CaL: corriente lenta de $\mathrm{Ca}^{2+}, I_{\mathrm{Na}}$, corriente de $\mathrm{Na}^{+}$, CaMKII. Quinasa dependiente de $\mathrm{Ca}^{2+} /$ calmodullina isoforma 2. Imagen modificada de "The multidimensional role of calcium in atrial fibrillation pathophysiology: mechanistic insights and therapeutic opportunities". Nattel, et. al. Euripean Heart Journal 2012. ${ }^{71}$

\section{c. Miocardiopatía diabética: arritmias en Diabetes Mellitus y prediabetes}

Como ya ha sido mencionado, la diabetes mellitus (DM) es un fenómeno causal, ampliamente reconocido, de insuficiencia cardiaca. La frecuencia de la misma se incrementa al doble en varones con DM y cinco veces más en mujeres diabéticas, comparados con sujetos controles de igual edad ${ }^{72}$. 
La miocardiopatía diabética (MCD) es una entidad única y distintiva, la cual no está asociada a la edad, hipertensión, obesidad, hipercolesterolemia, o enfermedad arterial aterosclerótica coronaria o alguna otra comorbilidad asociadas a DM. ${ }^{73}$

Esta se caracteriza por 5 cambios a nivel miocárdico:

1) macroangiopatía diabética: cambios bioquímicos y estructurales en la lámina media de las arterias coronarias extramurales,

2) microangiopatía diabética: cambios histológicos en la pared de capilares y arteriolas intramurales pequeñas junto con la detección de microaneurismas y engrosamiento de la membrana basal capilar,

3) cambios intersticiales en el miocardio con acumulación de tejido conectivo y glicoproteínas,

4) presencia de neuropatía autonómica cardiaca, y

5) disfunción de las células miocárdicas por pérdida de la homeostasis metabólica. ${ }^{74}$

En fases tempranas, la MCD presenta las anormalidades metabólicas clásicas de la diabetes, como los aumentos de la insulinemia, la trigliceridemia, los ácidos grasos, y la alteración de la curva de tolerancia oral a la glucosa. ${ }^{75}$ En etapas más avanzadas, se observan cambios irreversibles en el tejido miocárdico, como ser: anormalidades estructurales permanentes del colágeno por glicosilación, aumento de la fibrosis miocárdica, compromiso de la musculatura intramural y la existencia de neuropatía autonómica ${ }^{74}$.

La MCD se caracteriza por disfunción diastólica y sistólica, e hipertrofia ventricular izquierda evidenciada por ecocardiografía, tanto en humanos como en distintos modelos murinos de DMT1 y DMT2 ${ }^{76-79}$.

La anormalidad del llenado diastólico constituye un signo temprano de disfunción ventricular izquierda y puede preceder a las anormalidades de la función sistólica. La prolongación del tiempo de relajación isovolumétrica y prolongación del período de llenado rápido son algunas alteraciones de la relajación. ${ }^{80}$

Histológicamente, los corazones de pacientes diabéticos presentan signos de fibrosis, hipertrofia y dilatación. Estudios electrocardiográficos han evidenciado cambios en pacientes diabéticos en reposo, respecto de pacientes controles, producto del aumento de la duración de la onda $\mathrm{P}$, cambios en el eje QRS, inversión de la onda $\mathrm{T}$ y prolongación del intervalo $\mathrm{QT}^{80}$. Así mismo, se ha demostrado en ratones $\mathrm{db} / \mathrm{db}$ (modelo de DMT2) que la resistencia a la insulina por sí sola puede provocar el daño cardiaco y aumentar la sensibilidad de los corazones de roedores al daño por isquemia/reperfusión. ${ }^{81}$ 
Al comparar los modelos animales de DM con el humano surgen varios factores a tener en cuenta: la frecuencia cardiaca es diferente en ambos, y los roedores son menos propensos a desarrollar enfermedad aterosclerótica en arterias coronarias e isquemia espontánea que los humanos con $\mathrm{DM}^{82}$. Sin embargo, múltiples estudios en humanos soportan muchos de los mecanismos mencionados en estudios en animales $^{83-85}$.

Entre otras causas, y similar a lo que sucede en la insuficiencia cardiaca de otras etiologías, la falla cardiaca en DM crónica está asociada, en parte, a una alteración en la homeostasis del $\mathrm{Ca}^{2+}$ y a una disminución de la actividad $\mathrm{Ca}^{2+}$ ATPasa en las miofibrillas. Esto se debe a un cambio de isoformas en las cadenas de miosina y una alteración en la fosforilación de la cadena ligera de miosina, con la consiguiente disminución de la unión al $\mathrm{Ca}^{2+}$ y cooperatividad ${ }^{86}$.

Entre las múltiples hipótesis sobre la patogénesis de la MCD se encuentra: disfunción autonómica, desarreglo metabólico, anormalidades en la homeostasis de iones, alteraciones en proteínas estructurales, y fibrosis intersticial ${ }^{87,88}$. Es probable que la ausencia de insulina y la combustión lipídica aumentada por la acumulación de metabolitos de la oxidación de ácidos grasos, tenga consecuencias sobre el transporte de $\mathrm{Ca}^{2+}$ celular en el proceso de acoplamiento excitocontráctil. ${ }^{89}$

2. Arritmias a. Bases electrofisiológicas del acoplamiento excitocontráctil

\section{i. Metabolismo}

En el corazón sano, la principal fuente de energía (60-70\%) son los ácidos grasos (AG). Estos provienen del tejido adiposo, son transportados por la albúmina desde el hígado e intestino como quilomicrones y lipoproteínas de muy baja densidad (VLDL). El tejido cardiaco degrada los AG con la lipoproteína lipasa (LPL) ubicada en la superficie de las células endoteliales en la vasculatura coronaria. El ingreso de los AG se produce principalmente por difusión, aunque también puede producirse a través de proteínas transportadoras como la AG traslocasa/CD36 (FAT36), la proteína de unión de $A G$ de la membrana plasmática (FABPmp) y la proteína transportadora de AG (FATP). Al igual que el transportador de glucosa GLUT 4 (figura I.8), la proteína FAT36 se trasloca de un compartimento intracelular al sarcolema inducido por insulina.

Una vez dentro de la célula, los $A G$ se activan a través de la incorporación de cofactor A (CoA), siendo esta reacción catalizada por la acil-CoA sintetasa (ACS). Estos acil-CoA pueden tener tres destinos distintos dependiendo del estado metabólico del organismo:

1) la síntesis de triglicéridos (TG): un $10 \%$ es almacenado de esa manera, 
2) la formación de complejos lipoproteicos junto la apoproteína $B$ y la proteína de transferencia de AG microsomal (MTP); o

3) pueden entrar en la vía catabólica.

La catálisis de los ácidos grasos se produce a través de la $\beta$-oxidación, un proceso por medio del cual estos son oxidados sucesivamente, hasta su descomposición total en forma de acetil-coA. La $\beta$-oxidación ocurre dentro de la mitocondria, hacia donde los acil-CoA son transportados por la carnitina palmitoil transferasa 1 (CPT1), localizada en la membrana mitocondrial externa. La actividad de la CPT-1 puede ser inhibida con el aumento de la concentración citosólica de malonaldheído, la cual se regula a su vez por la acción de dos enzimas: la acetil-CoA carboxilasa (ACC) que cataliza su formación y la malonil-CoA decarboxilasa que lo degrada. Una vez dentro de la mitocondria, la acil carnitina es reconvertida a acil-CoA por la acción de la carnitina palmitoil transferasa 2 (CPT-2), en la membrana mitocondrial, para ser degrada luego via $\beta$-oxidación. El acetil-CoA generado de este modo, incrementa el poder reductor y la producción de ATP por medio del el ciclo de Krebs y la fosforilación oxidativa ${ }^{90}$. (Figura I.8)

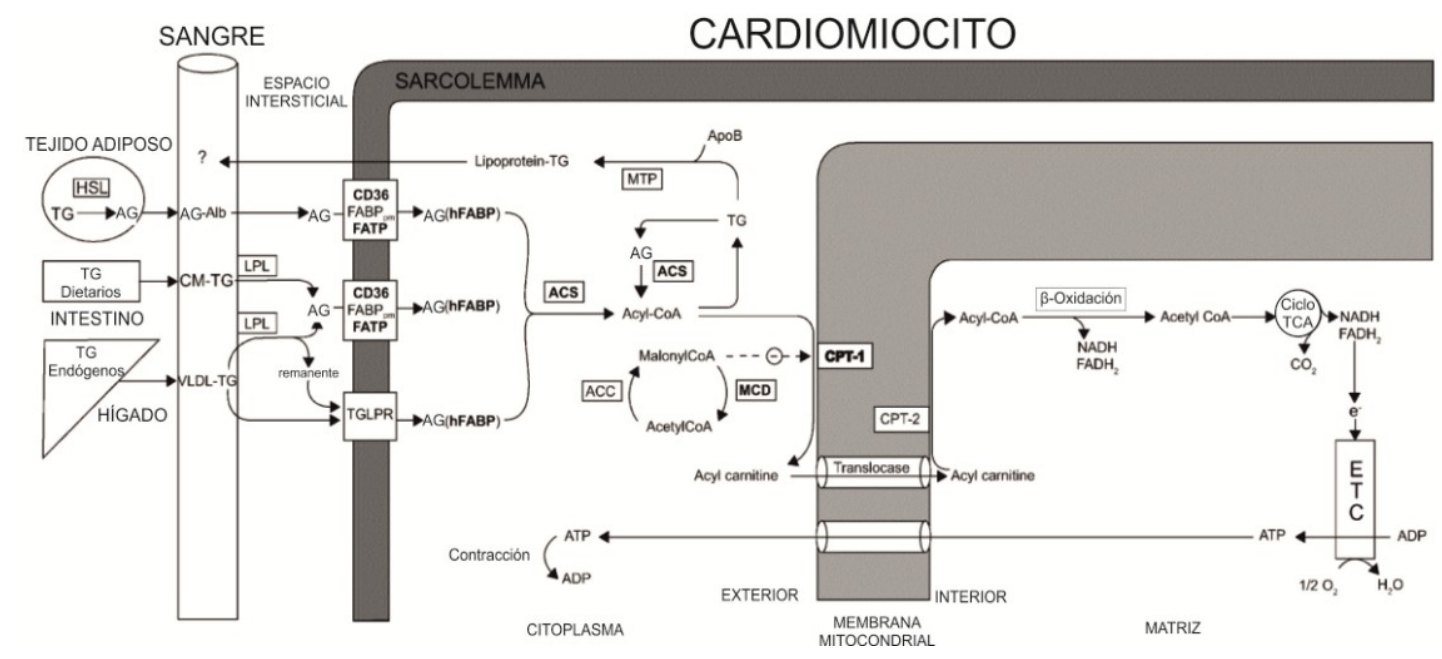

Figura I.8: Metabolismo cardiaco de ácidos grasos (AG). Hay dos fuentes exógenas de AG en la circulación que están disponibles para la utilización cardiaca: a) la lipolisis del tejido adiposo (catalizado por la lipasa sensible a hormona, HSL) produce AG circulantes unidos a albumina plasmática (Alb); y b) a partir de triglicéridos (TG) tomados de las lipoproteínas circulantes, por la acción hidrolítica de la lipoproteinlipasa (LPL) localizada en el endotelio de la vasculatura coronaria, se producen $A G$ o a través de la lipoproteína mediada por receptor (TGLPR). Los quilomicrones (CM) transportan TG que ingresan con la dieta, mientras que las lipoproteínas de muy baja densidad (VLDL) transportan TG endógenos formados en el hígado. El metabolismo intracelular de los AG involucra la formación de acil CoA y, luego, su esterificación a TG o entrada a la mitocondria (CPT-1 dependiente) para la $\beta$ - oxidación y la producción de energía por la cadena transportadora de electrones (ETC) y la 
fosforilación oxidativa. La actividad de CPT-1 está regulada por el contenido de malonil CoA, determinado por los efectos netos de la síntesis por la enzima acetil Coa carboxilasa (ACC) y la degradación catalizada por la enzima malonil CoA decarboxilasa (MCD). Imagen modificada de "Fatty acid metabolism is enhanced in type 2 diabetic hearts". Andrew N. Carley, David L. Severson. Biochimica et Biophysica Acta (BBA). 2005. ${ }^{90}$

Los cambios en los niveles de los sustratos y la alteración del metabolismo energético a nivel del miocardio, son factores que contribuye en gran medida al desarrollo de MCD. ${ }^{91,92}$ La DM se caracteriza por la reducción en el metabolismo de la glucosa y del lactato, acompañada por un incremento del metabolismo de los AG. ${ }^{90,93}$ A pesar del incremento en el uso de AG por el corazón diabético, la incorporación de AG por el miocito supera la tasa de oxidación, resultando en la acumulación lipídica en el miocardio, lo que promueve la acumulación de lípidos en tejidos ectópicos no adiposo ${ }^{94-96}$. El depósito de lípidos en el tejido cardiaco está relacionado con la presencia de insuficiencia cardiaca, sobre todo en modelo de ratones con DMT2. Además existe una correlación positiva con la expresión de genes regulados por el receptor activado por el proliferador de peroxisomas $\alpha$ (PPAR- $\alpha$ ), (como la deshidrogenasa de acil-CoA de cadena intermedia (MCAD) y CPT-1) y un aumento de los niveles de TNF- $\alpha$ en los corazones con falla cardiaca ${ }^{94}$. Los lípidos contribuyen a los cambios en la disponibilidad de sustrato que caracteriza al corazón diabético, entre ellos están el incremento en la cantidad de AG disponible para el corazón y la disminución de la señalización de la insulina, ambos mediados por la activación de vías transcripcionales como la red de señalización PPAR- $\alpha / P G C-1$, que regula el uso de sustratos en el miocardio ${ }^{97-100}$. Esta activación de PPAR- $\alpha$ incrementa la expresión de la piruvato deshidrogenasa quinasa 4 (reguladora de la oxidación de glucosa), y genes como FAT36, y malonilCoA descarboxilasa, llevando a la desrepresión de la CPT-1 y estimulando, así, la incorporación mitocondrial de AG y su oxidación. Otros genes involucrados en la $\beta$ oxidación blancos transcripcionales de PPAR- $\alpha$ son la acil CoA deshidrogenasa de cadenas medianas y largas, y la hidroxi acil CoA deshidrogenasa. El aumento del uso de $A G$ se relaciona con disfunción cardiaca en modelos de DM, siendo la PPAR- $\alpha$, una de las moléculas mediadoras del proceso deletéreo. ${ }^{97,98}$ En contraste, los agonistas de PPAR-y producen una sensibilización a la insulina en los tejidos dianas, como el adiposo y el cardiaco, entre otros. A partir de esto, su activación permite la disminución de los niveles de colesterol y mejora el metabolismo cardiaco. ${ }^{101}$ Pero de manera contradictoria, y aún en discusión, a pesar de la reducción en la oxidación de $A G$ y el incremento del uso de glucosa con la concomitante normalización de la homeostasis metabólica sistémica, el tratamiento 
de ratones $d b / d b$ de diferentes edades con agonistas de PPAR- $\gamma$ no puede revertir la disfunción cardiaca, lo que indicaría que otros factores estarían también involucrados en la disfunción contráctil ${ }^{78,102}$.

Otro mecanismo que puede contribuir al incremento de la absorción de AG en el miocardio en ratones con DMT2 es la redistribución de los CD36 a la membrana plasmática. Este es un receptor secuestrador de ligandos, como: colágeno, trambospondina y eritrocitos paracitados, LDL oxidada y nativa, fosfolípidos y ácidos grasos, que entre otras funciones, trasloca $A G$ de cadena larga hacia el interior de las células. ${ }^{103}$ Por otro lado, la señalización de la insulina alterada puede tener efectos independientes al receptor de insulina, a través de la vía Ras, que reducen el uso de la glucosa en el miocardio e incrementan la expresión de genes asociados con PPAR- $\alpha$, los cuales aumentan la utilización de AG. ${ }^{104}$

Prevenir la alteración del metabolismo de sustratos en ratones $d b / d b$ a través de la sobreexpresión perinatal del transportador de glucosa GLUT4 evita el desarrollo de disfunción cardiaca ${ }^{77,105}$, lo cual sugiere que la modulación del metabolismo de la glucosa tiene un papel de importancia en el desarrollo de MCD, aunque sea el sustrato metabólico menos utilizado por el miocardio.

Esta serie de cambios que se producen en el miocardio diabético llevan a una reducción de la eficiencia cardiaca, es decir la relación entre el trabajo cardiaco y el consumo de oxígeno ${ }^{106-109}$. El incremento de la expresión mitocondrial y citosólica de tioestearasas, enzimas capaces de catalizar la hidrólisis de los ésteres de AGCoA, también ha sido propuesto como contribuyente en la reducción de la eficiencia cardiaca incrementando el ciclo fútil de los $A G$, promoviendo la oxidación de $A G$ actuando sobre la proteína desacoplante 3 , cuya función es desacoplar la síntesis de ATP del metabolismo oxidativo. ${ }^{110,111}$

2. Arritmias a. Bases electrofisiológicas del acoplamiento excitocontráctil

\section{ii. Manejo del $\mathrm{Ca}^{2+}$}

La principal alteración en la homeostasis del $\mathrm{Ca}^{2+}$, que conduce a una disfunción cardiaca en la MCD, es la disminución de la actividad de bombasATPasas. ${ }^{112} \mathrm{La}$ disminución de la velocidad de retoma de $\mathrm{Ca}^{2+}$ por SERCa2a y de la ATPasa de $\mathrm{Ca}^{2+}$ de la membrana sarcolemal (PMCa), ${ }^{113,114}$ conduce a la disminución del contenido de $\mathrm{Ca}^{2+}$ del RS en miocitos de ratas con DMT1. Sin embargo, no hay cambios en las corrientes del canal de $\mathrm{Ca}^{2+}$ tipo $\mathrm{L}$ dependiente de voltaje. ${ }^{115}$

En el modelo de ratón db/db de DMT2 tanto la carga del RS como el eflujo de $\mathrm{Ca}^{2+}$ desde el mismo están reducidas en cardiomiocitos, así como también la expresión del RyR2. Por el contrario, la salida de $\mathrm{Ca}^{2+}$ por el NCX se encuentra aumentada ${ }^{116}$. En conjunto, estos resultados se asocian con una pérdida de $\mathrm{Ca}^{2+}$ disincrónica en 
diástole en ratones con DM, lo cual contribuye a la disminución de la carga del $\mathrm{RS}^{2}{ }^{2}$ A partir de experimentos en ratas en las que se indujo diabetes con estreptozotocina, que produce degeneración de las células $\beta$ de los islotes de Langerhans del páncreas por disminución del dinucleótido de nicotinamida-adenina (NAD) ${ }^{117}$ se ha evidenciado que la estimulación $\beta$-adrenérgica está deprimida. En consecuencia, existe una disminución en los miocitos del ingreso de $\mathrm{Ca}^{2+}$, que se revierte con la administración de insulina. Lo que indicaría que podría deberse a una falta de producción de AMPc luego de la estimulación de los receptores adrenérgicos. $^{118}$

Por otra parte, la activación del sistema renina angiotensina juega un rol importante en el desarrollo de la MCD. En el corazón diabético se establece un aumento en la expresión ARNm y densidad del receptor de angiotensina ${ }^{1119,120}$. Este aumento está asociado con incremento del daño oxidativo, apoptosis y necrosis de cardiomiocitos y células endoteliales en corazón $^{7,121}$, lo que contribuye al incremento de fibrosis intersticial y disminución de las unidades contráctiles. El incremento de la producción de las especies reactivas del oxígeno (ROS) y del nitrógeno (RNS), y la caída de las defensas antioxidantes en el corazón diabético son factores que, también, contribuyen al desarrollo y al progreso de la MCD ${ }^{122,123}$. Los ROS se forman por una reducción incompleta del oxígeno durante la respiración. Se incluye dentro de este grupo al radical superóxido, el radical hidroxilo y al peróxido de hidrógeno, sustancias altamente reactivas y oxidantes debido a la desestabilización por la presencia de electrones desapareados. Además de la producción durante la respiración, los ROS se generan por complejos enzimáticos como la dinucleótido nicotinamida-adenina fosfato oxidasa (NADPH ox.), óxido nítrico sintasa desacoplada, xantina oxidasa, lipooxigenasa, mieloperoxidasa y citocromo P450. Estos sistemas pueden estar constitutivamente expresados y activarse ante distintos estímulos o ser inducibles, por ejemplo ante el estímulo de angiotensina II. ${ }^{7,124}$ A su vez, la desintegración de los ROS es catalizada por complejos antioxidantes como la superóxido dismutasa, catalasa, glutatión reductasa y peroxireductasa. Los RNS incluyen al radical óxido nítrico y radical peroxinitrilo, generados por las óxido nítrico sintasas y la superóxido dismutasa que, al igual que los ROS, tienen efectos oxidantes y deletéreos sobre subestructuras celulares. ${ }^{125}$

En la MCD, los sistemas de producción de ROS, NADPH ox., óxido nítrico sintasa desacoplada y xantina oxidasa, están aumentados produciendo alteraciones morfológicas y funcionales sobre estructuras celulares vitales. Se ha demostrado que la sobreexpresión de la superóxido dismutasa mitocondrial en el corazón de un 
modelo de ratón con DMT1 revierte la alteración de la morfología y la función mitocondrial, y mantiene la función del cardiomiocito ${ }^{126}$; así como la sobreexpresión de las metalotioneínas (un grupo de proteínas intracelulares con sitios de unión a metales, que contienen una alta proporción de cisteínas, las cuales protegen a las células del daño oxidativo) previene la apoptosis y los signos de fibrosis ${ }^{122}$. Así mismo, existe evidencias que avalan el incremento de la producción de ROS no mitocondrial como la nicotinamida adenina dinucleotido fosfato oxidasa (NADPH ox.) o la reducción de la actividad de la óxido nítrico sintasa neuronal (NOS1) acoplado al incremento de la activación de la xantina oxidoreductasa ${ }^{127,128}$. Este incremento en la generación de ROS por encima del umbral en el que se comportan como moléculas de señalización fisiológicas, activa vías de señalización maladaptativas, que podrían contribuir a la patogénesis de la MCD, como el aumento en la fosforilación de ERK $1 / 2$ y JNK, entre otras, que conducen a hipertrofia del miocito y apoptosis. ${ }^{129}$

La mitocondria parecería cumplir un rol esencial en la secuencia de procesos que llevan a la MCD. Se ha observado una disminución de la respiración mitocondrial y de la expresión de proteínas involucradas en la fosforilación oxidativa en ratones obesos con DMT2 $2^{106}$. Además, las mitocondrias de corazones de animales con DMT1 mostraron una baja actividad de creatinina fosfoquinasa ${ }^{130,131}$ y ATP sintasa ${ }^{132}$. Otros defectos incluyen: la disminución de la retoma de $\mathrm{Ca}^{2+}$ por la mitocondria $^{133}$, que se atribuye en parte a un aumento de la permeabilidad ${ }^{134}$, y el incremento de la $\beta$-oxidación, lo que conduce a un aumento de la producción de sustrato reductor para la cadena de transporte de electrones. Sin embargo, la limitación en los componentes de la fosforilación oxidativa resulta en un incremento en la producción de superóxido, lo que podría desacoplar la mitocondria y reducir la eficiencia de la generación de ATP ${ }^{106,135}$. En corazones de ratones con diabetes inducida con aloxano (derivado de la oxidación del ácido úrico, que actúa como necrosante de las células $\beta$ del páncreas a través de la producción de ROS, induciendo DM) se observa un aumento en la nitración de proteínas mitocondriales. Esta modificación posttraduccional es causada por agentes nitrantes como el óxido nítrico, el dióxido de nitrógeno y el peroxinitrito, es usada como índice de daño oxidativo. $^{136}$. La elevada producción de peróxido de hidrógeno y los niveles reducidos de glutatión de los corazones diabéticos pueden ser atenuados con rotenona (un inhibidor del complejo I de la cadena respiratoria y del poro de transición mitocondrial), lo que sugeriría una fuente mitocondrial para los $\operatorname{ROS}^{137}$. El análisis ultraestructural de tejido miocárdico, en modelos de DMT1 y DMT2, ha revelado una proliferación mitocondrial. ${ }^{138}$ Esta evidencia podría ser explicada por la 
activación demostrada de genes de la vía regulatoria de PPAR- $\alpha / P G C 1-\alpha$ en modelos de $\mathrm{DM}^{139,140}$. A pesar de este aumento en la masa de mitocondrias, no es suficiente para aumentar la capacidad de los componentes de la fosforilación oxidativa y compensar la pérdida de función por el daño que sufren en el contexto de la $\mathrm{DM}^{138}$.

Los pacientes con DM que desarrollan MCD tienen una tendencia aumentada a presentar arritmias, entre otras complicaciones. Existen estudios que muestran que alrededor del $75 \%$ de los pacientes con DM presentan alteraciones del electrocardiograma en reposo, predominando en individuos de sexo masculino mayores de 50 años. Entre las afecciones más frecuentes se encuentran el bloqueo de rama derecha del Haz de His y prolongación de intervalo QT. ${ }^{141}$ Además, existe una relación entre la presencia de eventos anormales en el electrocardiograma y el riesgo de padecer una enfermedad cardiovascular, tanto en personas sin enfermedad de base como en pacientes con DMT2. En los primeros, el riesgo se incrementa entre dos y cuatro veces, mientras que en el segundo grupo, el riesgo de padecer una enfermedad cardiovascular en los próximos cinco años habiendo tenido un electrocardiograma anormal es ocho veces mayor. ${ }^{142,143}$ Entre las arritmias más frecuentes que se encontraron en modelos de diabetes en animales están la fibrilación ventricular y extrasístoles repetitivas, teniendo estos animales un aumento de la vulnerabilidad y una disminución del umbral de aparición de arritmias ante un proceso isquémico. ${ }^{144}$

La hiperglucemia, la resistencia a la insulina y el incremento del estrés oxidativo consecuente, vienen emparejados con un mayor riesgo a desarrollar daño cardiovascular. ${ }^{145}$ La neuropatía autonómica originada por la DM puede afectar el corazón produciendo arritmias ventriculares y muerte súbita, evidenciándose con un QT prolongado; dependiendo de la duración de la diabetes y los niveles de glucemia que maneje el paciente. Además, los factores agregados que presentan los pacientes con DM, como hipertensión y enfermedad coronaria, contribuyen al daño miocárdico. ${ }^{146}$

Existen controversias al correlacionar la DM con la fibrilación auricular. Si bien se observa una mayor ocurrencia de este tipo de fibrilación ante un estímulo adrenérgico y retrasos de conducción con depósitos fibróticos que pueden explicarlo, por otro lado, estudios como el Framingham y Manitoba descartan la DM como único factor causal de fibrilación atrial debido a que comparte antecedentes en común como hipertensión, aterosclerosis y obesidad. ${ }^{146}$ Anteriormente se han mencionado distintos mecanismos que conducen a la aparición de eventos arrítmicos. En cuanto a los mecanismos celulares a través de los cuales pueden 
desarrollarse las arritmias en pacientes con diabetes, encontramos la alteración de canales iónicos y la aparición de DADs. Se ha observado en trabajos anteriores que los corazones diabéticos exhiben un potencial de acción prolongado, lo que se correlaciona con un intervalo QT prolongado en el registro electrocardiográfico. ${ }^{147}$ Por otra parte, el miocardio ventricular de ratas diabéticas es más propenso a desarrollar posdespolarizaciones que las normales en condiciones de sobrecarga de $\mathrm{Ca}^{2+}{ }^{148}$ Las alteraciones en el manejo del $\mathrm{Ca}^{2+}$ en distintos modelos de $\mathrm{DM}$, por cambios en las proteínas involucradas (PMCa, RyR, NCX, entre otras), conducen a cambios del potencial de membrana volviendo a las células más susceptibles a la despolarización espontánea y a la producción de latidos ectópicos. En estados de resistencia a la insulina y tolerancia a la glucosa alterada existe una asociación con el QT prolongado en hombres mayores de 70 años, involucrando una repolarización miocárdica anormal. ${ }^{149}$ Sin embargo, es poca la literatura destinada a determinar los mecanismos moleculares de las arritmias en el estado de prediabetes.

\section{Muerte celular}

3. Muerte celular a. Apoptosis

i. Eventos citosólicos

ii. Eventos nucleares
Como ya ha sido comentado anteriormente, la diabetes mellitus se caracteriza por presentar un incremento en la frecuencia y severidad de infarto de miocardio. Además, los pacientes diabéticos tienen el doble de riesgo de desarrollar insuficiencia cardiaca tras sufrir infarto de miocardio. ${ }^{150} \mathrm{La}$ insuficiencia cardiaca es una afección en la cual el corazón no aporta la cantidad de sangre requerida por el cuerpo. Esta puede ocurrir cuando el miocardio pierde la potencia necesaria para expulsar la sangre del corazón adecuadamente (con fracción de eyección reducida), o cuando el miocardio se vuelve rígido y no se llena de sangre fácilmente (con fracción de eyección preservada). ${ }^{151}$

Existen varios mecanismos que intentan explicar el proceso celular y molecular que lleva a la insuficiencia cardiaca. Entre ellos podemos mencionar alteraciones en el manejo del $\mathrm{Ca}^{2+}$ y la muerte celular. ${ }^{12}$

Está ampliamente reconocido que una disminución de la magnitud y velocidad de la contracción y relajación de los miocitos aislados se relaciona directamente con la disminución de la contracción del corazón en la insuficiencia cardiaca. Esta depresión en la actividad contráctil de los miocitos se asocia a una reducción de la ganancia del acoplamiento excitocontráctil (AEC), es decir, menor salida de $\mathrm{Ca}^{2+}$ del retículo sarcoplasmático (RS) ante una determinada entrada de $\mathrm{Ca}^{2+}$ por el LTCC, disminuyendo de esta forma la amplitud del transitorio de $\mathrm{Ca}^{2+}$ y por lo tanto el acortamiento. ${ }^{152}$ La pérdida de ganancia del AEC de las células insuficientes 
resulta de una disminución de la carga de $\mathrm{Ca}^{2+}$ del $\mathrm{RS}$ debida a una reducción del nivel y función de SERCa2a, y a la alteración de su proteína reguladora, al incremento de la pérdida de $\mathrm{Ca}^{2+}$ a través del RyR2 (frecuentemente asociado a aumento de la fosforilación en los sitios dependientes de CaMKII y PKA), incremento de la actividad del NCX, que vacía al miocito del $\mathrm{Ca}^{2+}$ perdido por el RS, y/o a un proceso de pérdida de comunicación entre los LTCC y los RyR2. En conjunto, esto lleva a un aumento de la salida $\mathrm{Ca}^{2+}$ de la célula con la consecuente reducción en las reservas de $\mathrm{Ca}^{2+}$ del $\mathrm{RS}$ y el aumento de la $\left[\mathrm{Na}^{+}\right]_{i}{ }^{12,152}$

La muerte celular por apoptosis y/o necrosis es considerada un factor causal en la insuficiencia cardiaca. En muestras de pacientes ${ }^{153}$ o en modelos murinos ${ }^{154}$ con miocardiopatía isquémica y miocardiopatía dilatada idiopática, se observa rotura de ADN sin pérdida de la morfología de las células, lo cual, condice con la progresión hacia apoptosis. La pérdida de un gran número de células puede afectar al sistema de conducción y desencadenar arritmias fatales. ${ }^{155}$ La isquemia y el corazón infartado se caracterizan por la presencia de apoptosis y necrosis de los miocitos. La disminución del flujo sanguíneo en el corazón insuficiente puede contribuir a la apoptosis, la cual por disminución de la cantidad de miocitos ventriculares, contribuye a la disfunción cardiaca. Sin embargo, hay mecanismos intrínsecos del miocito, independientes de la irrigación, que conducen a la apoptosis en el miocardio insuficiente.

\section{a. Apoptosis}

a. Apoptosis

i. Eventos citosólicos

ii. Eventos nucleares
La apoptosis o muerte celular programada es el proceso ordenado por el que la célula muere ante estímulos extra o intracelulares. La apoptosis es fundamental en el remodelado durante el desarrollo embrionario, en el desarrollo de órganos y sistemas, en el mantenimiento de la homeostasis del número de células y en la defensa frente a patógenos. Es un proceso finamente regulado, que cuando se altera produce graves patologías, como ser: malformaciones, defectos en el desarrollo, enfermedades autoinmunes, enfermedades neurodegenerativas o aparición de tumores.

La apoptosis es un proceso ordenado, con una serie de fases citosólicas y nucleares: ${ }^{156}$

1) disminución del volumen celular y pérdida de las características de adhesión,

2) degradación de proteínas y fragmentación del ADN,

3) condensación cromatínica,

4) aparición de burbujas en superficie, 
5) fragmentación del núcleo,

6) formación de los cuerpos apoptóticos (rodeados de membrana) y

7) fagocitosis de estos cuerpos apoptóticos por macrófagos, sin que vierta el contenido celular al exterior.

En condiciones patológicas, la inducción de la apoptosis puede ser generada por factores externos o internos al entorno celular. Citoquinas como el TNF, radiaciones, falta o exceso de señales hormonales o de factores tróficos son algunos ejemplos de estímulos extracelulares que inducen apoptosis. Entre los factores internos que pueden inducir apoptosis se pueden mencionar las infecciones por patógenos, el incremento de $\mathrm{Ca}^{2+}{ }_{i}$ o de los $\mathrm{ROS}^{157}$, la deposición de sustancias tóxicas para la célula, como ocurre en la enfermedad de Alzheimer ${ }^{158} \mathrm{o}$ daños irreparables del ADN mediados por la molécula p53.

\section{i. Eventos citosólicos}

i. Eventos citosólicos ii. Eventos nucleares
Podemos diferenciar a los eventos citosólicos en dos grandes grupos, de acuerdo con las señales que les dan origen: la vía apoptótica Tipo I o extrínseca, mediada inicialmente por la superfamilia de los receptores de muerte, y la Tipo II o intrínseca, mediada por las mitocondrias. Cada una de ellas posee una cascada de señalización propia aunque pueden entrecruzarse a lo largo de sus respectivos segundos mensajeros. Dentro de la célula existe un conjunto de moléculas que generan una respuesta apoptótica y otras que la previenen, siendo el equilibrio entre estos factores lo que determina la viabilidad de la célula. ${ }^{159}$

La vía apoptótica Tipo I comienza con la activación de dos superfamilias de receptores: los del factor de necrosis tumoral (TNF-R1) y los receptores Fas. La unión del ligando a estos receptores induce su trimerización y el reclutamiento de las llamadas moléculas adaptadoras al dominio de muerte, por ejemplo FADD, TRADD, TRAF y RIP, que son las encargadas de generar la traducción de señales del receptor activado ${ }^{160}$, formando el complejo de señalización inductor de muerte. La formación de este complejo recluta al iniciador de la vía de las caspasas en la vía extrínseca, la caspasa 8. Subsecuentemente, la caspasa 8 es activada por autoproteólisis, siendo ahora capaz de clivar y activar al efector final de la vía de las caspasas, la caspasa 3 . Luego de la activación de los receptores, se induce la activación de moléculas efectoras y de segundos mensajeros, tales como las familias de las Proteínas Kinasas Activadoras Mitogénicas (MAPK), los factores nucleares $K$ de cadena liviana activadores de células $B(N F-K B)$ y las kinasas de la familia Akt. Estos segundos mensajeros son los encargados de activar la expresión 
y/o fosforilar a las proteínas efectoras pertenecientes a las familias de proteínas pro o antiapoptóticas. Estos dos grupos de proteínas generan el mayor control de la vía apoptótica inducida por receptores de muerte. El mecanismo apoptótico mediado por receptores de muerte se hace presente en el miocardio y es significativo, en los procesos donde se exacerba la respuesta inflamatoria del mismo. ${ }^{161}$

La vía apoptótica Tipo II está mediada por las mitocondrias. Los estímulos proapoptóticos, como la respuesta al aumento del $\mathrm{Ca}^{2+}$, el estrés oxidativo y la depleción de ATP, ${ }^{162}$ estimulan la permeabilización de la mitocondria por la formación de poros entre las membranas de la organela (poro de transición mitocondrial, mPTP), conformados por el canal aniónico dependiente de voltaje (VDAC) en la membrana externa, la adenosina nucleótido translocasa (ANT) en la membrana interna y la ciclofilina-D perteneciente a la matriz mitocondrial de la organela. La permeabilización de la mitocondria libera al citosol un notable número de proteínas que facilitan la señalización apoptótica, como citocromo C, Smac/DIABLO, endonucleasa $G$ y factor inductor de apoptosis, entre otros. El citocromo $\mathrm{C}$ se une con la proteína citoplasmática factor apoptótico activador de proteasa 1 (Apaf1) y reclutan a la caspasa 9, induciendo su activación, a este complejo se lo denomina apoptosoma. El apoptosoma induce la activación de la caspasa 3. Así mismo, el complejo Smac/DIABLO facilita esta activación de caspasas ya que, secuestra proteínas inhibitorias de caspasas; mientras que la endonucleasa $G$ y el factor inductor de apoptosis son translocadas al núcleo y facilitan la degradación del DNA. Por su parte, la caspasa 3 activada como efectora final de la vía intrínseca o extrínseca actuará clivando o facilitando la degradación del aparato contráctil, todo el contenido citosólico y la degradación del material nucleico. ${ }^{156,161}$ (figura I.9) 


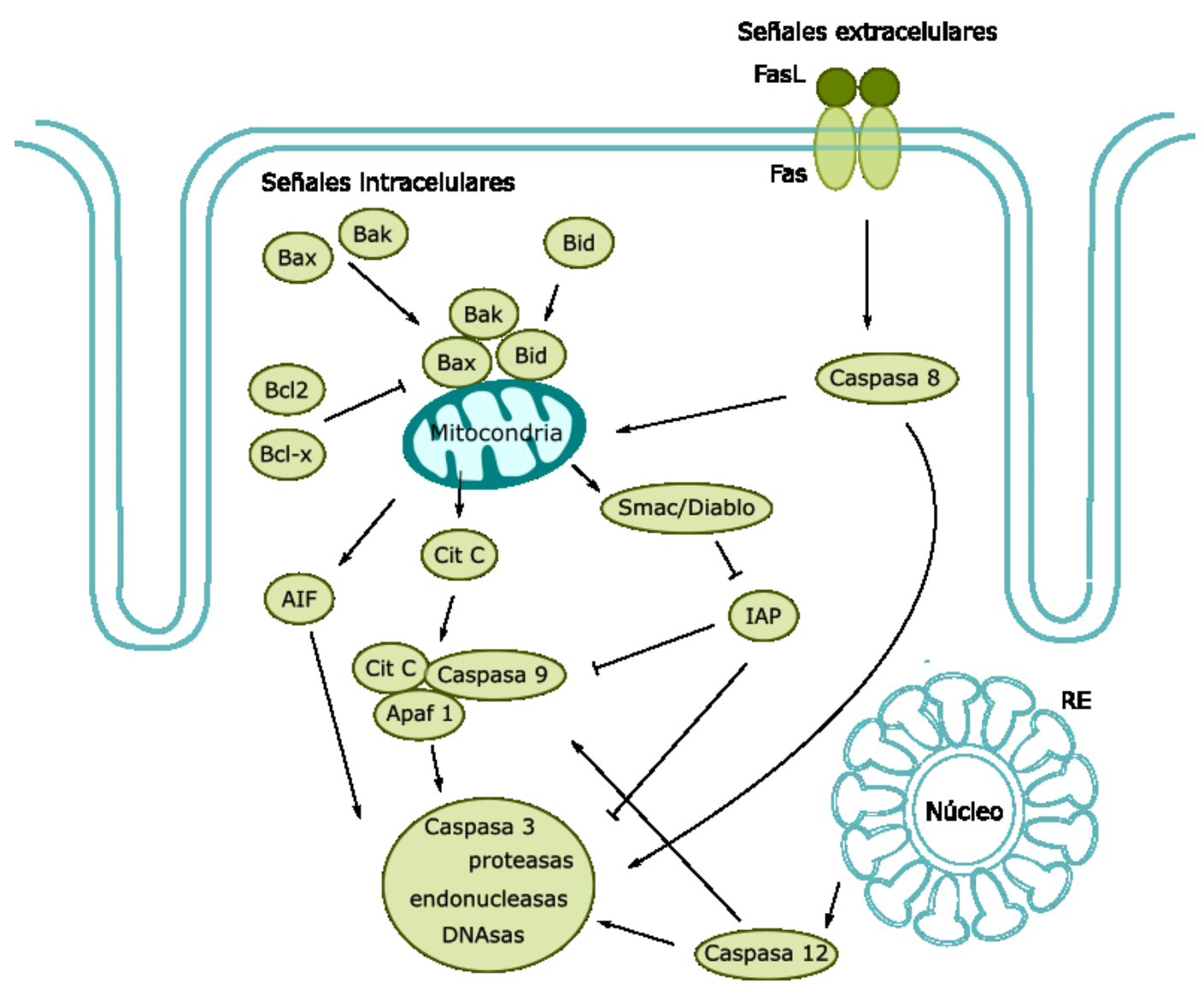

Figura 1.9: Mecanismos moleculares de apoptosis. Proteínas proapoptóticas: Proteína citoplasmática cofactor-1 apoptótico activador de proteasa (Apaf1), citocromo C (Cit C), Bax, Bak, Bid, factor inductor de apoptosis (AIF).Proteínas efectoras de la apoptosis: caspasa 3, proteasas, endonucleasas, DNAsas. Proteínas antiapoptóticas: proteína inhibidora de apoptosis (IAP), Bcl2, Bclx.Las flechas indican activación y las líneas truncadas inhibición.

Ha sido documentada una tercera vía apoptótica mediada por estrés del retículo endoplasmático (RE). Varios factores, como concentraciones altas de $\mathrm{Ca}^{2+}$ y la presencia de especies reactivas del oxígeno, impactan sobre el plegamiento de distintas proteínas del RE. La acumulación de proteínas no plegadas da lugar al estado de estrés del RE. Esto promueve la activación de la respuesta a proteína desplegada (UPR) que renueva el conjunto de proteínas afectadas a través de la regulación de chaperonas y componentes estructurales del RE. Sin embargo, ante un estrés excesivo, UPR puede activar una cascada de señalización que lleva a la muerte celular mediada por la quinasa del factor de iniciación eucariótico $2 \alpha$ PKR (PERK), la proteína inositol dependiente 1 (IRE1) y el factor de activación de la transcripción 6 (ATF6). En condiciones de estrés, la proteína de membrana regulada por glucosa 78 (GRP78) se disocia de los tres sensores mencionados e inicia el UPR. La fosforilación de PERK disminuye la síntesis de proteínas activando el factor de iniciación eucariótico a (elF2 $\alpha$ ). El proceso induce la muerte 
celular por la activación del factor de transcripción 4 (AT4) y la proteína homóloga a C/EBP (CHOP). IRE1 promueve la activación de factores proapoptóticos asociados a la inflamación, como caspasa 12, p38 MAPK y NF-Kß. ATF6 activa un factor de regulación transcripcional con actividad endoribonucleasa, XBP1. ${ }^{163}$ (figura I.10)

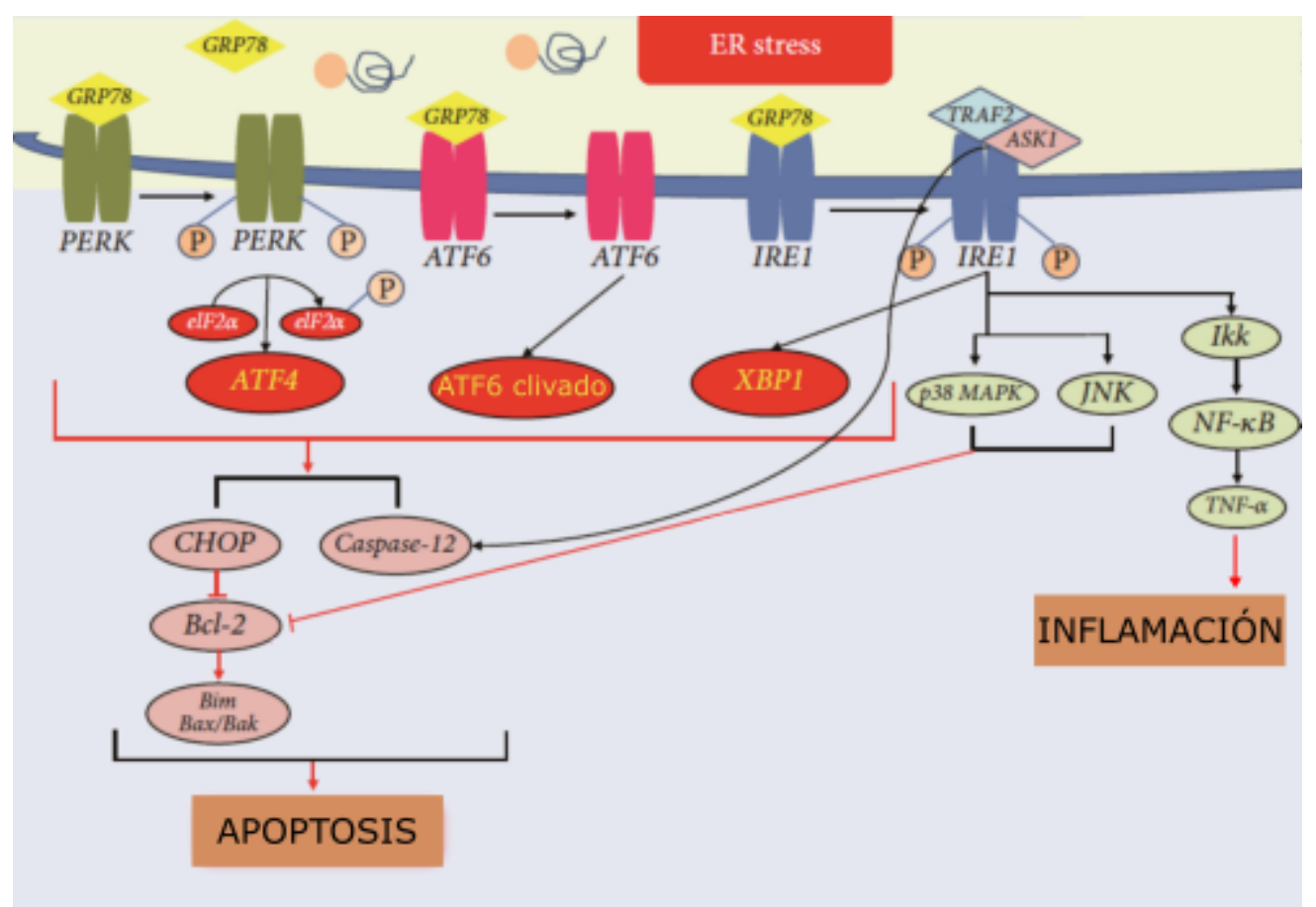

Figura I.10: Apoptosis mediada por el estrés del RE. Cuando se produce estrés prolongado en el retículo, la activación de vías de señalización apoptóticas mediada por CHOP y por JNK / p38 MAPK regulan la familia Bcl-2, que controla el equilibrio de la señalización pro- / antiapoptótico. El complejo IRE1a / TRAF2 / ASK1 también activa la caspasa-12 y finalmente induce la apoptosis celular. El complejo / TRAF2 / ASK1 IRE1a también contribuye a la expresión de inflamación que estimula la indución de la caspasa-1, IL-1 y y UR mediada por IL-6. Imagen modificada de Junyoung Hong, International Journal of Vascular Medicine, $2017^{163}$

Existen un conjunto de familias proteicas que regulan la apoptosis. Miembros de las mismas son los que interactúan en las distintas vías, y su interacción entrecruza las vías que median la apoptosis. La primera de ellas, es la familia de proteínas BCL-2, subdividida, a su vez, en tres sub-familias: la subfamilia formada por $\mathrm{Bcl} 2, \mathrm{Bcl}-\mathrm{XL}$, Bcl-W y NR-13 (antiapoptótica); la subfamilia que comprende Bak, Bax y Bcl-Xs (proapoptótica); ${ }^{164}$ y la subfamilia formada por Bim, Bid y Bad (proapoptótica). Las proteínas proapoptóticas son las que activan y modulan a las proteasas de la familia de las calpaínas, las caspasas y las catepsinas. El entrecruzamiento entre la vía Tipo I y la Tipo II pueden generarse a varios niveles, como por ejemplo la estimulación de Bax por JNK o Bid por la caspasa 8 quien también activa a la caspasa 3. La activación de la caspasa 3 (mediante la caspasa 8 activada por 
TRAF-2) genera la activación de Bid. ${ }^{159}$ Por otro lado, la asociación Bax/Bad puede formar un poro, induciendo la liberación del citocromo $\mathrm{C}$ como evento iniciador de la cascada apoptótica mediada por la mitocondria, e incrementar los niveles de ROS que son liberados desde la misma. La familia de las MAPKs cumple un rol importante en la regulación de la apoptosis mediada por las mitocondrias. En esta familia se incluyen las proteínas kinasas de regulación extracelular (ERK), JNK y p38 MAPK, entre otras. Algunas de las MAPKs interaccionan con miembros de la familia de proteínas BCL2 en los eventos apoptóticos mediados por mitocondrias. Como inductor de la apoptosis, las MAPKs pueden inducir la activación de Bax mediada por JNK, y como respuesta antiapoptótica ERK puede activar Akt quien inhibe a Bad y estimula ARC (dominio de reclutamiento de caspasas) e IAPs (péptido inhibidor de la apoptosis). ${ }^{159}$ Finalmente, se produce el burbujeo característico de la membrana y la formación de los cuerpos apoptóticos que se debe, principalmente, a la acción de caspasa 3 sobre las proteínas que regulan la degradación del citoesqueleto.

\section{ii. Eventos nucleares}

Otra característica importante del proceso de apoptosis es la rotura del ADN. Dentro de los eventos de clivaje de represores de DNAsas podemos mencionar los dirigidos por caspasas. A las DNAsas inducidas por caspasas se las denomina CAD. Estas median la respuesta de degradación del DNA en la vía apoptótica. A las $C A D$ se las encuentran normalmente reprimidas por una familia inhibidora de CAD (ICAD), que las arrestan en el citosol. Existe un segundo grupo de DNAsas activadas por el descenso de $\mathrm{pH} .{ }^{165}$

\section{b. Apoptosis en Diabetes Mellitus y prediabetes}

Los corazones de pacientes con MCD sufren un remodelado ventricular que incluye hipertrofia de miocardio y adelgazamiento de las paredes, lo que produce una

ii. Eventos nucleares

b. Apoptosis en Diabetes Mellitus y prediabetes alteración de la función cardiaca. Uno de los mecanismos que participa de este proceso es la muerte celular. ${ }^{121} \mathrm{Se}$ ha observado apoptosis en biopsias de miocardio de pacientes con DM, los cuales tienen un aumento significativo de muerte celular no asociada con isquemia de miocardio. Esto se ha corroborado en modelos de ratones con DMT1 y DMT2. ${ }^{166}$ El mecanismo por el cual se ve incrementada la muerte celular está en discusión. Por un lado, la hiperglucemia está asociada con el disparo de vías apoptóticas a través de Rac1, una pequeña 
proteína de unión a guanosina trifosfasto que forma parte del complejo de la NADPH oxidasa, mediante el incremento en la producción de ROS en modelos de ratones con $\mathrm{DM}^{167}$ Otro mecanismo potencial, es la activación del sistema reninaangiotensina, el cual se correlaciona con el incremento de estrés oxidativo, y apoptosis en cardiomiocitos y células endoteliales en corazones de paciente con DM, ${ }^{86,121}$ así como en modelos murínos. ${ }^{7}$

Por otro lado, se ha demostrado un incremento en la sensibilidad al $\mathrm{Ca}^{2+}$ del poro de transición mitocondrial asociado a un aumento en la producción de ROS mitocondriales en pacientes con DM; además de la activación de la vía intrínseca de muerte celular por caspasa 9 y no caspasa 8 . Estos resultados sugieren que el incremento de muerte celular observado en pacientes con DM podría estar mediado por la mitocondria, a través de la producción de ROS y sensibilización al $\mathrm{Ca}^{2+}$ del poro de transición mitocondrial. ${ }^{168}$

\section{CaMKII}

a. Generalidades

i. Estructura

La proteína quinasa dependiente de $\mathrm{Ca}^{2+} /$ calmodulina $\left(\mathrm{Ca}^{2+} / \mathrm{CaM}\right)$ II (CaMKII) es una Ser/Thr quinasa, codificada en cuatros genes diferentes, a partir de los cuales se expresan cuatro isoformas de la enzima, CaMKIla, $\beta, \gamma$, y $\delta$. CaMKIla y $\beta$ se expresan predominantemente en cerebro, mientras que CaMKIly y $\delta$ están presentes en todos los tejidos, siendo CaMKIIס la isoforma que predomina en corazón. Existen once formas de splicing alternativo de CaMKIIס (CaMKIIठA-K).

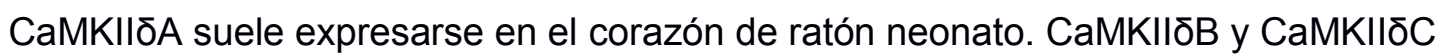
poseen la misma actividad del sitio catalítico y sensibilidad a $\mathrm{Ca}^{2+} / \mathrm{CaM}$. CaMKIIסB posee una secuencia de 11 aminoácidos en un sitio variable que le confiere una localización nuclear, mientras que CaMKIIסC se encuentra en el citoplasma.

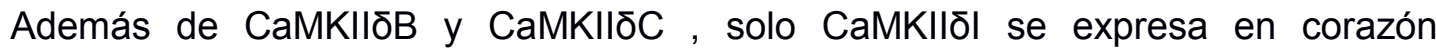
adulto. $^{169}$

Todas la isoformas de CaMKII se expresan como una proteína multimérica compuesta por 12 subunidades. Cada uno de estos monómeros posee un peso de 50kD con 480 aminoácidos de extensión aproximadamente y están conformados por tres dominios. El dominio C-terminal permite la asociación entre las subunidades para formar el multímero, el N-terminal es el sitio catalítico capaz de fosforilar los aminoácidos serina y treonina de sus sustratos; y la zona intermedia es el dominio regulatorio, el cual se pliega sobre el dominio catalítico (en condiciones 
basales) manteniendo al monómero en un estado de autoinhibición, y además, posee los sitios de unión a $\mathrm{Ca}^{2+} / \mathrm{CaM}$ y de modificaciones postraduccionales (figura I.11). ${ }^{170}$

A

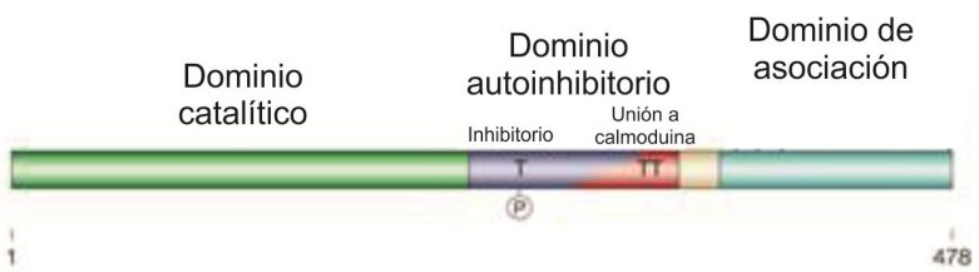

B
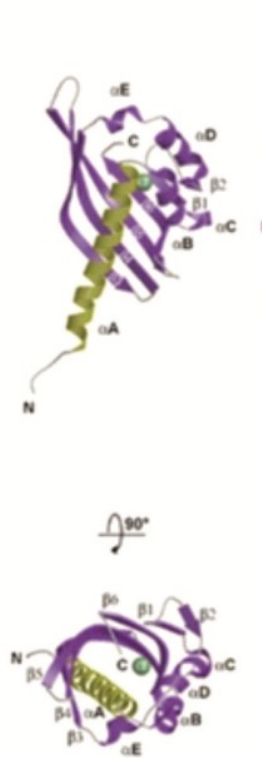

C
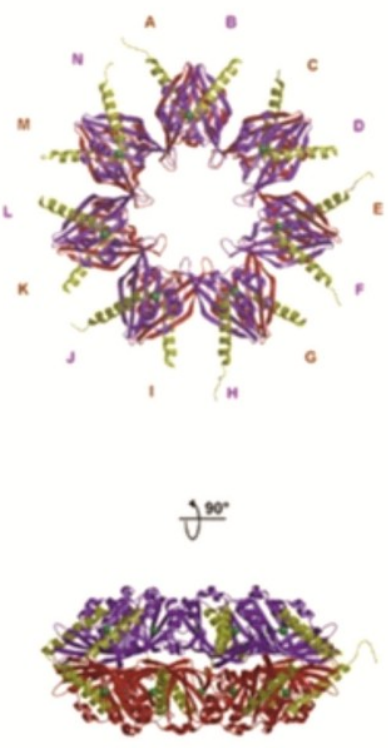

D

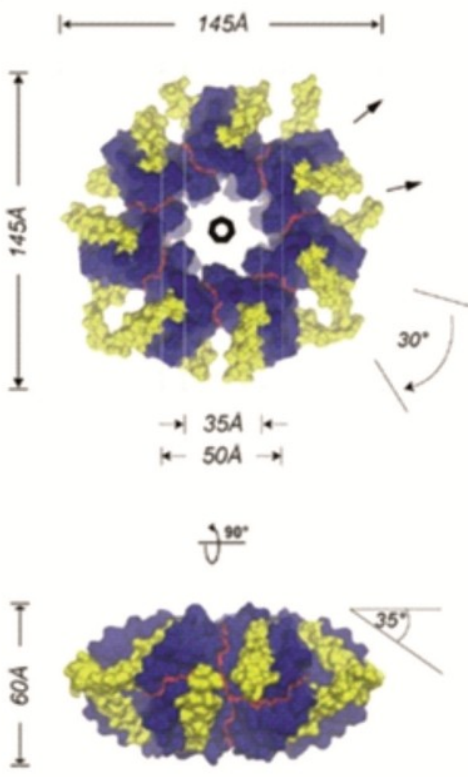

Figura l.11: Estructura de CaMKII. A, representación esquemática $B$, representación cristalográfica de una subunidad donde en amarillo se muestra el dominio catalítico y en violeta el dominio de unión entre subunidades. $C$, representación esquemática de la enzima. $D$, representación de superficie con medidas tomadas por rayos X. Imagen modificada de Hoelz, A., Molecular Cell, 2003.

\section{ii. Activación}

CaMKII es regulada, principalmente, por la unión de $\mathrm{Ca}^{2+} / \mathrm{CaM}$ al sitio regulatorio. Esta unión tiene un $\mathrm{K}_{\mathrm{d}}$ de $10-70 \mathrm{nM}^{171}$ cuando la $\left[\mathrm{Ca}^{2+}\right]_{i}$ es elevada. $\mathrm{A}$ una $\left[\mathrm{Ca}^{2+}\right]_{i}$ de $1,0 \mu \mathrm{M}$, CaM ocupa la mitad de los sitios ${ }^{172}$. Cuando $\mathrm{Ca}^{2+} / \mathrm{CaM}$ se une a CaMKII, ocurre un cambio conformacional que rompe la asociación entre el dominio catalítico y el regulatorio, exponiendo el sitio catalítico para la unión a los sustratos. Si bien existen otros mecanismos de activación, todos requieren de la unión a $\mathrm{Ca}^{2+} / \mathrm{CaM}$ como paso inicial. ${ }^{7}$ Cuando la unión a $\mathrm{Ca}^{2+} / \mathrm{CaM}$ es prolongada, como ocurre durante los transitorios de $\mathrm{Ca}^{2+}$ largos o frecuentes, se produce la 
autofosforilación entre las subunidades de CaMKII en el sitio $\mathrm{Thr}^{287}$ (Thr $^{286}$ en la isoforma $\alpha$ ). Esta fosforilación hace que la afinidad por $\mathrm{Ca}^{2+} / \mathrm{CaM}$ sea 1000 veces mayor ${ }^{173}$ y que se prevenga la reasociación del dominio catalítico con el regulatorio, aun cayendo la $\left[\mathrm{Ca}^{2+}\right]_{\mathrm{i} .}{ }^{174}$. La desfosforilación puede catalizada por un grupo de proteínas fosfatasas, PP1 o PP2A. La actividad de CaMKII puede ser modulada por otras modificaciones postraduccionales como la oxidación por ROS. ${ }^{7}$ El dominio regulatorio contiene un par de sitios sensibles a la oxidación, $\mathrm{Cis}^{280} / \mathrm{Met}^{281}$ en la isoforma $\alpha$ y $\mathrm{Met}^{281} / \mathrm{Met}^{282}$ en las isoformas $\beta$, y y $\delta$; los cuales, luego de la unión inicial de $\mathrm{Ca}^{2+} / \mathrm{CaM}$, se descubren y ante el estrés oxidativo se oxidan activando a la enzima. La enzima metionina sulfamida reductasa reduce los residuos oxidados de la quinasa. ${ }^{175} \mathrm{La}$ modificación postraslacional por O-GlcNAcilación puede observarse cuando existe una alteración en el manejo de la glucosa, como en la diabetes. La O-GIcNAcilación es catalizada por la enzima O-GlcNAc transferasa en presencia del sustrato UDP-N-acetilglucosamina, el cual es producido en condiciones de elevada glucosa como producto de la síntesis de hexosamina. ${ }^{176}$ Cuando CaMKII es inicialmente activada por $\mathrm{Ca}^{2+} / \mathrm{CaM}$ en presencia de alta concentración de glucosa, ésta sufre O-GlcNAcilación en el dominio regulatorio, en el sitio $\operatorname{Ser}^{280}$ (Ser ${ }^{279}$ en la isoforma $\alpha$ ), resultando en la activación autónoma de la quinasa. ${ }^{177}$ (figura I.12). Además, se ha encontrado un mecanismo de activación de CaMKII mediado por óxido nítrico (NO), ${ }^{178,179} \mathrm{y}$ al menos in vitro, se ha demostrado que CaMKII contiene un sitio de S-nitrosilación en $\mathrm{Cis}^{290}$.

Por otro lado, existen diferentes herramientas, ya sean farmacológicas como genéticas, para modular la acción de CaMKII. El inhibidor más usado en estudios celulares e in vitro, es el $\mathrm{KN}-93$, el cual inhibe competitivamente el sitio de unión de $\mathrm{Ca}^{2+} / \mathrm{CaM}$, e inhibe no competitivamente la unión del ATP. Este es capaz de evitar la autofosforilación, ya que actúa sobre su sitio de activación y no sobre el dominio catalítico. Debido a los efectos inespecíficos de KN-93, como la disminución en la $I_{C a}{ }^{180}$ los resultados obtenidos con $\mathrm{KN}-93$ deben compararse con KN-92, su análogo inactivo. Algunos estudios sobre el segmento regulatorio de CaMKII han permitido el desarrollo de inhibidores peptídicos, como son autocamtida-2 y autocamtida-3, que tras una sustitución permitieron la síntesis de AIP (del inglés, autocamtide inhibitory protein). A partir del desarrollo de estos inhibidores, se han generado ratones transgénicos que los expresan, ya sea en todas las células miocárdicas (ratones AC3-I) como dirigido al RS a través de la unión a PLN (SRAIP), lo que impide que CaMKII fosforile sus blancos en el RS. Recientemente, se ha diseñado un péptido que inhibe con elevada afinidad a CaMKII, CaMKIIN, el cual puede aplicarse de manera farmacológica o genética. Este péptido sólo se une a la 
conformación activa de CaMKII. ${ }^{181}$ Por otro lado, la actividad de CaMKII puede no solo modularse alterando su activación, sino también alterando sus blanco específicos, como por ejemplo los ratones modificados Ser2814A y Ser2814D, los cuales simulan constitutivamente la falta de fosforilación o la fosforilación permanente, respectivamente, de RyR. ${ }^{182}$

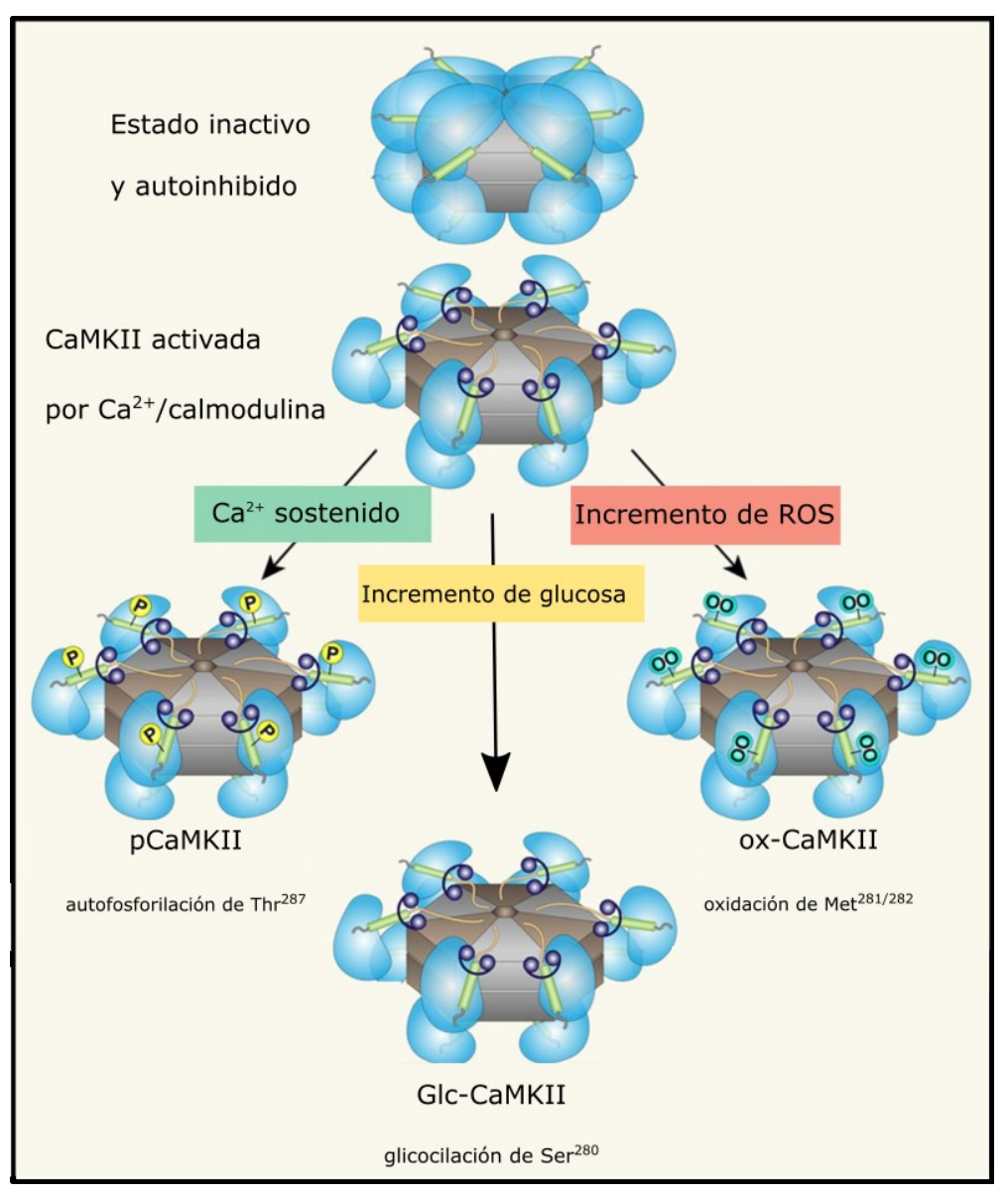

Figura I.12: Mecanismos de activación de CaMKII. Estructura y activación de proteína quinasa dependiente de $\mathrm{Ca}^{2+} /$ calmodulina II (CaMKII). CaMKII consiste en hexámeros apilados y cada monómero consiste en un dominio catalítico N-terminal y un dominio de asociación C-terminal que flanquea un dominio regulador central. CaMKIl se activa cuando el $\mathrm{Ca}^{2+}$ se une a la calmodulina, lo que hace que CaMKII adopte una conformación activa y extendida. La unión sostenida a $\mathrm{Ca}^{2+} /$ calmodulina calcificada conduce a la autofosforilación de $\operatorname{Thr}^{287}$ y a la activación sostenida de CaMKII. La oxidación de las metioninas del dominio regulador emparejado (281/282) también causa la activación sostenida de CaMKII. La O-GIcNAcilación del dominio regulatorio, en el sitio Ser ${ }^{280}$, mantiene a la enzima en su conformación extendida y activa. Imagen modificada de Heart Failure Compendium: Mechanisms of Altered $\mathrm{Ca}^{2+}$ Handling in Heart Failure. Min Luo, et. al., 2013. ${ }^{45}$

\section{b. Efectos de la actividad de CaMKII}

CaMKII ha sido identificada como un regulador importante de los canales iónicos y transportadores involucrados en el AEC en condiciones fisiológicas y patológicas. ${ }^{183}$ 
Los incrementos de la expresión y la función de CaMKII han sido relacionados con arritmias y disfunción contráctil, por fosforilación de sus blancos intracelulares, entre otros efectos deletéreos. CaMKII puede unirse a la subunidad $\alpha 1$ del LTCC y fosforilarla en los sitios $\operatorname{Ser}^{1512}$ y $S^{1570}{ }^{184}$. Esta modificación incrementa la amplitud de la $I_{C a}$ y enlentece progresivamente la inactivación durante una serie de contracciones luego de un intervalo en quiescencia (fenómeno que se denomina facilitación). Se ha descripto también que CaMKII fosforila el sitio $\operatorname{Thr}^{498}$ de la subunidad $\beta 2$ a del LTCC, también involucrada en la facilitación de la $I_{\text {Ca. }}$. A nivel de canal único, se observa un aumento de la probabilidad de apertura, lo cual se relaciona con EAD debido a las corrientes durante la fase 2 del PA. Aumentar la probabilidad de apertura del LTCC, a través de la actividad de CaMKII, prolonga el PA y se vincula con la propensión a arritmias generadas por EADs. ${ }^{183,185}$ Por otro lado, la fosforilación por CaMKII del RyR2 en el sitio Ser ${ }^{2814}$ incrementa su probabilidad de apertura. ${ }^{186}$ Esto se refleja en un aumento de la frecuencia de SpCa en modelos de cardiomiocitos animales transgénicos que sobreexpresan CaMKII. Este aumento de la pérdida de $\mathrm{Ca}^{2+}$ del RS puede aumentar la salida de $\mathrm{Ca}^{2+} \mathrm{a}$ través del NCX produciendo una corriente despolarizante suficientemente grande como para que se produzcan DAD que, de superar el potencial umbral, pueden disparar PA espontáneos, resultando en extrasístoles y arritmias ventriculares. Esto se ha corroborado en diversos estudios donde se inhibe genéticamente la posibilidad de RyR2 de fosforilarse, en los cuales puede observarse la prevención de fibrilación atrial y de arritmias ventriculares. ${ }^{187,188}$

La magnitud de la pérdida de $\mathrm{Ca}^{2+}$ del RS no solo depende de la probabilidad de apertura del RyR2, sino también de la carga del RS, la cual puede ser modulada por CaMKII a través de la fosforilación de PLN en el sitio $\mathrm{Thr}^{17}$. Esta modificación postraslacional libera la inhibición de PLN sobre SERCa2a incrementando la retoma de $\mathrm{Ca}^{2+}$ por el RS. ${ }^{189}$

La activación de CaMKII se ha relacionado, también, con la alteración de las propiedades de apertura del canal de $\mathrm{Na}^{+}$. La fosforilación de NaV1.5 en los sitios $\mathrm{Ser}^{516}, \mathrm{Thr}^{594}$ y Ser ${ }^{571}$ llevan a potenciales negativos a la inactivación dependiente del voltaje sin alterar la activación del canal, lo cual enlentece la recuperación aumentando la entrada lenta de $\mathrm{Na}^{+}{ }^{190} \mathrm{El}$ incremento de la $I_{\mathrm{Na}}$ puede contribuir al incremento de $\mathrm{Na}^{+}$observado en la insuficiencia cardiaca en donde CaMKII está sobre expresada, lo que limita la salida de $\mathrm{Ca}^{2+}$ por el $\mathrm{NCX}$, o incluso permite el ingreso de $\mathrm{Ca}^{2+}$ por esta vía. ${ }^{191} \mathrm{El}$ enlentecimiento de la salida de $\mathrm{Ca}^{2+}$ tiende a elevar el $\mathrm{Ca}^{2+}$ diastólico, contribuyendo al desarrollo de disfunción diastólica. La acumulación de $\mathrm{Ca}^{2+}$, también, tiende a incrementar el contenido del ion en el RS, 
potenciando un aumento de la contractilidad. El aumento del $\mathrm{Na}^{+}$dependiente de CaMKII ha sido asociado con disfunción diastólica y arritmias en modelos de insuficiencia cardiaca por sobreexpresión de CaMKIIסC. ${ }^{192}$ Se ha propuesto que la carga de $\mathrm{Ca}^{2+}$ debida al aumento de $\mathrm{Na}^{+}$, puede a su vez activar a CaMKII creando un círculo vicioso arritmogénico. ${ }^{193}$ Por otro lado, el $\mathrm{Na}^{+}$es un regulador importante de la bioenergética de los miocitos cardiacos, porque controla el ingreso de $\mathrm{Ca}^{2+} \mathrm{a}$ la mitocondria por el NCX mitocondrial, y además regula la producción de ROS. ${ }^{193}$ La alta concentración de $\mathrm{Na}^{+}$, observada en la insuficiencia cardiaca, puede afectar negativamente el metabolismo durante el marcapaseo rápido, por acumulación de $\mathrm{Ca}^{2+}$ en la mitocondria, disminución del potencial redox $\mathrm{NADH} / \mathrm{NAD}^{+}$e incremento de la formación de ROS. ${ }^{194}$

Las alteraciones en la cinética y expresión de los canales de $\mathrm{K}^{+}$han sido vinculados con procesos arritmogénicos. ${ }^{195}$ Además, se ha demostrado que CaMKII influye negativamente en la expresión de isoformas del canal asociado a $I_{\text {to }}$ en ratones que sobreexpresan CaMKIIס. ${ }^{196}$ Esta reducción de la corriente es secundaria a la disminución de la expresión de Kv4.2, acompañado de la prolongación del PA. En contraste la expresión de Kv1.4 aumenta con la fracción lenta de $I_{\text {to. }}{ }^{196}$ Este efecto de CaMKII puede estar mediado por la fosforilación en $\operatorname{Ser}^{438 / 459}$ de Kv4.2 y Ser ${ }^{123}$ de Kv1.4. ${ }^{197,198}$ Es interesante remarcar que este aumento de la $I_{\text {to }}$ dependiente de CaMKII puede ser importante en las arritmias inducidas por ROS, ya que éstos pueden activar a la quinasa. ${ }^{175}$ Además, ha sido demostrado que la inhibición de CaMKII puede abolir la activación de $I_{K 1}$ inducida por $\mathrm{Ca}^{2+}$, sugiriendo que CaMKII está involucrada en su regulación. ${ }^{199}$

CaMKII también tiene efectos genómicos que se desarrollan a través de la isoforma nuclear. Sus efectos sobre la regulación transcripcional pueden ser tanto benéficos como perjudiciales, como en la señalización hacia la hipertrofia y la insuficiencia cardiaca. En el caso que CaMKII esté sobreactivada o activada de manera crónica, ésta puede activar vías que aumentan las pérdidas de $\mathrm{Ca}^{2+}$, alterando por ejemplo la expresión de canales y transportadores involucrados en el AEC. ${ }^{189}$ Una de las vías en las que participa CaMKIIסB involucra a las histona-deacetilasas de clase II (HDAC). En condiciones basales las HDAC se encuentran desfosforiladas, unidas y reprimiendo factores de transcripción de hipertrofia, como el factor promotor de miocitos 2 (MEF2). Cuando esta es fosforilada por CaMKII o por la proteína quinasa D (PKD), se trasloca fuera del núcleo por la proteína chaperona 14-3-3 liberando la represión sobre MEF2. Por otro lado, calcineurina, una enzima fosfatasa, que 
funciona en paralelo con CaMKII, al activarse por $\mathrm{Ca}^{2+} / \mathrm{CaM}$, desfosforila el factor nuclear de células $T$ activadas (NFAT), el que interactúa con factores de transcripción involucrados en la hipertrofia e insuficiencia cardiaca, como GATA4. ${ }^{189}$

c. Rol de CaMKII cardiaca en la miocardiopatía de la Diabetes Mellitus y prediabetes

Existen numerosos mecanismos moleculares propuestos para el desarrollo de la

ii. Activación

c. Rol de CaMKII cardiaca en Diabetes Mellitus y prediabetes MCD, los cuales ya han sido mencionados, entre ellos la alteración del manejo del $\mathrm{Ca}^{2+}{ }^{115}$ Las investigaciones en modelos en roedores de DMT1 demostraron un aumento en los niveles de $\mathrm{Ca}^{2+}$ diastólico, una atenuación de la retoma de $\mathrm{Ca}^{2+}$ por el RS, con la consecuente disminución de la recuperación de la $\left[\mathrm{Ca}^{2+}\right]_{i}$ luego de un transitorio de $\mathrm{Ca}^{2+}$, y un compromiso del manejo del $\mathrm{Ca}^{2+}$ mitocondrial. ${ }^{113,200,201}$ Resultados similares han sido encontrados en modelos de ratones de DMT2, como la disminución del $\mathrm{Ca}^{2+}$ diastólico y sistólico, disminución de la velocidad de caída de $\mathrm{Ca}^{2+}$, pérdida de $\mathrm{Ca}^{2+}$ del RS y disminución de la carga de $\mathrm{Ca}^{2+}$ del $\mathrm{RS}^{116,202}$

Así mismo, la DM está asociada a un incremento del estrés oxidativo, que contribuye a las complicaciones de la enfermedad, ${ }^{125}$ condición en la que CaMKII es capaz de activarse por oxidación. ${ }^{9}$ Esta activación por oxidación ha sido postulada como un mecanismo potencial de fibrilación atrial ${ }^{203}$ y de arritmias ligadas a EAD y $D A D^{204}$. Además, en modelos de DM se ha obsevado que CaMKII puede OGlcNAcilarse debido a la glucemia elevada, desencadenado arritmias al aumentar la pérdida de $\mathrm{Ca}^{2+}$ del RS por hiperfosforillación de RyR2. ${ }^{177}$ Dada la relación entre CaMKII, la insuficiencia cardiaca y el manejo del $\mathrm{Ca}^{2+}$, es esperable la participación de esta quinasa en el desarrollo de la MCD. 


\section{OBJETIVOS}




\section{1) HIPOTESIS DE TRABAJO}

La hipótesis de trabajo propuesta postula que el aumento de la expresión/activación de la $\mathrm{Ca}^{2+}$-Calmodulina kinasa II (CaMKII), a través de la fosforilación de sus sustratos interviene en las alteraciones de la función y/o en la generación de arritmias observadas en el corazón con estado de tolerancia a la glucosa alterada (TGA), contribuyendo al desarrollo, mantenimiento o empeoramiento de la enfermedad cardiaca que se desarrolla con mayor gravedad en la diabetes manifiesta.

\section{2) OBJETIVOS GENERALES}

Comprobar la hipótesis de que la CaMKII participa en la cascada de señalización que conduce a la cardiotoxicidad causada por la TGA. Las anormalidades en la regulación de la glucosa en pacientes con insuficiencia cardiaca no se limitan solamente a la diabetes; la TGA y la insulinoresistencia están fuertemente vinculadas con la insuficiencia cardiaca. Estas alteraciones de la regulación de la glucemia se correlacionan con la severidad funcional, clínica y bioquímica de la insuficiencia cardiaca de pacientes no diabéticos. Por otro lado, está ampliamente demostrado que la actividad de la CaMKII juega un rol fundamental en la patogénesis de la insuficiencia cardiaca, activándose tempranamente en el proceso de la enfermedad, determinando hipertrofia, disfunción sistólica, diastólica, arritmias y apoptosis para culminar en insuficiencia cardiaca descompensada. Sin embargo, no se conoce en detalle la relación entre la actividad de la CaMKIl y las alteraciones que se producen en el corazón de sujetos con TGA.

\section{3) OBJETIVOS ESPECÍFICOS}

Objetivo 1. Caracterizar las alteraciones del corazón en un modelo de TGA inducido por una dieta rica en fructosa y comprobar la hipótesis de que la CaMKII está involucrada en dichas alteraciones.

Los estudios propuestos apuntan a caracterizar el daño cardiaco causado por una dieta rica en fructosa en ratas Wistar, y en ratones salvajes (WT) y transgénicos que expresan constitutivamente un inhibidor cardiaco de la CaMKII a nivel del retículo sarcoplasmático (RS) (SR-AIP). 
1.1. In vivo, estudiar los corazones de los animales por ecocardiografía y electrocardiografía y caracterizar el grado de hipertrofia y/o disfunción ventricular y el tipo y frecuencia de arritmias.

1.2. Ex vivo, evaluar los corazones de los animales a través de parámetros morfológicos e histológicos; realizar inmunohistoquímica para evidenciar la presencia de apoptosis, y ensayos bioquímicos para determinar la expresión y actividad de la CaMKII y de otras moléculas involucradas en el acoplamiento excitocontráctil y en la apoptosis. Conjuntamente medir especies reactivas del $\mathrm{O}_{2}$ para interpretar su participación en las vías estudiadas.

1.3. Ex vivo, también estudiar la función contráctil en miocitos aislados conjuntamente con medidas de $\mathrm{Ca}^{2+}$. Someter a las células a estrés para evidenciar la aparición de arritmias y compararlos con los controles.

Objetivo 2. Determinar si la activación de la CaMKIl en el modelo de TGA ocurre por la vía canónica (aumentos en el $\mathrm{Ca}^{2+}$ ), por aumento de los radicales libres (ROS), o por ambos.

Realizar ensayos en miocitos aislados de los animales mencionados en el objetivo 1. Para tal fin, utilizar inhibidores farmacológicos específicos de los posibles mediadores intracelulares y atrapantes de ROS. Se medirá la producción de ROS, y $\mathrm{Ca}^{2+}$ a través de epifluorescencia y microscopía confocal.

Objetivo 3. Comprobar si la inhibición in vivo de las vías propuestas previene la aparición de disfunción contráctil y arritmias, independientemente de la reversión de TGA en sí.

Corroborar las vías de señalización encontradas in vivo, a través de la inhibición específica DE los mediadores de la activación de CaMKII, los ROS, los aumentos en el $\mathrm{Ca}^{2+} \mathrm{o}$ ambos, y sus blancos celulares en la miocardiopatía inducida por TGA, hallados en los objetivos anteriores, intentaremos

Objetivo 4. Evaluar la presencia de apoptosis de cardiomiocitos en el modelo y relacionarla con las alteraciones del manejo del $\mathrm{Ca}^{2+}$, los $\mathrm{ROS}$ y la sobreactivación de CaMKII.

Buscar marcadores celulares de apoptosis en presencia y ausencia de inhibidores de CaMKII (KN-93), atrapadores de ROS (Tempol), los cuales serán correlacionados con cambios en el $\mathrm{Ca}^{2+}$ citosólico y mitocondrial. 


\section{MATERIALES Y MÉTODOS}




\section{Manejo de animales y tratamientos}

Todos los experimentos se realizaron de acuerdo con la guía para el cuidado y uso del animal de laboratorio (NHI publicación No.85-23, revisada en 2011), y fueron aprobados por el Comité Institucional de Cuidado y Uso de Animales de Experimentación (protocolo $\mathrm{n}^{\circ} \mathrm{T}-03-01-14$ ).

Las ratas Wistar macho (200 a 300g) fueron divididas en dos grupos: grupo control, alimentado con una dieta comercial estándar; y grupo dieta rica en fructosa, que recibió la misma dieta más $10 \%(\mathrm{P} / \mathrm{V})$ de fructosa en el agua de bebida, durante tres semanas, de acuerdo a un modelo de prediabetes ya estudiado. ${ }^{205,206}$

También se utilizaron ratones BalbC machos (tipo salvaje [WT]) y ratones transgénicos SR-AIP. Estos ratones expresan una secuencia que codifica un inhibidor de CaMKII, una secuencia marcadora de fluoresceína y una de anclaje al RS. El dominio inhibidor consiste en un tetrámero del péptido inhibidor autocamtida (AIP), con la siguiente secuencia, KKALRRQEAVDAL. El dominio de anclaje corresponde a un dominio transmembrana truncado de PLN mutado en Leu31Ala, el cual no es capaz de inhibir a la SERCa2a. ${ }^{207}$ La expresión de este inhibidor a nivel del RS, por su anclaje a la membrana, impide que la CaMKII fosforile sus blancos en esta organela. Ambas cepas se dividieron en tres grupos: grupo control, alimentados con una dieta comercial estándar; grupo fructosa, que recibió la misma dieta más 10\% (P/V) de fructosa en el agua de bebida; y el grupo fructosa + tempol, que recibió, además de la fructosa, 0,8 $\mathrm{mM}$ de 4-hydroxy-2,2,6,6tetramethylpiperidin-1-oxyl (Tempol, utilizado como antioxidante) $)^{208}$. Todos los tratamientos fueron realizados por tres semanas.

Antes y después del tratamiento los animales fueron pesados, se les midió la presión arterial sistólica por el método del manguito, se les realizó exámenes eco- y electrocardiográficos. Luego del sacrificio de los animales, se pesó el corazón y se midió la longitud de la tibia. Los corazones fueron destinados a los diferentes estudios que se detallaran luego. Durante todo el tratamiento se midió el consumo de agua y comida, y las calorías consumidas se calcularon teniendo en cuenta que el alimento aportó $3 \mathrm{Kcal} / \mathrm{g}$ y la solución de fructosa $0.4 \mathrm{kcal} / \mathrm{ml}$.

\section{Determinaciones plasmáticas}

Antes del sacrificio, se extrajeron, bajo anestesia con isofluorano, muestras de sangre de las ratas del plexo retroorbital. Las muestras extraídas fueron almacenadas en tubos heparinizados, para luego medir niveles de glucosa en sangre (OneTouchUltra, Johnson \& Johnson, Estados Unidos) y realizar la prueba intraperitoneal para tolerancia a la glucosa (TTGI). ${ }^{206}$ Esta última consiste en medir 
la glucemia en ayunas y, cada media hora, durante dos horas, luego de una inyección intraperitoneal de $2 \mathrm{mg}$ glucosa/g peso corporal. También se evaluaron los niveles plasmáticos de insulina (por el método de radioinmunoanálisis, Life Diagnostics, Inc., PA, USA, Cat. \# 2210-2) y triglicéridos (kit enzimático, BioSystems S.A., Barcelona, España). ${ }^{206}$ La insulinoresistencia se evaluó con el índice HOMA-IR, calculado como insulina $(\mu \mathrm{U} / \mathrm{ml}) \times$ glucosa $(\mathrm{mmol} / \mathrm{L}) / 22.5{ }^{27}$

En los ratones se midieron los niveles plasmáticos de glucosa para realizar el cálculo del área bajo la curva después del test de tolerancia intraperitoneal a la glucosa. Para esto se midió la glucemia antes de la inyección intraperitoneal de glucosa, a los 10 minutos se repitió la medición y luego cada media hora durante dos horas. Con estos datos se construyó una curva de glucemia en función del tiempo. El área bajo la curva se calculó utilizando el programa ImageJ. ${ }^{209}$ Una diferencia significativa en el área bajo la curva entre los animales con dieta control y con dieta rica en fructosa fue considerada un índice de deficiencia de la insulina inherente del estado de tolerancia a la glucosa alterada.

\section{Examen ecocardiográfico}

Se realizaron ecocardiografías en cada animal, bajo anestesia ligera (pentobarbital sódico, $35 \mathrm{mg} / \mathrm{kg}$ ). La función y la estructura cardiaca fueron evaluadas por ecocardiografía de modo M 2 dimensiones, con un transductor lineal de $7 \mathrm{MHz}$. Todas las mediciones, incluyendo dimensiones diastólicas, espesor de pared ventricular izquierda y diámetros del ventrículo izquierdo fueron realizadas según el método establecido por la Sociedad Americana de Ecocardiografía. ${ }^{210}$

La masa ventricular izquierda fue calculada a través de la ecuación: $1.04 \mathrm{x}$ $\left[(D D V I+G D S+G P P D){ }^{3}-(D D V I)^{3}\right],{ }^{211}$ donde DDVI corresponde al diámetro diastólico del ventrículo izquierdo, GSD al grosor diastólico del septum y GPPD al grosor de la pared posterior en diástole. El índice de masa ventricular izquierda se calculó dividiendo la masa ventricular izquierda por el peso del animal (en gramos) o por la longitud de la tibia (en milímetros). El porcentaje de acortamiento endocárdico se calculó utilizando la siguiente ecuación: $A E=\frac{(D D V I-D S V I) \times 100}{D D V I}$.

\section{Electrocardiograma}

El electrocardiograma (ECG) es el registro gráfico de los potenciales de actividad eléctrica del corazón desde la superficie corporal. El electrocardiografo es un galvanómetro capaz de captar la presencia, el sentido y la intensidad de las corrientes eléctricas pasando el registro a un papel. 
El registro electrocardiográfico depende de la propiedades eléctricas del corazón. El estímulo de activación auricular se inicia en el nódulo sinusal y se extiende por la aurícula derecha, septum interauricular y aurícula izquierda. La activación eléctrica de ambas aurículas forma la onda P. La activación avanza por la pared auricular, de manera que los registros endocárdicos y epicárdicos son los mismos, y se dirige hacia el nodo auriculoventricular a través de los haces internodales. La repolarización auricular se inscribe, en el ECG, como una onda de sentido opuesto a la de la $\mathrm{P}$ (onda Ta), la cual generalmente no es visible porque se encuentra superpuesta con la activación ventricular. Cuando el estímulo llega al nodo auriculoventricular se produce un retardo que se expresa en el ECG como intervalo PR. El estímulo de despolarización ventricular es conducido por el nodo auriculoventricular al Haz de His, sus ramas derecha e izquierda y por las fibras de Purkinje despolarizando los ventrículos en forma perpendicular de endocardio a epicardio. La despolarización ventricular produce el complejo QRS. La activación ventricular comienza por el septum interventricular, sigue por las masas paraseptales a nivel de la punta del corazón, luego, las paredes libres que representan la porción más importante, desplegándose desde el endocardio al epicardio, y desde la punta hasta la base, y la última sección es la base. La última parte en despolarizarse es la primera repolarizarse; esto es debido a que: 1) El endocardio demora en repolarizarse por estar sometido a la presión intracavitaria. 2) La temperatura del epicardio es mayor a la del endocardio. 3) El epicardio está mejor irrigado. La repolarización es más lenta que la despolarización y se expresa en el ECG con los segmentos ST y onda T. ${ }^{212}$

El trazado del ECG puede realizarse a través de distintas derivaciones (puntos de observación y registro de la actividad eléctrica). Existen derivaciones bipolares DI DII - DIII que registran la diferencia de potencial entre brazo izquierdo y brazo derecho, pierna izquierda y brazo derecho, y entre pierna izquierda y brazo izquierdo respectivamente. Las derivaciones unipolares y precordiales, las de los miembros forman el plano frontal y se denominan aumentadas (a), porque miden los potenciales absolutos de brazo derecho (aVR), brazo izquierdo ( $\mathrm{aVL}$ ), pie izquierdo (aVF). En el plano transversal las derivaciones son unipolares y los electrodos precordiales recogen el potencial absoluto de la actividad eléctrica cardiaca desde la zona en la que están ubicados. V1: Cuarto espacio intercostal paraesternal derecho. V2: Cuarto espacio intercostal paraesternal izquierdo. V3: En un punto medio entre V2 y V3. V4: Quinto espacio intercostal izquierdo. V5: Línea axilar anterior a nivel de V4. V6: Línea axilar media a nivel de V4. V7: Línea axilar posterior a nivel de V4. V8: Línea medio escapular a nivel de V4. V3R: Igual que V3 
pero derecha. V4R: Quinto espacio intercostal derecho. En V1 y V2 se registra la actividad eléctrica del ventrículo derecho, en V3 y V4 el tabique interventricular, y en V5 y V6 la del ventrículo izquierdo. ${ }^{212}$

En el presente trabajo se registraron electrocardiogramas (ECG) de superficie en DIl en el plano frontal en los ratones WT y SR-AIP, usando electrodos de ECG estándar y el sistema de adquisición de datos PowerLab 4ST. Los ECG fueron adquiridos con una frecuencia de muestreo de $40 \mathrm{KHz}$. Las grabaciones fueron realizadas durante un período de 30 minutos. Una carga catecolaminérgica (cafeína y epinefrina, $120 \mathrm{mg} / \mathrm{kg}$ y $1,6 \mathrm{mg} / \mathrm{Kg}$, respectivamente), se aplicó para desenmascarar la presencia de arritmias bajo condiciones de estrés, de acuerdo al protocolo propuesto previamente. ${ }^{213}$

Las arritmias fueron evaluadas mediante la cuantificación de extrasístoles ventriculares, fibrilación ventricular y auricular, y taquicardias ventricular durante el período de registro de 30 minutos. Se realizó una medida cuantitativa de los registros de ECG a partir de los cuales se obtuvo la frecuencia cardiaca, la duración de los intervalos RR, PR y QT, y la duración de la onda P y el complejo QRS. Debido a que la duración del intervalo QT depende de la frecuencia cardiaca se calculó la corrección de Bazett $\left(\mathrm{QT}_{\mathrm{c}}\right) . Q T c=Q T / \sqrt[2]{(R-R)} \cdot{ }^{214}$

\section{Aislamiento de miocitos}

Los animales fueron anestesiados con fármacos anestésicos y analgésicos, 75 $\mathrm{mg} / \mathrm{kg}$ de ketamina y $5 \mathrm{mg} / \mathrm{kg}$ de diazepam, verificándose este estado por la pérdida del reflejo corneal y la aparición de la respiración profunda diafragmática lenta. Luego, se realizó una toracotomía para la extracción del corazón. Los miocitos se aislaron por digestión enzimática. Para tal fin, los corazones fueron conectados a una cánula a través de aorta, suspendidos y montados en un aparato de Langendorff. ${ }^{215}$ Fueron perfundidos retrógradamente a $37^{\circ} \mathrm{C}$ con un flujo coronario constante $(12-14 \mathrm{ml} / \mathrm{min})$ con una solución de Krebs-Henseleit $(\mathrm{K}-\mathrm{H})^{216}$ de la siguiente composición (mM): 146,2 $\mathrm{NaCl}, 10,0$ HEPES, 0,35 $\mathrm{NaH}_{2} \mathrm{PO}_{4}, 1,05 \mathrm{MgSO}_{4}$, 10,0 glucosa ( $\mathrm{pH}$ ajustado a 7,4 con $\mathrm{NaOH}$ ). La solución fue burbujeada continuamente con $100 \% \quad \mathrm{O}_{2}$. Después de un período de estabilización de 5 minutos, se perfundió el corazón con una solución libre de $\mathrm{Ca}^{2+}$ nominal con EGTA $(10 \mathrm{mM})$, y posteriormente con un buffer con colagenasa $(118 \mathrm{u} / \mathrm{ml}), 0.1 \mathrm{mg} / \mathrm{ml}$ proteinasa y $1 \%$ de albúmina sérica bovina, en $\mathrm{K}-\mathrm{H}$ que contiene $50 \mu \mathrm{M} \mathrm{CaCl}_{2}$, hasta que los corazones presentaron flacidez (15 - $20 \mathrm{~min}$ ). Luego, fueron separados del aparato de perfusión mediante un corte en la unión atrioventricular; el tejido ventricular fue disgregado y separado del tejido aún no digerido. El tejido 
disgregado se lavó varias veces con soluciones $\mathrm{K}-\mathrm{H}$ con $1 \%$ de BSA y a concentraciones crecientes de $\mathrm{CaCl}_{2}$. Después de cada lavado, los miocitos se dejaron sedimentar por $10 \mathrm{~min}$. Este proceso permitió la recalcificación paulatina de los mismos, procedimiento que evita que los miocitos mueran por la paradoja del $\mathrm{Ca}^{2+}$, que es el deterioro que se produce cuando se recalcifica a los miocitos luego de un período de perfusión libre de $\mathrm{Ca}^{2+} \cdot 217$

Las células aisladas se mantuvieron en la solución $\mathrm{K}-\mathrm{H}$ con una $\left[\mathrm{Ca}^{2+}\right]$ de $1 \mathrm{mM}$ en el caso de los miocitos de ratas y de $2.5 \mathrm{mM}$ para los de ratón, a temperatura ambiente $\left(20-22^{\circ} \mathrm{C}\right)$, hasta el momento de ser usados.

\section{$\mathrm{Ca}^{2+}{ }_{\mathrm{i}} \mathrm{y}$ acortamiento celular}

Los miocitos cardiacos aislados de rata fueron incubados con Fura2-AM (10 $\mu \mathrm{mol} / \mathrm{L}$ por $15 \mathrm{~min}$ ). El uso de este indicador permite estimar el $\mathrm{Ca}^{2+}{ }_{\mathrm{i}}$ libre a través de la proporción de indicador unido al $\mathrm{Ca}^{2+}$ y de indicador libre.

El Fura2-AM es un indicador de doble-excitación/simple-emisión, que posee una alta afinidad para el $\mathrm{Ca}^{2+}$. La longitud de onda de excitación se centra en $380 \mathrm{~nm}$ (para el indicador libre) y $340 \mathrm{~nm}$ (para el indicador unido al $\mathrm{Ca}^{2+}$ ), generando una única emisión máxima centrada en 525 nm (figura M.1). El hecho que el Fura2-AM tenga doble excitación permite que sea normalizado, lo cual independiza, parcialmente, la medida de $\mathrm{Ca}^{2+}$ de las diferencias en la carga del indicador y del efecto de fotoblanqueo, aunque al mismo tiempo, dificulta el monitoreo de cambios rápidos de $\mathrm{Ca}^{2+}{ }_{i}$ ya que no hay una verdadera simultaneidad en el registro de las dos longitudes de onda utilizadas para obtener el cociente. El Fura2-AM, en su forma permeable de éster de acetometilo (AM), atraviesar las membranas celulares. Una vez en el interior celular, las estearasas endógenas "activan" al indicador transformándolo en su forma ácida, la cual es impermeable al sarcolema, lo que impide que el indicador salga de la célula. Una propiedad importante de los indicadores de $\mathrm{Ca}^{2+}$ es su selectividad por el $\mathrm{Ca}^{2+}$ sobre el $\mathrm{Mg}^{2+}$. El Fura2-AM tiene un $\mathrm{K}_{\mathrm{d}}$ para el $\mathrm{Ca}^{2+}$ de aproximadamente $350 \mathrm{nM}$, por lo que es muy específicos para la medición del $\mathrm{Ca}^{2+} \cdot{ }^{218}$ 


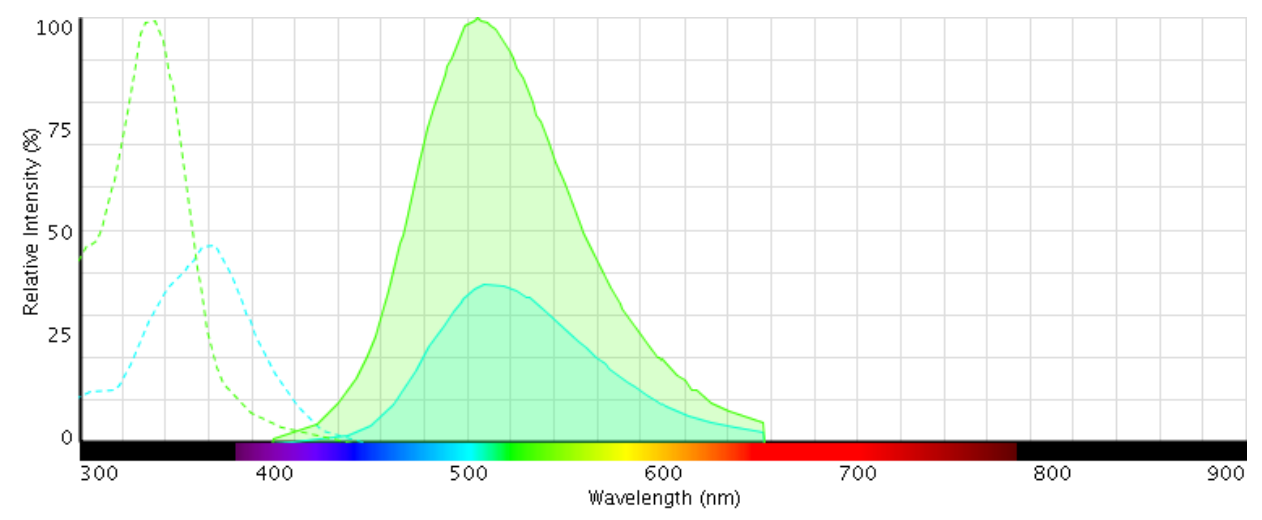

Fligura M.1: Espectros de exitación (línea punteada) y emisión (línea completa) de Fura2-AM libre (celeste) y unido a $\mathrm{Ca}^{2+}$ (verde). ThermoFisher Scientific

Los problemas que pueden suscitar el manejo de estos indicadores son: 1) la amortiguación que producen sobre la $\left[\mathrm{Ca}^{2+}\right]_{\mathrm{i}}$, lo que puede alterar los cambios cinéticos del $\mathrm{Ca}^{2+}$ y por lo tanto influir sobre las respuestas transitorias de $\mathrm{Ca}^{2+} ; 2$ ) la compartamentalización en las organelas (especialmente en mitocondrias), 3) la incompleta desesterificación, que resulta en una contribución de fluorescencia insensible al $\mathrm{Ca}^{2+}$ y 4) la contribución de fluorescencia dada por la autofluorescencia celular, debida a la producción de $\mathrm{NAD}(\mathrm{P}) \mathrm{H}$ mitocondrial. ${ }^{218}$ Estos problemas pudieron mitigarse con el uso de células controles para comparar.

La fluorescencia de $\mathrm{Ca}^{2+}$ fue medida con un sistema de epi-fluorescencia (Ion Optix, Milton, MA). Las células incubadas de indicador se colocaron en una cámara en un microscopio invertido (Nikon.TE 2000-U) y estuvieron continuamente perfundidas con una solución tamponada con $\mathrm{K}-\mathrm{H}$, con un flujo constante de $1 \mathrm{ml} / \mathrm{min}$ a temperatura ambiente $\left(20-22^{\circ} \mathrm{C}\right)$. Los miocitos fueron estimulados a través de electrodos de platino dos a cada lado de la cámara a $1 \mathrm{~Hz}$. La fluorescencia de Fura2-AM fue tomada como un índice del contenido de $\mathrm{Ca}^{2+}$, la longitud de reposo y el acortamiento de la célula fueron medidos por un detector de movimiento de vídeo (lon Optix). Se probó que cada miocito se contrajera y luego se los mantuvo en un estado quiescente durante 3 minutos. Después de este período fueron estimulados a $1 \mathrm{~Hz}$ hasta estabilización. La latencia de los eventos espontáneos de liberación de $\mathrm{Ca}^{2+}$ (EELC) fue medida en el estado de quiescencia desde el inicio del registro, hasta aparición del primer EELC. Un pulso de cafeína $(25 \mathrm{mM})$ fue aplicado rápidamente después de la estabilización, para evaluar la carga de $\mathrm{Ca}^{2+}$ del SR. La cafeína induce la apertura de los RyR2 y bloquea la actividad de la SERCa2a del $\mathrm{RS}$, lo que genera la liberación de $\mathrm{Ca}^{2+}$ del RS e impide su recaptura. ${ }^{219}$ Después del lavado del pulso de la cafeína, el protocolo se repitió en presencia de isoproterenol (Iso). El Iso es un agonista $\beta$-adrenérgico el cual, por sus efectos 
sobre el acoplamiento excitocontráctil, puede exacerbar distintos procesos subyacentes que predisponen a arritmias.

El mismo protocolo también fue realizado en presencia de un inhibidor de la CaMKII, KN-93, y KN-92 su análogo inactivo. KN-93 es un derivado de sulfonilo metoxibenceno que inhibe competitivamente la unión de CaM a CaMKII con un $\mathrm{K}_{\mathrm{i}}$ de $0,37 \mu \mathrm{M}$. KN-92 es un congénere de KN-93 sin actividad inhibidora de CaMKII y se utiliza como un control experimental. Ni KN-93 o KN-92 tienen efectos apreciables sobre otras quinasas serina / treonina como PKA o PKC. ${ }^{181}$ Además, la velocidad de decaimiento del pulso de cafeína $\left(\mathrm{K}_{\text {caf }}\right)$ se utilizó para estimar la velocidad de extrusión de $\mathrm{Ca}^{2+}$ por el $\mathrm{NCX}$ ya que en presencia de cafeína este es el transportador de mayor importancia para que el $\mathrm{Ca}^{2+}{ }_{\mathrm{i}}$ vuelva a valores diastólicos. La caída de los transitorios de $\mathrm{Ca}^{2+}$ se debe a la retoma de $\mathrm{Ca}^{2+}$ por la SERCa y al NCX funcionado en modo directo, mientras que la caída del pulso de cafeína se debe exclusivamente al funcionamiento del NCX. Esto nos permite estimar la actividad de la SERCa ( $\kappa_{\text {SERCa2a }}$ ), restando la constante de decaimiento del pulso de cafeína de la del transitorio $\left(\mathrm{K}_{\mathrm{t}}-\mathrm{K}_{\mathrm{caf}}\right)$.

Los datos de fluorescencia se almacenaron para análisis off-line (software de análisis de fluorescencia de ION asistente). Se realizó el análisis de las salidas espontáneas de $\mathrm{Ca}^{2+}$ de forma azarosa y ciega.

\section{Imágenes de microscopía confocal de cardiomiocitos intactos}

Se tomaron imágenes en confocalidad, en el modo de barrido lineal para la observación de transitorios de $\mathrm{Ca}^{2+}$ estimulados de manera externa, sparks y waves de $\mathrm{Ca}^{2+}$, y la actividad contráctil espontánea. Las células fueron incubadas con Fluo-3 AM 2 mM, por 20 min a temperatura ambiente. Fluo-3 AM es un indicador de $\mathrm{Ca}^{2+}$ desarrollado para su uso con fuentes de luz visible en la citometría de flujo y microscopía confocal de escaneo láser. Fluo-3 AM tiene un espectro de absorción compatible con excitación a $488 \mathrm{~nm}$ por fuentes de láser de ion argón, y un aumento importante de intensidad de fluorescencia en respuesta a la unión de $\mathrm{Ca}^{2+}$ (figura M.2). Las células se estimularon con láser de argón a 488nm y se midió la fluorescencia a $515 \mathrm{~nm}$. 


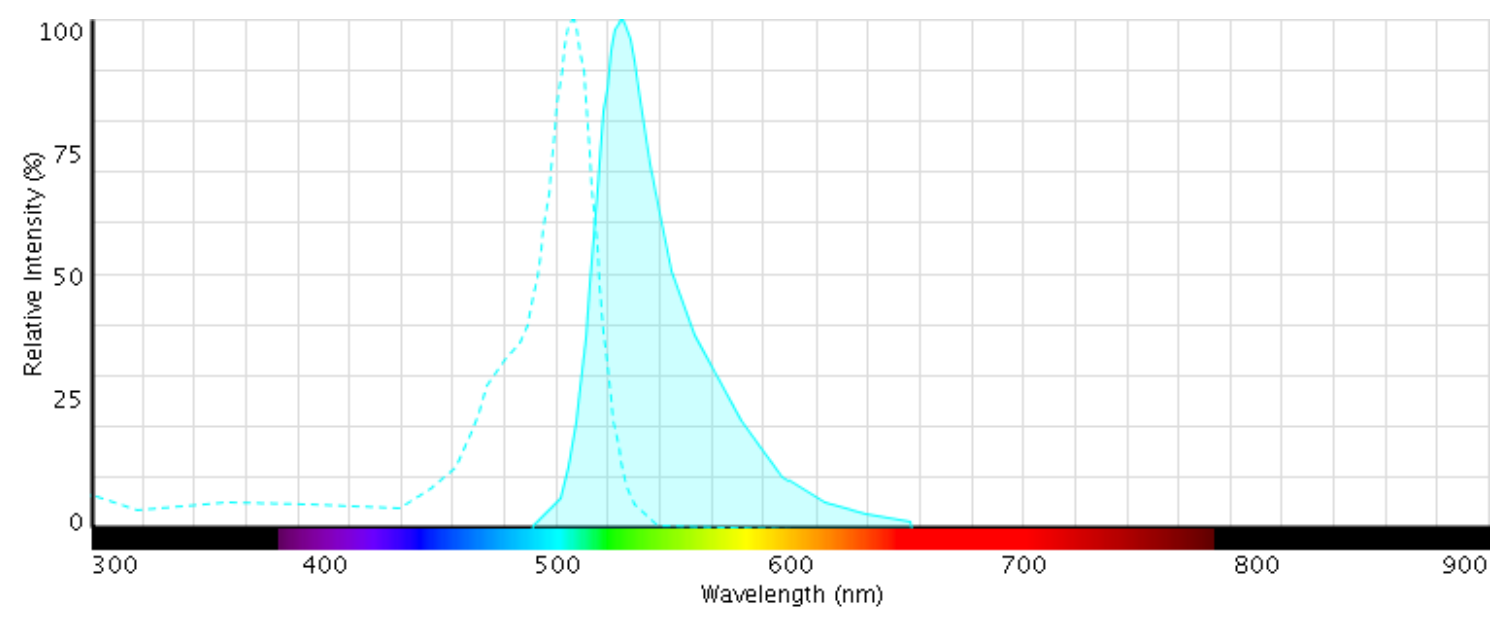

Figura M.2: Espectros de exitación (línea punteada) y emisión (línea completa) de Fluo3 unido a Ca ${ }^{2+}$ (celeste). ThermoFisher Scientific

Cada imagen consistió en exploraciones de líneas de 512 píxeles obtenidas en intervalos de $4 \mathrm{mseg}$. Los datos fueron visualizados utilizando Leica Application Suite $^{220}$ y los sparks se midieron utilizando el plugin "Sparkmaster" de ImageJ. ${ }^{221}$ Los sparks y las waves fueron obtenidas en células quiescentes, después de 5 min de estímulo a $0,5 \mathrm{~Hz}$ en presencia y ausencia de Iso $30 \mathrm{nmol} / \mathrm{l}$. La frecuencia de sparks en $(100 \mu \mathrm{m})^{-1} \mathrm{sec}^{-1}$ fue convertida a unidades $\mathrm{fl}^{-1 *} \mathrm{~s}^{-1}$ asignando un volumen de escaneo a los sparks, según lo propuesto por los autores Santiago et al., 2010. ${ }^{222}$ La pérdida de $\mathrm{Ca}^{2+}$ del RS debida a sparks se definió como la frecuencia de sparks x la masa de spark. La masa del spark, se calculó como amplitud x AMAM x DMAM (AMAM, ancho a la mitad de la altura máxima; DMAM, duración a la mitad de la altura máxima) (Figura M.3).

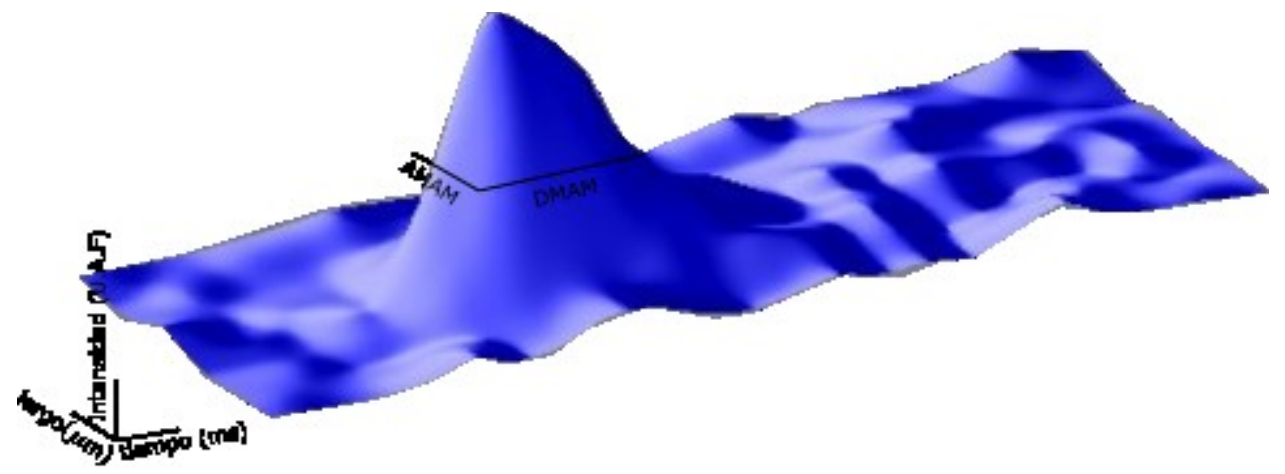

Figura M.3: Gráfico de superficie de un spark. El eje longitudinal muestra la progresión temporal del $\mathrm{Ca}^{2+}$ en un miocito intacto, el ancho muestra los cambios en el $\mathrm{Ca}^{2+}$ a lo largo de la célula y la altura representa la intensidad de fluorescencia en unidades arbitrarias de fluorescencia (U.A.F.). La imagen muestra, también, el ancho a la mitad de la amplitud máxima (AMAM) y la duración a la mitad de la amplitud máxima (DMAM). 


\section{Determinación de estrés oxidativo}

Producción cardiaca de anión superóxido $\left(\cdot \mathrm{O}_{2}^{-}\right)$

Se obtuvieron piezas de tejido de ventricular izquierdo (1-5 $\mathrm{mm})$, que fueron mantenidas en el buffer de ensayo $\left(\mathrm{NaCl} 118 \mathrm{mM}, \mathrm{KCl} 5 \mathrm{mM}, \mathrm{MgSO}_{4}\right.$ 1,2mM, $\mathrm{NaHCO}_{3} 20 \mathrm{mM}$, glucosa $10 \mathrm{mM}, \mathrm{MgCl}_{2} 0,8 \mathrm{mM}, \mathrm{pH} 7,4$ por burbujeo de $\mathrm{CO}_{2}$ al $5 \%$ ) durante 30 minutos. Posteriormente, se midió la producción de anión superóxido $\left(\cdot \mathrm{O}_{2}^{-}\right)$luego de una incubación de 20 minutos con lucigenina (Bis-N-metilacridinium) $5 \mu \mathrm{mol} / \mathrm{L}$, por el método de quimioluminiscencia, en un luminómetro (camaleón, Hidex). La lucigenina es un reactivo utilizado para la generación de quimioluminiscencia en presencia de un reductor y oxígeno, los cuales permiten la excitación de electrones desapareados y su posterior emisión luminiscente. Este reactivo es específico para el radical anión superóxido.Los datos obtenidos se normalizaron por el peso seco del tejido. Los aumentos en la producción de $\cdot \mathrm{O}_{2}{ }^{-}$se expresaron como diferencias de valores de control.

\section{Peroxidación lipídica}

La peroxidación lipídica se determinó a través de la medida de la tasa de producción de sustancias reactivas al ácido tiobarbitúrico (TBARS), expresada como $\mathrm{nmol} / \mathrm{mg}$ de proteína. El producto final de la peroxidación lipídica malondialdehído, un aldehído reactivo producido por la peroxidación lipídica de ácidos grasos poliinsaturados, forma un aducto con dos moléculas de ácido tiobarbitúrico para producir una especie química de color rosa que absorbe a 532$535 \mathrm{~nm}$. Para esta determinación, se utilizaron corazones enteros que fueron homogeneizados con un buffer fosfato ( $\mathrm{KCl} 140 \mathrm{mM}$, KH2PO4 $25 \mathrm{mM})$. Los homogenatos de corazón se centrifugaron a 1000xg por 10 minutos. Una cantidad de $0,5 \mathrm{ml}$ del sobrenadante se mezclada con $1,5 \mathrm{ml}$ de ácido tricloroacético $(10 \%$ p/v) y $1 \mathrm{ml}$ de ácido tiobarbitúrico $(0.67 \%$ p/v), fue llevada a ebullición por $15 \mathrm{~min}$. Después de enfriar la mezcla se determinó la absorbancia espectrofotométricamente a $535 \mathrm{~nm}$, utilizando un valor $\varepsilon 1.56 \times 10^{5}(\mathrm{mmol} / \mathrm{l})^{-1} \mathrm{~cm}^{-1}$. Los resultados fueron expresados en relación con la cantidad de proteínas en cada muestra.

\section{Western Blot}

Para los ensayos de Western Blot, los corazones extraídos de animales tratados fueron congelados y pulverizados. Luego, se homogeneizó $0,1 \mathrm{~g}$ de tejido en 4 volúmenes de buffer de lisis (en mmol/l, 20 glicerolfosfato de sodio, $20 \mathrm{NaF}, 1$ EGTA, 2 EDTA, 0,2 Na2VO4, 2 ditiotreitol, 10 benzamida, 1 fluoruro de 
fenilmetilsulfonilo, 0,001 pepstatina, $1 \%$ Igepal, $0,01 \%$ de Triton y $0,048 \mathrm{mg} / \mathrm{ml}$ leupeptina).

La concentraciones de proteínas en los homogenatos se determinó por el método colorimétrico de Bradford (BIORAD) ${ }^{223}$ por espectrofotometría a $595 \mathrm{~nm}$ usando albúmina sérica bovina como estándar. El mismo está basado en el cambio de color del colorante Coomassie brilliant blue G-250 en respuesta a diferentes concentraciones de proteínas. Este compuesto interacciona con aminoácidos básicos (especialmente arginina) y aromáticos. Esta unión del colorante con las proteínas provoca un cambio en el máximo de absorción del colorante desde 465 a $595 \mathrm{~nm}$.

Los lisados ( 90 $\mathrm{\mu g}$ de proteína total) fueron separados en geles de poliacrilamida al $10 \%$ o $6 \%$ con SDS, posteriormente se transfirieron las proteínas a membranas de difluoruro polivinilideno. Dichas membranas se incubaron durante la noche con los siguientes anticuerpos: fosfolamban (PLN) 1:1000 (ABR, Golden, CO, EE.UU.), Fosforilación en Thr $^{17}$ de fosfolamban (P-Thr17) 1:5000 (Badrilla, Leeds, Reino Unido), Receptor de rianodina (RyR2) 1:1000 (ABR, Golden, CO, EE.UU.), Fosforilación en Ser ${ }^{2814}$ y Ser ${ }^{2809}$ de RyR2 1:1000 (Badrilla, Leeds, Reino Unido), fosforilación de CaMKII 1:1000 (P-CaMKII. Abcam, Cambridge, MA, EE.UU.) y OxCaMKII 1:1000 (Millipore, Billerica, MA, EE.UU.), BAX 1:2000 (Millipore, Billerica, MA, EE.UU), Bcl2 1:2000 (Abcam, Cambridge, MA, EE.UU.), p38 1:3000 (Abcam, Cambridge, MA, EE.UU.), Fosforilación de p38 1:1000 (P-p38. Abcam, Cambridge, MA, EE.UU.). La señal $\beta$-actina o de la forma no fosforilada / oxidada se utilizó para normalizar la intensidad de la señal de las diferentes proteínas o fosfoproteínas. Luego de los anticuerpos específicos, se utilizaron anticuerpos secundarios antiratón o anticonejo según correspondiera. La inmunorreactividad se visualizó mediante un kit de detección de quimioluminiscencia a base de peroxidasa (Millipore, Billerica, MA, EE.UU.), utilizando un sistema de imagen ChemiDoc. La intensidad de señal de las bandas en las inmunotransferencias se cuantificó por densitometría, utilizando el software Image $\mathrm{J}(\mathrm{NIH})$.

\section{Medida de apoptosis por TUNEL}

Para la medida de apoptosis se utilizó la técnica fluorescente de TUNEL, que denota la fragmentación del DNA por DNAasas endógenas in situ, evento característico de la apoptosis, como se mencionó en la Introducción. Los corazones de ratas con dieta rica en fructosa y dieta control fueron fijados en $\rho$-formaldehído al $4 \%$, permeabilizadas con etanol y ácido acético y conservadas en alcohol $70 \%$ a - 
$20^{\circ} \mathrm{C}$ hasta ser coloreadas. Se utilizó un kit comercial para TUNEL (In Situ Cell Death Kit de detección, TMR rojo, Roche, Mannheim, Alemania). ${ }^{224}$

Las imágenes de las células positivas fueron obtenidas con un microscopio confocal (Olympus FV-1000, Japón), usando un objetivo 40x NA 0,95. Se contaron en 20 campos al azar para cada situación experimental mediante el análisis de imágenes de software v6.3 Olympus cellSens. ${ }^{225}$ Los resultados se expresaron como porcentaje de células positivas para TUNEL relacionados con el número total de células.

La tinción nuclear fue realizada utilizando la solución DAPI (1 ug / ml, 4, dihidrocloruro de 6-diamidino-2-fenilindol, Sigma, St Louis, MO). ${ }^{226}$ El contraste de interferencia diferencial (DIC) de las imágenes fué utilizado para a identificar los cardiomiocitos y células no cardiomiocíticas. También se identificaron los cardiomiocitos por tinción por inmunofluorescencia contra desmina.

\section{Aislamiento de mitocondrias}

Las mitocondrias de corazón de rata se aislaron por centrifugación diferencial. ${ }^{227}$ Los corazones fueron extirpados de ratas anestesiadas con pentobarbital y colocados en hielo con un buffer de aislamiento (BA) enfriado que contiene (en mM): 75 sacarosa, 225 manitol y 0,01 EGTA, pH 7,4. ${ }^{228}$ Posteriormente se retiraron de los corazones ambas aurículas y el ventrículo derecho, y el ventrículo izquierdo restante se homogeneizó manualmente con un homogeneizador Dounce, durante 14 minutos, en dos tandas de 7 minutos cada una, en presencia de proteínasa $(0,8$ $\mathrm{mg}$ en $5 \mathrm{ml}$ de BA, P8038; Sigma). ${ }^{229}$ El tejido homogeneizado se centrifugó 5 minutos a $2000 \mathrm{~g}\left(4^{\circ} \mathrm{C}\right)$, y se desechó el sedimento que contenía las células intactas y los núcleos. El sobrenadante resultante que contiene la fracción mitocondrial se centrifugó 10 minutos a $8000 \mathrm{~g}$ y el sedimento se resuspendió en buffer de aislamiento y se realizaron tres lavados centrifugando a $8000 \mathrm{~g}$ durante 5 min. El precipitado se resuspendió en buffer de aislamiento sin EGTA. Se determinó la concentración de proteína de la suspensión mitocondrial.

\section{Determinación del hinchamiento mitocondrial.}

El hinchamiento mitocondrial se midió como una disminución en la señal de dispersión de luz (DO), inducida por la adición de $20 \mathrm{mM}, 50 \mathrm{mM}, 100 \mathrm{mM}$ y $200 \mathrm{mM}$ $\mathrm{CaCl}_{2}$, que promueve la afluencia de solutos a través del poro de transición mitocondrial (mPTP) abierto y disminuye la dispersión de luz. ${ }^{230}$ Después de 5 min de preincubación a $37^{\circ} \mathrm{C}$, en un medio que contiene (en mM) $120 \mathrm{KCl}, 20 \mathrm{MOPS}$, 10 Tris $\cdot \mathrm{HCl}$, y $5 \mathrm{KH} 2 \mathrm{PO} 4$, a pH 7,4, se añadieron $50 \mathrm{mM}$ o $200 \mathrm{mM} \mathrm{CaCl} 2 .^{228}$ 
La disminución de la dispersión de luz se detectó con una temperatura controlada en un espectrofluorómetro Aminco Serie Bowman 2 operando con agitación continua con una longitud de onda de excitación de $520 \mathrm{~nm}$. La disminución de la dispersión de la luz se calculó para cada muestra como la diferencia entre los valores antes y después de la adición de $\mathrm{CaCl}_{2}$.

\section{Determinación de $\mathrm{Ca}^{2+}$ mitocondrial}

Para la observación de $\mathrm{Ca}^{2+}$ mitocondrial, se tomaron imágenes en confocalidad en el modo de barrido de línea. Células aisladas de ratas fueron incubadas con Fluo-3 AM $2 \mathrm{mM}$ por $20 \mathrm{~min}$, a temperatura ambiente. Estas fueron estimuladas con láser de argón a $488 \mathrm{~nm}$, la fluorescencia fue medida a $515 \mathrm{~nm}$. Cada imagen consistió en exploraciones de líneas de 512 píxeles obtenidas en intervalos de 4 mseg. Los datos fueron visualizados utilizando Leica Application Suite. ${ }^{220}$

Se registró la fluorescencia de las células durante la estimulación eléctrica a una frecuencia de $0.5 \mathrm{~Hz}$, para constatar la viabilidad celular. Posteriormente, se incubó las células, durante 20 minutos, en una solución $50 \mu \mathrm{M}$ de $\mathrm{MnCl}_{2}$. Este último atrapa al indicador impidiendo que éste se una al $\mathrm{Ca}^{2+}$ y fluorezca; esa concentración de $\mathrm{Mn}^{2+}$ no ingresa a la mitocondria y por lo tanto el indicador se apaga en toda la célula excepto en la mitocondria. ${ }^{231}$ Finalizada la incubación, se tomaron fotos en estado de quiescencia y durante el estímulo eléctrico a $0.5 \mathrm{~Hz}$, para observar el $\mathrm{Ca}^{2+}$ mitocondrial basal y que hubiera contracción sin transitorio (indicativo que el $\mathrm{Mn}^{2+}$ efectivamente disminuyó la fluorescencia citosólica). Altas concentraciones de $\mathrm{Mn}^{2+}$ son capaces de interferir en la correcta contracción de la célula por su similitud con el $\mathrm{Ca}^{2+}$. Debido a esto, se realizaron controles de contractilidad donde pudiese compararse la fuerza y velocidad de contracción antes y después del agregado de $\mathrm{Mn}^{2+}$, tanto en miocitos de ratas controles como tratadas con dieta rica en fructosa.

\section{Determinación del potencial mitocondrial}

Para la medida del potencial de membrana mitocondrial se midió por microscopía confocal en células aisladas de ratas el cambio de intensidad de fluorescencia del colorante específico JC-1. JC-1 es un indicador de carbocianina catiónica que se acumula en la mitocondria. El indicador existe como un monómero en bajas concentraciones y produce una fluorescencia verde. Al despolarizarse la membrana, el indicador se acumula en la misma formando J-agregados que presentan un amplio espectro de excitación y una emisión máxima a 590nm. Estas características convierten al JC-1 en un marcador sensible para el potencial de membrana mitocondrial. Para la medida de potencial mitocondrial los miocitos 
cardiacos se incubaron con $\mathrm{JC}-1(3 \mu \mathrm{M})$ a $37^{\circ} \mathrm{C}$ por 20 minutos, y después se lavaron durante 20 minutos. Las células incubadas se excitaron con láser de argón de $488 \mathrm{~nm}$ de longitud de onda y la fluorescencia emitida se recogió a $530 \mathrm{~nm}$ y 590 $\mathrm{nm}$. El potencial mitocondrial se expresó como la relación de fluorescencia emitida $(590 / 530 \mathrm{~nm})$ en porcentaje a la medida en células de ratas con dieta control. ${ }^{231}$

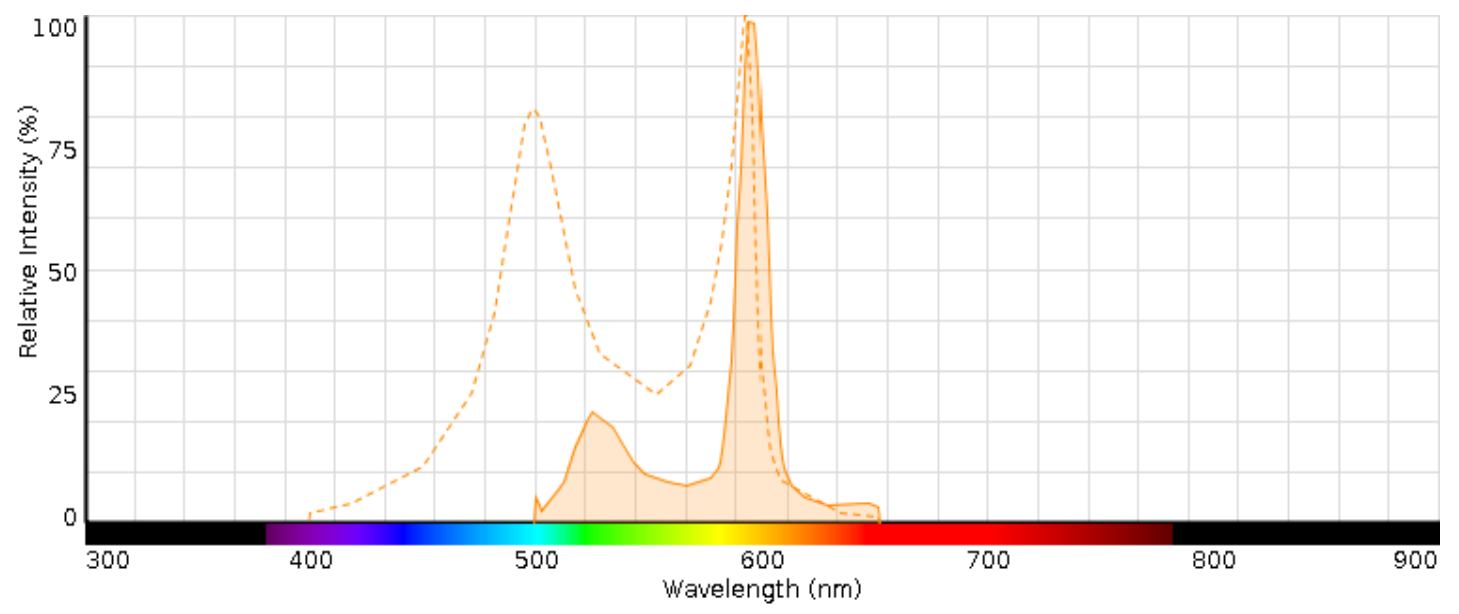

Figura M.4: Espectros de exitación (línea punteada) y emisión (línea completa) de JC1. ThermoFisher Scientific

\section{Estadística}

Las técnicas utilizadas nos brindaron datos numéricos de distintas características, los cuales fueron analizados a través de pruebas acordes a los datos obtenidos. Las pruebas de tipo paramétrico están sometidas a determinadas condiciones de aplicación, normalmente: normalidad, homoscedasticidad e independencia. Entendemos por normalidad el ajuste de los datos, en mayor o menor medida, a la curva normal; por independencia el que las " $n$ " observaciones hayan sido aleatoriamente extraídas y sean independientes entre sí; y por homoscedasticidad que las varianzas de las distribuciones intervinientes sean homogéneas. ${ }^{232}$

Las pruebas de tipo no paramétrico por el contrario no están sometidas a determinadas condiciones de aplicación y son adecuadas cuando se incumple alguno de los criterios previstos para las pruebas de significación de tipo paramétrico.

La normalidad de las variables fue evaluada a través del test de normalidad de Shapiro-Wilk, el cual evaluá la similitud de la distribución de los datos con la distribución de Gauss. Una vez determinado el tipo de dato que generaba cada técnica se determinó el tamaño muestral con un nivel de confianza del 95\% para 
establecer un tamaño muestral mínimo para cada técnica. Aquellas variables que mostraron condiciones de aplicación paramétricas se expresaron como media \pm error estándar y fueron evaluados, ya sea con la prueba t de Student (utilizado para tamaños muestrales pequeños) o ANOVA seguido por el test post hoc de Tukey (análisis de varianza con un test de comparación de medias de a pares para mútiples grupos), cuando se realizó la comparación entre los diferentes grupos. Los EELC mostraron un comportamiento no paramétrico, siguiendo una distribución $x^{2}$ (la distribución de chi-cuadrada es una distribución continua que se especifica por los grados de libertad y el parámetro de no centralidad, la distribución es positivamente asimétrica). Estos se expresaron como datos continuos no paramétricos. En estos casos, en los que la distribución de datos no fue normal, se utilizó la prueba de Mann-Whitney (se utiliza para comprobar la heterogeneidad de dos muestras ordinales, para observaciones independientes) para la comparación entre grupos. ${ }^{232}$ Un valor de $p<0,05$ fue considerado significativo. 


\section{RESULTADOS}




\section{Caracterización del modelo de dieta rica en fructosa}

En una primera instancia del trabajo se realizó una caracterización metabólica del modelo para luego poder visualizar los cambios ecocardiográficos. Las ratas con dieta rica en fructosa mostraron un aumento en los niveles séricos de insulina, triglicéridos, ácidos grasos no esterificados (AGNE), el área bajo la curva del nivel de glucosa en suero en función del tiempo después de la administración intraperitoneal de la carga de glucosa y la resistencia a la insulina, medido por el parámetro HOMA-IR, en comparación con las ratas control (Tabla R.1). Estos datos son consistentes con un patrón de resistencia a la insulina, es decir, mostraron un aumento de los niveles de insulina en sangre con una alteración del test de tolerancia intrapertoneal a la glucosa y aumento en la movilización de lípidos. ${ }^{75}$ En contraste, los niveles de glucosa en ayunas (GA) y el peso corporal fueron similares en los animales con dieta rica en fructosa y sus pares controles, lo que indica un estado prediabético sin DMT2 establecida.

\begin{tabular}{c|c|c|} 
& \multicolumn{2}{|c|}{ Tratamiento } \\
\cline { 2 - 3 } Parámetros & Control & Fructosa \\
\cline { 2 - 3 } Insulinemia (ng/ml) & $0.30 \pm 0.02$ & $1.09 \pm 0.28^{* *}$ \\
\cline { 2 - 3 } TG (mg/dl) & $114 \pm 5$ & $193 \pm 9^{*}$ \\
\cline { 2 - 3 } AGNE (mM) & $0.59 \pm 0.04$ & $0.77 \pm 0.05^{*}$ \\
\cline { 2 - 3 } HOMA-IR & $2.00 \pm 0.40$ & $4.97 \pm 1.20^{*}$ \\
\cline { 2 - 3 } $\begin{array}{c}\text { GA (mmol/L) } \\
\text { ABC (mmol } \\
\text { glucosa/L.min) } \\
\text { Peso corporal (g) }\end{array}$ & $80.8 \pm 2.3$ & $89.0 \pm 4.0$ \\
\cline { 2 - 3 } & $2433 \pm 575$ & $5231 \pm 1189^{*}$ \\
\cline { 2 - 3 } & $271.63 \pm 15.87$ & $309.00 \pm 8.86$ \\
\cline { 2 - 3 }
\end{tabular}

Tabla R.1: Caracterización metabólica de las ratas. TG: triglicéridos, AGNE: ácidos grasos no esterificados, HOMA-IR: por sus iniciales en inglés, homeostatic model assessment-Insulino Resistance (valoración de modelo homeostático- Insulinoresistencia), GA: glucosa en ayunas, ABC: área bajo la curva. Los valores son promedio \pm SEM. ${ }^{*} p<0.05,{ }^{* *} p<0,01 . n=4$ ratas.

Las tablas R.2 y R.3 muestran la cantidad de comida y agua, y las calorías ingeridas en ambos grupos de ratas y ratones, respectivamente. La ingesta de agua fue mayor y el consumo de alimentos menor en ratas y ratones alimentados con dieta rica en fructosa respecto de los animales controles. A su vez, la ingesta de calorías fue mayor en ratas con dieta rica en fructosa pero no en los ratones. Sin 
embargo, como mencionamos, el peso de los animales no se modificó, y los efectos de la diferencias en la ingesta calórica se discutirán posteriormente.

\begin{tabular}{c|c|c|}
\cline { 2 - 3 } Parámetros & \multicolumn{2}{|c|}{ Ratas Wistar } \\
\cline { 2 - 3 } & Control & Fructosa \\
\hline$n$ & 8 & 12 \\
\hline $\begin{array}{c}\text { Agua de bebida } \\
\text { (ml/día) }\end{array}$ & $30.18 \pm 2.64$ & $50.61 \pm 2.62^{*}$ \\
\hline Comida (g/día) & $18.29 \pm 0.801$ & $14.78 \pm 0.35^{*}$ \\
\hline $\begin{array}{c}\text { Calorías } \\
\text { (Kcal/día) }\end{array}$ & $54.87 \pm 1.82$ & $62.82 \pm 1.22^{*}$ \\
\cline { 2 - 3 }
\end{tabular}

Tabla R.2: Promedio de ingesta de alimento, agua y calorías en ratas tratadas con fructosa y control. Los valores son promedio \pm SEM. * $p<0.05$.

\begin{tabular}{c|c|c|c|c|}
\cline { 2 - 5 } & \multicolumn{2}{|c|}{ Ratón WT } & \multicolumn{2}{c|}{ Ratón SR-AIP } \\
\hline Parámetros & Control & Fructosa & Control & Fructosa \\
\hline$n$ & 9 & 17 & 4 & 12 \\
\hline $\begin{array}{c}\text { Agua de } \\
\text { bebida } \\
\text { (ml/día) }\end{array}$ & $5.24 \pm 0.33$ & $6.34 \pm 0.2^{*}$ & $5.58 \pm 0.57^{*}$ & $8.56 \pm 0.11^{*}$ \\
\hline $\begin{array}{c}\text { Comida } \\
\text { (g/día) }\end{array}$ & $4.07 \pm 0.16$ & $3.53 \pm 0.07^{*}$ & $4.23 \pm 0.27$ & $4.09 \pm 0.08$ \\
\hline $\begin{array}{c}\text { Calorías } \\
\text { (Kcal/día) }\end{array}$ & $14.37 \pm 0.59$ & $13.87 \pm 0.64$ & $14.96 \pm 1.02$ & $15.72 \pm 0.18$ \\
\cline { 2 - 5 }
\end{tabular}

Tabla R.3: Promedio de ingesta de alimento, agua y calorías de ratones tratados con fructosa y control. Los valores son promedio \pm SEM. * $p<0$. 05, comparados contra los valores controles.

Por otro lado, las ratas con dieta rica en fructosa desarrollaron hipertrofia cardiaca y disfunción sistólica, detectada por ecocardiografía. Como se muestra en la figura R.1 y la tabla R.4, la dieta rica en fructosa produjo un aumento en el peso del corazón normalizado por la longitud de la tibia y del índice de masa del ventrículo izquierdo. Al mismo tiempo, se observa una distención de las cavidades con una disminución del porcentaje de acortamiento, ambos característicos de una disfunción contráctil. La presión arterial sistólica fue similar $(p=0,70)$ en el grupo con dieta control $(118 \pm 2 \mathrm{~mm} \mathrm{Hg})$ y en el de dieta rica en fructosa $(115 \pm 4 \mathrm{~mm} \mathrm{Hg})$, lo que indica que las alteraciones de la estructura y función cardiaca de las ratas tratadas son independientes de la presión sanguínea. 

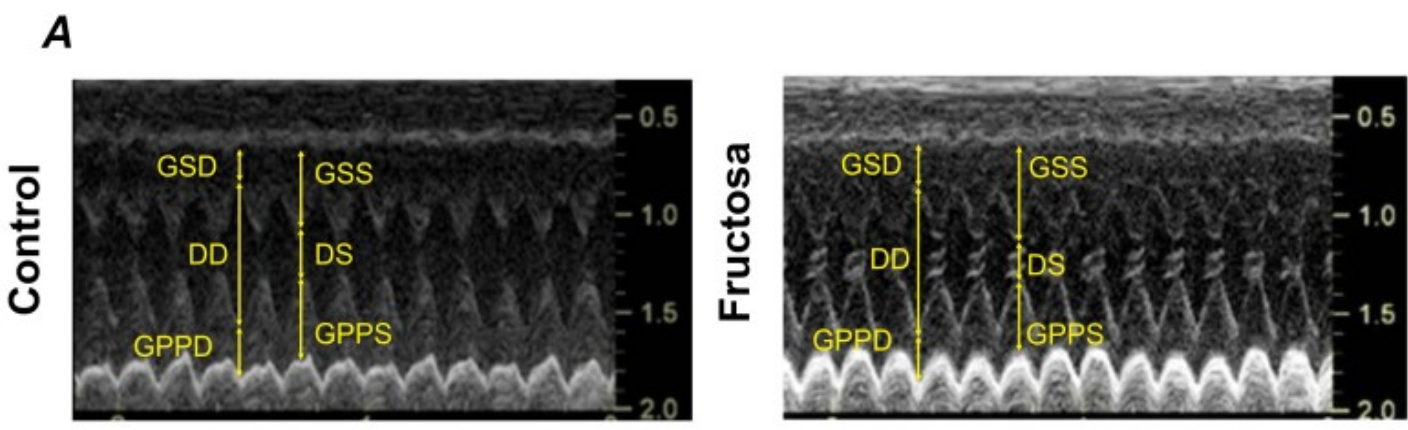

B
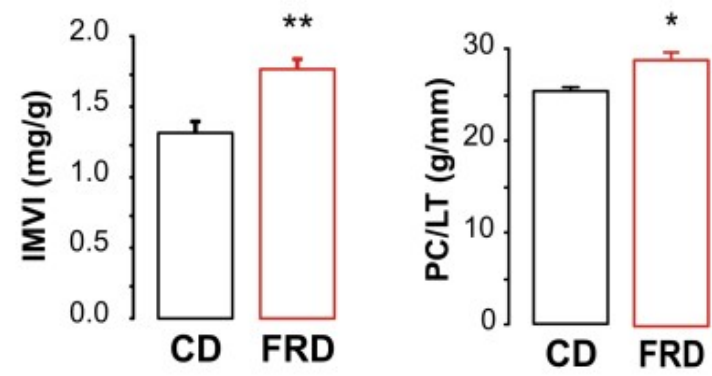

C

D
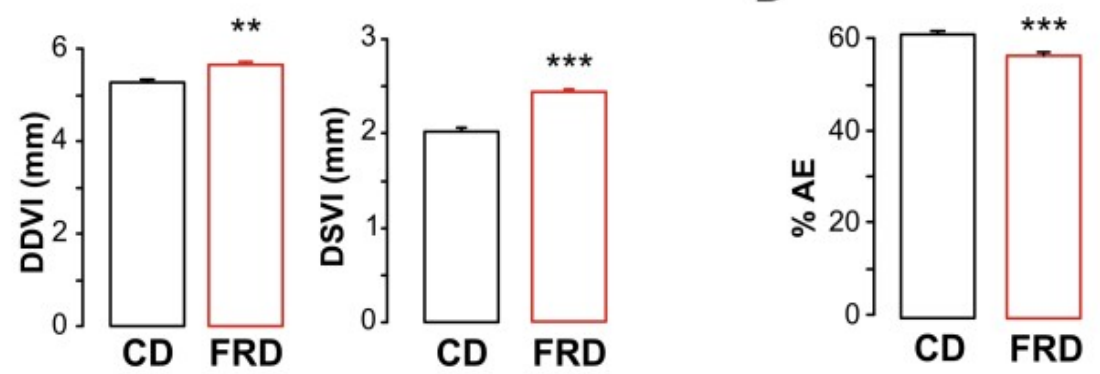

Fig. R.1. Alteraciones ecocardiográficas estructurales y funcionales del corazón en ratas con dieta rica en fructosa.

A, Imagen representativa de ecocardiografía del ventrículo izquierdo de rata control (CD) y con dieta rica en fructosa (FRD): diámetro en diástole (DD) y sístole (DS), GSD: espesor diastólico del tabique, GPPD: Espesor de la pared posterior ventricular izquierda diastólica, GSS: espesor sistólico del septum, GPPS: espesor sistólico de pared posterior; B, Parámetros de hipertrofia como el índice de masa del ventrículo izquierdo (IMVI) y el peso del corazón en relación a la longitud de la tibia (PC/LT); $C$, Dilatación del ventrículo izquierdo evaluada con el diámetro de las cavidades en diástole (DDVI) y sístole (DSVI); $D$, Porcentaje de acortamiento endocárdico. Los valores son promedio $\pm S E M$. * $p<0$. $05,{ }^{* *} p<0.01,{ }^{* * *} p<0,001 . N: 11$ animales control y 12 animales con dieta rica en fructosa. 


\begin{tabular}{|c|c|c|}
\hline Parámetros & Ratas Control & Ratas Fructosa \\
\hline $\mathbf{n}$ & 11 & 12 \\
\hline DD (mm) & $5.34 \pm 0.08$ & $5.69 \pm 0.03^{* \star *}$ \\
\hline DS (mm) & $2.08 \pm 0.04$ & $2.43 \pm 0.02^{\star * \star}$ \\
\hline GSD (mm) & $1.49 \pm 0.02$ & $1.58 \pm 0.01^{* * *}$ \\
\hline GPPD (mm) & $1.55 \pm 0.02$ & $1.63 \pm 0.02$ ** \\
\hline AE (\%) & $60.93 \pm 0.40$ & $57.27 \pm 0.43^{* * *}$ \\
\hline IMVI (mg/g) & $1.44 \pm 0.05$ & $1.76 \pm 0.04^{* * *}$ \\
\hline IMVI (mg/mm) & $13.03 \pm 0.40$ & $16.02 \pm 0.2^{* * *}$ \\
\hline
\end{tabular}

Tabla R.4. Parámetros ecocardiográficos de ratas control y tratadas con dieta rica en fructosa. El diámetro ventricular izquierdo en diástole (DD) y sístole (DS) se incrementaron significativamente en ratas tratadas con fructosa en comparación con corazones de ratas controles, en asociación con aumentos significativos en los índices de hipertrofia (IMVI: índice de masa ventricular izquierda, normalizado por peso corporal [mg/g] o [mg/mm] por la longitud tibial; GSD: espesor diastólico del tabique; GPPD: Espesor de la pared posterior ventricular izquierda diastólico). Por otra parte, la función sistólica (AE [\%]: acortamiento fraccional endocárdico) se redujo en ratas fructosa con respecto a las ratas control. Los valores son promedio \pm SEM. ${ }^{* *} p<0.01,{ }^{* * *} p<0,001$.

\section{La dieta rica en fructosa aumenta la liberación espontánea de $\mathrm{Ca}^{2+}$}

Los hallazgos observados en el animal entero nos llevaron a estudiar el manejo del $\mathrm{Ca}^{2+}$. El protocolo que realizamos para examinar el manejo del $\mathrm{Ca}^{2+}$ en miocitos aislados se muestra en la Fig. R.2A; que, como se explicó en los métodos, consistió en medir la fluorescencia de miocitos incubados con Fura2-AM, los cuales permanecieron en quiescencia durante 5 minutos y luego, fueron estimulados eléctricamente a $1 \mathrm{~Hz}$ de frecuencia, en presencia y ausencia del agonista $\beta$ adrenérgico, isoproterenol (Iso). El uso de Iso es un desafío que simula un estrés para la célula y podría desenmascarar eventos que en condiciones normales no se observarían. Al finalizar cada serie se realizó un pulso de cafeína para estimar la carga de $\mathrm{Ca}^{2+}$ del RS. En condiciones no estresantes (sin Iso), los cardiomiocitos aislados de ratas con dieta rica en fructosa mostraron un mayor número de eventos espontáneos de liberación de $\mathrm{Ca}^{2+}$ (EELC) (Fig. R.2A-D) que se correlaciona con contracciones espontáneas, lo cual se asoció con un período de latencia más corto 
(Fig. R.2E) en comparación con miocitos de ratas con dieta control. La frecuencia de EELC fue normalizada por el contenido de $\mathrm{Ca}^{2+}$ del RS. Esta normalización permite excluir que las diferencias de EELC se deban a cambios en la carga de $\mathrm{Ca}^{2+}$ del RS. Observando en detalle, se vio que solo los miocitos de ratas con dieta rica en fructosa y no los controles mostraron aumento de los eventos de liberación de $\mathrm{Ca}^{2+}$ disincrónicos, aún durante el marcapaseo (Fig. R.2Bb, $\mathrm{Bd}, \mathrm{Cb}$ y $\mathrm{Cd}$ ). El Iso aumentó el número de eventos de liberación espontánea de $\mathrm{Ca}^{2+}$ (Fig. R.2D), y bajó el tiempo de latencia (Fig. R.2E). Estos hallazgos sugieren que las ratas con dieta rica en fructosa ratas tienen patrones defectuosos proarrítmicos del manejo del $\mathrm{Ca}^{2+}{ }_{\mathrm{i}}$.

$A$
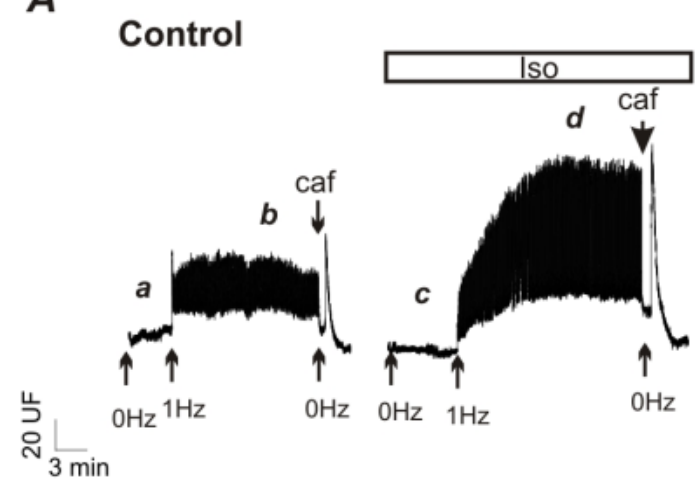

$B$
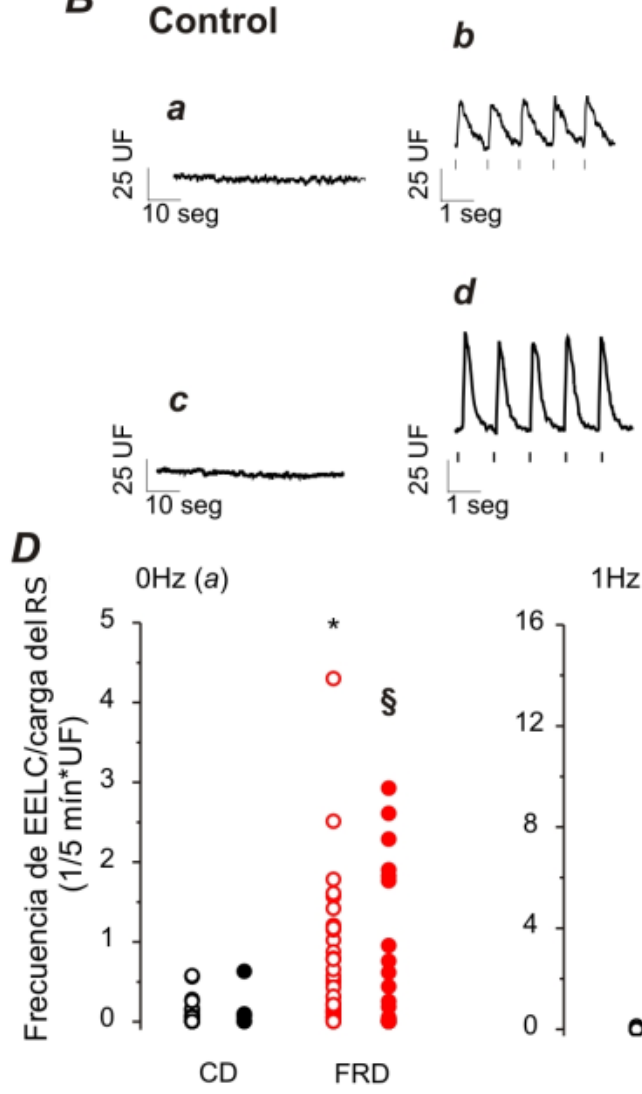

$1 \mathrm{~Hz}(b)$

C
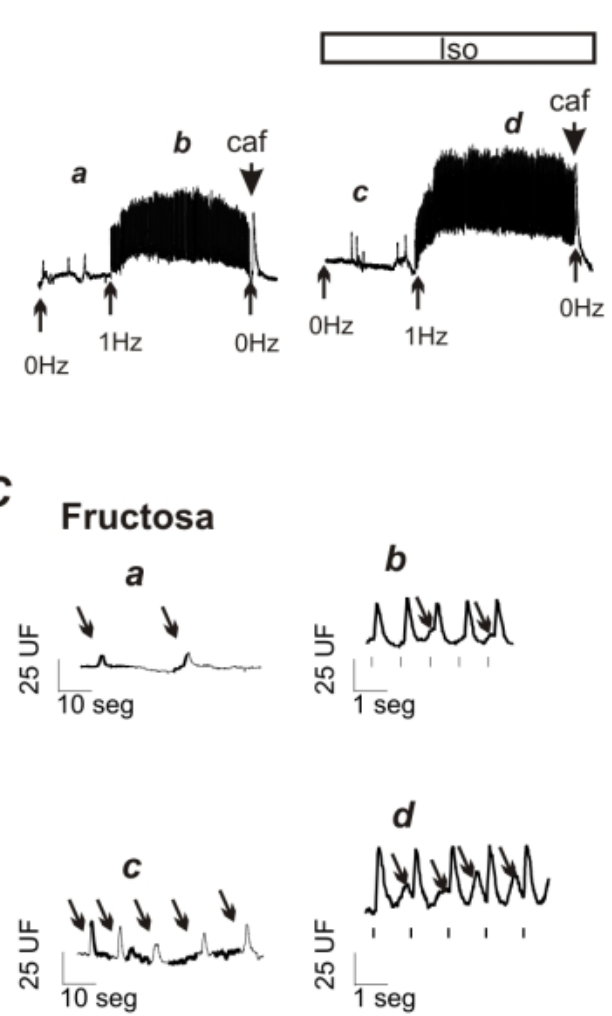

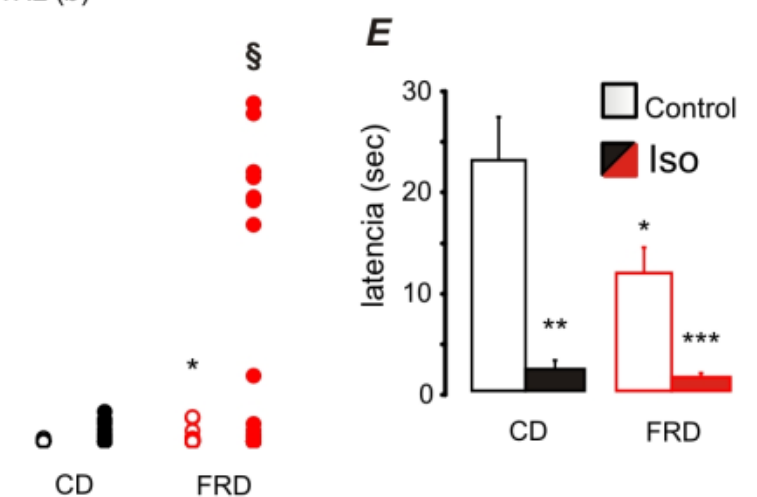


Fig. R.2. Incremento de eventos espontáneos de liberación de $\mathrm{Ca}^{2+}$ en miocitos aislados de ratas. A, Protocolo para el estudio de $\mathrm{Ca}^{2+}$ en miocitos de ratas con dieta control y dieta rica en fructosa. El $\mathrm{Ca}^{2+}$ fue registrado en condiciones de quiescencia (a y c) a una frecuencia de estimulación por campo de $1 \mathrm{~Hz}\left(\begin{array}{lll}b & y & d\end{array}\right)$ en ausencia y presencia de Isoproterenol (Iso). Se realizó un pulso de cafeína (caf) para evaluar la carga del retículo sarcoplasmático. B y $C$, registros de $\mathrm{Ca}^{2+}$, en una escala de tiempo ampliada, de miocitos aislados de ratas control y tratadas con fructosa, respectivamente, correspondientes a las letras a-d del panel $A$. $D$, gráficos de valores de frecuencia de eventos espontáneos de liberación de $\mathrm{Ca}^{2+}$ en ratas a $0 \mathrm{~Hz}$ y $1 \mathrm{~Hz}$ normalizados por el contenido de $\mathrm{Ca}^{2+}$ del SR en presencia y ausencia de Iso. E, tiempo de latencia de los eventos en miocitos de ambos grupos de ratas en todas las condiciones. $n=25$ a 40 miocitos de 4-6 ratas por grupo, * $p<$ $0.05,{ }^{* *} p<0.01,{ }^{* * *} p<0.001$ vs. $C D$ sin Iso; $\$ p<0.05$ vs. $C D$ con Iso.

Con el fin de medir la liberación local de $\mathrm{Ca}^{2+}$ del retículo sarcoplásmico (CaSp) y las waves $\mathrm{u}$ ondas de $\mathrm{Ca}^{2+}$ en cardiomiocitos aislados de rata, en las mismas condiciones experimentales de protocolo de la fig. R.2A, se utilizó microscopía confocal. En condiciones basales, la frecuencia, el ancho a la mitad de amplitud máxima (AMAM) y la amplitud de las CaSp no fueron diferentes entre cardiomiocitos aislados de ratas con dieta rica en fructosa y dieta control. En contraste, mostraron un aumento significativo de la frecuencia de waves de $\mathrm{Ca}^{2+} \mathrm{y}$ contracciones espontáneas (Fig. R.3A-B, y en la Tabla R.5). El Iso no afectó la frecuencia de CaSp, pero aumentó significativamente la frecuencia de waves y contracciones espontáneas en cardiomiocitos de ratas con dieta rica en fructosa (Fig. R.3A-B). Estos resultados muestran una alteración de la homeostasis del $\mathrm{Ca}^{2+}$, que fue de una magnitud suficiente como para desencadenar contracciones espontáneas en ratas con un estado prediabético. 
$\boldsymbol{A}$
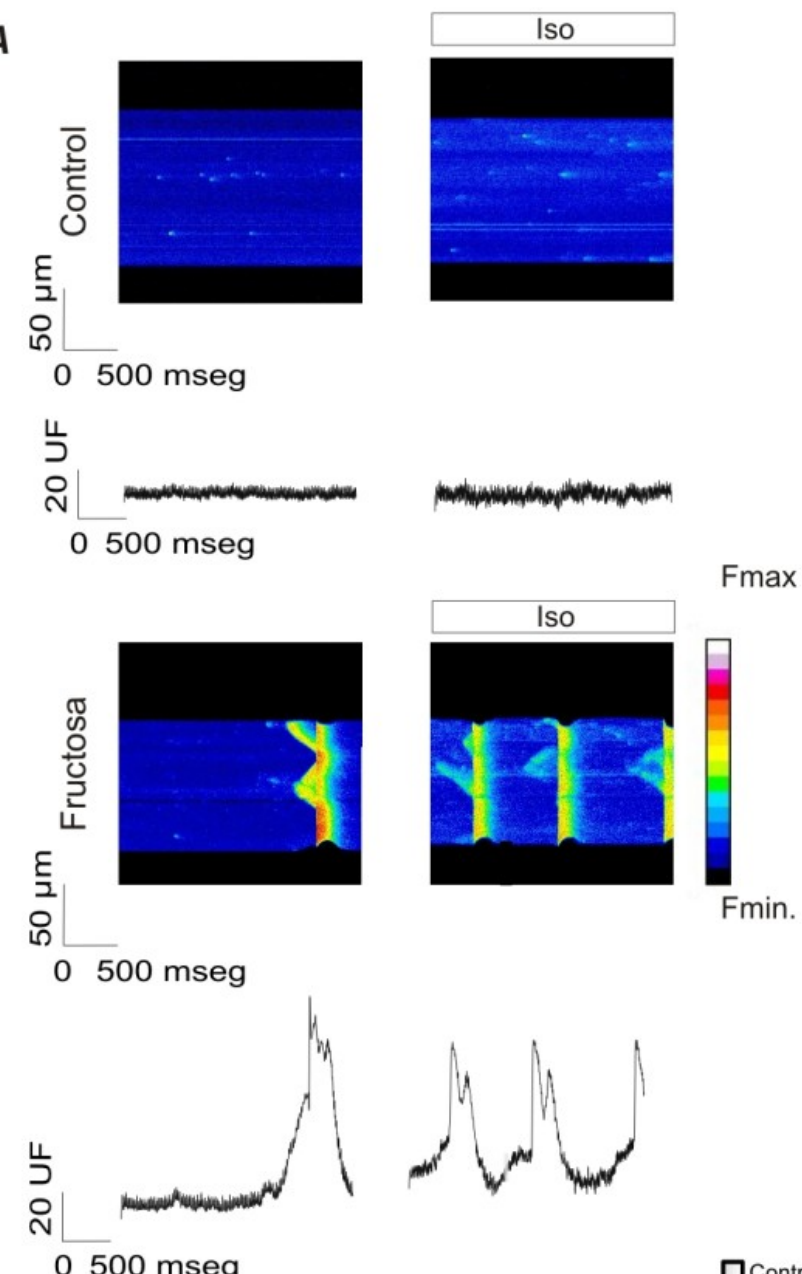

B

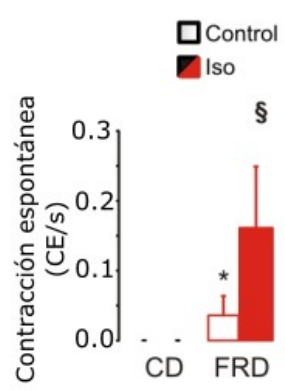

Fig. R.3. Incremento de la frecuencia de eventos espontáneos de liberación local $\mathrm{Ca}^{2+}$ del RS ( $\mathrm{Ca}^{2+}$ sparks $\mathrm{y}$ waves) en miocitos de ratas con dieta rica en fructosa respecto de las controles.

$A$, Imágenes de escaneo lineal de miocitos de ratas CD y FRD en presencia y ausencia de Isoproterenol (Iso), con sus respectivos trazos lineales. B, Valores promedio de frecuencia de CaSp, Waves y contracciones espontáneas (CE). Las barras representan el promedio \pm SEM. $n=20$ a 26 miocitos de 4 ratas por grupo, ${ }^{*} p<0.05$ comparado con $C D, \S p<0.05$ comparado con $C D+I$ so. 


\begin{tabular}{|c|c|c|}
\hline & Control & Fructosa \\
\hline$n$ & 20 & 26 \\
\hline \multicolumn{3}{|c|}{ Sparks de $\mathrm{Ca}^{2+}$} \\
\hline Frecuencia (Sp/fl/seg) & $18.84 \pm 5.31$ & $15.66 \pm 3.30$ \\
\hline Amplitud (F/F0) & $0.59 \pm 0.02$ & $0.63 \pm 0.02$ \\
\hline AMAM ( $\mu \mathrm{m})$ & $3.05 \pm 0.04$ & $3.22 \pm 0.05$ \\
\hline DMAM (mseg) & $24.52 \pm 0.97$ & $24.71 \pm 0.81$ \\
\hline $\begin{array}{c}\text { Pérdida de } \mathrm{Ca}^{2+} \\
\text { mediada por Sparks } \\
\text { (UF/fl/seg) }\end{array}$ & $484.69 \pm 30.14$ & $464.84 \pm 31.90$ \\
\hline \multicolumn{3}{|c|}{ Waves de $\mathrm{Ca}^{2+}$} \\
\hline Frecuencia (Wv/seg) & $0.05 \pm 0.02$ & $0.11 \pm 0.03 * * *$ \\
\hline \multicolumn{3}{|c|}{ Transitorios de $\mathrm{Ca}^{2+}$ espontáneos } \\
\hline Frecuencia (CE/seg) & $0.00 \pm 0.00$ & $0.04 \pm 0.03 * * *$ \\
\hline
\end{tabular}

Tabla R.5. Análisis de los eventos de liberación local de $\mathrm{Ca}^{2+}$ en ratas control y con dieta rica en fructosa.

La frecuencia de CaSp (Sparks de $\mathrm{Ca}^{2+}$ ) no fue diferente entre los cardiomiocitos aislados de ratas con dieta rica en fructosa (FRD) o ratas con dieta control (CD). Aun así, el aumento de las liberaciones de $\mathrm{Ca}^{2+}$ en forma de waves, en miocitos de FRD fue suficiente para desencadenar la actividad contráctil espontánea. Los valores son promedio \pm ES. AMAM, ancho en la mitad de amplitud máxima. DMAM, duración total en la mitad de amplitud máxima. UF, son unidades arbitrarias de fluorescencia. $n=20-26$ miocitos de 4-6 ratas por grupo. ${ }^{* * *} p<0,001$ vs control.

\section{CaMKII media las liberaciones espontáneas de $\mathrm{Ca}^{2+}$ en cardiomiocitos de animales prediabéticos}

La sobreexpresión y la hiperactivación de CaMKII aumentan la pérdida de $\mathrm{Ca}^{2+}$ del $\mathrm{RS},{ }^{186}$ que puede servir como un disparador molecular para las arritmias. ${ }^{188}$ Por esta razón, buscamos si CaMKII juagaba un rol en la actividad espontánea inducida por lo dieta rica en fructosa. En la figura R.4A se muestra que la forma activa fosforilada de CaMKII y la fosforilación de uno de sus sitios blanco, el residuo Thr $^{17}$ de PLN, se incrementaron en los corazones de ratas con dieta rica en fructosa en comparación con los controles, sin cambios en la expresión de otras proteínas involucradas en el manejo del $\mathrm{Ca}^{2+}$, como PLN y SERCa2a.

Un segundo grupo de experimentos tuvo como objetivo determinar si las liberaciones espontáneas de $\mathrm{Ca}^{2+}$ en los cardiomiocitos de ratas con dieta rica en 
fructosa podrían evitarse o reducirse en presencia de un inhibidor experimental de CaMKII. La figura R.4B-C muestra que el KN-93 impidió el aumento de los eventos de liberación espontánea de $\mathrm{Ca}^{2+}$ y las contracciones espontáneas en cardiomiocitos de ratas FRD bajo condiciones basales y estimuladas con Iso. Por el contrario, $\mathrm{KN}-92$, un análogo inactivo de $\mathrm{KN}-93$, no pudo evitarlas.

Estos experimentos revelan en conjunto que la CaMKII está efectivamente involucrada en la generación de los eventos arritmogénicos que se observan en los miocitos de animales tratados con fructosa.
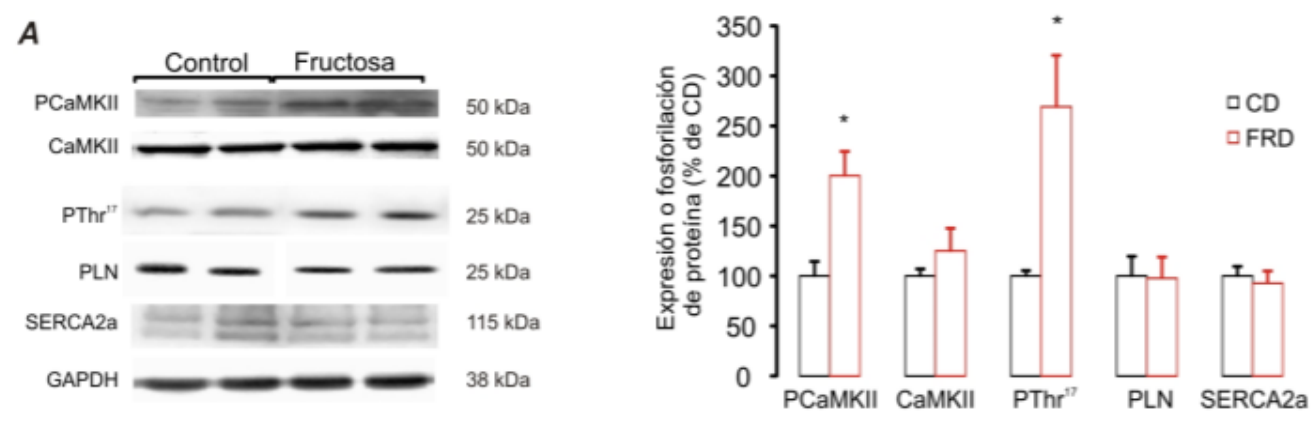

B

Fructosa
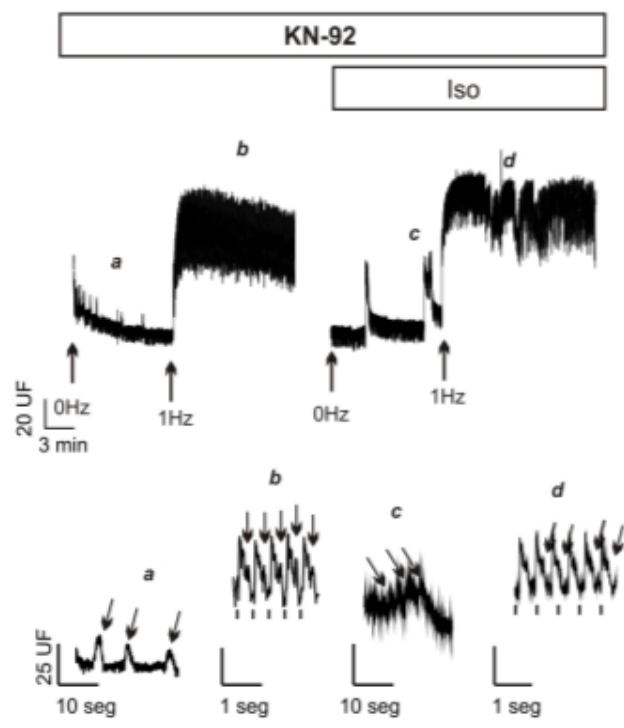

C

$\mathrm{OHz}$

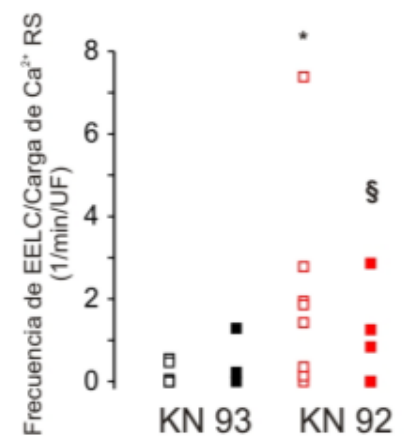

Fructosa
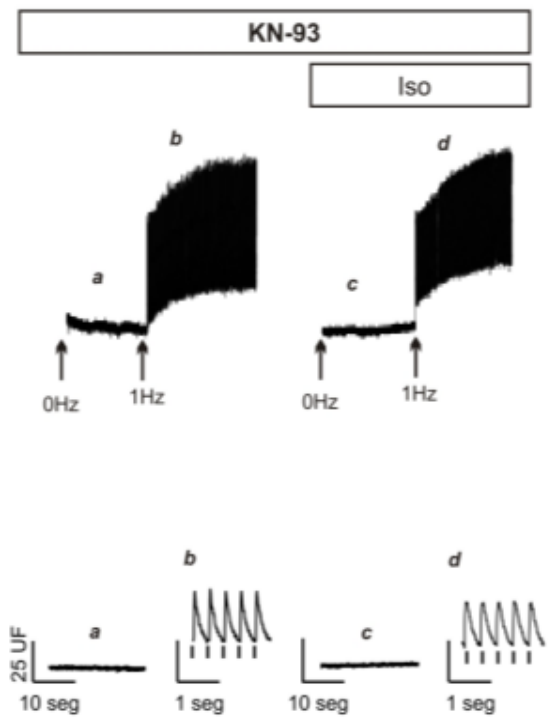

$1 \mathrm{~Hz}$

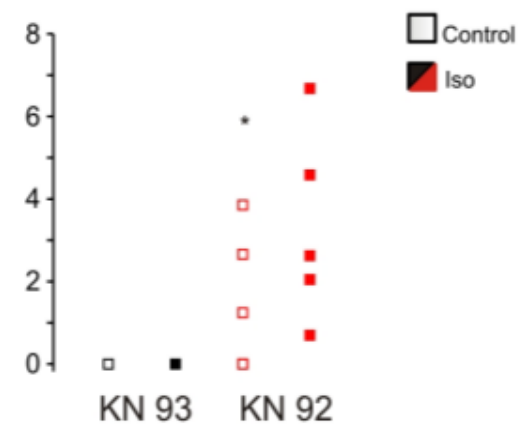

Fig. R4. La inhibición de CaMKII previene los eventos espontáneos de liberación de Ca ${ }^{2+}$ (EELC) en miocitos de ratas tratadas con fructosa. 
A, inmunoblots representativos de PCaMKII, CaMKII, PThr ${ }^{17}$, PLN, SERCa2a, y GAPDH como control de carga. A la derecha están los valores promedios. Los datos son promedio $\pm E S$. $n=4$ ratas por grupo. ${ }^{*} p<0.05$ comparado con $C D, \S p<0.05$ comparado con $C D+1$ so. $B$, registros de transitorios de $\mathrm{Ca}^{2+}$ continuos de miocitos de ratas perfundidos en presencia de KN-92 y KN-93, y en presencia y ausencia de isoproterenol (Iso). Debajo, están los registros en una escala de tiempo expandida, a los tiempos indicados con las letras a-d. Las flechas indican los EELC. C, valores de frecuencia de EELC a $0 \mathrm{~Hz}$ y $1 \mathrm{~Hz}$ con y $\sin$ Iso, normalizados por el contenido de $\mathrm{Ca}^{2+}$ del $R S$, en miocitos de ratas con dieta rica en fructosa incubados con KN-92 and KN-93. Los datos de son promedio \pm ES. $n=10$ a 17 miocitos de 3 ratas por grupo. ${ }^{*} p<0.05$ comparado con $C D, \S p<0.05$ comprarado con $C D+$ Iso.

\section{Mecanismos celulares de los eventos espontáneos de liberación de $\mathrm{Ca}^{2+}$ y actividad contráctil inducidos por CaMKII en los corazones prediabéticos}

Las CaSp y las waves de $\mathrm{Ca}^{2+}$ pueden ocurrir debido a la sobrecarga de $\mathrm{Ca}^{2+}$ del RS o como consecuencia de una alteración en la función del RyR2. ${ }^{63}$ Para develar cuál de estos mecanismos, si no ambos, estaban involucrados en los fenómenos proarritmogénicos hallados, estudiamos en profundidad el manejo del $\mathrm{Ca}^{2+}$ en miocitos aislados. Se encontró que la amplitud del transitorio de $\mathrm{Ca}^{2+}$ fue similar entre los animales con dieta control y con dieta rica en fructosa, pero la amplitud de los transitorios de $\mathrm{Ca}^{2+}$ inducidos por cafeína fue significativamente menor en las células de corazones de rata con dieta rica en fructosa respecto de las células de ratas con dieta control (Fig. R.5B), lo que, de acuerdo a lo observado anteriormente, puede deberse al aumento de la pérdida de $\mathrm{Ca}^{2+}$ en los cardiomiocitos de estas ratas (Fig. R.3). Estos aumentaron significativamente la fracción de liberación de $\mathrm{Ca}^{2+}$ (Amplitud de transitorio de $\mathrm{Ca}^{2+}$ por estímulo eléctrico/ Amplitud de transitorio de $\mathrm{Ca}^{2+}$ inducido por cafeína), en las células de ratas con dieta rica en fructosa con respecto a las células de ratas control, como se muestra en la figura R.5A-B. EI contenido de $\mathrm{Ca}^{2+}$ del RS se encontró significativamente disminuido en miocitos de ratas con dieta rica en fructosa (Fig. R.5B), a pesar del aumento en la actividad SERCa2a (Fig. R.5B, panel superior). Este aumento, puede deberse al aumento de la fosforilación dependiente de CaMKII en $\operatorname{Thr}^{17}$ de PLN, lo que contribuiría a evitar una mayor reducción de la carga de $\mathrm{Ca}^{2+}$ del RS. Además, aunque no se observó un cambio en el valor de $\mathrm{Ca}^{2+}$ diastólico en condiciones de quiescencia y bajo estímulo eléctrico, aumentó en gran medida cuando ocurrían los eventos espontáneos de liberación de $\mathrm{Ca}^{2+}$ en forma de ráfaga. Esto lo podemos observar en un experimento típico (Fig.5C) donde se ve que los miocitos de ratas con dieta control no desarrollaron eventos arritmogénicos y por lo tanto la fluorescencia diastólica se mantuvo estable. Por el contrario, en miocitos de ratas con dieta rica en fructosa, mientras no se evidenciaron eventos arritmogénicos (al inicio del registro) la fluorescencia basal fue similar a la de los miocitos de ratas control, pero cuando se dispararon los eventos se produjo un aumento significativo de la 
fluorescencia diastólica. Esto mismo se evidencia en los resultados promedio de este análisis en el gráfico de barras de la figura R.5C, barras a rayas.

En conjunto, los resultados sugieren que el aumento en la actividad espontánea no se asocia a una sobrecarga de $\mathrm{Ca}^{2+}$ del RS.

En vista de estos resultados, la otra alternativa que podría explicar el aumento de las liberaciones espontáneas es la alteración de la actividad en RyR2. Puesto que se ha demostrado que la fosforilación RyR2 dependiente de CaMKII aumenta la pérdida de $\mathrm{Ca}^{2+}$ del RS, la frecuencia de $\mathrm{CaSp}^{186}$ y las arritmias ${ }^{188}$, lo próximo a examinar fue el estado de fosforilación de RyR2 (Fig. R.5D). Por inmunoblotting se pudo observar un aumento en la fosforilación de RyR2 en el sitio Ser2814, que es reconocido como específico para CaMKII, en los corazones de ratas con dieta rica en fructosa en relación con ratas con dieta control, sin cambios en la expresión RyR2. En contraste, el grado de fosforilación catalizada por PKA en el sitio Ser2808, no se alteró en los corazones prediabéticos en comparación con los controles.

Por otro lado, el acortamiento de los miocitos mostró un aumento significativo en aquellos provenientes de rata con dieta rica en fructosa versus los de rata con dieta control (Fig. 5A-B), a pesar de tener transitorios con amplitudes similares, un hallazgo que está en concordancia con un aumento de sensibilidad al $\mathrm{Ca}^{2+}$ de los miofilamentos, y que ya ha sido descripto en un modelo similar. ${ }^{4}$ La contractilidad y los transitorios de $\mathrm{Ca}^{2+}$ que muestran los miocitos aislados están en contraste con los obtenidos en los estudios ecocardiográficos, donde se observó una disfunción sistólica a nivel de corazón entero (Fig. R.1 y Tabla R.1). La causa de esta discrepancia no es evidente para nosotros y requiere una mayor investigación. Posibles explicaciones a estos hallazgos son alteraciones en el tejido y a nivel de órgano entero (es decir, la fibrosis intersticial, la apoptosis, el compromiso vascular), y que no están presentes en miocitos aislados. Por ejemplo, la hiperglucemia sostenida puede aumentar la glicosilación de proteínas intersticiales tales como el colágeno, que se traduce en la rigidez miocárdica y alteración de la contractilidad. ${ }^{233}$

Todos estos resultados, en conjunto, son consistentes con la presencia de un sustrato proarritmogénico en las ratas con dieta rica en fructosa que subyace en una fosforilación del RyR2 dependiente de CaMKII, que es la que produce la pérdida de $\mathrm{Ca}^{2+}$ del RS. 


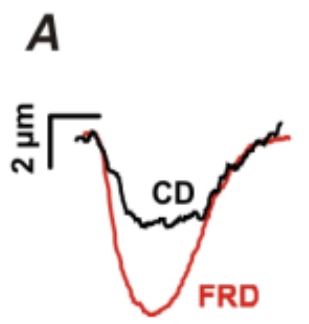

Acortamiento

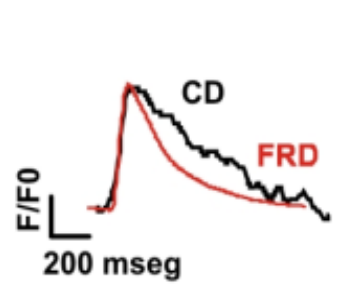

$\mathrm{Ca}_{\mathrm{i}} \mathrm{T}$

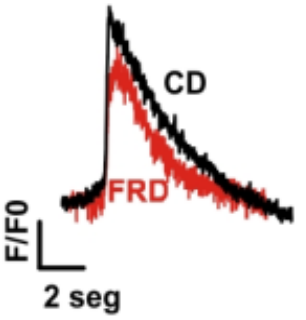

$\mathrm{Ca}_{i} \mathrm{~T}$ inducido por cafeína

B
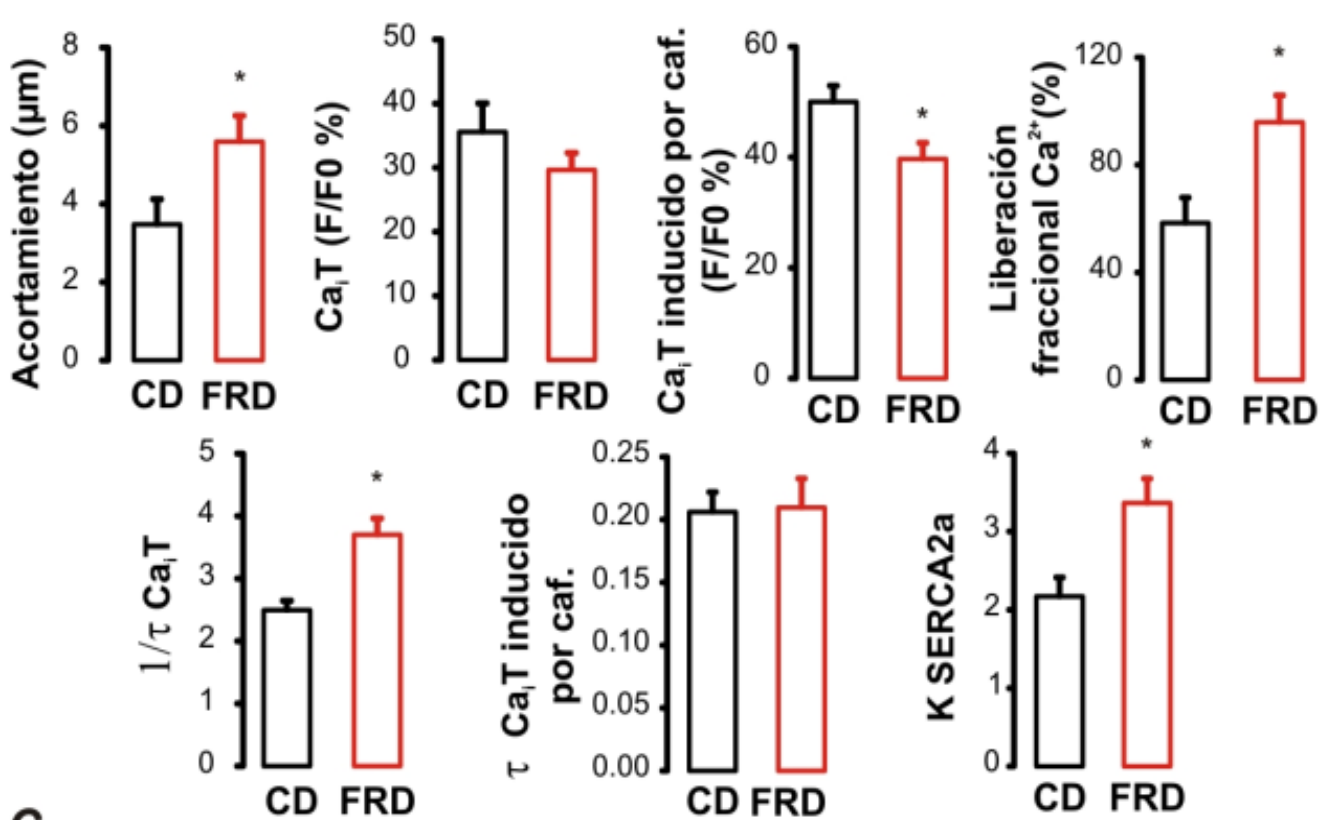

C
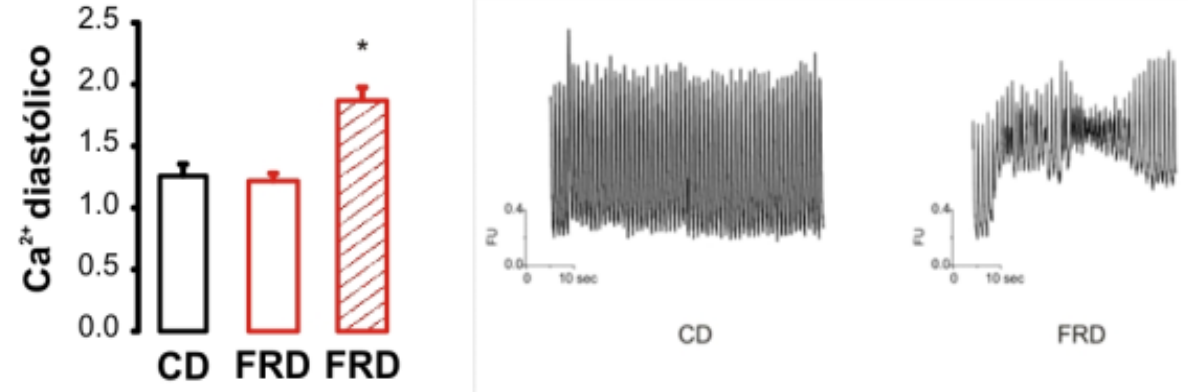

D

EELC
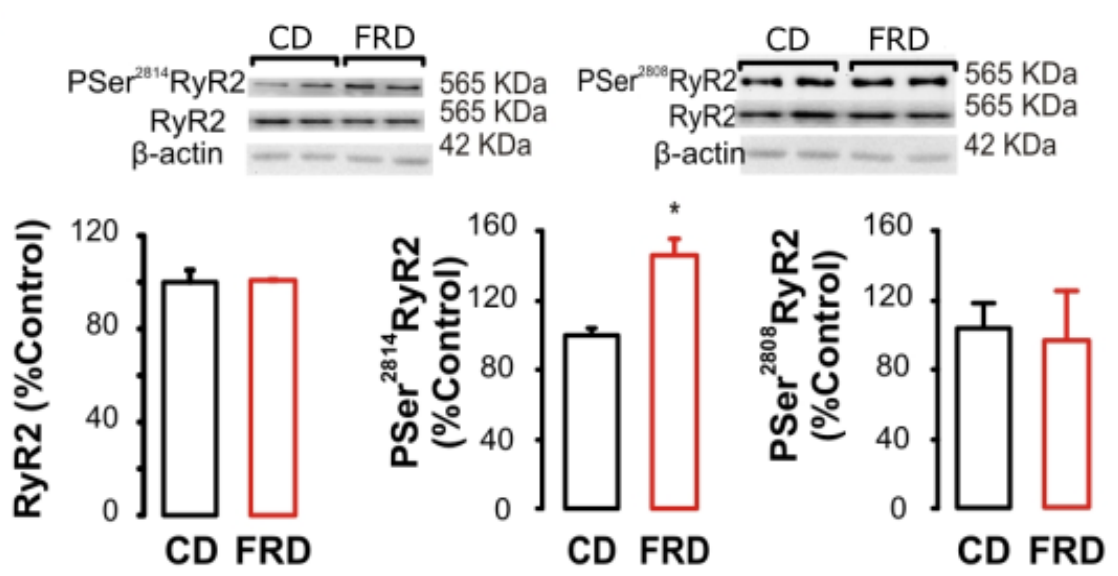
Fig. R.5. El tratamiento con fructosa incrementa la fosforilación dependiente CaMKIl de RyR2 y disminuye el contenido del RS.

$A$, Registros individuales representativos de contracción, transitorio de $\mathrm{Ca}^{2+}$ y transitorio de $\mathrm{Ca}^{2+}$ inducido por cafeína de miocitos de ratas controles y con dieta rica en fructosa ( $C D$ y FRD). $B$, valores promedios de acortamiento, amplitud de transitorio de $\mathrm{Ca}^{2+}$, liberación fraccional de $\mathrm{Ca}^{2+}$, velocidad de decaimiento del transitorio de $\mathrm{Ca}^{2+}\left(1 / t\right.$ de CaiT), amplitud transitorio de $\mathrm{Ca}^{2+}$ inducido por cafeína, velocidad de decaimiento del transitorio de $\mathrm{Ca}^{2+}$ inducido por cafeína y la actividad de SERCa2a (K $S E R C a 2 a)$, de miocitos de ratas CD y FRD. Los datos se expresaron como media $\pm E S, n=25$ a 40 miocitos de 4-6 ratas por grupo. C. valores promedio de $\mathrm{Ca}^{2+}$ diastólico con un registro típico representativo de fluorescencia, La barra a rayas representa el $\mathrm{Ca}^{2+}$ diastólico durante los episodios de liberación espontánea de $\mathrm{Ca}^{2+}$ en miocitos FRD. $n=18$ miocitos de 6 ratas. ${ }^{*} p<0.05$ comparado con $C D$. $D$, inmunoblots representativos y resultados promedio de la expresión de RyR2 (a la izquierda), PSer2814 de RyR2 (panel central) y PSer2808 (a la derecha). $\beta$-actina fue usada como control de carga. Los datos se expresaron como promedio \pm SEM. $n=4$ ratas por grupo, ${ }^{*} p<0.05$.

\section{Mecanismo de activación de CaMKII y desestabilización de RyR2}

Como se mencionó en la introducción, CaMKII se activa de manera canónica por aumento en la unión a $\mathrm{Ca}^{2+} / \mathrm{CaM}^{171}$ Sin embargo, ni el $\mathrm{Ca}^{2+}$ diastólico ni la amplitud del transitorio de $\mathrm{Ca}^{2+}$ aumentaron en los miocitos aislados de ratas alimentadas con dieta rica en fructosa, y a pesar de ello, hubo un aumento significativo en la frecuencia de eventos de liberación de $\mathrm{Ca}^{2+}$ en las ratas con dieta rica en fructosa con respecto a los animales controles, tanto con o sin estimulación eléctrica dependiente de la hiperactividad de CaMKII. Las liberaciones espontáneas de $\mathrm{Ca}^{2+}$ aisladas no produjeron ninguna alteración del $\mathrm{Ca}^{2+}$ diastólico, pero, cuando éstas se presentaron como ráfagas de eventos espontáneos, se asociaron a un aumento en el $\mathrm{Ca}^{2+}$ diastólico (Fig. R.5C), que perduró durante los eventos arritmogénicos de manera reversible. Por otra parte, el aumento de $\mathrm{Ca}^{2+}$ citosólico que se produjo durante liberación espontánea de $\mathrm{Ca}^{2+}$, estimado con la integral de estos eventos durante un período de $3 \mathrm{~min}$ antes de la estimulación eléctrica, se incrementó significativamente en $3,14 \pm 1,4 \%(p<0,05)$ en los miocitos aislados de ratas con dieta rica en fructosa respecto de sus pares controles. Sin embargo, como se observa en los valores promedio (Fig. R5C), el $\mathrm{Ca}^{2+}$ diastólico no se modificó fuera de lo que representan las ráfagas arritmogénicas, por lo que es probable que exista otra fuente de activación de CaMKII.

Por otra parte, experimentos anteriores han demostrado que CaMKII puede mantener su actividad por ROS, incluso a niveles de $\mathrm{Ca}^{2+}$ subdiastólicos ${ }^{7}$ y que las arritmias inducidas por ROS estaban vinculados a la capacidad de ROS para activar CaMKII ${ }^{175}$. Además, como se ha mencionado en la introducción, en la MCD 
los sistemas de producción de ROS se sobreexpresan al mismo tiempo que aumentan su actividad. Por esta razón, evaluamos la posibilidad de que un aumento en la producción de ROS pueda contribuir al aumento en la actividad CaMKII en los miocitos de ratas con dieta rica en fructosa. La figura R.6A-B muestra que la peroxidación lipídica (determinada por TBARS) y la producción de ROS $\left(\mathrm{O}_{2}^{-}\right)$aumentó de manera significativa en los animales con dieta rica en fructosa. Además, pudimos detectar un aumento significativo en la oxidación de CaMKII en el sitio Met 281/282 (ox-CaMKII). La figura R.6C representa inmunoblots típicos y los resultados generales que indican el aumento en ox-CaMKII, confirmando nuestra hipótesis. Estos resultados revelan el aumento en la producción de ROS y la oxidación de CaMKII en los animales tratados con fructosa.

$A$

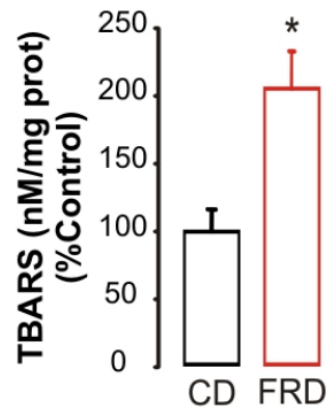

B

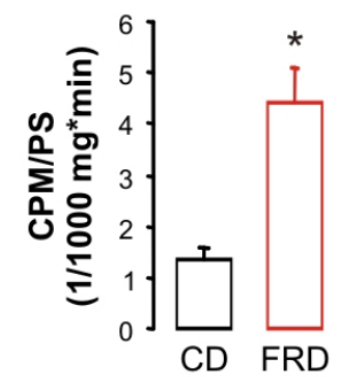

C
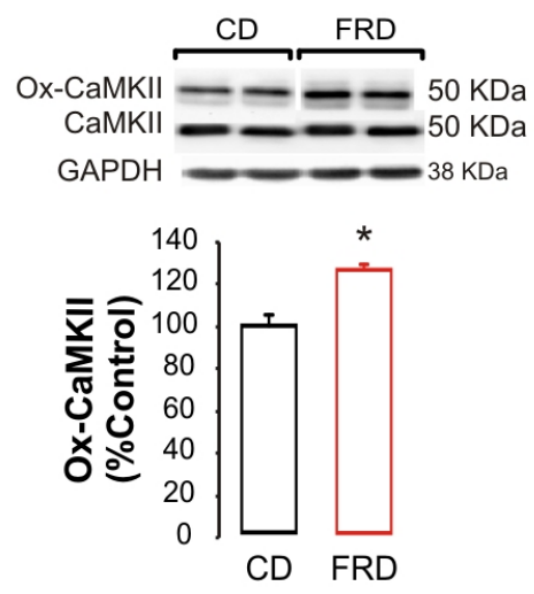

Fig. R.6. La peroxidación lipídica, la producción de ROS y ox-CaMKII están aumentados en ratas con dieta rica en fructosa vs. ratas con dieta control.

$A$, datos promedios de peroxidación lipídica medida por TBARS; $B$, ROS evaluado por quimioluminiscencia, cuentas por minuto (CPM) normalizado por peso seco (PS) del tejido; $C$, inmunoblots representativos $y$ valores promedios de CaMKII oxidada (oxCaMKII) y total de ratas $C D$ and FRD. Los datos se expresaron como media \pm ES. $n=4$ ratas por grupo, ${ }^{*} p<0.05$.

Para investigar con más profundidad el posible papel de ROS y CaMKII en el patrón arritmogénico observado en el modelo de rata con dieta rica en fructosa, se utilizaron ratones salvaje (WT) con dieta rica en fructosa y dieta control, y ratones transgénicos 
SR-AIP, como una herramienta genética para confirmar los resultados obtenidos en rata. Los ratones SR-AIP expresan un péptido inhibidor de CaMKII, AIP, dirigido a la membrana del RS por fusión con el dominio transmembrana de PLN. Esta herramienta química impide que la CaMKII fosforile sus sustratos en el RS, es decir, PLN y RyR2. Como se muestra en la Tabla R.6, los ratones con dieta rica en fructosa WT y SR-AIP presentan incrementos significativos en el área bajo la curva de la prueba de tolerancia a la glucosa intraperitoneal, lo que indica una condición de prediabetes similar a las ratas. A diferencia del modelo en ratas, en la tabla R.7, puede observarse no solo un aumento en la frecuencia de waves y contracciones espontáneas sino también en la frecuencia y la amplitud de los sparks, repercutiendo en un aumento de la pérdida de $\mathrm{Ca}^{2+}$ mediada por sparks.

\begin{tabular}{|c|c|c|c|c|}
\hline \multirow{2}{*}{ Ratones } & \multirow{2}{*}{$n$} & \multirow{2}{*}{ Parámetros } & \multicolumn{2}{|c|}{ Tratamiento } \\
\hline & & & Control & Fructosa \\
\hline \multirow{3}{*}{ WT } & \multirow{3}{*}{9} & $\mathrm{GA}(\mathrm{mmol} / \mathrm{L})$ & $155.2 \pm 10.47$ & $143.0 \pm 8.72$ \\
\hline & & $\begin{array}{c}\mathrm{ABC}(\mathrm{mmol} \\
\text { glucosa/L.min) }\end{array}$ & $947 \pm 98$ & $1281 \pm 57^{*}$ \\
\hline & & Peso corporal (g) & $31.22 \pm 0.71$ & $25.36 \pm 3.22$ \\
\hline \multirow{3}{*}{ SR-AIP } & \multirow{3}{*}{9} & $\mathrm{GA}(\mathrm{mmol} / \mathrm{L})$ & $161.0 \pm 15.66$ & $219.2 \pm 42.8$ \\
\hline & & $\begin{array}{c}\text { ABC (mmol } \\
\text { glucosa/L.min) }\end{array}$ & $1106 \pm 108$ & $1720 \pm 160^{* *}$ \\
\hline & & Peso corporal (g) & $28.24 \pm 0.74$ & $27.10 \pm 0.35$ \\
\hline
\end{tabular}

Tabla R.6: Caracterización metabólica de los ratones. GA: glucosa en ayunas, ABC: área bajo la curva, WT: por sus iniciales en inglés, wild type (cepa salvaje). Los datos se expresaron como media \pm SEM, ${ }^{*} p<0.05,{ }^{* *} p<0.01$.

Estas diferencias no se observaron en ratones SR-AIP lo cual remarca el efecto del tratamiento con dieta rica en fructosa sobre la fosforilación de blancos de CaMKII a nivel del RS.

Por otro lado, la figura R.7A muestra que en los ratones WT, la dieta rica en fructosa, aumentó significativamente $(p=0,02)$ el estrés oxidativo (TBARS) en comparación con los ratones cotratados con Tempol. 


\begin{tabular}{|c|c|c|c|c|}
\hline \multirow[b]{3}{*}{$n$} & \multicolumn{2}{|c|}{ Ratones WT } & \multicolumn{2}{|c|}{ Ratones SR-AIP } \\
\hline & Control & Fructosa & Control & Fructosa \\
\hline & 14 & 21 & 15 & 5 \\
\hline \multicolumn{5}{|c|}{ Sparks de $\mathrm{Ca}^{2+}$} \\
\hline $\begin{array}{l}\text { Frecuencia } \\
\text { (Sp/fl/seg) }\end{array}$ & $2.79 \pm 0.94$ & $7.86 \pm 1.77^{*}$ & $0.62 \pm 0.36^{*}$ & $0.10 \pm 0.05$ \\
\hline Amplitud (F/F0) & $0.55 \pm 0.03$ & $0.70 \pm 0.04 * *$ & $0.45 \pm 0.05$ & $0.64 \pm 0.09$ \\
\hline AMAM $(\mu \mathrm{m})$ & $3.80 \pm 0.14$ & $3.27 \pm 0.08^{* *}$ & $3.59 \pm 0.26$ & $3.96 \pm 0.64$ \\
\hline DMAM (mseg) & $39.11 \pm 3.83$ & $21.43 \pm 1.14^{* * *}$ & $24.86 \pm 3.57 * *$ & $36.67 \pm 7.86$ \\
\hline $\begin{array}{c}\text { Pérdida de } \mathrm{Ca}^{2+} \\
\text { mediada por } \\
\text { Sparks } \\
\text { (UF/fl/seg) }\end{array}$ & $220.21 \pm 23.58$ & $335.26 \pm 33.98 * *$ & $27.39 \pm 8.40 * * *$ & $9.28 \pm 2.26$ \\
\hline \multicolumn{5}{|c|}{ Waves de $\mathrm{Ca}^{2+}$} \\
\hline Frecuencia (Wv/seg) & $0.08 \pm 0.02$ & $0.18 \pm 0.04^{*}$ & $0.04 \pm 0.02$ & $0.01 \pm 0.01$ \\
\hline \multicolumn{5}{|c|}{ Transitorios de $\mathrm{Ca}^{2+}$ espontáneos } \\
\hline Frecuencia (CE/seg) & $0.02 \pm 0.01$ & $0.10 \pm 0.002 *$ & $0.01 \pm 0.01$ & $0.01 \pm 0.01$ \\
\hline
\end{tabular}

\section{Tabla R.7. Análisis de los eventos de liberación local de $\mathrm{Ca}^{2+}$ en ratones $C D$ y FRD.}

En los ratones WT con FRD se visualizó un aumento de las liberaciones de $\mathrm{Ca}^{2+}$, tanto locales (sparks) como propagadas (waves y transitorios); lo cual pudo prevenirse en los SR-AIP. Estos resultados indican que CaMKII, a través de su acción sobre el RS contribuye en la generación de un sustrato arritmogénico, lo que se observa, en ratones prediabéticos. Los valores son promedio $\pm E S$. AMAM, ancho en la mitad de amplitud máxima. DMAM, duración total en la mitad de amplitud máxima. UF, son unidades arbitrarias de fluorescencia. $n=5-21$ miocitos de ratones de 3-4 WT y SR-AIP, control y fructosa. ${ }^{*} p<0.05,{ }^{* *} p<0.01,{ }^{* \star *} p<0,001$ vs WT control.

Para explorar la posible participación de los ROS en la aparición de los eventos de liberación espontánea de $\mathrm{Ca}^{2+}$ por el tratamiento con fructosa en ratones WT, estos fueron cotratados con Tempol, un atrapador intracelular de ROS. El cotratamiento de los ratones WT con Tempol impidió el aumento en TBARS y la fosforilación de RyR2 en el sitio de CaMKII (Fig. R.7A-B). Por otra parte, los eventos espontáneos producidos por el tratamiento con fructosa también fueron prevenidos con Tempol (Fig. R.7C-D). Tomados en conjunto, los resultados sugieren que los ROS están implicados en la actividad espontánea de los animales con dieta rica en fructosa a través de la fosforilación de RyR2 dependiente de CaMKII. Para profundizar en este punto, hemos realizado experimentos en ratones SR-AIP. 


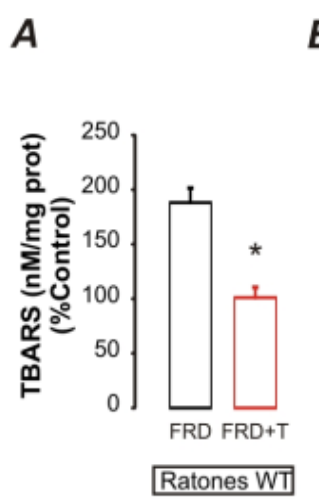

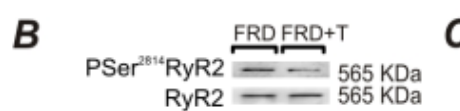

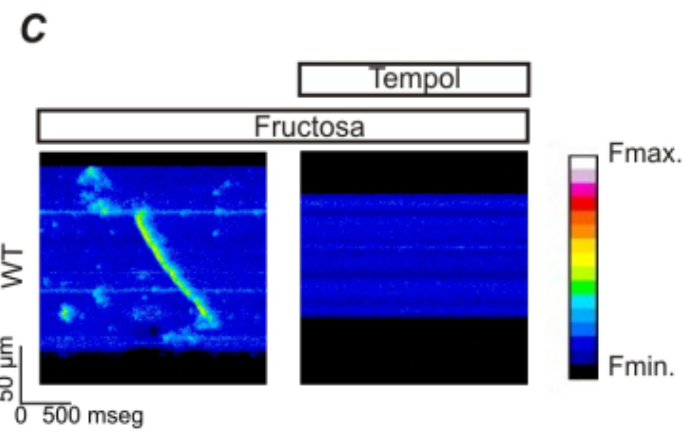

Ratones WT

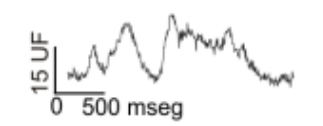

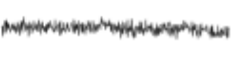
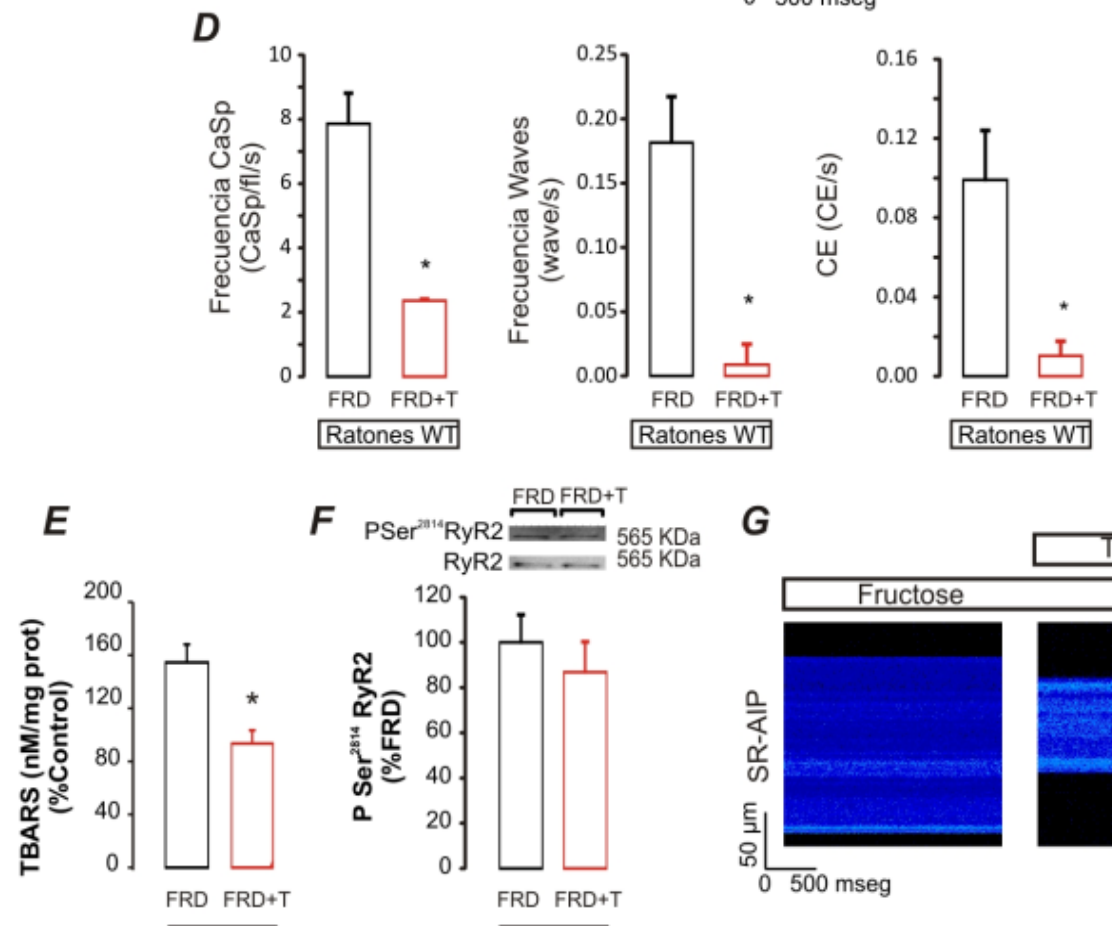

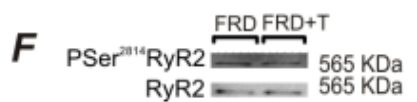

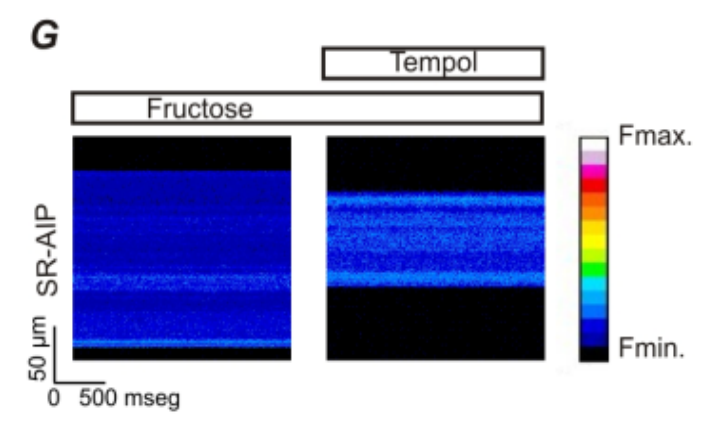

SR-AIP
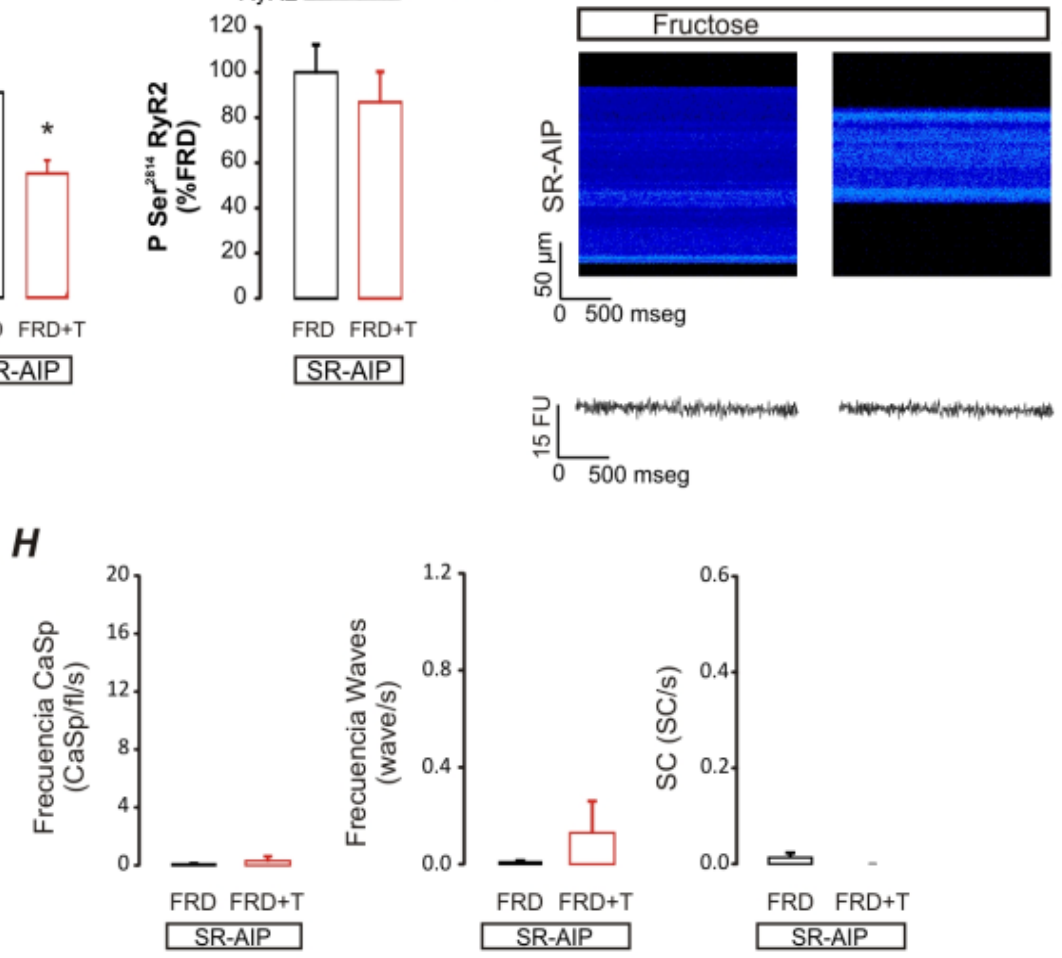

Fig. R.7. Rol de los ROS en los eventos espontáneos de liberación de $\mathrm{Ca}^{2+}$ y en la activación de CaMKII.

A, resultados promedio de TBARS que muestran la peroxidación lipídica aumentada en ratones WT con dieta rica en fructosa (FRD) y la disminuión significativa que produce el cotratamiento con Tempol. Los datos se expresan como media \pm ES. $n=4$ ratones por grupo. B, fosforilación de RyR2 en el sitio 
dependiente de CaMKII, S2814, en presencia y ausencia de Tempol en ratones WT FRD. Los datos se expresan como media $\pm E S$. $n=4$ ratones por grupo. $C$, imágenes de escaneo lineal de miocitos de ratones WT FRD y FRD + Tempol (FRD + T). Debajo, están los respectivos trazos lineales. Se puede ver cómo el Tempol previno el incremento de eventos espontáneos de $\mathrm{Ca}^{2+}$ producido por el tratamiento con fructosa. $D$, valores promedios de frecuencia de CaSp, Waves y contracciones espontáneas (CE). E, la peroxidación lipídica en ratones SR-AIP FRD incrementó con la dieta rica en fructosa y fue también prevenida con el cotratamiento con Tempol. F, fosforilación dependiente de CaMKII de RyR2 en el sitio Ser2814 en presencia y ausencia de Tempol en ratones SR-AIP FRD. G, imágenes de escaneo lineal de miocitos de ratones WT FRD y FRD+ Tempol $(F R D+T)$ en ratones SR-AIP. $H$ valores promedios de frecuencia de CaSp, Waves y SC. Los ratones SR-AIP no mostraron eventos de $\mathrm{Ca}^{2+}$, a pesar del incremento en ROS. Los datos se expresan como media \pm ES. $n=10$ a 15 miocitos de 4 ratones por grupo. Nótese que en el caso de los ratones SR-AIP los valores de CaSp, waves y CE son casi imperceptibles ya que por propósitos comparativos se mantuvo la escala del panel D.

La figura R.7E muestra que el Tempol en los ratones con dieta rica en fructosa, como sucedía con los WT, impidió el aumento en el estrés oxidativo producido por la dieta $(p \leq 0,05)$. El tratamiento con Tempol también evitó significativamente el aumento de ox-CaMKII en ratones SR-AIP tratados con fructosa en un 75,04 \pm $7,34 \%$. Acorde con lo que se esperaba, los ratones SR-AIP con dieta rica en fructosa no mostraron cambios en la fosforilación de RyR2 dependiente de CaMKII ni en la frecuencia de eventos de liberación espontánea de $\mathrm{Ca}^{2+}$, ya sea en ausencia o presencia de Tempol (Fig. R.7F-H), a pesar de presentar el aumento de estrés oxidativo producido por la dieta rica en fructosa.
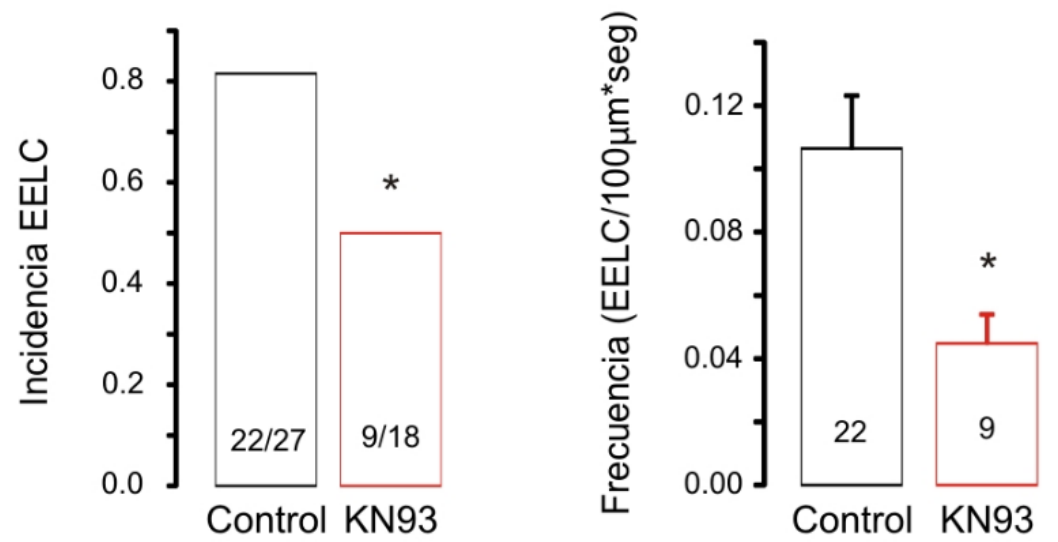

Fig. R.8. La inhibión de CaMKII disminuye la incidencia de eventos espontáneos de liberación de $\mathrm{Ca}^{2+}$ en miocitos aislados tratados con $\mathrm{H}_{2} \mathrm{O}_{2}$.

Efecto de $\mathrm{H}_{2} \mathrm{O}_{2} 200 \mu \mathrm{M}$ en la incidencia (izquierda) y frecuencia de eventos espontáneos de liberación de $\mathrm{Ca}^{2+}$ (EELC) (derecha) en miocitos cargados con Fluo-3 en presencia y ausencia de inhibición de CaMKII con KN93. El $\mathrm{H}_{2} \mathrm{O}_{2}$ produjo Waves de $\mathrm{Ca}^{2+}$ que se previnieron con la inhibición de CaMKII lo 
que indica que el estrés oxidativo puede activar la CaMKII y producir EELC. Los datos son promedios con sus respectivos SEM. $N$, indicado en cada barra. * $p<0,05$ respecto de células control (sin $K N-93)$.

Por último, se realizó una serie adicional de experimentos en los miocitos aislados de ratones WT con dieta control previamente tratados con $\mathrm{H}_{2} \mathrm{O}_{2}$ para simular en miocitos aislados sanos el aumento del estrés oxidativo que sufren los miocitos de animales tratados con fructosa. Estos experimentos se realizaron en presencia y ausencia de KN-93 para apoyar los resultados mostrados en la figura R.4. Los mismos mostraron que la inhibición de CaMKII fue capaz de prevenir la liberación espontánea de $\mathrm{Ca}^{2+}$ inducida por $\mathrm{H}_{2} \mathrm{O}_{2}$ (Fig. R.8).

En resumen, estos resultados indican que el incremento en el estrés oxidativo es un evento previo a la activación de CaMKII y que la activación de dicha quinasa por oxidación induce cambios proarrítmicos en el manejo del $\mathrm{Ca}^{2+}$ en los animales tratados con dieta rica en fructosa.

\section{La aparición de eventos de liberación de $\mathrm{Ca}^{2+}$ predispone a la aparición de alteraciones electrocardiográficas}

Los resultados anteriores muestran que la dieta rica en fructosa produce alteraciones proarritmogenicas en los cardiomiocitos. Entre ellas, las salidas espontáneas de $\mathrm{Ca}^{2+}$, contracciones espontáneas y la activación de CaMKII y RyR2. A partir de estos resultados, se buscó evaluar los efectos de los cambios intracelulares sobre el corazón entero in vivo. Para ello, se realizó electrocardiografía (ECG) en animales conscientes durante 30 minutos para evaluar si los eventos celulares observados se traducían en arritmias en los animales in vivo. Los ratones WT con dieta control mostraron ritmo sinusal normal, en contraste con los ratones tratados con dieta rica en fructosa en los cuales se puso en evidencia, a partir de mediciones de ECG continuos, una bradicardia significativa (Tabla R.8A y la Fig. R.9Al-ii). Esto se vió acompañado por un aumento en intervalos de tiempo del ECG (RR, QT y QTc). Por otra parte, los ratones WT con dieta rica en fructosa exhibieron transitoriamente al menos una de las siguientes alteraciones en el ECG, fibrilación auricular (FA), bloqueo auriculoventricular (bloqueo $\mathrm{AV}$ ), taquicardia ventricular bidireccional, latidos ectópicos ventriculares, taquicardia ventricular sostenida y fibrilación ventricular después de una carga de cafeína + epinefrina (Tabla R.8B y Fig. R.9Aiii-v), maniobra que se realizó para desenmascarar posibles arritmias inducidas por estrés. 
A
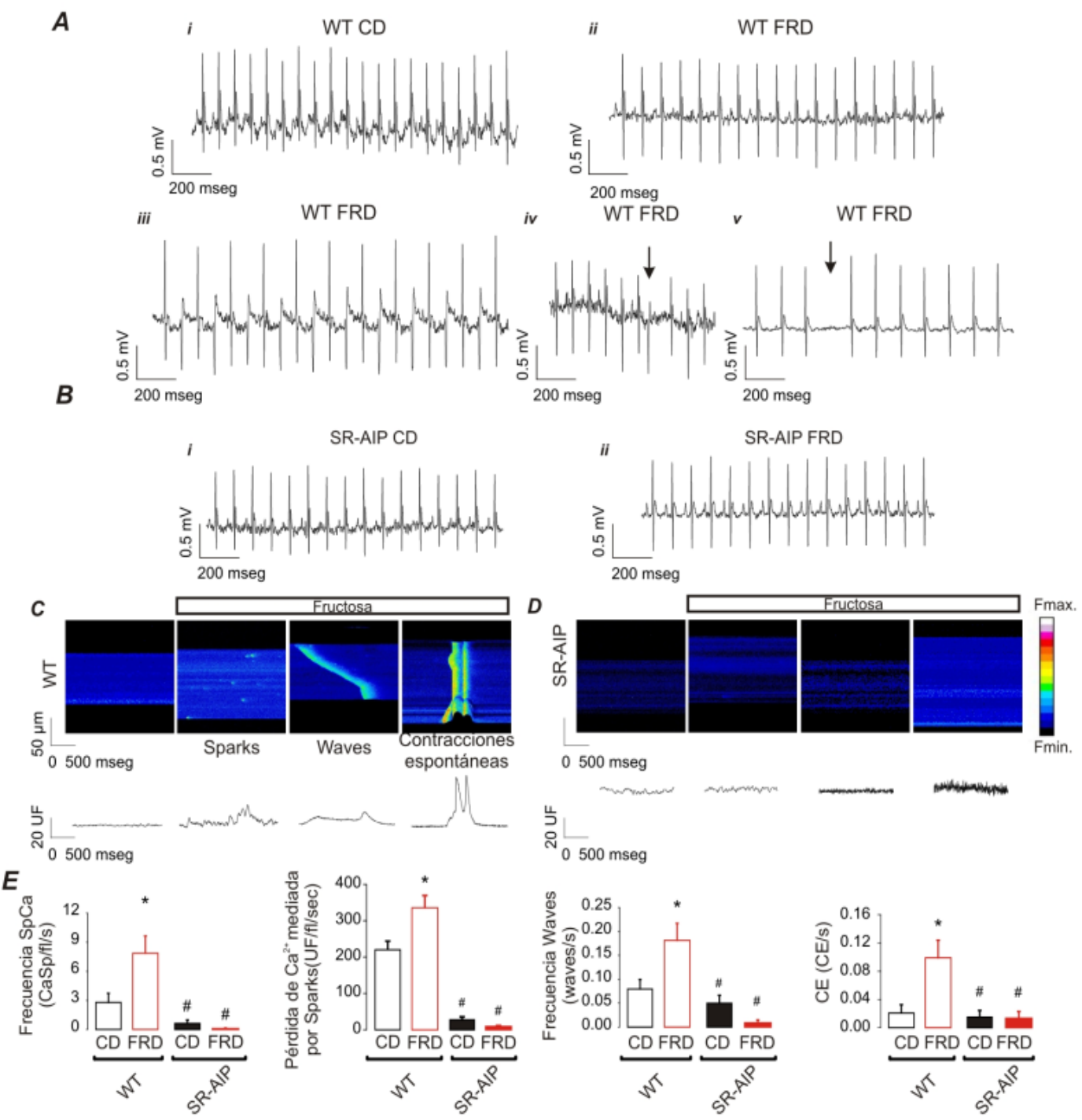

Fig. R.9. La dieta rica en fructosa induce arritmias y eventos de liberación de $\mathrm{Ca}^{2+}$ en ratones $W T$, las cuals se previenen en ratones SR-AIP.

$A$ y $B$, registros representativos de ECG de ratones WT y SR-AIP controles (CD) y tratados con dieta rica en fructosa (FRD). A, ritmo sinusal normal en ratones WT CD (i), ratones WT FRD con bradicardia (ii), taquicardia bidireccional (iii), latidos ventriculares ectópicos (iv, flecha) y bloqueo auriculoventricular (v, flecha). $B$, ritmo sinusal normal en ratones $S R-A I P$, tanto $C D$ (i) como FRD (ii). C y $D$, Imágenes de escaneo lineal de miocitos de ratones WT y SR-AIP, CD y FRD, respectivamente. Debajo aparecen sus respectivos trazos lineales. $E$, valores promedios de frecuencia de CaSp, Waves y CE, y pérdida de $\mathrm{Ca}^{2+}$ de miocitos de ratones WT y SR-AIP, CD y FRD. Los ratones SR-AIP estuvieron protegidos contra las arritmias y los EELC locales. Los datos se expresaron como media \pm SEM. $n=14$ a 21 miocitos de 4 ratones por grupo, ${ }^{*} p<0.05$ comparado con WT $C D ; \# p<0.05$ comparado con WT FRD. 


\begin{tabular}{|c|c|c|c|c|}
\hline & \multicolumn{2}{|c|}{ WT } & \multicolumn{2}{|c|}{ SR-AIP } \\
\hline & $\overline{C D}$ & FRD & $C D$ & FRD \\
\hline$n$ & 6 & 7 & 6 & 6 \\
\hline FC (Ipm) & $682 \pm 10$ & $584 \pm 35^{*}$ & $567 \pm 37^{*}$ & $529 \pm 13^{*}$ \\
\hline RR (mseg) & $88.1 \pm 1.6$ & $105.2 \pm 7.2^{*}$ & $108.2 \pm 7.2^{*}$ & $113.7 \pm 2.8^{*}$ \\
\hline PR (mseg) & $30.9 \pm 1.8$ & $30.6 \pm 0.6$ & $33.5 \pm 1.7$ & $35.5 \pm 1.4^{*}$ \\
\hline P (mseg) & $11.8 \pm 0.7$ & $12.9 \pm 0.5$ & $14.3 \pm 1.3$ & $15.5 \pm 1.0^{*}$ \\
\hline QRS (mseg) & $12.2 \pm 0.6$ & $12.9 \pm 0.5$ & $13.7 \pm 0.9$ & $14.5 \pm 0.4^{*}$ \\
\hline QT (mseg) & $52.6 \pm 1.9$ & $60.8 \pm 2.8^{*}$ & $67.6 \pm 4.7^{*}$ & $70.4 \pm 3.6^{*}$ \\
\hline QTc (mseg) & $56.0 \pm 1.9$ & $59.4 \pm 1.6^{*}$ & $64.9 \pm 2.9$ & $65.9 \pm 2.8$ \\
\hline
\end{tabular}

Tabla R.8A. Características de ECG de ratones control y tratados con fructosa.

Frecuencia cardiaca, $F C$. Duración del intervalo $R R, R R$. Duración del intervalo $P R, P R$. Duración de onda $P, P p$. Duración del complejo QRS, QRS. Duración del intervalo QT, QT. Duración corregida por la frecuencia cardiaca del intervalo $Q T, Q T c .{ }^{*} p<0.05$ respecto de $W T C D$.

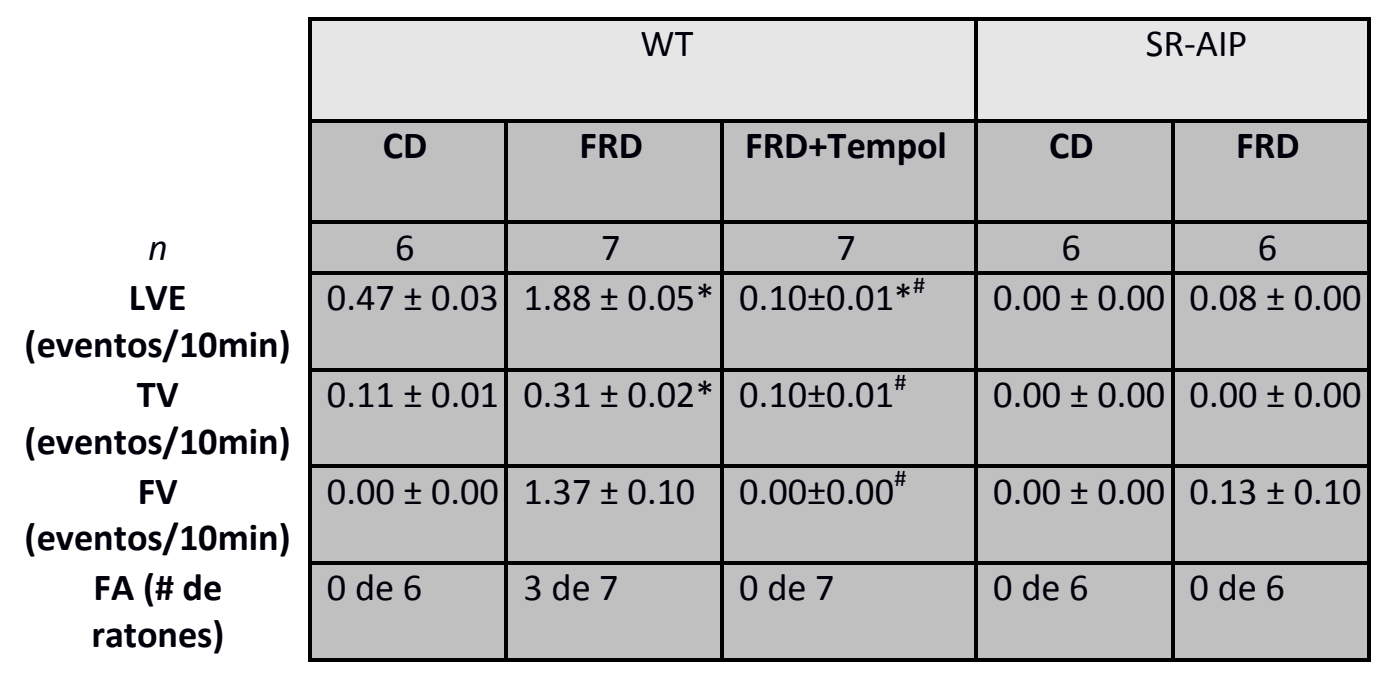

Tabla R.8B. Alteraciones arritmicas del ECG en ratones control y tratados con fructosa (WT y $S R-A I P)$.

Los resultados muestran que los eventos arrítmicos en los ratones tratados con dieta rica en fructosa (FRD) desafiados con cafeína y epinefrina se redujeron significativamente en ratones SR-AIP y en ratones WT FRD tratados conjuntamente con Tempol en comparación con los ratones WT FRD. Esto indica que CaMKIl y ROS contribuyen al patrón arrítmico observado en ratones prediabéticos por su acción a nivel del SR. Los valores son promedio $\pm E S$, de eventos/10 min. LVE: latidos ventriculares ectópicos; TV: taquicardia ventricular; FV: fibrilación ventricular; FA: fibrilación auricular. ${ }^{*} p<0.05$ vs ratones control respectivos a cada cepa. $\# p<0.05$ vs ratones $F R D$ respectivos sin Tempol. 
Todos estos eventos arrítmicos estuvieron ausentes en ratones WT controles y tratados con dieta rica en fructosa cotratados con Tempol (Tabla R.8B) y en ratones SR-AIP controles y tratados con dieta rica en fructosa (Fig. R.9B). Las figuras R.7C, D, R.9C-E y la tabla R.7 muestran que los ratones WT con dieta rica en fructosa presentaron una mayor frecuencia de CaSp, waves de $\mathrm{Ca}^{2+}$ y actividad contráctil espontánea que los WT con dieta control, y que los ratones SR-AIP, ya sea con dieta control como con dieta rica en fructosa. En conjunto, estos resultados indicarían que las acciones de CaMKII sobre el RS probablemente contribuyen al patrón arrítmico observado en animales prediabéticos.

\section{La dieta rica en fructosa promueve apoptosis en miocitos cardiacos}

En la tabla R.4 y en la figura R.1 puede observarse una disminución de la fracción de acortamiento del corazón. Esta pérdida de fuerza para contraerse puede deberse a distintos procesos, entre ellos, alteraciones en el manejo del $\mathrm{Ca}^{2+}$, desensibilización al $\mathrm{Ca}^{2+}$ de las miofibrillas y la apoptosis, entre otras. ${ }^{12}$

En el análisis del manejo del $\mathrm{Ca}^{2+}$ y el acortamiento de los miocitos cardiacos, representado en la figura $\mathrm{R} .5$, puede observarse que no hay cambios en la amplitud del transitorio de $\mathrm{Ca}^{2+}$ en los miocitos de ratas con dieta rica en fructosa. No obstante, estas células mostraron un mayor acortamiento, lo que significa, en conjunto con lo anterior, que los miofilamentos presentaron una mayor sensibilidad al $\mathrm{Ca}^{2+}$, ya que para niveles similares de $\mathrm{Ca}^{2+}$ las células provenientes de ratas $\mathrm{FRD}$ presentaron una mayor amplitud de acortamiento celular. Esto último se contrapone con el concepto de que un mayor acortamiento de las proteínas contráctiles lleva a un aumento de la fracción de acortamiento del corazón entero, por esto, debe existir otra causa para este comportamiento del corazón entero. Se realizaron, entonces, pruebas en busca de apoptosis de miocitos que pueda explicar la pérdida de fuerza cardiaca. Para esto se realizó la técnica de TUNEL que marca de rojo los núcleos apoptóticos, se midió por western blot la expresión de la proteína proapoptótica Bax y la antiapoptótica $\mathrm{Bcl} 2$, y se medió la fosforilación de la proteína p38 MAPK involucrada en la vía intrínseca de la apoptosis. La figura R.10 A, muestra una serie de fotos representantivas donde se ve la presencia de desmina (marca células musculares), con DAPI se resaltan los núcleos y en rojo pueden verse los núcleos TUNEL positivos. Las barras representan la cantidad de ratas con distinta cantidad de células TUNEL positivas, en estas se pone en evidencia que las ratas con dieta rica en fructosa presentaron una mayor cantidad de células con apoptosis. Estos resultados se corroboraron con la relación entre Bax y Bcl2 que también aumentó 
en los corazones de las ratas tratadas respecto de sus pares con dieta control. Además, se observó un aumento de la fosforilación de p38 MAPK, el cual es indicativo de la participación de la mitocondria en el proceso apoptótico.

A

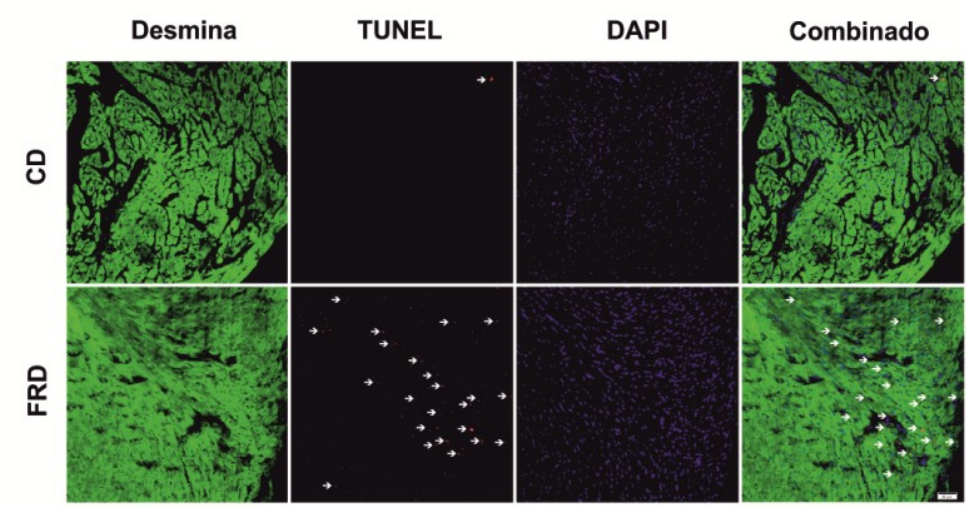

B
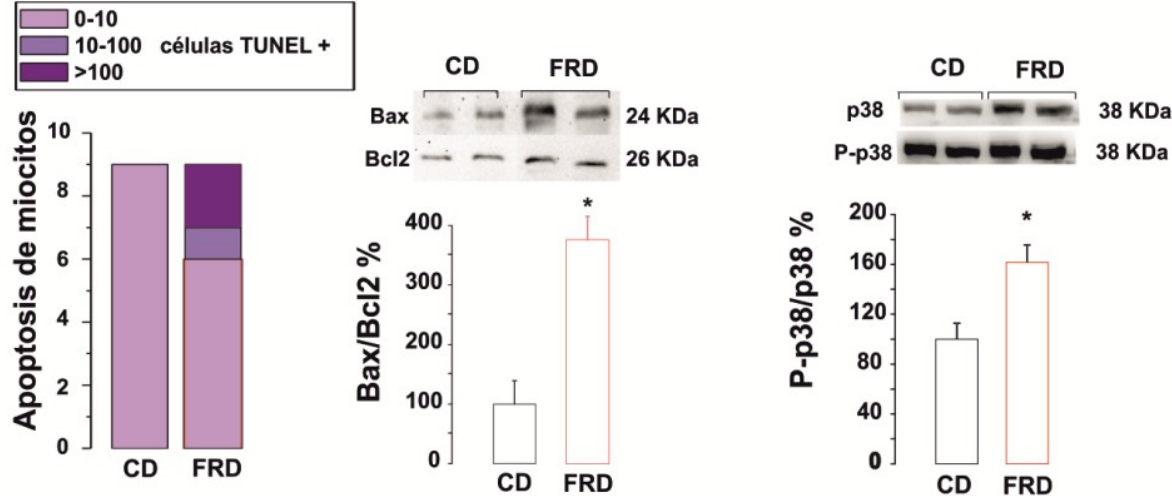

Fig. R.10: Apoptosis en ratas con dieta rica en fructosa.

A. Las fotografías muestran la tinción con desmina para denotar las células musculares; TUNEL, para denotar la fragmentación de ADN; DAPI para ver la totalidad de núcleos y una última imagen en donde convergen todas las tinciones. FRD aumenta significativamente la apoptosis cardiaca. B. En los gráficos de barra se observa la proporción de células con apoptosis en ambos grupos, la relación entre una proteína proapoptótica (Bax) y una proteína antiapoptótica (Bc/2), calculada a partir de la técnica de western blot y la fracción de la proteína p38MAPK fosforilada.

Además de su papel en acoplamiento excitocontráctil, el $\mathrm{Ca}^{2+}$ regula la producción de ATP y otros procesos celulares como la muerte, entre otras. $\mathrm{El} \mathrm{Ca}^{2+}$ mitocondrial sigue las fluctuaciones del $\mathrm{Ca}^{2+}$ citosólico y se cree que este mecanismo permite una estrecha relación entre los requerimientos de ATP y su producción. $\mathrm{El} \mathrm{Ca}^{2+}$ que ingresa a la mitocondria, además de la regulación del metabolismo, contribuye a la 
inducción del poro de transición mitocondrial cuando se producen aumentos sostenidos de $\mathrm{Ca}^{2+}$, lo que podría llevar a la despolarización de la mitocondria y al inicio de la vía intrínseca de apoptosis. Se ha demostrado una mayor sensibilidad al $\mathrm{Ca}^{2+}$ del poro de transición mitocondrial debido a la presencia de un estado alterado del equlibrio redox de la mitocondria. ${ }^{234}$ Debido a que observamos un aumento en la salida de $\mathrm{Ca}^{2+}$ del $\mathrm{RS}$ con una disminución de la carga del mismo sin aumento sostenido del $\mathrm{Ca}^{2+}$ diastólico y que es conocida la existencia de una relación directa entre el RS y la mitocondria ${ }^{235}$ es lógico especular que el $\mathrm{Ca}^{2+}$ liberado en los EELC podía ingresar a la mitocondria y producir alteraciones en la organela que justifique la apoptosis observada. En la figura R.11 A se observa un gráfico de barras donde se representa el promedio de los niveles de $\mathrm{Ca}^{2+}$ en la mitocondria, y en el cual se observa un aumento significativo del mismo en ratas tratadas con dieta rica en fructosa respecto de las ratas con dieta control, lo que nos permite inferir la sensibilidad del poro de transición mitocondrial a la apertura inducida por $\mathrm{Ca}^{2+}$. Para comprobar esto se realizaron ensayos de sensibilidad al hinchamiento mitocondrial mediado por el poro gracias al agregado de $\mathrm{Ca}^{2+}$ a un pool de mitocondrial aisladas. En el panel superior a la izquierda de la figura R11.B se ven ejemplos representativos de las caidas de densidad óptica (DO) ante el agregado de distintas concentración de $\mathrm{Ca}^{2+}$ (una mayor caida indica una mayor sensibilidad a la apertura), en el panel superior derecho se muestran dos registros representativos a $50 \mu \mathrm{m}$ de $\mathrm{Ca}^{2+}$, en negro mitocondrias aisladas de corazones de ratas con dieta control y en rojo mitocondrias aisladas de corazones de ratas con dieta rica en fructosa, en las cuales puede verse una mayor caida de DO en las mitocondrias de ratas tratadas comparándolas con las controles. En el panel inferior se graficaron los promedios de las diferencias de DO para cada concentración de $\mathrm{Ca}^{2+}$. El corrimiento de la curva hacia la derecha muestra una mayor sensibilidad del hinchamiento mitocondrial al $\mathrm{Ca}^{2+}$ para las mitocondrias de ratas con dieta rica en fructosa. A partir de estos resultados, se buscó confirmarlos por otro método indicador del deterioro mitocondrial en cardiomiocitos intactos, la medida del potencial de la membrana mitocondrial con un indicador específico, JC-1, que cambia su color de rojo a verde ante la despolarización de la membrana mitocndrial. En la figura R.11 C se puede ver una menor relación entre la emisión roja y la verde del indicador en las céluas de ratas con dieta rica en fructosa versus las que tuvieron dieta control, indicando un grado mayor de despolarización. Al mismo grupo de células se les agregó $\mathrm{H}_{2} \mathrm{O}_{2}$ como estímulo agresivo para forzar la despolarización, y se observó una disminución de la relación de fluorescencia en 
ambos grupos manteniéndose la diferencia entre las células de ratas tratadas y los controles.

En su conjunto, estos resultados pusieron en evidencia la presencia de apoptosis y la participación de la mitocondria en el proceso.
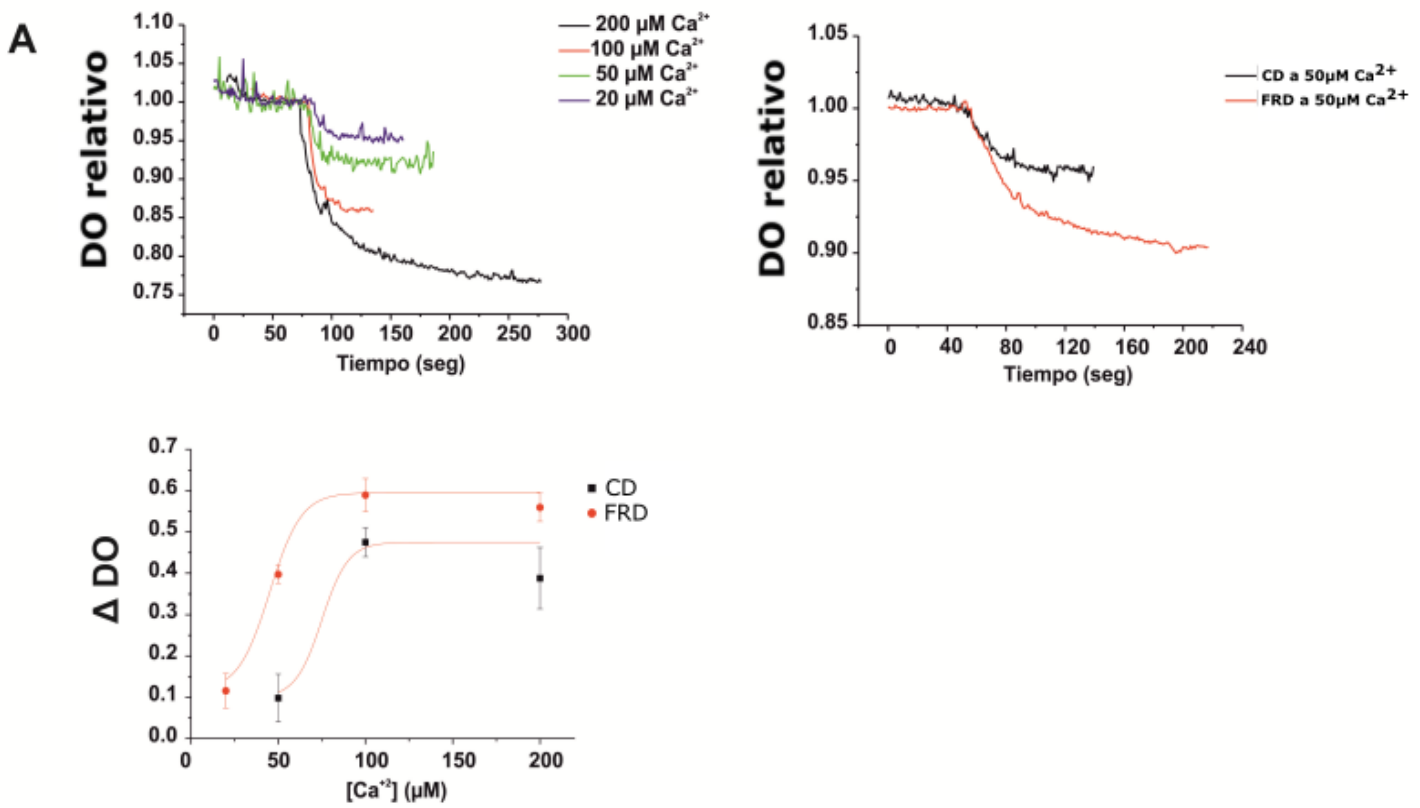

B

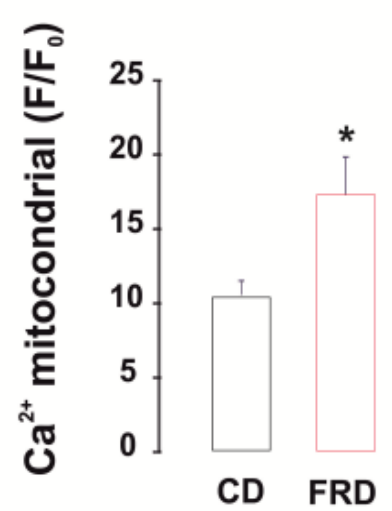

C

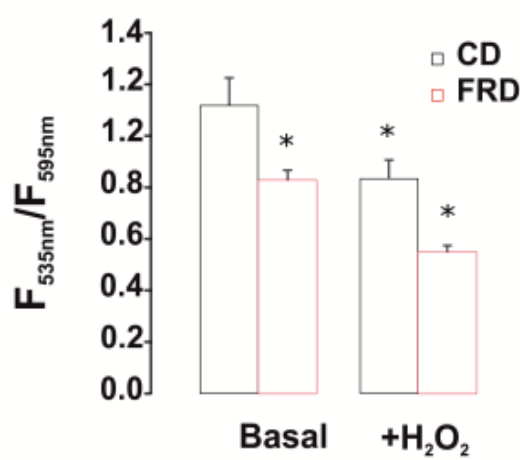

\section{Fig. R.11: Apoptosis en ratas con dieta rica en fructosa}

A. Protocolo de hinchamiento mitocondrial. A la izquierda, se observa la caída de $D O$ a medida que se agregan distintas concentraciones de $\mathrm{Ca}^{2+}$ a las mitocondrias aisladas. A la derecha se muestra una curva experimental obtenida en mitocondrias de animales CD (negro) y FRD (Rojo) luego del agregado de $50 \mu \mathrm{M}$ de $\mathrm{Ca}^{2+}$. Las mitocondrias FRD denotaron una caída significativamente mayor que las provenientes de animales con CD. B. Se midieron las concentraciones basales de $\mathrm{Ca}^{2+}$ mitocondrial por microscopia confocal, utilizando Fluo-3 AM como indicador en miocitos aislados de rata. La figura muestra un aumento del $\mathrm{Ca}^{2+}$ mitocondrial en las ratas FRD. C. Las mitocondrias de ratas con dieta rica en fructosa (FRD) mostraron mayor despolarización en el comienzo del experimento comparadas con el control y tuvieron un descenso más rápido luego del agregado de $\mathrm{H}_{2} \mathrm{O}_{2}$. 


\section{DISCUSIÓN}


La prevalencia de la tolerancia a la glucosa alterada está creciendo en todo el mundo ${ }^{88}$ con un consecuente incremento en el riesgo de desarrollar DMT2 y enfermedades cardiovasculares. La tolerancia a la glucosa alterada ha demostrado ser un estado precursor de diabetes y usualmente coexiste con un estado de resistencia a la insulina, con un riesgo mayor de morbilidad cardiovascular y mortalidad. Los resultados de este estudio mostraron que los miocitos ventriculares de animales con dieta rica en fructosa desarrollaron eventos cardiacos arritmogénicos. Además, indicaron que la fosforilación de RyR2 dependiente de CaMKII forma parte del mecanismo proarritmogénico observado a nivel celular en ratas y ratones con dieta rica en fructosa. Finalmente, el aumento de la actividad de CaMKII que se produce en el modelo es dependiente del incremento de estrés oxidativo producido por la dieta rica en fructosa.

\section{La dieta rica en fructosa como modelo de prediabetes}

La Asociación Americana de Diabetes indicó que la DMT2 está usualmente precedida por un desorden metabólico conocido como prediabetes, también predice que en 10 años el $50 \%$ de los individuos con prediabetes presentarán DMT2 manifiesta ${ }^{14}$. Este estado se caracteriza por un nivel aumentado de glucemia en ayunas o después de la prueba de tolerancia oral a la glucosa, sin alcanzar los valores de un paciente con diabetes manifiesta. La prediabetes constituye un factor de riesgo importante para el desarrollo de diabetes y/o sus complicaciones crónicas, como retinopatía o enfermedades cardiovasculares ${ }^{236,237}$.

La administración de dieta rica en fructosa a ratas por 3 semanas induce cambios en el metabolismo de glucosa (tolerancia a la glucosa alterada) y lípidos, disfunción endócrina, resistencia a la insulina e incremento del estrés oxidativo ${ }^{206}$. En este modelo se observa una alteración de las enzimas del metabolismo de los hidratos de carbono como la disminución de la actividad de la glucoquinasa y el aumento de la actividad de la glucosa-6-fosfatasa, lo cual promueve la resistencia a la insulina. ${ }^{238}$ A pesar de la falta de obesidad, existe un aumento en los depósitos lipídicos con aumento del tamaño de los adipocitos, característico de una redistribución de la grasa que se produce alrededor de los tejidos y no en un sitio u órgano en particular. ${ }^{239}$ Todos estos cambios son comparables con aquellos que se observan en personas con DMT2/prediabetes, por esta razón la dieta rica en fructosa es un modelo útil para el estudio de prediabetes. De hecho, en estudios previos, el modelo de dieta rica en fructosa ya ha sido utilizado para la evaluación 
de la función miocárdica. ${ }^{4,240}$ Se ha observado en el modelo de resistencia a la insulina por el consumo de fructosa, un incremento en la producción de ROS en corazón, dependiente de la NADPH oxidasa. ${ }^{125}$ Por esto, el incremento en el estrés oxidativo es tanto una consecuencia como un causante de la resistencia a la insulina por alteración de la sensibilidad del receptor de insulina debido a la disminución de factores de transcripción PDX-1. Como se mencionó en la introducción, PDX-1 disminuye por el estrés oxidativo, y ayuda a la reparación y regeneración de células $\beta$ del páncreas y a la respuesta por inducción del receptor de insulina. ${ }^{5,22}$ Además, se ha encontrado una correlación entre el aumento de la producción de ROS y la hipertrofia cardiaca. ${ }^{238}$

Se ha postulado que el modelo de prediabetes por consumo de altas cantidades de fructosa produce resistencia a la insulina, principalmente, por modificación posttraduccional del receptor de insulina. Sobre este receptor pueden actuar la tirosina fosfatasa y proteínas serina/treonina quinasa (como JNK). Ambas regulan negativamente al receptor de insulina en animales tratados con fructosa, impidiendo su autofosforilación y la fosforilación de sus sustratos. ${ }^{241}$

Nosotros pudimos reproducir este modelo en ratas y ratones. En estos últimos se apreciaron características propias del modelo tales como, la alteración de la prueba de tolerancia a la glucosa intraperitoneal. El uso de ratones con dieta rica en fructosa nos permitió utilizar herramientas de modificación genética para un mejor entendimiento de las vías y los mecanismos subyacentes.

\section{Promoción de eventos espontáneos de liberación de $\mathrm{Ca}^{2+}{ }_{i}$ y contracciones espontáneas}

Ha sido descripto el incremento en el riesgo de muerte a largo plazo en pacientes con prediabetes ${ }^{242,243}$, y de arritmias en jóvenes con diabetes ${ }^{244}$. Estos antecedentes indicarían que probablemente, durante la ventana asintomática previa al diagnóstico de DM, habría cambios a nivel celular que favorezcan un escenario proarritmogénico no detectado. Nordin et al. ${ }^{148}$, observó un aumento de la propensión a DADs en un modelo de ratas diabéticas por estreptozotocina y se sabe que los pacientes diabéticos poseen varias alteraciones del ECG, como la dispersión de la duranción del intervalo QT. ${ }^{245}$ Además, el metabolismo anormal de la glucosa y la glucemia alterada en ayuno fueron asociadas con un aumento en la incidencia de fibrilación atrial. ${ }^{94}$ Sin embargo, la posibilidad de que la condición de prediabetes predisponga a arritmias ventriculares no ha sido descripta. En nuestro 
modelo de tolerancia a la glucosa alterada, mostramos un aumento en la frecuencia de eventos espontáneos de liberación de $\mathrm{Ca}^{2+}$, incluyendo CaSp y waves que pueden o no culminar en contracciones espontáneas en miocitos ventriculares. Asimismo, encontramos anormalidades en el ECG, incluyendo episodios de fibrilación auricular, latidos ventriculares espontáneos y arritmias ventriculares in vivo. Por consiguiente estos resultados revelan que en los animales con dieta rica en fructosa, es evidente la presencia de un sustrato arritmogénico antes de que aparezcan las manifestaciones clínicas propias de la DMT2.

Por otra parte, es conocido que la activación del receptor $\beta$-adrenérgico puede provocar arritmias cardiacas debido a la liberación de $\mathrm{Ca}^{2+}$ del $\mathrm{RS}$ en diástole, a través, de la fosforilación del RyR2 por PKA. La activación de los receptores $\beta$ adrenérgicos puede actuar sobre los RyR2 por activación de CaMKII mediada por EPAC (proteína intercambiadora activada por AMPc), a través de mecanismos que involucran el aumento de $\mathrm{Ca}^{2+}$ que produce la activación $\beta$-adrenérgica. ${ }^{246} \mathrm{En}$ nuestro estudio, el estrés producido por catecolaminas conduce a un aumento en la frecuencia de eventos espontáneos de liberación de $\mathrm{Ca}^{2+}$ en miocitos de ventrículo izquierdo, que parece ser sustancialmente dependiente de la hiperactividad de CaMKII e independiente de la actividad $\beta$-adrenérgica ya que, el estado de fosforilación de sitio del RyR2 $\left(\operatorname{Ser}^{2808}\right)$ dependiente de PKA fue similar tanto en animales controles como en los tratados con frucotsa.

\section{Relación entre patrón arritmogénico y la fosforilación de RyR2}

Muchos estudios han mostrado que el manejo anormal del $\mathrm{Ca}^{2+}$ desarrolla un papel central en la iniciación y/o mantenimiento de arritmias auriculares y ventriculares en animales y humanos ${ }^{11,247}$. Los defectos en los flujos de $\mathrm{Ca}^{2+}$ predisponen a liberaciones espontáneas, no sincronizadas de $\mathrm{Ca}^{2+}$ del retículo sarcoplásmico (RS), los cuales pueden activar corrientes hacia adentro por el NCX lo cual puede llevar a la generación de despolarizaciones tempranas (DADs) ${ }^{248}$. Además, la fosforilación de RyR2 dependiente de CaMKII incrementa la pérdida de $\mathrm{Ca}^{2+}$ del RS y la susceptibilidad a las arritmias cardiacas en un número de modelos, ${ }^{11,187}$ sugiriendo que la inhibición de CaMKII podría proteger contra las condiciones proarritmogénicas en una variedad de enfermedades caracterizadas por aumento de ROS y alteración del $\mathrm{Ca}^{2+}{ }_{\text {i }}$. Los resultados presentados muestran un incremento de los sparks de $\mathrm{Ca}^{2+}$, waves y contracciones espontáneas en los animales con dieta rica en fructosa. Este aumento de frecuencia de eventos ocurrió en ausencia de un contenido de $\mathrm{Ca}^{2+}$ elevado en el RS respecto al control y fue inhibido por el 
bloqueo de la actividad de CaMKII a nivel del RS. Esto sugiere que la fosforilación de RyR2 dependiente de CaMKII es un paso crítico para el incremento de eventos proarritmogénicos en el modelo de prediabetes inducido por una dieta rica en fructosa. Es intertesante destacar, que hubo un aumento en la fosforilación en el sitio $\mathrm{Thr}^{17}$ de PLN en los corazones de animales con dieta rica en fructosa. Esto puede, en parte, explicar el incremento en la actividad de SERCa2a detectada en nuestros experimentos, lo cual podría estimular la pérdida de $\mathrm{Ca}^{2+}$ del $\mathrm{RS}$ al recargar más rápidamente el mismo. Sin embargo, la pérdida continua de $\mathrm{Ca}^{2+}$ es lo que podría haber llevado a la disminución de la carga de $\mathrm{Ca}^{2+}$ del RS, y el aumento de la actividad de SERCa2a mantendría el influjo hacia el RS permitiendo al RyR2 tener sustrato para la liberación espontánea.

En conflicto con nuestros resultados, Nishio et al. ${ }^{249}$ sugirió que CaMKII se encuentra activa previa a la generación de ROS en un modelo de rata diabética por estreptozotocina, y que es la quinasa la que genera la producción de ROS. A pesar de que esta discrepancia pueda deberse a la diferencia entre los modelos o diferentes estados evolutivos y etiologías de la enfermedad, nuestros resultados sostienen que la activación de CaMKII está mediada por ROS, como se discutirá más adelante. Nosotros hemos demostrado que los ratones SR-AIP prediabéticos, con un incremento en la peroxidación lipídica, que refleja un estado de estrés oxidativo, estuvieron protegidos contra el desarrollo de eventos de liberación espontánea de $\mathrm{Ca}^{2+}$ y las alteraciones en el ECG. El aumento de ROS, a pesar de estar presente en los ratones SR-AIP tratados con dieta rica en fructosa, no fue suficiente para causar liberaciones espontáneas de $\mathrm{Ca}^{2+}$ en los miocitos aislados $\mathrm{ni}$ de provocar arritmias en los animales in vivo. Estos resultados indican que la producción de ROS antecede a la activación de CaMKII en la vía que lleva a alteraciones en el manejo del $\mathrm{Ca}^{2+} \mathrm{y}$ arritmias, y que los efectos de la CaMKII son necesarios para el desarrollo de las anomalías observadas, ya que la elevación de los ROS por si mismos, al menos en los niveles de este estudio, no fue capaz de inducir alteraciones en la homeostasis del $\mathrm{Ca}^{2+}$.

\section{Posibles mecanismos que podrían conducir a la activación de CaMKII}

De forma canónica, CaMKII se activa tras la unión sostenida con $\mathrm{Ca}^{2+} / \mathrm{CaM}$, que produce la autofosforilación en el sitio $\mathrm{Thr}^{287}$. CaMKII fosforilada incrementa la afinidad por $\mathrm{Ca}^{2+} / \mathrm{CaM}$ de manera alostérica y permite que se sostenga la actividad de CaMKII independiente de $\mathrm{Ca}^{2+} / \mathrm{CaM}$. Otra modificación postraduccional que puede sufrir CaMKII es la oxidación en Met ${ }^{281 / 282}$. La oxidación de CaMKII induce un 
cambio similar a la unión de $\mathrm{Ca}^{2+} / \mathrm{CaM}$ pero de manera independiente al mismo. ${ }^{175}$ Nuestros datos han demostrado que el $\mathrm{Ca}^{2+}$ diastólico en estado basal no fue diferente en los animales tratados con fructosa comparados con los controles. El $\mathrm{Ca}^{2+}$ diastólico solo aumentó durante los períodos en que se producían los eventos de liberación espontánea de $\mathrm{Ca}^{2+}$ en forma de "ráfagas". Nuestro grupo de trabajo ha descripto previamente, que la oxidación de CaMKII sensibiliza la enzima al $\mathrm{Ca}^{2+}$, por lo que es capaz de activarse a concentraciones de $\mathrm{Ca}^{2+}$ más bajas ${ }^{250}$. Esto sugiere que en condiciones de aumento de la producción de ROS puede producirse la activación de CaMKII sin cambios en los niveles de $\mathrm{Ca}^{2+} / \mathrm{CaM}$. Por lo tanto, nuestros hallazgos sugieren que la principal fuente de activación de CaMKII es la producción de ROS en los animales con dieta rica en fructosa. La reciente descripción de la activación de CaMKII por O-GIcNAcilación u óxido nítrico ${ }^{177,251}$ estuvo fuera del estudio de esta tesis. A pesar de esto, en nuestro estudio, evitar el incremento de ROS con Tempol fue suficiente para prevenir la generación de los CaSp y waves, que potencialmente culminan en arritmias. Lo que implicaría que si estos procesos (O-GlcNAcilación o nitrosilación) estuvieron presentes, no son de la magnitud suficiente como para superar o reemplazar el efecto del aumento en los ROS.

\section{Hipertrofia e insuficiencia cardiaca en ratas prediabéticas}

Ha sido descripto que tanto humanos como animales con diabetes pueden desarrollar cardiomiopatía e hipertrofia ${ }^{108,252-255}$. La patogenia de estas alteraciones cardiacas está lejos de ser clara. Se han propuestos mecanismos multifactoriales, incluyendo la disfunción autonómica, alteraciones metabólicas y la disminución del estado energético, anormalidades en la homeostasis de iones, alteración en las proteínas estructurales y fibrosis intersticial. En cuanto a nuestro estudio, este es el primer informe que muestra que el tratamiento con fructosa produce hipertrofia cardiaca en ratas, aunque nuestro enfoque no se centró en investigar los mecanismos de la hipertrofia en estos animales. Es de amplio conocimiento que en la hipertrofia cardiaca y la insuficiencia cardiaca, el manejo alterado del $\mathrm{Ca}^{2+}$ intracelular está involucrado en la disfunción contráctil y contribuye al desarrollo de arritmias. $^{256-258}$ Una pregunta importante que surge de este estudio es si las alteraciones del ECG de corazones de ratas con dieta rica en fructosa son consecuencia de la hipertrofia observada en estos corazones. Los presentes resultados no pueden negar o apoyar esta posibilidad. Nuestro estudio demostró la alteración de la manipulación de $\mathrm{Ca}^{2+}$ intracelular y el incremento del $\mathrm{Na}^{+}$(que fue 
de $340 \pm 35 \%, n=3$ animales por grupo, $p<0.0001$ ) en ratas con dieta rica en fructosa, similar a lo que se ha descrito en diferentes modelos de hipertrofia ${ }^{257,259,260}$. Por tanto, es posible que las alteraciones que se encuentran como base de las arritmias en el corazón de la dieta rica en fructosa, también estén involucrados en el desarrollo de la hipertrofia. Por otra parte, aunque la evaluación del metabolismo energético de los corazones de los animales con dieta rica en fructosa no fue el objetivo de este trabajo, se ha demostrado que los cambios metabólicos en modelos de DMT2 disminuyen la eficacia cardiaca y energética ${ }^{261}$. En particular, una disminución del estado energético (determinado, entre otras cosas, por el consumo de oxígeno y la producción de ATP) de los corazones de animales con dieta rica en fructosa también podría contribuir al desarrollo de hipertrofia cardiaca.

En resumen, hemos descrito una vía proarrítmica en el estado prediabético. Aquí presentamos evidencia que muestra la vulnerabilidad del estado de prediabetes para inducir un aumento de la actividad de CaMKII dependiente de ROS, que a su vez produce un aumento de la fosforilación de RyR2 y de la pérdida de $\mathrm{Ca}^{2+}$ del RS capaz de inducir actividad contráctil espontánea. Por lo tanto, las estrategias terapéuticas para disminuir la activación de CaMKII y la producción de ROS pueden contribuir a prevenir o reducir el patrón arritmogénico de la prediabetes.

La evidencia experimental indica que un factor crítico en la transición de la hipertrofia cardíaca compensada a la no compensada es la pérdida de células de los miocitos por apoptosis y necrosis. ${ }^{262}$ Como hemos comentado anteriormente, la diabetes mellitus se caracteriza por presentar un incremento en la frecuencia y severidad de infarto de miocardio. Además, los pacientes diabéticos tienen el doble de riesgo de desarrollar insuficiencia cardiaca tras sufrir infarto de miocardio. ${ }^{138}$ En este estudio puede observarse una disminución de la fracción de acortamiento del corazón. Esta pérdida de fuerza para contraerse puede deberse a distintos procesos, entre ellos, alteraciones en el manejo del $\mathrm{Ca}^{2+}$, desensibilización al $\mathrm{Ca}^{2+}$ de las miofibrillas y la apoptosis, entre otras. ${ }^{12}$ Los resultado han mostrado que la relación entre la fracción de acortamiento y el $\mathrm{Ca}^{2+}$ liberado en cada contracción por los miocitos de ratas tratadas con fructosa fue mayor comparado con los animales con dieta control, sugiriendo una mayor sensibilidad de los miofilamentos al $\mathrm{Ca}^{2+}$. Este aumento da lugar a la hipótesis que la apoptosis y el remodelado del corazón pueden ser factores influyentes en la pérdida de fuerza de eyección observada en los animales con dieta rica en fructosa.

Los presentes resultados muestran que el tratamiento de aanimales con dieta rica en fructosa promueve la apoptosis como lo demuestra el aumento significativo en 
los núcleos TUNEL-positivos y la relación Bax / Bcl-2, lo que sugiere la participación de RS / mitocondrias en el proceso apoptótico. ${ }^{263}$

Varios estudios han investigado la muerte celular en corazones diabéticos. Estos estudios indican que la apoptosis se potencia y se asocia con un aumento del ventrículo izquierdo y un aumento de la fibrosis después del infarto de miocardio en cardiomiocitos diabéticos. ${ }^{264,265}$ Además, varias líneas de evidencia indican que CaMKII constituye un intermedio común por el cual diversos estímulos inductores de la muerte activan la apoptosis de los cardiomiocitos. ${ }^{266}$ Por otra parte, diferentes resultados sugieren un fuerte vínculo entre el manejo anormal del $\mathrm{Ca}^{2+}$ de los miocitos, la disfunción mitocondrial y la apoptosis. ${ }^{267-269}$ De hecho, numerosos datos respaldan la hipótesis de que el movimiento de $\mathrm{Ca}^{2+}$ desde el SR a mitocondrias es un proceso clave en algunas rutas apoptóticas. ${ }^{263}$ En este contexto, ha sido demostrado que la muerte de los miocitos desencadenada por mitocondrias aumenta por la activación de CaMKII a través de un aumento de la corriente de $\mathrm{Ca}^{2+}$ tipo $\mathrm{L}$ y la liberación de $\mathrm{Ca}^{2+}$ del $\mathrm{RS}^{267} \mathrm{La}$ excesiva $\left[\mathrm{Ca}^{2+}\right]$ dentro de las mitocondrias puede inducir apoptosis al abrir el poro de transición de permeabilidad mitocondrial (mPTP). ${ }^{270}$

Este estudio muestra que en ratas FRD con tolerancia alterada a la glucosa, una etapa que precede ampliamente a la diabetes y MCD manifiesta, hay un aumento significativo de la muerte apoptótica y en el daño mitocondrial, expresado en una sensibilización de la mitocondria al hinchamiento y al daño por $\mathrm{H}_{2} \mathrm{O}_{2}$. Un análisis exahustivo es requerido para poner en evidencia los mecanismos que relacionan las pérdidas de $\mathrm{Ca}^{2+}$ del RS disparadas por la activación de CaMKII y el daño mitocondrial que conduce a la apoptosis.

\section{Relevancia clínica y limitaciones potenciales}

Un reto importante para la prevención de la DMT2, su evolución y sus complicaciones es el reconocimiento de la etapa inicial de prediabetes. El comienzo insidioso de la DMT2 incluye una fase subclínica prolongada de prediabetes. En este modelo animal de prediabetes, mostramos una tendencia llamativa a presentar alteraciones del ECG. El hallazgo de que CaMKII está hiperactiva en pacientes diabéticos y el conocido aumento de la pérdida de $\mathrm{Ca}^{2+}$ por RyR2 en arritmias clínicas $^{271-273}$ abogan por la posible relevancia clínica de nuestro trabajo. Estos resultados sugieren, además, que la presencia del estado de prediabetes debe motivar una búsqueda cuidadosa de las arritmias y viceversa. Una posible limitación de nuestro modelo es que el consumo de calorías en la dieta de ratas ricas en 
fructosa es ligeramente, pero significativamente mayor en comparación con las ratas control de la dieta. Si este aumento de la ingesta calórica tiene un papel modulador sobre la actividad de CaMKII, remodelación miocárdica y arritmogénesis descrito aquí, no se puede determinar a partir de los resultados actuales y merece una mayor investigación. Sin embargo, el hecho de que se obtuvieron resultados similares en ratones en los que el consumo de calorías fue similar entre los animales con dieta control y dieta rica en fructosa, argumenta en contra de esta posibilidad. En este sentido, se ha demostrado previamente que la fosforilación de CaMKII no se vio afectada por los cambios en la ingesta calórica ${ }^{274}$. Somos conscientes, sin embargo, de las limitaciones de cualquier modelo animal para imitar la prediabetes en los seres humanos y por lo tanto la extrapolación de nuestros resultados a la práctica clínica debe ser muy cautelosa. Además, el vínculo entre prediabetes, arritmias cardiacas y la disfunción RyR2 y la pérdida de $\mathrm{Ca}^{2+}$ en los pacientes es desconocido y requiere una amplia labor en estudios posteriores. Por otra parte, múltiples procesos complejos posibles (activación CaMKII, señalización ROS, etc.) pueden contribuir a la génesis de defectos de miocardio en individuos prediabéticos. Se necesitan estudios experimentales y de traslación a pacientes para evaluar la posibilidad de que las pérdidas de $\mathrm{Ca}^{2+}$ del RS dependientes de CaMKII también puedan constituir un mecanismo central para el desarrollo y progresión de las arritmias ventriculares en pacientes prediabéticos. 
BIBLIOGRAFÍA 
1. Arrieta, F. et al. Diabetes mellitus y riesgo cardiovascular: recomendaciones del Grupo de Trabajo Diabetes y Enfermedad Cardiovascular de la Sociedad Española de Diabetes (SED, 2015). Clínica E Investig. En Arterioscler. 27, 181-192 (2015).

2. Dobrin, J. S. \& Lebeche, D. Diabetic cardiomyopathy: signaling defects and therapeutic approaches. Expert Rev. Cardiovasc. Ther. 8, 373-391 (2010).

3. Consenso de Prediabetes. Documento de Posición de la Asociación Latinoamericana de Diabetes (ALAD). Consensos ALAD 17, (2009).

4. Mellor, K. M., Wendt, I. R., Ritchie, R. H. \& Delbridge, L. M. D. Fructose diet treatment in mice induces fundamental disturbance of cardiomyocyte $\mathrm{Ca} 2+$ handling and myofilament responsiveness. Am. J. Physiol. Heart Circ. Physiol. 302, H964-972 (2012).

5. Basciano, H., Federico, L. \& Adeli, K. Fructose, insulin resistance, and metabolic dyslipidemia. Nutr. Metab. 2, 5 (2005).

6. Watanabe, K., Sekiya, M., Tsuruoka, T., Funada, J. \& Kameoka, H. Effect of insulin resistance on left ventricular hypertrophy and dysfunction in essential hypertension. J. Hypertens. 17, 1153-1160 (1999).

7. Velez Rueda, J. O., Palomeque, J. \& Mattiazzi, A. Early apoptosis in different models of cardiac hypertrophy induced by high renin-angiotensin system activity involves CaMKII. J. Appl. Physiol. Bethesda Md 1985 112, 2110-2120 (2012).

8. Erickson, J. R. et al. S-Nitrosylation Induces Both Autonomous Activation and Inhibition of Calcium/Calmodulin-dependent Protein Kinase II $\delta . J$. Biol. Chem. 290, 25646-25656 (2015).

9. Daniels, L. et al. The role of CaMKII in diabetic heart dysfunction. Heart Fail. Rev. 20, 589-600 (2015). 
10. Jing-Zhi Yan, Zhuo Xu \& Wei Lu. Protein Kinase C Promotes N -Methyl- D aspartate (NMDA) Receptor Trafficking by Indirectly Triggering Calcium/

Calmodulin-dependent Protein Kinase II (CaMKII) Autophosphorylation. 28,

11. Said, M. et al. Calcium-calmodulin dependent protein kinase II (CaMKII): a main signal responsible for early reperfusion arrhythmias. J. Mol. Cell. Cardiol. 51, 936-944 (2011).

12. Rodriguez, J. S. et al. Increased $\mathrm{Na}+/ \mathrm{Ca} 2+$ Exchanger Expression/Activity Constitutes a Point of Inflection in the Progression to Heart Failure of Hypertensive Rats. PLoS ONE 9, e96400 (2014).

13. Simeon I. Taylor. Diabetes Mellitus. in The Metab olic and Molecular Bases of Inherited Disease 843-890 (McGraw - Hill, 1995).

14. American Diabetes Association. Standards of Medical Care in Diabetes--2014. Diabetes Care 37, S14-S80 (2014).

15. OMS | Programa de Diabetes de la OMS. WHO Available at: http://www.who.int/diabetes/es/. (Accessed: 15th February 2016)

16. Must A et al. THe disease burden associated with overweight and obesity. JAMA 282, 1523-1529 (1999).

17. Valmore Bermúdez et al. Biología molecular de los transportadores de glucosa: clasificación, estructura y distribución. 26, (2007).

18. Dra. Ana María Gómez Medina. Fisiopatología de la diabetes mellitus tipo 1 (DM1). Scribd

19. Gurlo, T., Kawamura, K. \& von Grafenstein, H. Role of inflammatory infiltrate in activation and effector function of cloned islet reactive nonobese diabetic CD8+ T cells: involvement of a nitric oxide-dependent pathway. J. Immunol. Baltim. Md 1950 163, 5770-5780 (1999). 
20. Mandrup-Poulsen, T. The role of interleukin-1 in the pathogenesis of IDDM.

Diabetologia 39, 1005-1029 (1996).

21. Cailleau, C., Diu-Hercend, A., Ruuth, E., Westwood, R. \& Carnaud, C.

Treatment with neutralizing antibodies specific for IL-1beta prevents

cyclophosphamide-induced diabetes in nonobese diabetic mice. Diabetes 46, 937940 (1997).

22. Fisiopatologia de La Diabetes Mellitus Tipo 2 J Castillo. Scribd Available at: https://es.scribd.com/doc/110839711/Fisiopatologia-de-La-Diabetes-Mellitus-Tipo-2-

J-Castillo. (Accessed: 2nd October 2015)

23. Federici, M. et al. High Glucose Causes Apoptosis in Cultured Human

Pancreatic Islets of Langerhans A Potential Role for Regulation of Specific Bcl

Family Genes Toward an Apoptotic Cell Death Program. Diabetes 50, 1290-1301 (2001).

24. Shimabukuro, M., Wang, M. Y., Zhou, Y. T., Newgard, C. B. \& Unger, R. H. Protection against lipoapoptosis of beta cells through leptin-dependent maintenance of Bcl-2 expression. Proc. Natl. Acad. Sci. U. S. A. 95, 9558-9561 (1998).

25. Efanova, I. B. et al. Glucose and tolbutamide induce apoptosis in pancreatic beta-cells. A process dependent on intracellular $\mathrm{Ca} 2+$ concentration. J. Biol. Chem. 273, 33501-33507 (1998).

26. Saafi, E. L., Konarkowska, B., Zhang, S., Kistler, J. \& Cooper, G. J.

Ultrastructural evidence that apoptosis is the mechanism by which human amylin evokes death in RINm5F pancreatic islet beta-cells. Cell Biol. Int. 25, 339-350 (2001).

27. Matthews, D. R. et al. Homeostasis model assessment: insulin resistance and beta-cell function from fasting plasma glucose and insulin concentrations in man. Diabetologia 28, 412-419 (1985). 
28. Kajimoto, Y. \& Kaneto, H. Role of oxidative stress in pancreatic beta-cell dysfunction. Ann. N. Y. Acad. Sci. 1011, 168-176 (2004).

29. Flores, Jesús, Juan Antonio Armijo \& África Mediavilla. Farmacología humana. (ELSEVIER España, S.A., 2004).

30. Tolosa, M. J. A. Efecto de drogas antidiabéticas sobre la diferenciación de células progenitoras de médula ósea y la microarquitectura de tejido óseo de rata. (Facultad de Ciencias Exactas, 2013).

31. Aiello E. - Bases ionicas, moleculares y geneticas del sindrome del QT prolongado. Available at: http://www.fac.org.ar/revista/01v30n1/aiello/aiello.htm. (Accessed: 18th November 2015)

32. Amira Ponce Zumino, Elena Ruiz-Petrich, Ernesto Aiello. Origen y propagación del impulso cardíaco. Actividad eléctrica del corazón. in Fisiología Humana 246-256 (El ateneo).

33. Cho, J. H. et al. Delayed Repolarization Underlies Ventricular Arrhythmias in Rats With Heart Failure and Preserved Ejection Fraction. Circulation 136, $2037-$ 2050 (2017).

34. Hiraoka, M., Kawano, S., Hirano, Y. \& Furukawa, T. Role of cardiac chloride currents in changes in action potential characteristics and arrhythmias. Cardiovasc. Res. 40, 23-33 (1998).

35. Faivre, J. F. \& Findlay, I. Action potential duration and activation of ATPsensitive potassium current in isolated guinea-pig ventricular myocytes. Biochim. Biophys. Acta 1029, 167-172 (1990).

36. Ottolia, M., Torres, N., Bridge, J. H. B., Philipson, K. D. \& Goldhaber, J. I. $\mathrm{Na} / \mathrm{Ca}$ exchange and contraction of the heart. J. Mol. Cell. Cardiol. 61, 28-33 (2013).

37. Chen, P.-S. et al. The Initiation of the Heart Beat. Circ. J. 74, 221-225 (2010). 
38. Tamargo, J. et al. Efectos del óxido nítrico sobre la función cardíaca. Rev. Esp. Cardiol. 6, 3-20 (2006).

39. Antiarrítmicos $\mid$ Goodman \& Gilman. Manual de farmacología y terapéutica, 2e | AccessMedicina | McGraw-Hill Medical. Available at:

http://accessmedicina.mhmedical.com/content.aspx?bookid=1468\&sectionid=934947

04. (Accessed: 27th February 2018)

40. Sadayappan, S. \& de Tombe, P. P. Cardiac myosin binding protein-C: redefining its structure and function. Biophys. Rev. 4, 93-106 (2012).

41. Alicia R. Mattiazzi. Músculo esquelético, cardiaco y liso. in Fisiología Humana 59-93 (El ateneo, 2000).

42. Navarro-López, F. Miocardiopatía hipertrófica. Bases genéticas e implicaciones clínicas. Rev. Esp. Cardiol. 57, 22-32 (2004).

43. Rueda, A., de Alba-Aguayo, D. R. \& Valdivia, H. H. [Ryanodine receptor, calcium leak and arrhythmias]. Arch. Cardiol. México 84, 191-201 (2014).

44. A Fabiato \& Fabiato, and F. Calcium and Cardiac Excitation-Contraction Coupling. Annu. Rev. Physiol. 41, 473-484 (1979).

45. Luo, M. \& Anderson, M. E. Mechanisms of Altered Ca2+ Handling in Heart Failure. Circ. Res. 113, 690-708 (2013).

46. Hofmann, F., Flockerzi, V., Kahl, S. \& Wegener, J. W. L-Type CaV1.2 Calcium Channels: From In Vitro Findings to In Vivo Function. Physiol. Rev. 94, 303-326 (2014).

47. Rios, E. El “cuplón”; unidad funcional del acoplamiento contráctil. AnFaMed 1, $5-28(2014)$.

48. Niggli, E. et al. Posttranslational modifications of cardiac ryanodine receptors: Ca2+ signaling and EC-coupling. Biochim. Biophys. Acta 1833, 866-875 (2013). 
49. Niggli, E. et al. Posttranslational modifications of cardiac ryanodine receptors: $\mathrm{Ca} 2+$ signaling and EC-coupling. Biochim. Biophys. Acta BBA - Mol. Cell Res. 1833, 866-875 (2013).

50. Zhang, H. et al. Hyperphosphorylation of the cardiac ryanodine receptor at serine 2808 is not involved in cardiac dysfunction after myocardial infarction. Circ. Res. 110, 831-840 (2012).

51. Kranias, E. G. \& Hajjar, R. J. Modulation of Cardiac Contractility by the Phopholamban/SERCA2a Regulatome. Circ. Res. 110, 1646-1660 (2012).

52. Dan, P., Lin, E., Huang, J., Biln, P. \& Tibbits, G. F. Three-Dimensional Distribution of Cardiac $\mathrm{Na}+-\mathrm{Ca} 2+$ Exchanger and Ryanodine Receptor during Development. Biophys. J. 93, 2504-2518 (2007).

53. Jayasinghe, I. D., Cannell, M. B. \& Soeller, C. Organization of ryanodine receptors, transverse tubules, and sodium-calcium exchanger in rat myocytes. Biophys. J. 97, 2664-2673 (2009).

54. Pitts, B. J. Stoichiometry of sodium-calcium exchange in cardiac sarcolemmal vesicles. Coupling to the sodium pump. J. Biol. Chem. 254, 6232-6235 (1979).

55. Shattock, M. J. et al. $\mathrm{Na}+/ \mathrm{Ca} 2+$ exchange and $\mathrm{Na}+/ \mathrm{K}+-\mathrm{ATPase}$ in the heart. $J$. Physiol. 593, 1361-1382 (2015).

56. Song, L.-S. et al. $\beta$-Adrenergic Stimulation Synchronizes Intracellular Ca2+ Release During Excitation-Contraction Coupling in Cardiac Myocytes. Circ. Res. 88, 794-801 (2001).

57. Zipes, Libby, Bonow \& Braunwald. Tratatdo de cardiologia. 1, (ELSEVIER España, S.A., 2013).

58. Types of Arrhythmia - NHLBI, NIH. Available at: http://www.nhlbi.nih.gov/health/health-topics/topics/arr/types\#. (Accessed: 26th November 2015) 
59. Healey, J. S. \& Connolly, S. J. Atrial fibrillation: hypertension as a causative agent, risk factor for complications, and potential therapeutic target. Am. J. Cardiol. 91, 9-14 (2003).

60. Lokshyn, S., Mewis, C. \& Kuhlkamp, V. Atrial fibrillation in coronary artery disease. Int. J. Cardiol. 72, 133-136 (2000).

61. Sharma, S. K. \& Verma, S. H. A Clinical Evaluation of Atrial Fibrillation in Rheumatic Heart Disease. J. Assoc. Physicians India 63, 22-25 (2015).

62. Li, J. et al. The Role of Inflammation and Oxidative Stress in Atrial Fibrillation. Heart Rhythm Off. J. Heart Rhythm Soc. 7, 438-444 (2010).

63. Bers, D. M. Cardiac Sarcoplasmic Reticulum Calcium Leak: Basis and Roles in Cardiac Dysfunction. Annu. Rev. Physiol. 76, 107-127 (2014).

64. Venetucci, L. A., Trafford, A. W. \& Eisner, D. A. Increasing Ryanodine Receptor Open Probability Alone Does Not Produce Arrhythmogenic Calcium Waves Threshold Sarcoplasmic Reticulum Calcium Content Is Required. Circ. Res. 100, 105-111 (2007).

65. Vermeulen, J. T. Mechanisms of Arrhythmias in Heart Failure. J. Cardiovasc. Electrophysiol. 9, 208-221 (1998).

66. Pogwizd, S. M., Schlotthauer, K., Li, L., Yuan, W. \& Bers, D. M. Arrhythmogenesis and Contractile Dysfunction in Heart Failure Roles of SodiumCalcium Exchange, Inward Rectifier Potassium Current, and Residual $\beta$-Adrenergic Responsiveness. Circ. Res. 88, 1159-1167 (2001).

67. Antzelevitch, C. \& Burashnikov, A. Overview of Basic Mechanisms of Cardiac Arrhythmia. Card. Electrophysiol. Clin. 3, 23-45 (2011).

68. Weiss, J. N., Garfinkel, A., Karagueuzian, H. S., Chen, P.-S. \& Qu, Z. Early Afterdepolarizations and Cardiac Arrhythmias. Heart Rhythm Off. J. Heart Rhythm Soc. 7, 1891-1899 (2010). 
69. Role of CaMKII and PKA in Early Afterdepolarization of Human Ventricular Myocardium Cell: A Computational Model Study. Available at: https://www.ncbi.nlm.nih.gov/pmc/articles/PMC5178856/. (Accessed: 2nd February 2018)

70. Early after/depolarizations and triggered activity: mechanisms and autonomic regulation - Charpentier - 2009 - Fundamental \& Clinical Pharmacology - Wiley Online Library. Available at: http://onlinelibrary.wiley.com/doi/10.1111/j.14728206.1993.tb00216.x/abstract. (Accessed: 4th February 2016)

71. Nattel, S. \& Dobrev, D. The multidimensional role of calcium in atrial fibrillation pathophysiology: mechanistic insights and therapeutic opportunities. Eur. Heart J. 33, 1870-1877 (2012).

72. Kannel, W. B. \& McGee, D. L. Diabetes and cardiovascular disease. The Framingham study. JAMA 241, 2035-2038 (1979).

73. Bertoni, A. G., Tsai, A., Kasper, E. K. \& Brancati, F. L. Diabetes and idiopathic cardiomyopathy: a nationwide case-control study. Diabetes Care 26, 2791-2795 (2003).

74. Uusitupa, M. I., Mustonen, J. N. \& Airaksinen, K. E. Diabetic heart muscle disease. Ann. Med. 22, 377-386 (1990).

75. Laclaustra Gimeno, M., Bergua Martínez, C., Pascual Calleja, I. \& Casasnovas Lenguas, J. A. Síndrome metabólico. Concepto y fisiopatología. Rev. Esp. Cardiol. 5, 3-10 (2006).

76. Christoffersen, C. et al. Cardiac lipid accumulation associated with diastolic dysfunction in obese mice. Endocrinology 144, 3483-3490 (2003).

77. Semeniuk, L. M., Kryski, A. J. \& Severson, D. L. Echocardiographic assessment of cardiac function in diabeticdb/db and transgenic $\mathrm{db} / \mathrm{db}$-hGLUT4 mice. Am. $J$. Physiol. - Heart Circ. Physiol. 283, H976-H982 (2002). 
78. Aasum, E. et al. Cardiac function and metabolism in Type 2 diabetic mice after treatment with BM 17.0744, a novel PPAR-alpha activator. Am. J. Physiol. Heart Circ. Physiol. 283, H949-957 (2002).

79. Levelt, E. et al. Relationship between Left Ventricular Structural and Metabolic Remodelling in Type 2 Diabetes Mellitus. Diabetes 65, 44-52 (2016).

80. María E. Batista Álvarez. Enfermedad muscular cardíaca diabética. Rev Cubana Endocrinol 9, 132-148 (1998).

81. Aasum, E., Hafstad, A. D., Severson, D. L. \& Larsen, T. S. Age-dependent changes in metabolism, contractile function, and ischemic sensitivity in hearts from db/db mice. Diabetes 52, 434-441 (2003).

82. Boudina, S. \& Abel, E. D. Diabetic Cardiomyopathy Revisited. Circulation 115, 3213-3223 (2007).

83. Herrero, P. et al. Increased Myocardial Fatty Acid Metabolism in Patients With Type 1 Diabetes Mellitus. J. Am. Coll. Cardiol. 47, 598-604 (2006).

84. Doria, A., Nosadini, R., Avogaro, A., Fioretto, P. \& Crepaldi, G. Myocardial metabolism in type 1 diabetic patients without coronary artery disease. Diabet. Med. J. Br. Diabet. Assoc. 8 Spec No, S104-107 (1991).

85. Peterson, L. R. et al. Effect of Obesity and Insulin Resistance on Myocardial Substrate Metabolism and Efficiency in Young Women. Circulation 109, 2191-2196 (2004).

86. Dhalla, N. S., Liu, X., Panagia, V. \& Takeda, N. Subcellular remodeling and heart dysfunction in chronic diabetes. Cardiovasc. Res. 40, 239-247 (1998).

87. Spector, K. S. Diabetic cardiomyopathy. Clin. Cardiol. 21, 885-887 (1998).

88. Tziakas, D. N., Chalikias, G. K. \& Kaski, J. C. Epidemiology of the diabetic heart. Coron. Artery Dis. 16 Suppl 1, S3-S10 (2005). 
89. Boudina, S. \& Abel, E. D. Diabetic cardiomyopathy, causes and effects. Rev. Endocr. Metab. Disord. 11, 31-39 (2010).

90. Carley, A. N. \& Severson, D. L. Fatty acid metabolism is enhanced in type 2 diabetic hearts. Biochim. Biophys. Acta BBA - Mol. Cell Biol. Lipids 1734, 112-126 (2005).

91. Lopaschuk, G. D. Metabolic abnormalities in the diabetic heart. Heart Fail. Rev. 7, 149-159 (2002).

92. Taegtmeyer, H., McNulty, P. \& Young, M. E. Adaptation and Maladaptation of the Heart in Diabetes: Part I General Concepts. Circulation 105, 1727-1733 (2002).

93. Stanley, W. C., Lopaschuk, G. D. \& McCormack, J. G. Regulation of energy substrate metabolism in the diabetic heart. Cardiovasc. Res. 34, 25-33 (1997).

94. Sharma, S. et al. Intramyocardial lipid accumulation in the failing human heart resembles the lipotoxic rat heart. FASEB J. 18, 1692-1700 (2004).

95. McGavock, J. M., Victor, R. G., Unger, R. H. \& Szczepaniak, L. S. Adiposity of the Heart*, Revisited. Ann. Intern. Med. 144, 517-524 (2006).

96. Szczepaniak, L. S. et al. Myocardial triglycerides and systolic function in humans: In vivo evaluation by localized proton spectroscopy and cardiac imaging. Magn. Reson. Med. 49, 417-423 (2003).

97. Finck, B. N. et al. The cardiac phenotype induced by PPAR $\alpha$ overexpression mimics that caused by diabetes mellitus. J. Clin. Invest. 109, 121-130 (2002).

98. Finck, B. N. et al. A critical role for PPAR $\alpha$-mediated lipotoxicity in the pathogenesis of diabetic cardiomyopathy: Modulation by dietary fat content. Proc. Natl. Acad. Sci. 100, 1226-1231 (2003).

99. Duncan, J. G., Fong, J. L., Medeiros, D. M., Finck, B. N. \& Kelly, D. P. InsulinResistant Heart Exhibits a Mitochondrial Biogenic Response Driven by the 
Peroxisome Proliferator-Activated Receptor- $\alpha /$ PGC-1 $\alpha$ Gene Regulatory Pathway. Circulation 115, 909-917 (2007).

100. Yang, J. et al. CD36 Deficiency Rescues Lipotoxic Cardiomyopathy. Circ. Res. 100, 1208-1217 (2007).

101. PPAR Gamma and Metabolism. Medscape Available at: http://www.medscape.com/viewarticle/461349. (Accessed: 12th January 2016)

102. Carley, A. N. et al. Treatment of type 2 diabetic $\mathrm{db} / \mathrm{db}$ mice with a novel PPAR $\gamma$ agonist improves cardiac metabolism but not contractile function. Am. J. Physiol. Endocrinol. Metab. 286, E449-E455 (2004).

103. Coort, S. L. M. et al. Enhanced Sarcolemmal FAT/CD36 Content and Triacylglycerol Storage in Cardiac Myocytes From Obese Zucker Rats. Diabetes 53, $1655-1663$ (2004).

104. Belke, D. D. et al. Insulin signaling coordinately regulates cardiac size, metabolism, and contractile protein isoform expression. J. Clin. Invest. 109, 629-639 (2002).

105. Belke, D. D., Larsen, T. S., Gibbs, E. M. \& Severson, D. L. Altered metabolism causes cardiac dysfunction in perfused hearts from diabetic $(\mathrm{db} / \mathrm{db})$ mice. Am. $J$. Physiol. - Endocrinol. Metab. 279, E1104-E1113 (2000).

106. Boudina, S. et al. Reduced Mitochondrial Oxidative Capacity and Increased Mitochondrial Uncoupling Impair Myocardial Energetics in Obesity. Circulation 112, 2686-2695 (2005).

107. Buchanan, J. et al. Reduced cardiac efficiency and altered substrate metabolism precedes the onset of hyperglycemia and contractile dysfunction in two mouse models of insulin resistance and obesity. Endocrinology 146, 5341-5349 (2005).

108. Mazumder, P. K. et al. Impaired cardiac efficiency and increased fatty acid oxidation in insulin-resistant ob/ob mouse hearts. Diabetes 53, 2366-2374 (2004). 
109. How, O.-J. et al. Increased Myocardial Oxygen Consumption Reduces Cardiac Efficiency in Diabetic Mice. Diabetes 55, 466-473 (2006).

110. Durgan, D. J. et al. Distinct transcriptional regulation of long-chain acyl-CoA synthetase isoforms and cytosolic thioesterase 1 in the rodent heart by fatty acids and insulin. Am. J. Physiol. - Heart Circ. Physiol. 290, H2480-H2497 (2006).

111. Stavinoha, M. A. et al. Evidence for mitochondrial thioesterase 1 as a peroxisome proliferator-activated receptor- $\alpha$-regulated gene in cardiac and skeletal muscle. Am. J. Physiol. - Endocrinol. Metab. 287, E888-E895 (2004).

112. Zhao, X.-Y. et al. Decreased cardiac sarcoplasmic reticulum Ca2+-ATPase activity contributes to cardiac dysfunction in streptozotocin-induced diabetic rats. $J$. Physiol. Biochem. 62, 1-8 (2006).

113. Lopaschuk, G. D., Tahiliani, A. G., Vadlamudi, R. V., Katz, S. \& McNeill, J. H. Cardiac sarcoplasmic reticulum function in insulin- or carnitine-treated diabetic rats. Am. J. Physiol. - Heart Circ. Physiol. 245, H969-H976 (1983).

114. Pierce, G. N. \& Dhalla, N. S. Cardiac myofibrillar ATPase activity in diabetic rats. J. Mol. Cell. Cardiol. 13, 1063-1069 (1981).

115. Choi, K. M. et al. Defective intracellular Ca2+ signaling contributes to cardiomyopathy in Type 1 diabetic rats. Am. J. Physiol. - Heart Circ. Physiol. 283, H1398-H1408 (2002).

116. Pereira, L. et al. Mechanisms of $[\mathrm{Ca} 2+] \mathrm{i}$ Transient Decrease in Cardiomyopathy of db/db Type 2 Diabetic Mice. Diabetes 55, 608-615 (2006).

117. Akbarzadeh, A. et al. Induction of diabetes by Streptozotocin in rats. Indian J. Clin. Biochem. 22, 60-64 (2007).

118. op den Buijs, J. et al. beta-Adrenergic activation reveals impaired cardiac calcium handling at early stage of diabetes. Life Sci. 76, 1083-1098 (2005). 
119. Fiordaliso, F. et al. Myocyte death in streptozotocin-induced diabetes in rats in angiotensin II- dependent. Lab. Investig. J. Tech. Methods Pathol. 80, 513-527 (2000).

120. Khatter, J. C., Sadri, P., Zhang, M. \& Hoeschen, R. J. Myocardial Angiotensin II (Ang II) Receptors in Diabetic Rats. Ann. N. Y. Acad. Sci. 793, 466-472 (1996).

121. Frustaci, A. et al. Myocardial Cell Death in Human Diabetes. Circ. Res. 87, 1123-1132 (2000).

122. Cai, L. et al. Attenuation by Metallothionein of Early Cardiac Cell Death via Suppression of Mitochondrial Oxidative Stress Results in a Prevention of Diabetic Cardiomyopathy. J. Am. Coll. Cardiol. 48, 1688-1697 (2006).

123. Cai, L. Suppression of nitrative damage by metallothionein in diabetic heart contributes to the prevention of cardiomyopathy. Free Radic. Biol. Med. 41, 851-861 (2006).

124. Madamanchi, N. R. \& Runge, M. S. Redox signaling in cardiovascular health and disease. Free Radic. Biol. Med. 0, 473-501 (2013).

125. Ansley, D. M. \& Wang, B. Oxidative stress and myocardial injury in the diabetic heart. J. Pathol. 229, 232-241 (2013).

126. Shen, X., Zheng, S., Metreveli, N. S. \& Epstein, P. N. Protection of Cardiac Mitochondria by Overexpression of MnSOD Reduces Diabetic Cardiomyopathy. Diabetes 55, 798-805 (2006).

127. Saraiva, R. M. et al. Reduced neuronal nitric oxide synthase expression contributes to cardiac oxidative stress and nitroso-redox imbalance in ob/ob mice. Nitric Oxide 16, 331-338 (2007).

128. Li, S.-Y. et al. Cardiac contractile dysfunction in Lep/Lep obesity is accompanied by NADPH oxidase activation, oxidative modification of 
sarco(endo)plasmic reticulum Ca2+-ATPase and myosin heavy chain isozyme switch. Diabetologia 49, 1434-1446 (2006).

129. Kwon, S. H., Pimentel, D. R., Remondino, A., Sawyer, D. B. \& Colucci, W. S. $\mathrm{H} 2 \mathrm{O} 2$ regulates cardiac myocyte phenotype via concentration-dependent activation of distinct kinase pathways. J. Mol. Cell. Cardiol. 35, 615-621 (2003).

130. Savabi, F. Mitochondrial creatine phosphokinase deficiency in diabetic rat heart. Biochem. Biophys. Res. Commun. 154, 469-475 (1988).

131. Awaji, Y. et al. Isoenzyme profiles of creatine kinase, lactate dehydrogenase, and aspartate aminotransferase in the diabetic heart: comparison with hereditary and catecholamine cardiomyopathies. Cardiovasc. Res. 24, 547-554 (1990).

132. Pierce, G. N. \& Dhalla, N. S. Heart mitochondrial function in chronic experimental diabetes in rats. Can. J. Cardiol. 1, 48-54 (1985).

133. Tanaka, Y., Konno, N. \& Kako, K. J. Mitochondrial dysfunction observed in situ in cardiomyocytes of rats in experimental diabetes. Cardiovasc. Res. 26, 409-414 (1992).

134. Oliveira, P. J. et al. Enhanced permeability transition explains the reduced calcium uptake in cardiac mitochondria from streptozotocin-induced diabetic rats. FEBS Lett. 554, 511-514 (2003).

135. Boudina, S. \& Abel, E. D. Mitochondrial uncoupling: a key contributor to reduced cardiac efficiency in diabetes. Physiol. Bethesda Md 21, 250-258 (2006).

136. Turko, I. V. et al. Protein Tyrosine Nitration in the Mitochondria from Diabetic Mouse Heart IMPLICATIONS TO DYSFUNCTIONAL MITOCHONDRIA IN DIABETES. J. Biol. Chem. 278, 33972-33977 (2003).

137. Ghosh, S. et al. Cardiomyocyte apoptosis induced by short-term diabetes requires mitochondrial GSH depletion. Am. J. Physiol. - Heart Circ. Physiol. 289, H768-H776 (2005). 
138. Shen, X. et al. Cardiac mitochondrial damage and biogenesis in a chronic model of type 1 diabetes. Am. J. Physiol. - Endocrinol. Metab. 287, E896-E905 (2004).

139. Leone, T. C. et al. PGC-1 $\alpha$ Deficiency Causes Multi-System Energy Metabolic Derangements: Muscle Dysfunction, Abnormal Weight Control and Hepatic Steatosis. PLoS Biol 3, e101 (2005).

140. Lin, J. et al. Defects in adaptive energy metabolism with CNS-linked hyperactivity in PGC-1alpha null mice. Cell 119, 121-135 (2004).

141. Gerardo Reyes Delgado, Carlos Martínez Bohórquez, Lucia Flores Gómez \& José Martín Torres Benítez. Hallazgos Electrocardiográficos en Diabéticos Hospitalizados sin Cardiopatías Previas. Rev. Esc. Med. "DR JOSÉ SIERRA FLORES” Univ. NORESTE 8-16,

142. De Bacquer, D., De Backer, G., Kornitzer, M. \& Blackburn, H. Prognostic value of ECG findings for total, cardiovascular disease, and coronary heart disease death in men and women. Heart 80, 570-577 (1998).

143. de Santiago Nocito, A. M., García Lledó, A., Ramos Lledó, E. \& Santiago González, C. Valor pronóstico de las alteraciones electrocardiográficas en pacientes diabéticos tipo 2 asintomáticos desde el punto de vista cardiovascular. SEMERGEN Med. Fam. 30, 375-381 (2004).

144. Bakth, S. et al. Arrhythmia susceptibility and myocardial composition in diabetes. Influence of physical conditioning. J. Clin. Invest. 77, 382-395 (1986).

145. Malmberg, K. et al. Impact of Diabetes on Long-Term Prognosis in Patients With Unstable Angina and Non-Q-Wave Myocardial Infarction Results of the OASIS (Organization to Assess Strategies for Ischemic Syndromes) Registry. Circulation 102, 1014-1019 (2000).

146. Nakou, E. S., Mavrakis, H. \& Vardas, P. E. Are diabetic patients at increased risk of arrhythmias. Hell. J Cardiol 53, 335-339 (2012). 
147. Zhang, Y. et al. Ionic mechanisms underlying abnormal QT prolongation and the associated arrhythmias in diabetic rabbits: a role of rapid delayed rectifier $\mathrm{K}+$ current. Cell. Physiol. Biochem. Int. J. Exp. Cell. Physiol. Biochem. Pharmacol. 19, 225-238 (2007).

148. Nordin, C., Gilat, E. \& Aronson, R. S. Delayed afterdepolarizations and triggered activity in ventricular muscle from rats with streptozotocin-induced diabetes. Circ. Res. 57, 28-34 (1985).

149. Dekker, J. M. et al. QTc Duration is Associated With Levels of Insulin and Glucose Tolerance: The Zutphen Elderly Study. Diabetes 45, 376-380 (1996).

150. Greer, J. J. M., Ware, D. P. \& Lefer, D. J. Myocardial infarction and heart failure in the $\mathrm{db} / \mathrm{db}$ diabetic mouse. Am. J. Physiol. Heart Circ. Physiol. 290, H146$153(2006)$.

151. Rigolli, M. \& Whalley, G. A. Heart failure with preserved ejection fraction. $J$. Geriatr. Cardiol. JGC 10, 369-376 (2013).

152. Røe, Å. T., Frisk, M. \& Louch, W. E. Targeting Cardiomyocyte Ca2+ Homeostasis in Heart Failure. Curr. Pharm. Des. 21, 431-448 (2015).

153. Olivetti, G. et al. Apoptosis in the Failing Human Heart. N. Engl. J. Med. 336, 1131-1141 (1997).

154. Arends, M. J., Morris, R. G. \& Wyllie, A. H. Apoptosis. The role of the endonuclease. Am. J. Pathol. 136, 593-608 (1990).

155. Empel, V. et al. Myocyte apoptosis in heart failure. Cardiovasc. Res. 67, 21-29 (2005).

156. Elmore, S. Apoptosis: A Review of Programmed Cell Death. Toxicol. Pathol. 35, 495-516 (2007). 
157. Brookes, P. S., Yoon, Y., Robotham, J. L., Anders, M. W. \& Sheu, S.-S. Calcium, ATP, and ROS: a mitochondrial love-hate triangle. Am. J. Physiol. - Cell Physiol. 287, C817-C833 (2004).

158. Uchida, Y. Molecular mechanisms of regeneration in Alzheimer's disease brain. Geriatr. Gerontol. Int. 10, S158-S168 (2010).

159. Bishopric, N. H., Andreka, P., Slepak, T. \& Webster, K. A. Molecular mechanisms of apoptosis in the cardiac myocyte. Curr. Opin. Pharmacol. 1, 141-150 (2001).

160. Ashkenazi, A. \& Dixit, V. M. Death Receptors: Signaling and Modulation. Science 281, 1305-1308 (1998).

161. Baines, C. P. \& Molkentin, J. D. STRESS signaling pathways that modulate cardiac myocyte apoptosis. J. Mol. Cell. Cardiol. 38, 47-62 (2005).

162. El poro de transición de permeabilidad mitocondrial (PTPm) como blanco de estrategias cardioprotectoras en daño por isquemia-reperfusión miocárdica: rol de los anestésicos inhalatorios. Revista Chilena de Anestesia (2016).

163. Hong, J., Kim, K., Kim, J.-H. \& Park, Y. The Role of Endoplasmic Reticulum Stress in Cardiovascular Disease and Exercise. International Journal of Vascular Medicine (2017). doi:10.1155/2017/2049217

164. Luca Scorrano, S. J. K. Scorrano L, Korsmeyer SJ.. Mechanisms of cytochrome c release by proapoptotic BCL-2 family members. Biochem Biophys Res Commun 304: 437-444. Biochem. Biophys. Res. Commun. 304, 437-44 (2003).

165. Counis, M.-F. \& Torriglia, A. Acid DNases and their interest among apoptotic endonucleases. Biochimie 88, 1851-1858 (2006).

166. Barouch, L. A. et al. Cardiac Myocyte Apoptosis Is Associated With Increased DNA Damage and Decreased Survival in Murine Models of Obesity. Circ. Res. 98, 119-124 (2006). 
167. Shen, E. et al. Rac1 Is Required for Cardiomyocyte Apoptosis During Hyperglycemia. Diabetes 58, 2386-2395 (2009).

168. Anderson, E. J. et al. Increased propensity for cell death in diabetic human heart is mediated by mitochondrial-dependent pathways. Am. J. Physiol. - Heart Circ. Physiol. 300, H118-H124 (2011).

169. Gray, C. B. B. \& Heller Brown, J. CaMKIIdelta subtypes: localization and function. Front. Pharmacol. 5, (2014).

170. Erickson, J. R. Mechanisms of CaMKII Activation in the Heart. Front. Pharmacol. 5, (2014).

171. Gaertner, T. R. et al. Comparative Analyses of the Three-dimensional Structures and Enzymatic Properties of $\alpha, \beta, \gamma$, and $\delta$ Isoforms of Ca2+-Calmodulin-dependent Protein Kinase II. J. Biol. Chem. 279, 12484-12494 (2004).

172. Rostas, J. A. P. \& Dunkley, P. R. Multiple Forms and Distribution of Calcium/Calmodulin-Stimulated Protein Kinase II in Brain. J. Neurochem. 59, 11911202 (1992).

173. Meyer, T., Hanson, P. I., Stryer, L. \& Schulman, H. Calmodulin Trapping by Calcium-Calmodulin-Dependent Protein Kinase. Science 256, 1199-1202 (1992).

174. Lai, Y., Nairn, A. C., Gorelick, F. \& Greengard, P. Ca2+/calmodulin-dependent protein kinase II: identification of autophosphorylation sites responsible for generation of $\mathrm{Ca} 2+/$ calmodulin-independence. Proc. Natl. Acad. Sci. U. S. A. 84, 5710-5714 (1987).

175. Erickson, J. R. et al. A Dynamic Pathway for Calcium-Independent Activation of CaMKII by Methionine Oxidation. Cell 133, 462-474 (2008).

176. Hart, G. W., Housley, M. P. \& Slawson, C. Cycling of O-linked $\beta-N-$ acetylglucosamine on nucleocytoplasmic proteins. Nature 446, 1017-1022 (2007). 
177. Erickson, J. R. et al. Diabetic hyperglycaemia activates CaMKII and arrhythmias by O-linked glycosylation. Nature 502, 372-376 (2013).

178. Gutierrez, D. A., Fernandez-Tenorio, M., Ogrodnik, J. \& Niggli, E. NOdependent CaMKII activation during $\beta$-adrenergic stimulation of cardiac muscle. Cardiovasc. Res. 100, 392-401 (2013).

179. Zhang, D.-M. et al. Intracellular signalling mechanism responsible for modulation of sarcolemmal ATP-sensitive potassium channels by nitric oxide in ventricular cardiomyocytes. J. Physiol. 592, 971-990 (2014).

180. Li, L., Satoh, H., Ginsburg, K. S. \& Bers, D. M. The effect of Ca2+-calmodulindependent protein kinase II on cardiac excitation-contraction coupling in ferret ventricular myocytes. J. Physiol. 501, 17-31 (1997).

181. Pellicena, P. \& Schulman, H. CaMKII inhibitors: from research tools to therapeutic agents. Front. Pharmacol. 5, (2014).

182. Mazzocchi, G. et al. Phospholamban ablation rescues the enhanced propensity to arrhythmias of mice with CaMKII-constitutive phosphorylation of RyR2 at site S2814. J. Physiol. 594, 3005-3030 (2016).

183. Maier, L. S. \& Bers, D. M. Role of Ca2+/calmodulin-dependent protein kinase (CaMK) in excitation-contraction coupling in the heart. Cardiovasc. Res. 73, 631640 (2007).

184. Sun, A. Y. \& Pitt, G. S. Pinning down the CaMKII targets in the L-type Ca2+ channel: an essential step in defining CaMKII regulation. Heart Rhythm Off. J. Heart Rhythm Soc. 8, 631-633 (2011).

185. Greenstein, J. L., Foteinou, P. T., Hashambhoy-Ramsay, Y. L. \& Winslow, R. L. Modeling CaMKII-mediated regulation of L-type Ca2+ channels and ryanodine receptors in the heart. Front. Pharmacol. 5, (2014). 
186. Guo, T., Zhang, T., Mestril, R. \& Bers, D. M. Ca2+/Calmodulin-Dependent Protein Kinase II Phosphorylation of Ryanodine Receptor Does Affect Calcium Sparks in Mouse Ventricular Myocytes. Circ. Res. 99, 398-406 (2006).

187. Chelu, M. G. et al. Calmodulin kinase II-mediated sarcoplasmic reticulum Ca2+ leak promotes atrial fibrillation in mice. J. Clin. Invest. 119, 1940-1951 (2009).

188. McCauley, M. D. \& Wehrens, X. H. T. Ryanodine Receptor Phosphorylation, Calcium/Calmodulin-dependent Protein Kinase II, and Life-threatening Ventricular Arrhythmias. Trends Cardiovasc. Med. 21, 48-51 (2011).

189. Mattiazzi, A. et al. Chasing cardiac physiology and pathology down the CaMKII cascade. Am. J. Physiol. - Heart Circ. Physiol. 308, H1177-H1191 (2015).

190. Wagner, S. et al. Ca2+/calmodulin-dependent protein kinase II regulates cardiac $\mathrm{Na}+$ channels. J. Clin. Invest. 116, 3127-3138 (2006).

191. Weber, C. R., Piacentino, V., Houser, S. R. \& Bers, D. M. Dynamic Regulation of Sodium/Calcium Exchange Function in Human Heart Failure. Circulation 108, $2224-2229$ (2003).

192. Sossalla, S. et al. Diastolic dysfunction and arrhythmias caused by overexpression of CaMKIISC can be reversed by inhibition of late $\mathrm{Na}+$ current. Basic Res. Cardiol. 106, 263-272 (2011).

193. Grandi, E. \& Herren, A. W. CaMKII-dependent regulation of cardiac $\mathrm{Na}+$ homeostasis. Front. Pharmacol. 5, (2014).

194. Liu, T. \& O’Rourke, B. Enhancing Mitochondrial Ca2+ Uptake in Myocytes From Failing Hearts Restores Energy Supply and Demand Matching. Circ. Res. 103, 279-288 (2008).

195. Mustroph, J., Maier, L. S. \& Wagner, S. CaMKII regulation of cardiac K channels. Front. Pharmacol. 5, (2014). 
196. Wagner, S. et al. Ca/Calmodulin Kinase II Differentially Modulates Potassium Currents. Circ. Arrhythm. Electrophysiol. 2, 285-294 (2009).

197. Roeper, J., Lorra, C. \& Pongs, O. Frequency-Dependent Inactivation of Mammalian A-Type K+ Channel KV1.4 Regulated by Ca2+/Calmodulin-Dependent Protein Kinase. J. Neurosci. 17, 3379-3391 (1997).

198. Varga, A. W. et al. Calcium-Calmodulin-Dependent Kinase II Modulates Kv4.2 Channel Expression and Upregulates Neuronal A-Type Potassium Currents. $J$. Neurosci. 24, 3643-3654 (2004).

199. Nagy, N. et al. [Ca2+]i-induced augmentation of the inward rectifier potassium current (IK1) in canine and human ventricular myocardium. Pflüg. Arch. - Eur. J. Physiol. 465, 1621-1635 (2013).

200. Bugger, H. \& Abel, E. D. Molecular mechanisms of diabetic cardiomyopathy. Diabetologia 57, 660-671 (2014).

201. Bugger, H. \& Abel, E. D. Rodent models of diabetic cardiomyopathy. Dis. Model. Mech. 2, 454-466 (2009).

202. Belke, D. D., Swanson, E. A. \& Dillmann, W. H. Decreased Sarcoplasmic Reticulum Activity and Contractility in Diabetic db/db Mouse Heart. Diabetes 53, $3201-3208$ (2004)

203. Purohit, A. et al. Oxidized Ca2+/Calmodulin-Dependent Protein Kinase II Triggers Atrial Fibrillation. Circulation 128, 1748-1757 (2013).

204. Song, Y., Shryock, J. C. \& Belardinelli, L. An increase of late sodium current induces delayed afterdepolarizations and sustained triggered activity in atrial myocytes. Am. J. Physiol. - Heart Circ. Physiol. 294, H2031-H2039 (2008).

205. Rebolledo, A. et al. Early alterations in vascular contractility associated to changes in fatty acid composition and oxidative stress markers in perivascular adipose tissue. Cardiovasc. Diabetol. 9, 65 (2010). 
206. Alzamendi, A. et al. Fructose-rich diet-induced abdominal adipose tissue endocrine dysfunction in normal male rats. Endocrine 35, 227-232 (2009).

207. Ji, Y. et al. Targeted Inhibition of Ca2+/Calmodulin-dependent Protein Kinase II in Cardiac Longitudinal Sarcoplasmic Reticulum Results in Decreased Phospholamban Phosphorylation at Threonine 17. J. Biol. Chem. 278, 25063-25071 (2003).

208. Reddan, J. et al. Tempol and deferoxamine protect cultured rabbit lens epithelial cells from $\mathrm{H} 2 \mathrm{O} 2$ insult: insight into the mechanism of $\mathrm{H} 2 \mathrm{O} 2$-induced injury. Lens Eye Toxic. Res. 9, 385-393 (1992).

209. ImageJ. Available at: https://imagej.nih.gov/ij/index.html. (Accessed: 17th February 2018)

210. Sahn, D. J., DeMaria, A., Kisslo, J. \& Weyman, A. Recommendations regarding quantitation in M-mode echocardiography: results of a survey of echocardiographic measurements. Circulation 58, 1072-1083 (1978).

211. Caiani, E. G. et al. Improved quantification of left ventricular mass based on endocardial and epicardial surface detection with real time three dimensional echocardiography. Heart 92, 213-219 (2006).

\section{TCO. LIC. JAVIER SANDRI. ELECTROCARDIOGRAFÍA.}

213. Gonano, L. A. et al. Calcium-calmodulin kinase II mediates digitalis-induced arrhythmias. Circ. Arrhythm. Electrophysiol. 4, 947-957 (2011).

214. Bazett, C. An Analysis of the Time Relationships of Electrocardiograms. Ann. Noninvasive Electrocardiol. 2, 177-194 (2006).

215. Di Carlo, M. N. et al. CaMKII-dependent phosphorylation of cardiac ryanodine receptors regulates cell death in cardiac ischemia/reperfusion injury. J. Mol. Cell. Cardiol. 74, 274-283 (2014). 
216. Krebs, H. A \& Henseleit, K. Formation of urea in the animal body. Hoppe. Seylers Z. Physiol. Chem. 210, 33-66 (1932).

217. Powell, T. The isolation and characterization of calcium-tolerant myocytes. Basic Res. Cardiol. 80 Suppl 2, 15-18 (1985).

218. Grzegorz Grynkiewicz, Martin Poenie \& Roger Tsien. A new generation of $\mathrm{Ca} 2+$ indicators with greatly improved fluorescence properties. Hournal Biol. Chem. 260, 3440-3450 (1985).

219. Kong, H. et al. Caffeine Induces Ca2+ Release by Reducing The Threshold for Luminal Ca2+ Activation of the Ryanodine Receptor. Biochem. J. 414, 441-452 (2008).

220. Leica, Microsystems. Available at: https://www.leicamicrosystems.com/es/productos/software-de-microscopia/detalles/product/leicaapplication-suite/. (Accessed: 31st January 2018)

221. Picht, E., Zima, A. V., Blatter, L. A. \& Bers, D. M. SparkMaster: automated calcium spark analysis with ImageJ. Am. J. Physiol. Cell Physiol. 293, C1073-1081 (2007).

222. Santiago, D. J. et al. Ca sparks do not explain all ryanodine receptor-mediated SR Ca leak in mouse ventricular myocytes. Biophys. J. 98, 2111-2120 (2010).

223. Bradford Protein Assay || Bio-Rad. Available at: http://www.bio-rad.com/esar/product/bradford-protein-assay. (Accessed: 31st January 2018)

224. In Situ Cell Death Detection Kit, TMR red | Sigma-Aldrich. Available at: https://www.sigmaaldrich.com/catalog/product/roche/12156792910?lang=es\&region $=$ AR. $($ Accessed: 31 st January 2018)

225. cellSens | Olympus Life Science. Available at: https://www.olympuslifescience.com/es/software/cellsens/. (Accessed: 31st January 2018) 
226. DAPI 4',6-Diamidine-2'-phenylindole dihydrochloride | Sigma-Aldrich.

Available at:

https://www.sigmaaldrich.com/catalog/product/roche/10236276001?lang=es\&region

$=$ AR\&gclid $=$ CjwKCAiA78XTBRBiEiwAGv7EKns18bk8uYxhZyASC030PzDz8Zzq

7_rgFFJ3WHzAgTR4RiAcxFq_xhoCqDMQAvD_BwE. (Accessed: 31st January

2018)

227. Le, S. B. et al. Inhibition of Mitochondrial Respiration as a Source of Adaphostin-induced Reactive Oxygen Species and Cytotoxicity. J. Biol. Chem. 282, $8860-8872$ (2007).

228. Pardo, A. C., Rinaldi, G. J. \& Mosca, S. M. Mitochondrial calcium handling in normotensive and spontaneously hypertensive rats: correlation with systolic blood pressure levels. Mitochondrion 20, 75-81 (2015).

229. Proteinase, bacterial P8038. Sigma-Aldrich Available at:

https://www.sigmaaldrich.com/catalog/product/sigma/p8038. (Accessed: 31st January 2018)

230. Baines, C. P. et al. Protein Kinase Ce Interacts With and Inhibits the Permeability Transition Pore in Cardiac Mitochondria. Circ. Res. 92, 873-880 (2003).

231. Abdallah, Y. et al. Interplay between $\mathrm{Ca} 2+$ cycling and mitochondrial permeability transition pores promotes reperfusion-induced injury of cardiac myocytes. J. Cell. Mol. Med. 15, 2478-2485 (2011).

232. GÓMEZ, M. C. X. \& CASTELLANOS SAN MARTIN, R. Fundamentos de las técnicas multivariantes. (UNED, 2004).

233. Avendano, G. F. et al. Effects of glucose intolerance on myocardial function and collagen-linked glycation. Diabetes 48, 1443-1447 (1999). 
234. Bugger, H. \& Abel, E. D. Mitochondria in the diabetic heart. Cardiovasc. Res. 88, 229-240 (2010).

235. Lukyanenko, V., Chikando, A. \& Lederer, W. J. Mitochondria in cardiomyocyte Ca2+ signaling. Int. J. Biochem. Cell Biol. 41, 1957-1971 (2009).

236. Litwak, L. et al. Prevalence of diabetes complications in people with type 2 diabetes mellitus and its association with baseline characteristics in the multinational Alchieve study. Diabetol. Metab. Syndr. 5, 57 (2013).

237. Buysschaert, M. \& Bergman, M. Definition of Prediabetes. Med. Clin. North Am. 95, 289-297 (2011).

238. Delbosc, S. et al. Involvement of oxidative stress and NADPH oxidase activation in the development of cardiovascular complications in a model of insulin resistance, the fructose-fed rat. Atherosclerosis 179, 43-49 (2005).

239. G Baret, J. P. Increased Intraabdominal Adipose Tissue Mass in Fructose Fed Rats: Correction by Metformin. Exp. Clin. Endocrinol. Amp Diabetes Off. J. Ger. Soc. Endocrinol. Ger. Diabetes Assoc. 110, 298-303 (2002).

240. Bouchard-Thomassin, A.-A., Lachance, D., Drolet, M.-C., Couet, J. \& Arsenault, M. A high-fructose diet worsens eccentric left ventricular hypertrophy in experimental volume overload. Am. J. Physiol. - Heart Circ. Physiol. 300, H125H134 (2011).

241. Wei, Y., Wang, D., Topczewski, F. \& Pagliassotti, M. J. Fructose-mediated stress signaling in the liver: implications for hepatic insulin resistance. $J$. Nutr. Biochem. 18, 1-9 (2007).

242. Unwin, N., Shaw, J., Zimmet, P. \& Alberti, K. G. M. M. Impaired glucose tolerance and impaired fasting glycaemia: The current status on definition and intervention. Diabet. Med. 19, 708-723 (2002). 
243. Curb, J. D. et al. Sudden Death, Impaired Glucose Tolerance, and Diabetes in Japanese American Men. Circulation 91, 2591-2595 (1995).

244. Schannwell, C. M., Schneppenheim, M., Perings, S., Plehn, G. \& Strauer, B. E. Left ventricular diastolic dysfunction as an early manifestation of diabetic cardiomyopathy. Cardiology 98, 33-39 (2002).

245. Robillon, J. F. et al. Assessment of cardiac arrhythmic risk in diabetic patients using QT dispersion abnormalities. Diabetes Metab. 25, 419-423 (1999).

246. Pereira, L. et al. Epac2 Mediates Cardiac $\beta 1$-Adrenergic Dependent SR Ca2+ Leak and Arrhythmia. Circulation 127, 913-922 (2013).

247. Vest, J. A. et al. Defective Cardiac Ryanodine Receptor Regulation During Atrial Fibrillation. Circulation 111, 2025-2032 (2005).

248. Wu, Y., Roden, D. M. \& Anderson, M. E. Calmodulin Kinase Inhibition Prevents Development of the Arrhythmogenic Transient Inward Current. Circ. Res. 84, 906-912 (1999).

249. Nishio, S. et al. Activation of CaMKII as a key regulator of reactive oxygen species production in diabetic rat heart. J. Mol. Cell. Cardiol. 52, 1103-1111 (2012).

250. Palomeque, J. et al. Angiotensin II-induced oxidative stress resets the $\mathrm{Ca} 2+$ dependence of $\mathrm{Ca} 2+$-calmodulin protein kinase II and promotes a death pathway conserved across different species. Circ. Res. 105, 1204-1212 (2009).

251. Curran, J. et al. Nitric Oxide-Dependent Activation of CaMKII Increases Diastolic Sarcoplasmic Reticulum Calcium Release in Cardiac Myocytes in Response to Adrenergic Stimulation. PLoS ONE 9, e87495 (2014).

252. Asghar, O. et al. Diabetic cardiomyopathy. Clin. Sci. 116, 741-760 (2009).

253. Ilercil, A. et al. Relationship of impaired glucose tolerance to left ventricular structure and function: The Strong Heart Study. Am. Heart J. 141, 992-998 (2001). 
254. Parry, H. M. et al. Genetic variants predicting left ventricular hypertrophy in a diabetic population: a Go-DARTS study including meta-analysis. Cardiovasc. Diabetol. 12, 109 (2013).

255. Struthers, A. D. \& Morris, A. D. Screening for and treating left-ventricular abnormalities in diabetes mellitus: a new way of reducing cardiac deaths. The Lancet 359, 1430-1432 (2002).

256. Cranefield, P. F. \& Aronson, R. S. Torsades de pointes and early afterdepolarizations. Cardiovasc. Drugs Ther. 5, 531-537 (1991).

257. Mészáros, J., Khananshvili, D. \& Hart, G. Mechanisms underlying delayed afterdepolarizations in hypertrophied left ventricular myocytes of rats. Am. J. Physiol. - Heart Circ. Physiol. 281, H903-H914 (2001).

258. Baartscheer, A., Schumacher, C. A., Belterman, C. N. W., Coronel, R. \& Fiolet, J. W. T. SR calcium handling and calcium after-transients in a rabbit model of heart failure. Cardiovasc. Res. 58, 99-108 (2003).

259. Baartscheer, A., Schumacher, C. A., Belterman, C. N. W., Coronel, R. \& Fiolet, J. W. T. $[\mathrm{Na}+] \mathrm{i}$ and the driving force of the $\mathrm{Na}+/ \mathrm{Ca} 2+$-exchanger in heart failure. Cardiovasc. Res. 57, 986-995 (2003).

260. Gray, R. P., McIntyre, H., Sheridan, D. S. \& Fry, C. H. Intracellular sodium and contractile function in hypertrophied human and guinea-pig myocardium. Pflüg. Arch. 442, 117-123 (2001).

261. Heather, L. C. \& Clarke, K. Metabolism, hypoxia and the diabetic heart. J. Mol. Cell. Cardiol. 50, 598-605 (2011).

262. Whelan, R. S., Kaplinskiy, V. \& Kitsis, R. N. Cell death in the pathogenesis of heart disease: mechanisms and significance. Annu. Rev. Physiol. 72, 19-44 (2010). 
263. Pinton, P., Giorgi, C., Siviero, R., Zecchini, E. \& Rizzuto, R. Calcium and apoptosis: ER-mitochondria Ca2 + transfer in the control of apoptosis. Oncogene 27, $6407-6418$ (2008).

264. Cai, L. et al. Hyperglycemia-induced apoptosis in mouse myocardium: mitochondrial cytochrome C-mediated caspase-3 activation pathway. Diabetes $\mathbf{5 1}$, 1938-1948 (2002).

265. Bäcklund, T. et al. Sustained cardiomyocyte apoptosis and left ventricular remodelling after myocardial infarction in experimental diabetes. Diabetologia $\mathbf{4 7}$, 325-330 (2004).

266. Zhu, W. et al. Activation of CaMKIIdeltaC is a common intermediate of diverse death stimuli-induced heart muscle cell apoptosis. J. Biol. Chem. 282, 10833-10839 (2007).

267. Chen, X. et al. Ca2+ influx-induced sarcoplasmic reticulum $\mathrm{Ca} 2+$ overload causes mitochondrial-dependent apoptosis in ventricular myocytes. Circ. Res. 97, 1009-1017 (2005).

268. Vila-Petroff, M. et al. CaMKII inhibition protects against necrosis and apoptosis in irreversible ischemia-reperfusion injury. Cardiovasc. Res. 73, 689-698 (2007).

269. Salas, M. A. et al. The signalling pathway of CaMKII-mediated apoptosis and necrosis in the ischemia/reperfusion injury. J. Mol. Cell. Cardiol. 48, 1298-1306 (2010).

270. Crow, M. T., Mani, K., Nam, Y.-J. \& Kitsis, R. N. The mitochondrial death pathway and cardiac myocyte apoptosis. Circ. Res. 95, 957-970 (2004).

271. Luo, M. et al. Diabetes increases mortality after myocardial infarction by oxidizing CaMKII. J. Clin. Invest. 123, 1262-1274 (2013).

272. Voigt, N. et al. Cellular and Molecular Mechanisms of Atrial Arrhythmogenesis in Patients With Paroxysmal Atrial Fibrillation. Circulation 129, 145-156 (2014). 
273. Oort, R. J. van et al. Ryanodine Receptor Phosphorylation by

Calcium/Calmodulin-Dependent Protein Kinase II Promotes Life-Threatening

Ventricular Arrhythmias in Mice With Heart Failure. Circulation 122, 2669-2679 (2010).

274. Paulino, E. C. et al. Exercise Training and Caloric Restriction Prevent Reduction in Cardiac Ca2+-Handling Protein Profile in Obese Rats. Hypertension 56, 629-635 (2010). 